Marine particle dynamics:

sinking velocities, size distributions, fluxes, and microbial degradation rates

By

Andrew M. P. McDonnell

B. S., University of California, Los Angeles, 2005

Submitted in partial fulfillment of the requirements for the degree of

Doctor of Philosophy

at the

MASSACHUSETTS INSTITUTE OF TECHNOLOGY

and the

WOODS HOLE OCEANOGRAPHIC INSTITUTION

February 2011

(C) 2011 Andrew M. P. McDonnell

All rights reserved.

The author hereby grants to MIT and WHOI permission to reproduce and to distribute publicly paper and electronic copies of this thesis document in whole or in part in any medium now known or hereafter created.

Signature of Author

Joint Program in Oceanography

Massachusetts Institute of Technology and Woods Hole Oceanographic Institution

January 7,2010

Certified by

Dr. Ken O. Buesseler

Thesis Supervisor

Accepted by

Dr. Roger Summons

Chair, Joint Committee for Chemical Oceanography 


\title{
Marine particle dynamics: sinking velocities, size distributions, fluxes, and microbial degradation rates by
}

Andrew M. P. McDonnell

\begin{abstract}
Submitted to the Massachusetts Institute of Technology and the Woods Hole Oceanographic Institution in partial fulfillment of the requirements for the degree of Doctor of Philosophy in Chemical Oceanography
\end{abstract}

\begin{abstract}
The sinking flux of particulate matter into the ocean interior is an oceanographic phenomenon that fuels much of the metabolic demand of the subsurface ocean and affects the distribution of carbon and other elements throughout the biosphere. In this thesis, I use a new suite of observations to study the dynamics of marine particulate matter at the contrasting sites of the subtropical Sargasso Sea near Bermuda and the waters above the continental shelf of the Western Antarctic Peninsula (WAP). An underwater digital camera system was employed to capture images of particles in the water column. The subsequent analysis of these images allowed for the determination of the particle concentration size distribution at high spatial, depth, and temporal resolutions. Drifting sediment traps were also deployed to assess both the bulk particle flux and determine the size distribution of the particle flux via image analysis of particles collected in polyacrylamide gel traps. The size distribution of the particle concentration and flux were then compared to calculate the average sinking velocity as a function of particle size. I found that the average sinking velocities of particles ranged from about 10-200 $\mathrm{m} \mathrm{d}^{-1}$ and exhibited large variability with respect to location, depth, and date. Particles in the Sargasso Sea, which consisted primarily of small heterogeneous marine snow aggregates, sank more slowly than the rapidly sinking krill fecal pellets and diatom aggregates of the WAP. Moreover, the average sinking velocity did not follow a pattern of increasing velocities for the larger particles, a result contrary to what would be predicted from a simple formulation of Stokes' Law. At each location, I derived a best-fit fractal correlation between the flux size distribution and the total carbon flux. The use of this relationship and the computed average sinking velocities enabled the estimation of particle flux from measurements of the particle concentration size distribution. This approach offers greatly improved spatial and temporal resolution when compared to traditional sediment trap methods for measuring the downward flux of particulate matter. Finally, I deployed specialized in situ incubation chambers to assess the respiration rates of microbes attached to sinking particles. I found that at Bermuda, the carbon specific remineralization rate of sinking particulate matter ranged from 0.2 to $1.1 \mathrm{~d}^{-1}$, while along the WAP, these rates were very slow and below the detection limit of the instruments. The high microbial respiration rates and slow sinking velocities in the Sargasso Sea resulted in the strong attenuation of the flux with respect to depth, whereas the rapid sinking velocities and slow microbial degradation rates of the WAP resulted in nearly constant fluxes with respect to depth.
\end{abstract}

Thesis Supervisor: Dr. Ken O. Buesseler

Title: Senior Scientist, Marine Chemistry and Geochemistry Department, Woods Hole Oceanographic Institution 
"Work and study hard, help the earth and all its creatures, but take the time to have some fun."

-GRANDPA BOB 


\section{ACKNOWLEDGEMENTS}

I am extraordinarily fortunate to have worked under the supervision of my thesis advisor, Ken Buesseler. The scientific, educational, and collegial environment that he leads through his lab, Café Thorium, is second to none. Since before I joined his lab in 2007, his door has always been open for me to drop in to discuss ideas, plan the next step in my research, ask questions, share new results, or edit a manuscript. Ken was wonderful at promoting consistent progress on my thesis and always managed to do it in a way that motivated and energized me to proceed forward. He provided all the resources I needed to succeed. I also greatly appreciate his bigpicture view of things and the trust he placed in me when I required flexibility in my scheduling.

My committee consisting of Phil Boyd, Scott Gallager, Mick Follows and Phoebe Lam has been fantastic. Our meetings and emails have always been productive and I always ended up leaving them with good perspectives and new ideas. I am thankful to my pre-general exam advisors, Scott Doney and Dierdre Toole, for their supervision and collaboration in the early years of my tenure in the Joint Program. Many of the scientists here at WHOI such as Carl Lamborg, Dave Glover, Ben Van Mooy, and Jim Yoder have been helpful to offer assistance to me along the way.

I am very grateful to have Stephanie Owens as a lab mate and friend. We have shared many long days at sea and in the office, and I have very much enjoyed her wonderful company. Thank you, Stephanie, for all your help processing samples, generally keeping things well organized, and providing extra motivation when I needed it most.

Jim Valdes has been an indispensable help over the last 5 years. He made possible much of the technical gear for deploying the drifting moorings that served as the observational backbone of much of my thesis. I also owe Steve Pike huge thank you for all of his help at sea and in the lab. It has been great having a friend a colleague like him in the lab.

The observational work presented in this thesis would not have been possible without help from many others who volunteered their time to me while at sea. For this I am thankful to Kelsey Collasius, Nicole Benoit, Naomi Levine, Irina Marinov, Kathleen Munsen, Brad Issler, Doug Bell, Michael Garzio, Brian Pointer, and the captains and crews of the ARSV Laurence M. Gould, RVIB Nathaniel B. Palmer, and the RV Atlantic Explorer. I am very appreciative of the collaborative work and logistical support offered by the scientists and staff of the Bermuda Atlantic Time-Series. The cruises in Antarctica would not have been possible without the generous support and flexibility we were offered from Hugh Ducklow, Debbie Steinberg, Oscar Schofield, Doug Martinson, Bill Fraser, Joseph Torres, Craig Smith and Dave DeMaster.

Donna Mortimer, Sheila Clifford, and Mary Zawoysky were always so helpful and kind at resolving the numerous administrative tasks. I am thankful to everyone in the Academic Programs office for their kind help during this journey.

I owe much of my passion for oceanography to Nicolas Gruber. During my last two years as an undergraduate at UCLA, I had the pleasure to join his laboratory where I gained an excellent introduction to the field from an exceptional teacher and mentor. Without those experiences, I would not be where I am today.

On a personal level, I have so many people to thank. Mom and Dad, you two mean the world to me and I am so thankful for your never-ending love, support, and encouragement. I am acutely aware of it every day, despite the fact that I've been living thousands of miles away. Grandpa Bob, you are my role model. Your instructions printed on the previous page and the way you live by them are spot on and serve as an excellent set of principles to live up to. Scott and Davina, thank you for the good times we have shared together over the last few years and for 
your compassion when times have been tough. My aunts and uncles and extended family have been very supportive along the way.

During my thesis, I have received encouragement and shared many good times with a great group of friends here in Woods Hole. This includes Kelton McMahon, Alysia Cox, Taylor Crockford, Stephanie Owens, Casey Saenger, Emily Roland, Jessie Kneeland, Caitlin Frame, Eoghan Reeves, Fern Gibbons, Colleen Petrik, Christine Mingione Thompson, Laura Hmelo, Naomi Levine, Annette Hynes, Kate Buckman, Abigail Noble, Erin Bertrand, Kim Popendorf, Whitney Bernstein, Carly Buchwald, Nick Woods, Ben Hodges, John Ahern, Kate Furby, Michelle Bringer, Hunter Oates, Claudine Hauri and many more. Many of my friends outside of Woods Hole helped me find a balance in my life by giving me the opportunity to step away from my thesis to enjoy some good times outdoors and gain much-needed perspective. Thanks and love to my friends Dana Sulas, Anna de Regt, Cim Wortham, Pavel Gorelik, Hannah Waight, Dierdre Mooney, Jim Mediatore, Ken Hill, Nathan Turner, and a whole host of others from the MIT Outdoor Club. I also thank Jon and Sara Siegrist, Lucas Jones, Jeff Anderle, Lindy Wagner, Jason Stone, and Chelsea Long for staying in touch with me and remaining close friends despite my departure from California over five years ago.

A great variety of funding sources supported my thesis work and made possible the virtually unconstrained pursuit of the scientific questions that most interested me during my journey as a graduate student. It is my belief that a graduate experience such as this could not have occurred anywhere other than in the WHOI-MIT Joint Program in Oceanography. In particular, support from the WHOI Academic Programs Office gave me the flexibility to adjust my research directions multiple times in my pre-general exam years, choose a thesis topic based on my scientific interests rather than funding availability, and sustain my thesis progress when support from research grants was not available. A variety of internal and external resources gave me unhindered access to the sea. The Scurlock Bermuda Biological Station for Research Fund provided travel support to and from Bermuda. A grant from the National Science Foundation (NSF) Carbon and Water Program (06028416) enabled all the Sargasso Sea research as well as the opportunity to develop and test much of the methodology presented in this thesis. Internal awards from the WHOI Rinehart Access to the Sea Program and the WHOI Coastal Oceans Institute provided early funding that supported my first season of research in Antarctica and were instrumental in securing the larger external NSF Office of Polar Programs (OPP) Western Antarctic Peninsula Flux Project (OPP 0838866) grant for a second year of science in the region. The NSF OPP Palmer Long-Term Ecological Research Project and the Food for Benthos on the Antarctic Continental Shelf Project provided logistical support in the region. Phoebe Lam and Scott Doney's grant from the WHOI Ocean Carbon and Climate Institute supported a semester of my time. The Henry G. Houghton Fund and the MIT Student Assistance Fund subsidized educational costs, textbooks, equipment, and travel expenses to conferences. In my first year I was supported by funding from Scott Doney's NSF grant (OCCE-0312710). 


\section{TABLE OF CONTENTS}

$\begin{array}{llr}\text { CHAPTER } 1 \text { Introduction } & 15\end{array}$

CHAPTER 2 Variability in the average sinking velocity of marine particles 33

ChAPTER $3 \quad$ Particle distributions and fluxes along the western Antarctic 61

CHAPTER 4 Particle concentration, sinking velocity, and flux in the Sargasso 101 Sea

CHAPTER 5 Sinking velocities and microbial respiration control the attenuation of particle flux through the ocean's twilight zone

$\begin{array}{lll}\text { CHAPTER } 6 & \text { Conclusions and future directions } & 159\end{array}$

APPENDIX I High particle export over the continental shelf of the west 165

APPENDIX II Calibration of the video plankton recorder 179

APPENDIX III MATLAB code for processing and analyzing images from the

APPENDIX IV MATLAB code for processing and analyzing the merged polyacrylamide gel images

APPENDIX V Table of average sinking velocities 


\section{LIST OF FigURES}

\section{CHAPTER 1}

Figure 1

Schematic of the Ocean's Biological Pump $\quad 19$

Figure 2 Previously measured sinking velocities as a function of particle diameter

\section{CHAPTER 2}

Figure 1

Figure 2

Map of study sites along the western Antarctic Peninsula (WAP)

Figure 3

Images of particles collected in the polyacrylamide gel traps

Particle size distributions of flux, concentration, and average

Figure 4 Particle size distributions of flux, concentration, and average

sinking velocity at three depths at PS1

Figure 5 Comparison of particulate matter and the particle size distribution

of flux, concentration, and average sinking velocity during two occupations of PS2 in Marguerite Bay

Figure 6 Model explaining observed average sinking velocity size

distributions during the two occupations of PS2 in Marguerite

Bay

\section{CHAPTER 3}

Figure 1 Maps of place names, sampling locations, and bathymetry for the

Figure 2 Relationship between particle volume concentration and

particulate organic carbon concentration

Figure 3 Relationship between the frequency of spikes in the transmissometer signal and the large particle volume

Figure 4 Relationship between the frequency of spikes in the transmissometer signal and the numeric concentrations of different particle sizes

Figure 5 Carbon flux profiles measured via the drifting sediment trap array

Figure 7 stations along the WAP

Figure 8 Carbon flux estimated from the power-law relationship of particle density plotted vs. the carbon flux measured in the standard bulk sediment traps

Figure 9 The fraction of carbon flux as a function of particle size for the WAP

Figure 10 Comparison of carbon flux measured by the drifting sediment trap arrays to those estimated from the concentration size distribution

Figure 11 Monthly average satellite-derived chlorophyll $a$ concentration

Figure 12 Spatial maps of the small particle concentration along the WAP in 2009 and 2010

Figure 13 Spatial maps of the concentration of medium-sized particles 
along the WAP in 2009 and 2010

Figure 14 Spatial maps of the large particle concentration along the WAP in 2009 and 2010

Figure 15 Maps of particle flux estimated from the concentration size distribution along the WAP

\section{CHAPTER 4}

Figure 1

Photographs of particles collected in a polyacrylamide gel trap in

Figure 2 Particle size distributions of the flux, concentration and average

Figure 3 Particle size distributions of the flux, concentration and average

Figure 4 Particle size distributions of the flux, concentration and average

Figure 5 Particle size distributions of the flux, concentration and average

Figure 6 Carbon flux estimated from the power-law relationship of particle density plotted vs. the carbon flux measured in the standard bulk sediment traps at BATS

Figure 7 The fraction of carbon flux as a function of particle size at BATS

Figure 8 Comparison of carbon flux measured by the drifting sediment

trap arrays to those estimated from the concentration size distribution

Figure 9 Maps of numeric particle concentrations in the BATS region

$127-128$ during September 2009

Figure 10 Map of estimated particle fluxes in the BATS region during September 2009

Figure 11 Profiles of the estimated particle fluxes in the BATS region during September 2009

\section{CHAPTER 5}

Figure 1

Figure 2

Figure 3

Schematic of the RESPIRE incubation sediment trap

RESPIRE incubation data from the BATS site

RESPIRE incubation data from the western Antarctic Peninsula

Figure 5 Sediment trap data and modeled flux attenuation profiles at the

Figure 6 Sediment trap data and modeled flux attenuation profiles from the

WAP

\section{APPENDIX I \\ Figure 1}

Comparison of particle fluxes at the LTER trap site as measured by the moored conical trap, cylindrical drifting traps, and water column measurements of ${ }^{234} \mathrm{Th}$

\section{APPENDIX II}


Figure 1

Figure 2

Figure 3
Schematic of the Video Plankton Recorder

Plot of large ROIs as a function of target distance for Calibration A

Plot of large ROIs as a function of target distance for Calibration B
180

182

183 


\section{LIST OF TABLES}

\section{CHAPTER 2}

Table 1

List of particle size bin limits

\section{CHAPTER 3}

Table 1

Table 2

Western Antarctic Peninsula cruise dates

82

Average sinking velocities as a function of particle size

CHAPTER 4

Table 1

Table 2

Table 3

Table 4

Table 5

List of the drifting trap deployments in the Sargasso Sea during 2009

List of VPR deployments in September 2009

Comparison of zooplankton abundances to

Average sinking velocities calculated at BATS in 2009

119

Best-fit parameters for the power-law relationship calculated for the

relationship between the numeric flux size distribution and the carbon flux in the Sargasso Sea and along the WAP

\section{ChAPTER 5}

Table 1

Comparison of carbon-specific remineralization rates and flux weighted average sinking velocities at BATS and the WAP

\section{APPENDIX I}

Table 1

Summary of particulate carbon fluxes, ${ }^{234} \mathrm{Th}$ fluxes, and export ratios

APPENDIX II

Table 1

Calibrated image volumes and depths of field for the VPR

\section{APPENDIX V}

Table 1

Average sinking velocities at WAP reported in Chapter 2

208

APPENDIX VI

Table 1

Commonly used abbreviations in this thesis

210 
Chapter ONe

Introduction 


\section{The Ocean's Biological Pump}

In the well-lit surface layer of the world's oceans, a diverse assemblage of photosynthetic organisms converts light and inorganic nutrients into organic matter. Subsequently, a fraction of this organic material is transported to depth via sinking particulate organic matter (POM), advected dissolved organic matter (DOM), or actively migrating zooplankton (Figure 1). This seemingly subtle process, collectively termed the ocean's biological pump, is a major structuring force that shapes the biogeochemical complexion of the biosphere.

POM is an important component of the ocean's biological pump and the marine food web (Alldredge and Silver 1988; Biddanda and Benner 1997; Duarte 2002; Fowler and Knauer 1986; Kiørboe 2000; Kiørboe and Jackson 2001). It constitutes a vehicle for transporting organic matter and other constituents to depth via sinking. The cycling and transport of POM in the oceans, therefore, has a large impact on the distribution and concentrations of carbon and other dissolved elements in the water column (Chase et al. 2002; Howard et al. 2006; Whitfield and Turner 1987). The downward physical transport of POC via sinking and its remineralization at depth works against the homogenizing effects of ocean mixing to establish a vertical gradient of dissolved inorganic carbon. This process is important in regulating atmospheric $p \mathrm{CO}_{2}$ (Siegenthaler and Sarmiento 1993; Volk and Hoffert 1985). It has been estimated that without the ocean's biological pump, the concentration of $\mathrm{CO}_{2}$ in the atmosphere would be about 200 ppm higher than it is today (Sarmiento and Toggweiler 1984).

While approximately 10-15 $\mathrm{Pg}{\mathrm{POC} \mathrm{yr}^{-1}}^{-}$are exported out of euphotic zone of the open ocean (Kwon and Primeau 2006), only a tiny fraction of that export ( 0.1 Pg POC $\left.\mathrm{yr}^{-1}\right)$ reaches the sediments away from the continental margins (Sarmiento and Gruber 2006). This phenomenon is due to the fact that POM is efficiently remineralized (converted from POC into dissolved organic and inorganic constituents) during its transit to depth. In the mesopelagic zone (defined here as the base of the euphotic zone to $1000 \mathrm{~m}$ ), a highly specialized and adapted ecosystem metabolizes much of this flux, resulting in a strong attenuation of POM flux and concentration in this depth range (Martin et al. 1987). Data from sediment traps has revealed that the length scales at which POM fluxes attenuate through the mesopelagic zone vary considerably throughout the oceans (Berelson 2001; Buesseler et al. 2007a; Buesseler et al. 2007b; Lutz et al. 2002). Global modeling studies have also demonstrated that large-scale distributions of bioactive tracers such as nitrogen, phosphorous, dissolved inorganic carbon, and total alkalinity are highly 


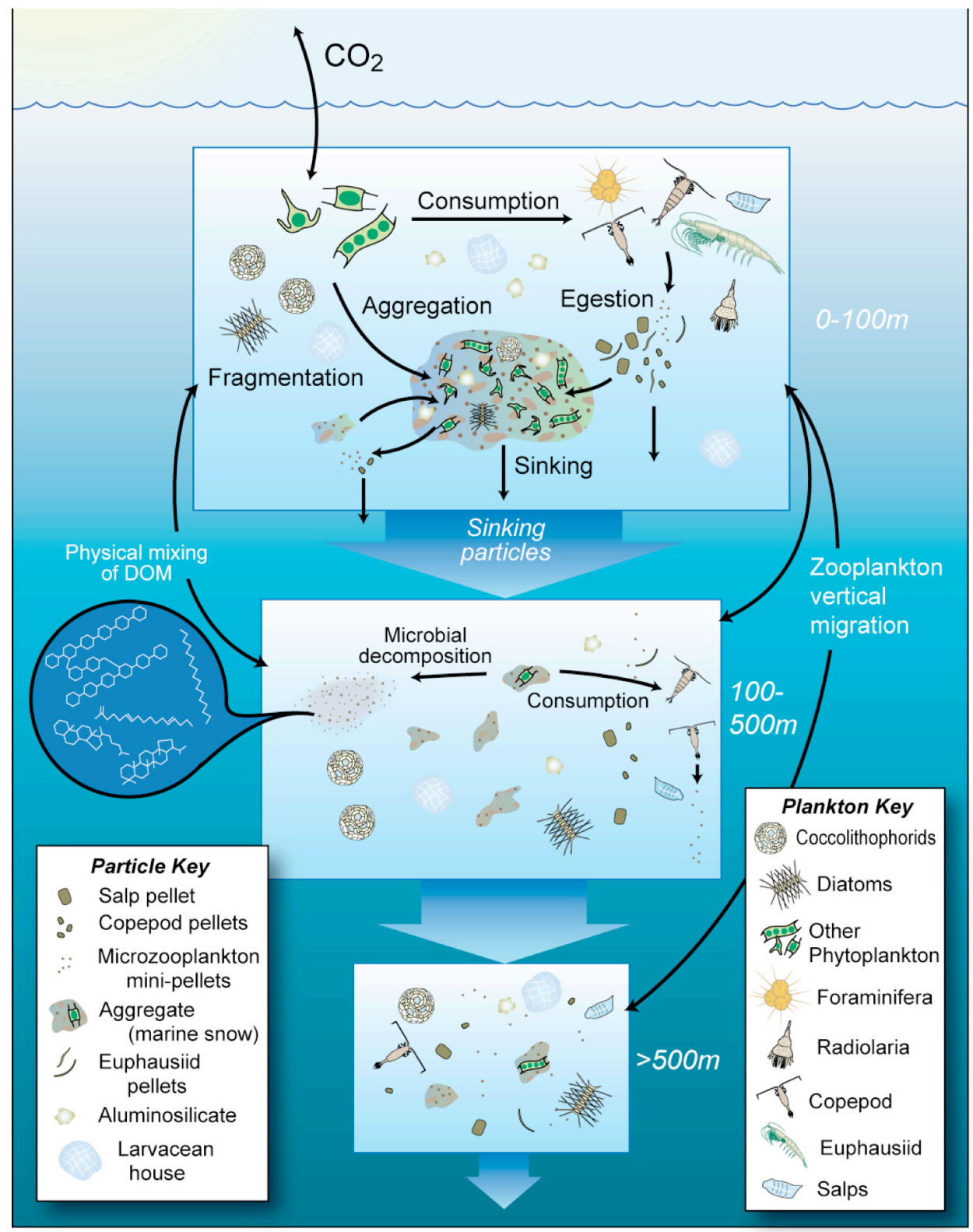

Figure 1. Schematic depicting the various components of the ocean's biological pump (Buesseler et al. 2007a). Carbon dioxide and nutrients are fixed into organic matter by phytoplankton in the surface waters. A fraction of this material is transported to deeper waters via the process of sinking particles, physical mixing of dissolved organic matter, and through the vertical migration of zooplankton. In the subsurface waters, heterotrophic organisms consume and reprocess this material, which generally reduces the vertical flux with respect to depth in the water column. Through these processes, the ocean's biological pump redistributes carbon and other elements throughout the biosphere. 
dependent on the remineralization length scale of sinking POM (Howard et al. 2006; Schlitzer 2002; Schlitzer 2004). In fact, a recent modeling study by Kwon et al. (2009) found that by increasing the depth at which $63 \%$ (i.e., 1-1/e) of the sinking carbon is remineralized by only 24 m globally, atmospheric carbon dioxide concentrations declined by 10-27 ppm. Thus, quantifying the processes that produce, alter, consume, and transport particles in the mesopelagic zone is crucial to our understanding of ocean biogeochemical dynamics and global climate. Despite its importance, our present understanding of the biological pump is extremely limited. This is largely due to the experimental and logistical challenges of studying such a complex and inaccessible ecosystem. New strategies, technologies, sampling methods, and data analysis techniques are required to gain further insight into these dynamic processes (Bishop 2009; Schofield et al. 2010).

In this thesis, I employ innovative sampling strategies that enable a new level of understanding of the ocean's biological pump. In the sections below, I review our current understanding of the relevant aspects of this process, and outline how subsequent chapters address some of these questions.

\section{Particulate Matter in the Ocean}

Particulate matter (PM) in the ocean consists of a variety of materials, including individual live organisms, zooplankton carcasses, organic debris, zooplankton fecal pellets, transparent exopolymer particles (TEP), and minerals of both biogenic and terrestrial origin. The adhesive, coagulative nature of these small particles leads to the formation of larger aggregates known as marine snow (Alldredge and Gotschalk 1989; Alldredge and Jackson 1995; Logan et al. 1995; McCave 1984). Particles in the size range of $100 \mu \mathrm{m}$ to several millimeters constitute a significant proportion of particle mass in the oceans and are the major contributors to the sinking flux of organic matter (Fowler and Knauer 1986; Turner 2002). This size range includes primarily marine snow and zooplankton fecal pellets that together make up the dominant form of sinking PM in the ocean due to their high sinking velocities (Alldredge and Gotschalk 1988; Alldredge and Silver 1988; Asper 1987; McCave 1975; Small et al. 1979). Information on the abundance and distribution of PM can provide insight on the balance between processes of particle production and removal (Bishop et al. 1986). Unfortunately, conventional methods for studying PM, such as bottle samples, in situ filtration, or bulk sediment traps, do not provide detailed information about the size distribution or morphology of the particulate matter. Instead, these 
methods provide only low-resolution data in time and space on the integrated stocks or sinking fluxes of PM. In situ optical methods, however, can rapidly and non-destructively image particles in the water column, allowing for the analysis of particle abundance and size distribution (Gorsky et al. 1992; Honjo et al. 1984).

Recent advances in digital imagery and image analysis have enabled detailed particle characterization with improved spatial and temporal coverage over conventional sampling methods (Ashjian et al. 2001; Ashjian et al. 2005; Diercks and Asper 1997; Gorsky et al. 2000; Guidi et al. 2007; Iversen et al. 2010; Lampitt et al. 1993; MacIntyre et al. 1995; Nowald et al. 2006; Pilskaln et al. 1998; Ratmeyer and Wefer 1996; Stemmann et al. 2000). Quantification of particle size is a useful attribute because several studies have demonstrated that a variety of particle properties depend on it. For example, particle mass, carbon and nitrogen content (Alldredge 1998), settling speed (Alldredge and Gotschalk 1988), coagulation rate (Jackson and Burd 1998; Jackson and Lochmann 1993), and the extent of colonization by microbes (Kiørboe 2003) and zooplankton (Kiørboe 2003) are related to particle length and/or size. In addition, microbial activity and zooplankton consumption rates of particles may also depend on particle size (Kiørboe 2000; Ploug and Grossart 2000). Unfortunately many of these relationships were determined for particles in the epipelagic zone, and it is uncertain whether similar relationships exist in the mesopelagic zone.

Biophysical process models of particles are also beginning to shed light on the dynamics that are important in controlling particle size distributions and fluxes in the mesopelagic zone (Jackson and Burd 2002; Stemmann et al. 2004a; Stemmann et al. 2004b) but these models lack sufficient observational data for validation. Their authors emphasize the necessity for improved measurements and parameterizations of sinking rates, biological particle transformations by microbes and zooplankton, and the biochemical nature of particulate matter in the mesopelagic (Stemmann et al. 2004b).

\section{Particulate Flux and its Attenuation with Depth}

The downward flux of PM has been measured for several decades with various types of ocean sediment traps and these measurements have provided important information about the fluxes of carbon and the attenuation of flux with depth (Berelson 2001; Honjo 1980). It has long been recognized, however, that there are many factors that can bias the accuracy and complicate the interpretation of sediment trap measurements (Baker et al. 1988). These include trap 
hydrodynamic biases (Butman et al. 1986; Gardner 1980), the influence zooplankton swimmers (Lee et al. 1988), and the degradation and solubilization of collected material during deployments (Antia 2005; Kahler and Bauerfeind 2001). New trap designs and flux correction methods have improved confidence and reduced the uncertainties in these flux measurements (Buesseler et al. 2007a). Of particular importance in reducing the hydrodynamic bias has been the development of neutrally buoyant sediment traps that drift in a near-Lagrangian manner, thereby minimizing fluid flow and shear over the trap aperture (Buesseler et al. 2000; Lampitt et al. 2008; Valdes and Price 2000). In addition to issues with biases, sediment traps are only capable of providing flux information that has been integrated over large time and space scales (Siegel and Deuser 1997; Siegel et al. 2007), so resolving transient and spatially heterogeneous export events (Karl et al. 1996; Sweeney et al. 2003) has proven difficult. While sediment traps have been indispensable tools for studying sinking fluxes of PM, this data by itself does not elucidate the processes that account for these observations or how they would be altered by changes in climate or ecosystem structure, for example. Additional oceanographic tools need to be developed and utilized to elucidate the dynamics of these complex processes and their effect on the fluxes.

The efficiency at which POM is transported to depth in the ocean can be defined in terms of a remineralization length scale. The longer the remineralization length scale, the further particles penetrate into the depths of the ocean before they become remineralized. On a basic level, the magnitude of particle fluxes and the remineralization length scale are dependent on the concentration of particles in the water, their sinking velocities, and the rates at which they are destroyed on their transit to depth. Traditionally, the attenuation of the flux and concentration of POM in the mesopelagic zone has been empirically parameterized by simple power-law (Martin et al. 1987) or exponential functions (Walsh et al. 1988). While these parameterizations have proven extremely useful and are widely applied in even some of the most modern and sophisticated ocean biogeochemical models, they were created for the interpolation of POM flux data at various depths, and say little about the complex set of mechanisms operating to produce these observations. Instead of relying on empirical parameterizations such as these, this thesis addresses the questions of particle concentrations, fluxes, sinking velocities, and particle degradation rates to gain a more mechanistic understanding of fluxes through mesopelagic zone.

\section{Sinking Velocities of Particulate Matter}






Figure 2. A compilation of sinking rates as a function of the equivalent spherical diameter from Stemmann et al. (2004b) showing the wide range in particle sinking velocity as a function of particle size. The solid line numbered 7 depicts the velocities predicted by one formulation of Stokes' Law.

Particle flux can be described as the product of the particle concentration and the sinking speed (Banse 1990; Bishop et al. 1977). Accordingly, knowledge of particle sinking velocities (and their variability in time and space) paired with measurements of particle concentration can be used to compute fluxes with much higher spatial and temporal resolution than is currently possible with sediment trap technology. Attempts at measuring sinking speeds have been made, but they are notoriously difficult to carry out accurately. Such attempts included settling columns on ships/land (Shanks and Trent 1980), SCUBA divers with stopwatches visually tracking marine snow (Alldredge and Gotschalk 1988), early cameras on ROVs or sediment traps (Asper 1987; Pilskaln et al. 1998), or settling velocity traps (Peterson et al. 2005). These studies and many more have provided a wide range of measured sinking rates (Figure 2), likely a reflection of high measurement uncertainty, but also real variability in sinking rates at different times and places due to complex factors such as fluid viscosity, particle source material, morphology, porosity, density, and other variable particle characteristics. No simple relationships have been discovered and the simple application of Stokes' Law appears to be insufficient to describe all of the observed variability.

It is also unclear if these types of measured sinking velocities are useful in the calculation of particle flux from the concentration in the water column. Many of the previous observations 
inherently quantify the velocities of the particles that are sinking rapidly. In the ocean, a large proportion of the particles in the water column are neutrally buoyant and do not contribute to the downward flux of PM. These observations suggest that sinking rates will need to be accurately quantified concomitantly with measurements of particle abundance in order to have confidence in estimates of flux calculated from sinking velocity and abundance. As the variability in measured sinking velocities appears to range over several orders of magnitude even for particles with the same apparent diameter (Figure 2), the general use of these velocities to estimate the flux from particle concentrations would introduce large errors in the estimated fluxes. Furthermore, the fact that many studies and models of particle flux through the mesopelagic zone still rely on sinking velocities determined over two decades ago by SCUBA divers with stop watches tracking particles in surface waters off of the coast of California is indicative of the need for good measurements of particle sinking velocities.

\section{Microbial Degradation of Sinking Particles}

Marine aggregates are inhabited by high densities of attached and metabolically active microbes (Simon et al. 1990). These microbes are known to utilize enzymes released into the microenvironment, bound to the cell surface, and within the cell in order to solubilize POM into DOM and also oxidize it into its dissolved inorganic constituents (Smith et al. 1992)(Smith et al. 1992)(Smith et al. 1992)(Smith et al. 1992)(Smith et al. 1992)(Smith et al. 1992)(Smith et al. 1992). These microbial processes, coupled with chemical dissolution of minerals, physical degradation of organic material, and advection/diffusion of pore fluids into the surrounding water lead to a net loss of organic material from the sinking particulate fraction and thereby account for a portion of the attenuation of sinking flux with depth. Little is known, however, about how these small-scale processes contribute to the attenuation of POC flux with depth or how they vary with time, locale, depth, or source material. The magnitude of these processes has been an issue of considerable debate, with some early studies concluding that marine snow was a relatively poor site for the active remineralization of organic matter, and, therefore, microbial degradation of sinking aggregates is a minor factor in the attenuation of particle fluxes with depth (Alldredge and Youngbluth 1985; Ducklow et al. 1982; Karl et al. 1988). Other studies found quite the opposite, however, calculating that POM could be broken down on short timescales of hours to days (Ploug and Grossart 2000; Ploug et al. 1999; Smith et al. 1992). Many of these studies were 
done under laboratory conditions with laboratory-grown aggregates and were not designed for comparison to the oceanographic process of flux attenuation.

The net effect of remineralization of sinking particulate matter has also been investigated with the use of tracer techniques to determine oxygen utilization rates in the mesopelagic zone (Jenkins 1977; Jenkins 1982; Jenkins 1987; Levine et al. 2009). These methods are subject to some uncertainties, but they do provide integrated estimates of respiration for comparison with particle flux attenuation, demonstrating that most of the exported POM is being remineralized in the mesopelagic zone, as expected (Broecker et al. 1991; Jenkins 1987). Inverse global ocean models have also been employed to estimate where organic matter remineralization is taking place (Schlitzer 2002; Usbeck et al. 2003). Tracer-based methods such as these have proven useful in assessing the rates of remineralization over large temporal and spatial scales, as well as monitoring long-term changes in subsurface biogeochemical cycles. However, at the present time, it is unclear whether these changes are due to changes in the supply of sinking particulate matter to mid-water depths, the rates at which these particles are remineralized at depth, or if changes in ocean circulation and mixing play a role.

Proxy measurements of bacterial production in the water column have also become common using the ${ }^{3} \mathrm{H}$-thymidine method (Chin-Leo and Kirchman 1988; Fuhrman and Azam 1982). Many assumptions and poorly constrained conversion factors are necessary to convert these results into bacterial carbon demand. Steinberg et al. (2008) used ${ }^{3} \mathrm{H}$-thymidine measurements of bacterial production to partition between the contributions of zooplankton and bacteria to the decomposition of sinking organic matter. Ultimately, however, the carbon demand of free-living microbes is not the factor that controls the attenuation of sinking POM fluxes because these microbes do not metabolize or solubilize sinking POM directly. Rather, they fuel their metabolism with DOM derived from the enzymatic hydrolysis of sinking particles (Azam 1998; Cho and Azam 1988; Smith et al. 1992) and zooplankton activity (Banse 1990; Jumars et al. 1989). The attenuation of particulate flux as measured by sediment traps is disconnected in time and space from both the large-scale tracer distributions and carbon demand measurements of free-living microbes. In other words, if the remineralization length scale changes, this may not be immediately reflected in measurements of bacterial carbon demand or oxygen utilization rates. It is therefore imperative to develop and utilize new measurement techniques that can more directly quantify the processes responsible for flux attenuation and that will provide data on the 
appropriate spatial and temporal scales of these processes. This will give us a better understanding of the biogeochemical function of the ocean's mesopelagic zone.

\section{Objectives of this thesis}

In this thesis, I address some of the unknown rates and attributes important to the ocean's biological pump. This is accomplished by utilizing new instruments and methods to quantify and describe the key properties of particle concentration, flux, and rates of particle attached microbial respiration. These results are from three years of research cruises in two different oceanic environments, the Sargasso Sea and the waters above the continental shelf along the western Antarctic Peninsula (WAP), allowing for the comparison of particle dynamics in two highly contrasting environments and demonstrating the utility of these new methodological approaches. In Chapter 2, I present the methodological background for measurements of the particles size distribution of both the flux and concentration. Comparing the size distributions of particle flux and concentration enabled the determination of the average sinking velocity of marine particles along the WAP. Chapter 3 uses the Video Plankton Recorder to map the particle size distributions across the $700 \times 200 \mathrm{~km}$ WAP sampling grid, providing a new look at the spatial variability of particle concentration in this region. In addition, I evaluate the similarities between large particle concentrations determined with the VPR and an approach that analyzes the frequency of spikes in the transmissometer data. I also establish the relationship between the numeric flux size distribution and the carbon flux collected in the drifting sediment traps. This relationship and the average sinking velocities presented in Chapter 2 facilitates the estimation of particle flux across the sampling grid at much higher resolutions than are possible with conventional sediment traps. Chapter 4 presents the average sinking velocity data for the Sargasso Sea, and derives similar relationships that are used to produce high-resolution maps of particle concentration and flux in this region. Finally, Chapter 5 presents new data of microbial respiration rates associated with sinking particles. Combined with the average sinking velocity data presented in the previous chapters, this chapter demonstrates how differences in these rates control the remineralization length scale at each location. 


\section{References}

Alldredge, A. 1998. The carbon, nitrogen and mass content of marine snow as a function of aggregate size. Deep-sea research. Part 1. Oceanographic research papers 45: 529-541.

Alldredge, A. L., and C. Gotschalk. 1988. In Situ Settling Behavior of Marine Snow. Limnology and Oceanography 33: 339-351.

Alldredge, A. L., and C. C. Gotschalk. 1989. Direct observations of the mass flocculation of diatom blooms: Characteristics, settling velocities and formation of diatom aggregates. Deep-Sea Research 36: 159-171.

Alldredge, A. L., and G. A. Jackson. 1995. Aggregation in marine systems. Deep-Sea Research II 42: 7 .

Alldredge, A. L., and M. W. Silver. 1988. Characteristics, dynamics and significance of marine snow. Progress in Oceanography 20: 41-82.

Alldredge, A. L., and M. J. Youngbluth. 1985. The significance of macroscopic aggregates(marine snow) as sites for heterotrophic bacterial production in the mesopelagic zone of the Subtropical Atlantic. Deep-Sea Research 32: 1445-1456.

Antia, A. N. 2005. Particle-associated dissolved elemental fluxes: revising the stochiometry of mixed layer export. Biogeosciences Discussions 2: 275-302.

Ashjian, C. J., C. S. Davis, S. M. Gallager, and P. Alatalo. 2001. Distribution of plankton, particles, and hydrographic features across Georges Bank described using the Video Plankton Recorder. Deep-Sea Res. II 48: 245-282.

Ashjian, C. J., S. M. Gallager, and S. Plourde. 2005. Transport of plankton and particles between the Chukchi and Beaufort Seas during summer 2002, described using a Video Plankton Recorder. Deep-sea research. Part 2. Topical studies in oceanography 52: 3259-3280.

Asper, V. L. 1987. Measuring the flux and sinking speed of marine snow aggregates. Deep-sea research. Part A. Oceanographic research papers 34: 1-17.

Azam, F. 1998. Microbial control of oceanic carbon flux: the plot thickens. Science 280: 694696.

Baker, E. T., H. B. Milburn, and D. A. Tennant. 1988. Field Assessment of Sediment Trap Efficiency Under Varying Flow Conditions. Journal of Marine Research JMMRAO 46.

Banse, K. 1990. New views on the degradation and disposition of organic particles as collected by sediment traps in the open sea. Deep Sea Research Part I: Oceanographic Research Papers 37: 1177-1195.

Berelson, W. M. 2001. The flux of particulate organic carbon into the ocean interior: A comparison of four US JGOFS regional studies. Oceanography 14: 59-67.

Biddanda, B., and R. Benner. 1997. Major contribution from mesopelagic plankton to heterotrophic metabolism in the upper ocean. Deep Sea Research Part I: Oceanographic Research Papers 44: 2069-2085.

Bishop, J. 2009. Autonomous observations of the ocean biological carbon pump.

Bishop, J. K. B., M. H. Conte, P. H. Wiebe, M. R. Roman, and C. Langdon. 1986. Particulate matter production and consumption in deep mixed layers: Observations in a warm-core ring. Deep-Sea Res 33: 1813-1841.

Bishop, J. K. B., J. M. Edmond, D. R. Ketten, M. P. Bacon, and W. B. Silker. 1977. The chemistry, biology, and vertical flux of particulate matter from the upper $400 \mathrm{~m}$ of the equatorial Atlantic Ocean. Deep-Sea Res 24: 1-548.

Broecker, W. S., S. Blanton, W. M. Smethie Jr, and G. Ostlund. 1991. Radiocarbon decay and oxygen utilization in the deep Atlantic Ocean. Global Biogeochemical Cycles 5: 87-117. 
Buesseler, K. O., A. N. Antia, M. Chen, S. W. Fowler, W. D. Gardner, O. Gustafsson, K. Harada, A. F. Michaels, M. van der Loeff, and M. Sarin. 2007a. An assessment of the use of sediment traps for estimating upper ocean particle fluxes. Journal of Marine Research 65: $345-416$.

Buesseler, K. O., C. H. Lamborg, P. W. Boyd, P. J. Lam, T. W. Trull, R. R. Bidigare, J. K. B. Bishop, K. L. Casciotti, F. Dehairs, and M. Elskens. 2007b. Revisiting Carbon Flux Through the Ocean's Twilight Zone. Science 316: 567.

Buesseler, K. O., D. K. Steinberg, A. F. Michaels, R. J. Johnson, J. E. Andrews, J. R. Valdes, and J. F. Price. 2000. A comparison of the quantity and composition of material caught in a neutrally buoyant versus surface-tethered sediment trap. Deep-Sea Research I 47: 277294.

Butman, C. A., W. D. Grant, and K. D. Stolzenbach. 1986. Predictions of sediment trap biases in turbulent flows: a theoretical analysis based on observations from the literature. J. Mar. Res 44: 1-644.

Chase, Z., R. F. Anderson, M. Q. Fleisher, and P. W. Kubik. 2002. The influence of particle composition and particle flux on scavenging of $\mathrm{Th}, \mathrm{Pa}$ and $\mathrm{Be}$ in the ocean. Earth and Planetary Science Letters 204: 215-229.

Chin-Leo, G., and D. L. Kirchman. 1988. Estimating Bacterial Production in Marine Waters from the Simultaneous Incorporation of Thymidine and Leucine. Applied and Environmental Microbiology 54: 1934-1939.

Cho, B. C., and F. Azam. 1988. Major role of bacteria in biogeochemical fluxes in the ocean's interior. Nature 332: 441-443.

Diercks, A. R., and V. L. Asper. 1997. In situ settling speeds of marine snow aggregates below the mixed layer: Black Sea and Gulf of Mexico. Deep Sea Research Part I: Oceanographic Research Papers 44: 385-398.

Duarte, C. M. 2002. Respiration and organic carbon inputs to the mesopelagic ocean.

Ducklow, H. W., D. L. Kirchman, and G. T. Rowe. 1982. Production and Vertical Flux of Attached Bacteria in the Hudson River Plume of the New York Bight as Studied with Floating Sediment Traps. Applied and Environmental Microbiology 43: 769-776.

Fowler, S. W., and G. A. Knauer. 1986. Role of large particles in the transport of elements and organic compounds through the oceanic water column. Progress in oceanography 16: 147-194.

Fuhrman, J. A., and F. Azam. 1982. Thymidine incorporation as a measure of heterotrophic bacterioplankton production in marine surface waters: Evaluation and field results. Marine Biology 66: 109-120.

Gardner, W. D. 1980. Sediment trap dynamics and calibration: a laboratory evaluation. Journal of Marine Research 38: 17-39.

Gorsky, G., C. Aldorf, M. Kage, M. Picheral, Y. Garcia, and J. Favole. 1992. Vertical distribution of suspended aggregates determined by a new underwater video profiler. Annales de l'Institut océanographique(Monaco) 68: 275-280.

Gorsky, G., M. Picheral, and L. Stemmann. 2000. Use of the Underwater Video Profiler for the Study of Aggregate Dynamics in the North Mediterranean. Estuarine, Coastal and Shelf Science 50: 121-128.

Guidi, L., L. Stemmann, L. Legendre, M. Picheral, L. Prieur, and G. Gorsky. 2007. Vertical distribution of aggregates $(>110 \mu \mathrm{m})$ and mesoscale activity in the northeastern Atlantic: Effects on the deep vertical export of surface carbon. Limnol. Oceanogr. 52: 7-18.

Honjo, S. 1980. Material fluxes and modes of sedimentation in the mesopelagic and bathypelagic zones. Journal of Marine Research 38: 53-97. 
Honjo, S., K. W. Doherty, Y. C. Agrawal, and V. L. Asper. 1984. Direct optical assessment of large amorphous aggregates(marine snow) in the deep ocean. Deep-sea research. Part A. Oceanographic research papers 31: 67-76.

Howard, M. T., A. M. E. Winguth, C. Klaas, and E. Maier-Reimer. 2006. Sensitivity of ocean carbon tracer distributions to particulate organic flux parameterizations. Global Biogeochemical Cycles 20.

Iversen, M. H., N. Nowald, H. Ploug, G. A. Jackson, and G. Fischer. 2010. High resolution profiles of vertical particulate organic matter export off Cape Blanc, Mauritania: Degradation processes and ballasting effects. Deep Sea Research Part I: Oceanographic Research Papers 57: 771-784.

Jackson, G. A., and A. B. Burd. 1998. Aggregation in the marine environment. Environ. Sci. Technol 32: 2805-2814.

---. 2002. A model for the distribution of particle flux in the mid-water column controlled by subsurface biotic interactions. Deep-Sea Research Part II 49: 193-217.

Jackson, G. A., and S. Lochmann. 1993. Modeling coagulation of algae in marine ecosystems. Environmental Particles 2: 387-414.

Jenkins, W. J. 1977. Tritium-Helium Dating in the Sargasso Sea: A Measurement of Oxygen Utilization Rates. Science 196: 291.

---. 1982. Oxygen utilization rates in North Atlantic subtropical gyre and primary production in oligotrophic systems. Nature 300: 246-248.

--- 1987. $3 \mathrm{H}$ and $3 \mathrm{He}$ in the Beta Triangle: Observations of Gyre Ventilation and Oxygen Utilization Rates. Journal of Physical Oceanography 17: 763-783.

Jumars, P. A., D. L. Penry, J. A. Baross, M. J. Perry, and B. W. Frost. 1989. Closing the microbial loop: dissolved carbon pathway to heterotrophic bacteria from incomplete ingestion, digestion and absorption in animals. Deep-sea research. Part A. Oceanographic research papers 36: 483-495.

Kahler, P., and E. Bauerfeind. 2001. Organic Particles in a Shallow Sediment Trap: Substantial Loss to the Dissolved Phase. Limnology and Oceanography 46: 719-723.

Karl, D. M., J. R. Christian, J. E. Dore, D. V. Hebel, R. M. Letelier, L. M. Tupas, and C. D. Winn. 1996. Seasonal and interannual variability in primary production and particle flux at Station ALOHA. Deep Sea Research Part II: Topical Studies in Oceanography 43: 539-568.

Karl, D. M., G. A. Knauer, and J. H. Martin. 1988. Downward flux of particulate organic matter in the ocean: a particle decomposition paradox. Nature 332: 438-441.

Kiørboe, T. 2000. Colonization of Marine Snow Aggregates by Invertebrate Zooplankton: Abundance, Scaling, and Possible Role. Limnology and Oceanography 45: 479-484.

---. 2003. Marine snow microbial communities: scaling of abundances with aggregate size. Aquatic Microbial Ecology 33: 67-75.

Kiørboe, T., and G. A. Jackson. 2001. Marine Snow, Organic Solute Plumes, and Optimal Chemosensory Behavior of Bacteria. Limnology and Oceanography 46: 1309-1318.

Kwon, E. Y., and F. Primeau. 2006. Optimization and sensitivity study of a biogeochemistry ocean model using an implicit solver and in situ phosphate data. Global Biogeochemical Cycles 20.

Kwon, E. Y., F. Primeau, and J. L. Sarmiento. 2009. The impact of remineralization depth on the air-sea carbon balance. Nature Geosci 2: 630-635.

Lampitt, R., B. Boorman, L. Brown, M. Lucas, I. Salter, R. Sanders, K. Saw, S. Seeyave, S. Thomalla, and R. Turnewitsch. 2008. Particle export from the euphotic zone: Estimates 
using a novel drifting sediment trap, 234Th and new production. Deep Sea Research Part I: Oceanographic Research Papers 55: 1484-1502.

Lampitt, R. S., W. R. Hillier, and P. G. Challenor. 1993. Seasonal and diel variation in the open ocean concentration of marine snow aggregates. Nature 362: 737-739.

Lee, C., S. G. Wakeham, and J. I. Hedges. 1988. The measurement of oceanic particle flux-Are "swimmers" a problem. Oceanography 1: 34-36.

Levine, N., M. Bender, and S. Doney. 2009. The 180 of dissolved O2 as a tracer of mixing and respiration in the mesopelagic ocean. Global Biogeochemical Cycles 23.

Logan, B. E., U. Passow, A. L. Alldredge, H. P. Grossart, and M. Simon. 1995. Rapid formation and sedimentation of large aggregates is predictable from coagulation rates(half-lives) of transparent exopolymer particles(TEP). Deep Sea Research(Part II, Topical Studies in Oceanography) 42: 230-214.

Lutz, M., R. Dunbar, and K. Caldeira. 2002. Regional variability in the vertical flux of particulate organic carbon in the ocean interior. Global Biogeochem. Cycles 16: 10.1029.

MacIntyre, S., A. L. Alldredge, and C. C. Gotschalk. 1995. Accumulation of Marine Snow at Density Discontinuities in the Water Column. Limnology and Oceanography 40: 449468.

Martin, J. H., G. A. Knauer, D. M. Karl, and W. W. Broenkow. 1987. VERTEX: Carbon cycling in the Northeast Pacific. Deep-Sea Research 34: 267-285.

McCave, I. N. 1975. Vertical flux of particles in the ocean. Deep-Sea Res 22: 491-502.

---. 1984. Size spectra and aggregation of suspended particles in the deep ocean. Deep-sea research. Part A. Oceanographic research papers 31: 329-352.

Nowald, N., G. Karakas, V. Ratmeyer, G. Fischer, R. Schlitzer, R. A. Davenport, and G. Wefer. 2006. Distribution and transport processes of marine particulate matter off Cape Blanc (NW-Africa): results from vertical camera profiles. Ocean Science Discussions 3: 903938.

Peterson, M., S. Wakeham, C. Lee, M. Askea, and J. Miquel. 2005. Novel techniques for collection of sinking particles in the ocean and determining their settling rates. Limnology and Oceanography: Methods 3: 520-532.

Pilskaln, C. H., C. Lehmann, J. B. Paduan, and M. W. Silver. 1998. Spatial and temporal dynamics in marine aggregate abundance, sinking rate and flux: Monterey Bay, central California. Deep Sea Research Part II: Topical Studies in Oceanography 45: 1803-1837.

Ploug, H., and H. P. Grossart. 2000. Bacterial Growth and Grazing on Diatom Aggregates: Respiratory Carbon Turnover as a Function of Aggregate Size and Sinking Velocity. Limnology and Oceanography 45: 1467-1475.

Ploug, H., H. P. Grossart, F. Azam, and B. B. Joergensen. 1999. Photosynthesis, respiration, and carbon turnover in sinking marine snow from surface waters of Southern California Bight: implications for the carbon cycle in the ocean. Marine Ecology Progress Series 179: $1-11$.

Ratmeyer, V., and G. Wefer. 1996. A high resolution camera system (ParCa) for imaging particles in the ocean: System design and results from profiles and a three-month deployment. Journal of Marine Research 54: 589-603.

Sarmiento, J., and J. Toggweiler. 1984. A new model for the role of the oceans in determining atmospheric pCO 2. Nature 308: 621-624.

Sarmiento, J. L., and N. Gruber. 2006. Ocean Biogeochemical Dynamics. Princeton University Press.

Schlitzer, R. 2002. Carbon export fluxes in the Southern Ocean: Results from inverse modeling and comparison with satellite-based estimates. Deep Sea Res., Part II 49: 1623-1644. 
---. 2004. Export Production in the Equatorial and North Pacific Derived from Dissolved Oxygen, Nutrient and Carbon Data. Journal of Oceanography 60: 53-62.

Schofield, O., H. Ducklow, D. Martinson, M. Meredith, M. Moline, and W. Fraser. 2010. How Do Polar Marine Ecosystems Respond to Rapid Climate Change? Science 328: 1520.

Shanks, A. L., and J. D. Trent. 1980. Marine snow: sinking rates and potential role in vertical flux. Deep-Sea Res 27: 137-143.

Siegel, D. A., and W. G. Deuser. 1997. Trajectories of sinking particles in the Sargasso Sea: modeling of statistical funnels above deep-ocean sediment traps. Deep Sea Research Part I: Oceanographic Research Papers 44: 1519-1541.

Siegel, D. A., E. Fields, and K. O. Buesseler. 2007. A Bottom-Up View of the Biological Pump: Modeling Source Funnels above Ocean Sediment Traps. Submitted to Deep-Sea Research I.

Siegenthaler, U., and J. L. Sarmiento. 1993. Atmospheric carbon dioxide and the ocean. Nature 365: 119-125.

Simon, M., A. L. Alldredge, and F. Azam. 1990. Bacterial carbon dynamics on marine snow. Mar. Ecol. Prog. Ser 65: 205-211.

Small, L. F., S. W. Fowler, and M. Y. Ünlü. 1979. Sinking rates of natural copepod fecal pellets. Marine Biology 51: 233-241.

Smith, D. C., M. Simon, A. L. Alldredge, and F. Azam. 1992. Intense hydrolytic enzyme activity on marine aggregates and implications for rapid particle dissolution. Nature 359: 139142.

Steinberg, D., B. Van Mooy, K. Buesseler, P. Boyd, T. Kobari, and D. Karl. 2008. Bacterial vs. zooplankton control of sinking particle flux in the ocean's twilight zone. Limnology and Oceanography 53: 1327-1338.

Stemmann, L., G. A. Jackson, and G. Gorsky. 2004a. A vertical model of particle size distributions and fluxes in the midwater column that includes biological and physical processes. II. Application to a three year survey in the NW Mediterranean Sea. Deep Sea Res., Part I.

Stemmann, L., G. A. Jackson, and D. Ianson. 2004b. A vertical model of particle size distributions and fluxes in the midwater column that includes biological and physical processes-Part I: model formulation. Deep-Sea Research I 51: 865-884.

Stemmann, L., M. Picheral, and G. Gorsky. 2000. Diel variation in the vertical distribution of particulate matter $(>0.15 \mathrm{~mm})$ in the NW Mediterranean Sea investigated with the Underwater Video Profiler-Les sites-ateliers du programme Frontal. Deep Sea Research Part I: Oceanographic Research Papers 47: 505-531.

Sweeney, E. N., D. J. McGillicuddy, and K. O. Buesseler. 2003. Biogeochemical impacts due to mesoscale eddy activity in the Sargasso Sea as measured at the Bermuda Atlantic Timeseries Study (BATS). Deep Sea Res., Part II 50: 3017-3039.

Turner, J. T. 2002. Zooplankton fecal pellets, marine snow and sinking phytoplankton blooms. Aquatic Microbial Ecology 27: 57-102.

Usbeck, R., R. Schlitzer, G. Fischer, and G. Wefer. 2003. Particle fluxes in the ocean: comparison of sediment trap data with results from inverse modeling. Journal of Marine Systems 39: 167-183.

Valdes, J. R., and J. F. Price. 2000. A Neutrally Buoyant, Upper Ocean Sediment Trap. Journal of Atmospheric and Oceanic Technology 17: 62-68.

Volk, T., and M. I. Hoffert. 1985. Ocean carbon pumps-Analysis of relative strengths and efficiencies in ocean-driven atmospheric $\mathrm{CO} 2$ changes. IN: The carbon cycle and atmospheric CO2: Natural variations archean to present; Proceedings of the Chapman 
Conference on Natural Variations in Carbon Dioxide and the Carbon Cycle, Tarpon Springs, FL, January 9-13, 1984 (A86-39426 18-46). Washington, DC, American Geophysical Union, 1985, p. 99-110.

Walsh, I., J. Dymond, and R. Collier. 1988. Rates of recycling of biogenic components of settling particles in the ocean derived from sediment trap experiments. Deep-sea research. Part A. Oceanographic research papers 35: 43-58.

Whitfield, M., and D. R. Turner. 1987. The Role of Particles in Regulating the Composition of Seawater. IN: Aquatic Surface Chemistry: Chemical Processes at the Particle-Water Interface. John Wiley and Sons, New York.: 457-493. 


\title{
Chapter TWO
}

\section{Variability in the average sinking velocity of marine particles}

\author{
Andrew M. P. McDonnell ${ }^{1}$ \\ Ken O. Buesseler ${ }^{2}$
}

This manuscript was published in Limnology and Oceanography, 2010, Volume 55(5), pages 2085-2096 under the same title. It is used here with copyright permission from the American Society of Limnology and Oceanography and the consent of the co-author.

\footnotetext{
${ }^{1}$ MIT-WHOI Joint Program in Chemical Oceanography

${ }^{2}$ Woods Hole Oceanographic Institution, Department of Marine Chemistry and Geochemistry, Woods Hole, Massachusetts
} 


\begin{abstract}
We used a new combination of sampling techniques involving in situ imaging of particles in the water column and the collection of particle flux in viscous polyacrylamide gels to estimate the average sinking velocities ( $W_{i, \text { avg }}$ ) of marine particles ranging from equivalent spherical diameters of $70 \mu \mathrm{m}$ to $6 \mathrm{~mm}$ at several locations, depths, and times along the west Antarctica Peninsula to explore the variability of $W_{i, \text { avg }}$. During the January 2009 deployments, $W_{i, \text { avg }}$ ranged from about 10 to $150 \mathrm{~m} \mathrm{~d}^{-1}$ with the fastest velocities at the large and small ends of the sizes considered. A repeat occupation of one station in Marguerite Bay in February 2009 gave $W_{i, \text { avg }}$ size distributions quite different from the previous month with rapidly sinking small particles and very slow $W_{i, \text { avg }}$ for the large particle classes. These results demonstrate the importance of diatom aggregates and krill fecal pellets to the ocean's biological pump in this region. The observed variability in space and time suggests that global relationships between particle concentrations and fluxes or simple theoretical formulations of sinking velocity as function of particle size (such as a single parameterization of Stokes' Law) are unsuitable for yielding accurate estimates of particle flux from measurements of the particle size distribution. Combining measurements of $W_{i, \text { avg }}$ with high-frequency sampling of the particle concentration size distribution would enable the estimation of particle fluxes at much higher temporal and spatial resolutions than is currently possible with conventional sediment trapping methods.
\end{abstract}

\title{
Introduction
}

The sinking of biogenic particulate matter is the central component of the ocean's biological pump in which carbon and other bio-active and particle-reactive elements are transported into the ocean's interior (Volk and Hoffert 1985). This process plays a major role in determining the distributions of many elements throughout the oceans and in controlling the airsea balance of carbon dioxide (Broecker and Peng 1982; Fowler and Knauer 1986; Sarmiento and Gruber 2006). One of the dominant factors that sets the strength and efficiency of the biological pump is the velocity at which this particulate matter sinks from the euphotic zone to depth. Decades of studies have revealed that the sinking velocities of marine particles range over several orders of magnitude (Turner 2002), and no single formulation of Stokes' law seems to be able to account for this wide range in observed velocities (Stemmann et al. 2004, their figure 2). The measurement and interpretation of the sinking velocities of natural marine particles has proven to be a difficult undertaking. Settling speeds have been measured in laboratory settling 
columns (Silver and Alldredge 1981; Gorsky et al. 1984; Hansen et al. 1996), however the collection, handling, and storage of these fragile particles can easily change their physical characteristics and settling speeds. Others have directly observed sinking particles via carefully choreographed self contained underwater breathing apparatus (SCUBA) experiments in surface waters (Shanks and Trent 1980; Alldredge and Gotschalk 1988) or with in situ settling columns that use cameras to track the progress of particles as they sink through the field of view (Diercks and Asper 1997; Asper and Smith 2003). Time-series analysis of sediment traps at different depths has also been used to infer velocities from the time lag between flux events at different trap depths (Honjo 1996; Xue and Armstrong 2009). In addition, sophisticated sediment traps with indented rotating spheres (IRS) and rotating sample cups allowed for the sorting of the flux into discrete groups as a function of sinking velocity (Peterson et al. 2005; Trull et al. 2008; Lee et al. 2009). These various methods and measurements have produced estimates of sinking velocities for marine particles that span a huge range of about 5 to $2700 \mathrm{~m} \mathrm{~d}^{-1}$, but commonly lie between tens to a few hundred $\mathrm{m} \mathrm{d}^{-1}$ (Turner 2002; Armstrong et al. 2009). Results from settling columns, flux-timing experiments, and settling velocity traps are all fundamentally different measurements and each type of sinking velocity must be interpreted and applied in very specific ways (Armstrong et al. 2009).

Recent advances in digital in situ imaging systems have made possible the rapid and high-resolution measurement of particle abundances and size distributions in the water column, as reviewed by Stemmann et al. (2004). These developments have intensified our need for a robust understanding of particle sinking velocities because the particle concentration $\left(C_{i}\right.$, No. $\left.\mathrm{m}^{-3} \mu \mathrm{m}^{-1}\right)$ obtained from these instruments can be used to calculate the downward particle flux $\left(F_{i}\right.$, No. $\mathrm{m}^{-2}$ $\left.\mathrm{d}^{-1} \mu \mathrm{m}^{-1}\right)$ if the average sinking velocities $\left(W_{i, \text { avg }}, \mathrm{m} \mathrm{d}^{-1}\right)$ for size class, $i$, are known, $F_{i}=C_{i} \cdot W_{i, \text { avg }}$

Thus, knowledge of the average sinking velocities of marine particles and their variability with respect to location, depth, time, and particle size is essential for the utilization of in situ imaging systems as a tool to study the dynamics of the ocean's biological pump. Unfortunately, the methods described above for measuring sinking velocities are not usually appropriate for the oceanographic application of Eq. 1 because they tell us little about the actual relationship between the downward flux and the concentration of the highly heterogeneous collection of particles that exists in the water column at any given place or time. 
Only one study (Asper 1987), to our knowledge, has directly compared the flux size distribution $\left(\mathrm{FSD}=\Sigma F_{i}\right)$ with the concentration size distribution $\left(\mathrm{CSD}=\Sigma C_{i}\right)$, but this was done over 20 years ago when quantification of particle flux and concentration was done painstakingly with film cameras. A few recent imaging studies have analyzed the relationship between the CSD and the bulk particle flux as collected in sediment traps (Walsh and Gardner 1992; Guidi et al. 2008; Iversen et al. 2010). For the first time, this technique has allowed for the highresolution mapping of particle fluxes estimated from the CSD. However, standard sediment traps give only the total flux summed over all particle sizes and therefore they cannot provide explicit information about the relationship between the CSD and the FSD. Instead, these studies relied on the assumption that a single power law model based on Stokes' Law can adequately describe the sinking velocity as a function of particle size, implying that larger particles always sink faster than smaller ones. Additionally, the single relationship used by Guidi et al. (2008) was derived from a collection of loosely paired bulk flux and CSD data from several regions and depths throughout the ocean. Their approach therefore does not take into account any spatial or temporal variability that may arise in the relationship between flux and CSD due to changes in particle density, drag coefficients, source, type, geometry, composition, or other factors that may influence the sinking velocity of particles (Berelson 2002; De La Rocha et al. 2008; Ploug et al. 2008). In fact, Iversen et al. (2010) applied the relationship derived by Guidi et al. (2008) to measurements of the CSD at a study site off Cape Blanc, Mauritania and found that it led to estimates of sinking fluxes that were a factor of 10 smaller than what was measured in sediment traps at the site. This suggests that there exists a wide range of relationships between particle fluxes and concentrations throughout the oceans, and a single parameterization of sinking velocity derived from a quasi-global relationship is not capable of accurately predicting fluxes from measurements of the CSD.

To improve the utility of in situ imaging systems in the study of the biological pump, oceanographers need a robust method to determine the average sinking velocity distribution $\left(\mathrm{ASVD}=\Sigma W_{i, \text { avg }}\right)$ for all sizes of particles involved in this process. It is also necessary to make these measurements on temporal and spatial scales that sufficiently capture the inherent variability in the ASVD.

In this study, we overcome some of the limitations of bulk particle flux measurements from traps by employing the use of viscous polyacrylamide gel traps to collect the flux as individual particles during a short 36-hour deployment of a drifting array, thereby making it 
possible to quantify the FSD at multiple depths (Jackson et al. 2005). By dividing $F_{i}$ by simultaneous measurements of $C_{i}$ from an in situ imaging system at the drifter site, we calculated $W_{i, \text { avg }}$ for each size class (Eq. 1). The results allow us to document the variability of the ASVD at different locations, depths, and times. This method for determining the average sinking velocities of marine particles is advantageous because it does not rely on theoretical assumptions about the variation of sinking velocity as a function of particle size and negates the need to utilize empirical or hard to measure parameters in the calculation of sinking velocities from formulations such as Stokes' Law. Moreover, since $W_{i, \text { avg }}$ is the average downward velocity of all the particles present in a given size class, it accounts for the neutrally and positively buoyant particles that have the potential to influence the CSD but not the downward flux (Asper et al. 1992, Azetsu-Scott and Passow 2004). In effect, the ASVD informs us about the actual relationship that exists between the particle concentration and the sinking flux.

\section{Methods}

Measurements of particle CSD and FSD were collected during a pair of cruises along the WAP from January through March 2009. Our study was conducted in the region of the multidecadal Palmer Long-Term Ecological Research (PAL) study (Ducklow et al. 2007). We focused our efforts at three process study stations (PS, Fig. 1). PS1 [64 $29.3^{\prime}$ S, 65 $57.6^{\prime} \mathrm{W}$ ] was located at the northern end of the study area at the site of the PAL moored time-series sediment trap. PS2 [68 $\left.10.5^{\prime} \mathrm{S}, 6^{\circ} 59.8^{\prime} \mathrm{W}\right]$ was located at the head of Marguerite Bay, while PS3 [ $69^{\circ} 31.9^{\prime} \mathrm{S}, 75^{\circ} 30.7^{\prime} \mathrm{W}$ ] was in the far south of the study area, about $20 \mathrm{~km}$ north of Charcot Island.

\section{Measurement of the particle concentration size distribution}

The concentrations of particles in the water column were measured with the Autonomous Video Plankton Recorder (VPR), manufactured by Seascan. The VPR is an underwater video microscope system that takes still images of particles in an undisturbed parcel of water located between the camera housing and strobe illuminator as the instrument is lowered and raised through the water column on a non-conducting wire at approximately $30 \mathrm{~m} \mathrm{~min}^{-1}$. A full description of the instrument can be found in Davis et al. (1996).

At a profiling velocity of $30 \mathrm{~m} \mathrm{~min}^{-1}$, and a sampling frequency of $12 \mathrm{~Hz}$, overlapping image volumes are possible due to ship rolling, but based on successive image analysis, these events are 
rare. Nevertheless, we attempted to avoid overlapping images and double counting of particles by utilizing only every second image from the vertical profile. We conducted two vertical profiles at each location and data was utilized from both the up-casts and the down-casts. The images were analyzed with a custom routine we wrote in MATLAB (The MathWorks) using the image analysis toolbox. Images were converted into grey scale and a threshold was applied to detect regions of interest (ROIs) in the image, yielding a binary map of detected particles. These binary ROIs were then run through a dilation-erosion routine with a three-pixel disk structuring element (Gonzales et al. 2004) to bridge small gaps between loosely associated particles held together by transparent exopolymeric particles (TEP, Passow et al. 2001). The number of pixels associated with each particle was used to calculate the projected particle area in $\mu \mathrm{m}^{2}$. Particles were binned into discrete size bins (Table 1) based on their equivalent spherical diameters (ESD), where ESD is defined as the diameter of the sphere with the same projected area as the imaged particle. It is important to note that ESD is not a perfect description of particle size for particles that have shapes that deviate from that of a sphere. Errors may arise because of rotational asymmetries in particles and the fact that the VPR only views particles from a single direction.

We used zoom setting 'S2' on the VPR which produces a field of view of 2.14 by 2.15 $\mathrm{cm}$ and a depth of field of $13.4 \mathrm{~cm}$. The depth of field was calibrated using a transparent polycarbonate plate with many small holes drilled at regular intervals. This target was moved through the image volume at known intervals and images were processed as usual with a grayscale threshold. Each hole on the target that is within the image volume produces a round particle-like ROI in the captured images. In this manner, the number of ROIs detected was plotted as a function of target distance. The distances at which the slope of this curve reaches a maximum and minimum were defined as the limits of the depth of field. In addition, the distance (in pixels) between the centroids of adjacent ROIs was divided by the known distance (in $\mu \mathrm{m}$ ) between the holes in the polycarbonate target in order to calculate the ratio of pixels per millimeter in the image plane. We found that throughout the image volume, this ratio varied from 43 to 51 pixels $\mathrm{mm}^{-1}$ with a larger ratio at the end of the depth of field closest to the camera. This variability introduces some errors into the determination of each particle's size, but this error is likely to be distributed in a Gaussian manner around the average value of 47 pixels $\mathrm{mm}^{-1}$. Variation of the parameters used in the image analysis routines can also affect the results achieved. We explored a variety of different image processing parameters for the VPR images via manual tuning and subsequent evaluation and verification of the processed images. 
The particle CSD was calculated by dividing the number of particle counts for each size bin by the total imaged volume, where the total imaged volume is equal to the number of images analyzed in that $50 \mathrm{~m}$ depth range multiplied by the image volume of each VPR photograph. Under typical deployment configurations, the total imaged volume for each $50 \mathrm{~m}$ depth bin is approximately $150 \mathrm{~L}$. Each size-specific number concentration value, $C_{i}$, was then normalized by the width of the logarithmically spaced size bin that it occupies (Table 1), giving particle CSD in the units of No. $\mathrm{m}^{-3} \mu \mathrm{m}^{-1}$. The sizes of the depth intervals and particle size bins were chosen somewhat arbitrarily to balance the competing concerns of high resolution with respect to depth and particle size vs. the uncertainties that arise in the CSD from a small number of particle counts in increasingly higher-resolution bins. Uncertainty in the observed CSDs was of particular concern for the largest particles in the size range sampled by the VPR because they are so rare that they needed to be grouped into increasingly larger size bins (hence the logarithmic bin spacing of Table 1) and a large volume of water needed to be sampled (this was accomplished by using $50 \mathrm{~m}$ depth bins).

The CSDs used in this study were determined from VPR deployments conducted during the 36-hour collection phase and within $1 \mathrm{~km}$ of the drifting polyacrylamide gel traps described below. This proximity is essential to this type of comparison study in order to ensure that measurements of the particle flux and concentration are representative of the same particle populations.

\section{Measurement of the particle flux size distribution}

Drifting sediment trap arrays were deployed to measure the sinking flux of particulate matter. The drifter was configured with traps at three depths, where the depths were spaced from about $25 \mathrm{~m}$ below the base of the euphotic zone down to $100 \mathrm{~m}$ above the bottom. Cylindrical traps with a collection area of $0.0113 \mathrm{~m}^{2}$ and a height of $70 \mathrm{~cm}$ were outfitted with a polycarbonate jar containing $200 \mathrm{~mL}$ of $16 \%$ polyacrylamide gel (Fig. 2), a method used in several previous studies (Lundsgaard 1995; Waite and Nodder 2001; Ebersbach and Trull 2008). The gel jar took up the entire area at the base of the trap cylinder. We followed the gel preparation protocol described in F. Ebersbach (unpubl.). Traps collected particles for 36 hours, after which lids were closed, and the drifting array was retrieved within 36 hours of the end of the collection period. Upon retrieval, the gel tubes were allowed to sit for 12 additional hours in order to ensure full penetration of the sinking particles into the viscous gel media. 
The polyacrylamide gels were photographed with a with a Nikon SMZ-1500 stereomicroscope outfitted with a 1 Megapixel digital camera in order to produce images for the analysis of particle size and abundance in the particle flux (Jackson et al. 2005). We used transmitted light, the widest zoom ( $0.75 \mathrm{X}$ objective), and a narrow aperture to maximize the depth of field and allow for the imaging of all the particles in the gel. A faint grid $(1 \mathrm{x} 1 \mathrm{~cm})$ was printed on a transparency film and secured underneath the gel jar facilitating the systematic photography of the gel over its entire area. This process yielded about 80 images that were subsequently merged together manually with the photomerge tool in Photoshop (Adobe Creative Suite 2). These large composite images are about 50 Megapixels, and are capable of resolving particles over a large range of sizes ( $\sim 50 \mu \mathrm{m}$ to several $\mathrm{cm}$ in diameter, Fig. 2$)$. The large composite image was cropped to remove the edges of the gel jars and then processed with Photoshop's edge detection and threshold algorithms. The result is a binary image that identifies the two-dimensional projected shape and area of each particle. Occasionally the large fecal pellets collected in the gels would overlap. To avoid counting two particles as a single larger one, these images were manually edited to separate overlapping particles while preserving the original particle size and shape. The processed binary images were then analyzed in MATLAB in the same manner as those from the VPR. This gives a particle FSD which is reported as the number of particles collected per unit area per time, and then normalized by the width of the logarithmically spaced size bins, and therefore has the units of No. $\mathrm{m}^{-2} \mathrm{~d}^{-1} \mu \mathrm{m}^{-1}$.

Flux collection biases could potentially affect our measurements of the particle FSD. In general, sediment traps are known to suffer from biases in the under or over collection of bulk fluxes. It is also possible that they may select or exclude certain particle sizes or types. Additionally, the flow of water across the trap opening could potentially break apart some of the most delicate aggregates if the fluid shear exceeds the particle's physical strength (Alldredge et al. 1990). The fact that we observed many large and intact diatom and detrital aggregates in the gels (see Results) suggests that there was no severe disaggregation taking place, but given the available data, we cannot rule out the possibility that this process was occurring to some extent. We deployed an acoustic current meter (Falmouth Scientific) at the bottom of the drifting array to measure the water velocities relative to the polyacrylamide gel traps. Relative water velocities were typically at or below $10-15 \mathrm{~cm} \mathrm{~s}^{-1}$, putting the collection conditions within the range of velocities where hydrodynamic flux-biasing concerns are thought to be minor for cylindrical traps with high aspect ratios (Gardner 2000). Moreover the 'Clap' trap design used in this study did 
compare favorably to neutrally buoyant sediment traps with respect to flux and composition in studies conducted in the North Pacific (Lamborg et al. 2008). Unfortunately, the quantitative effects of these types of biases are notoriously difficult to ascertain and predict (Buesseler et al. 2007). Also, like all current sediment trap designs, the gel traps only measure the downward fluxes of particles, and any ascending particles (Azetsu-Scott and Passow 2004) that may be present in the water column would not be accounted for in the flux measurement.

\section{Calculation of average sinking velocities}

With measurements of the particle FSD and CSD we calculated the ASVD at each location and time that there were simultaneous measurements of particle flux and concentration. This was done by dividing $F_{i}$ by $C_{i}$ (Eq. 1), giving $W_{i, \text { avg }}$ in units of $\mathrm{m} \mathrm{d}^{-1}$. By this methodology, if neutrally or positively buoyant particles are present in the water column, they would contribute velocities of $0 \mathrm{~m} \mathrm{~d}^{-1}$ to the average, as they would be detected with the VPR, but not collected in the polyacrylamide gel traps.

\section{Error analysis}

The errors associated with each particle flux and concentration measurement are dependent on the number of particles detected in each case. Following counting statistics theory, the standard deviation associated with each measurement was computed as the square root of the number of particle counts. Thus, the greater the number of particle counts, the smaller the relative error. The error in $W_{i, \text { avg }}$ was computed via propagation of error from the relative errors in the flux and concentration data using the formulation appropriate for the division of two variables,

$$
\frac{\sigma_{W_{i, \text { avg }}}}{W_{i, \text { avg }}}=\sqrt{\left(\frac{\sigma_{F_{i}}}{F_{i}}\right)^{2}+\left(\frac{\sigma_{C_{i}}}{C_{i}}\right)^{2}-2 \frac{\sigma_{F_{i}} \sigma_{C_{i}}}{F_{i} C_{i}} \rho_{F, C}}
$$

where $\rho_{F, C}$ is the Pearson's correlation coefficient and $\sigma$ is the standard deviation of each respective variable. Using all of the flux and concentration data pairs in this study, we determined a $\rho_{F, C}$ of 0.74 .

\section{Results}

The high resolution of the merged gel images allowed for the accurate determination of particle flux from about $44 \mu \mathrm{m}$ to $2300 \mu \mathrm{m}$. Smaller particles were unable to be reliably 
resolved, and particles larger than $2300 \mu \mathrm{m}$ were so rarely collected in the polyacrylamide gel traps that it was difficult to quantify their exact flux. The measured particle fluxes in this size range varied from to $10^{-1}$ particles $\mathrm{m}^{-2} \mathrm{~d}^{-1} \mu \mathrm{m}^{-1}$ for the largest particles to $7 \times 10^{4}$ particles $\mathrm{m}^{-2} \mathrm{~d}^{-1}$ $\mu \mathrm{m}^{-1}$ for the smallest size class (Figs. 3, 4, 5). A close visual inspection of the gel images reveals that most of the particles could be separated into two distinct particle types: small particles that are nearly spherical and long cylindrical fecal pellets (Fig. 2). The small particles include diatom aggregates, detritus, and protozoans and their minipellets (González 1992), while the large cylindrical fecal pellets are primarily from the Antarctic krill species Euphausia superba (D. Steinberg pers. comm.). The fact that we observed marine snow aggregates still intact in the gel suggests that the gel trap is quite effective at preserving the structure of even the most fragile particles.

Particle concentrations ranged from $10^{-2}$ to $10^{3}$ particles $\mathrm{m}^{-3} \mu \mathrm{m}^{-1}$ (Figs. 3, 4, 5) and followed similar patterns with respect to ESD as have been widely observed for collections of natural particles in the ocean (Jackson et al. 1997; Guidi et al. 2008). The detectable size range from the VPR was slightly more restricted than that of the polyacrylamide gel traps and reliably ranged from 73 to $1400 \mu \mathrm{m}$. Particles larger than this were either not present or far too rare to quantify based on the volume of water imaged with the VPR. Additionally, on the zoom setting used in this study, the VPR has an image area of $2.14 \times 2.15 \mathrm{~cm}$, so particles that approach this size are unlikely to be fully imaged, and therefore were omitted from the image analysis routine. As the large particles were the most rarely encountered, their concentrations are subject to the largest errors. The digital resolution of the VPR theoretically allows for the detection of particles as small as $25 \mu \mathrm{m}$, but this is approaching the size of an individual pixel, and therefore is difficult to distinguish from image noise. There is also the potential for certain particles to be undersampled by the VPR, particularly at the small end of the size spectrum (Jackson et al. 1997). Because of this, we only report concentration data for particles with an ESD larger than $73 \mu \mathrm{m}$.

\section{Average sinking velocities}

During the January deployments at the three process stations, $W_{i \text {,avg }}$ ranged from about 25 to $150 \mathrm{~m} \mathrm{~d}^{-1}$ depending on the size class and location (Fig. 3C, F, I). The general pattern of the ASVD during January was similar between all three sites. The slowest velocities of about $25 \mathrm{~m}$ $\mathrm{d}^{-1}$ were found for particles with ESDs of about 120 to $320 \mu \mathrm{m}$. Particles with ESDs smaller than $120 \mu \mathrm{m}$ and larger than about $320 \mu \mathrm{m}$ sank more quickly than those in the middle size classes. 
$W_{i, \text { avg }}$ increased with increasing ESD from about $320 \mu \mathrm{m}$ up to $1400 \mu \mathrm{m}$ for these three stations. Particles larger than $1400 \mu \mathrm{m}$ were rare and, as a result, it was difficult to accurately determine their fluxes and concentrations. When a few of the largest particles were observed (Fig. 3, open bars), the calculated $W_{i, \text { avg }}$ generally showed elevated sinking velocities relative to other size classes at all three process stations in January, but the errors due to low particle counts prevent us from drawing firm conclusions about $W_{i, \text { avg }}$ for the largest size classes.

The ASVD was also calculated at three different depths at each site. Fig. 4 shows the flux, concentration, and calculated ASVD at 50, 150, and $250 \mathrm{~m}$, from the January 2009 deployment at PS1. There was some variability in $W_{i, \text { avg }}$ with respect to depth especially at the larger size classes (Fig. 4C, F, I). In particular, $W_{i, \text { avg }}$ was significantly faster at $250 \mathrm{~m}$ when compared to $150 \mathrm{~m}$ depth for all size classes larger than $120 \mu \mathrm{m}$. At $50 \mathrm{~m}$, the VPR showed low particle concentrations (Fig. 4B), which led to large errors in $W_{i, \text { avg }}$ and greater variability with respect to ESD. At the deeper trap depths, particle concentrations were higher and the errors associated with a small number of particle counts were less pronounced.

The ASVD did not always follow the same pattern of high velocities for the smallest and largest particles, as was observed at the three process stations in January. A repeat occupation of PS2 in late February yielded significantly different results (Fig. 5). In February, the smallest particle size bin had the fasted calculated $W_{i, \text { avg }}$ of $295 \mathrm{~m} \mathrm{~d}^{-1}$ and the ASVD declined sharply as a function of ESD until the largest size class of 850-1400 $\mu \mathrm{m}$ which had an $W_{i, \text { avg }}$ of only $9 \mathrm{~m} \mathrm{~d}^{-1}$. As discussed above, the ASVD observed in January at PS2 had high velocities for the largest particles and a high $W_{i, \text { avg }}$ of $145 \mathrm{~m} \mathrm{~d}^{-1}$ for the smallest size class, with particles in the middle of the size range having the slowest calculated average sinking velocities. Fig. 5A, E shows portions of the gels from PS2 during both the January and the February occupations. In January, there was an abundance of large krill fecal pellets and few small particles collected in the polyacrylamide gel traps. Approximately one month later at the same location, large krill fecal pellets were not present in the gel traps and there was an increase in the flux of the smaller aggregates and mini-pellets. The resulting ASVD from these two occupations are markedly different.

\section{Discussion}

The fact that the highest sinking velocities were found in the largest and smallest size classes was a surprising result, especially given that most models of sinking velocity (e.g., 
Stokes' Law) predict increasing settling speeds as particle size increases. Closer inspection of the material collected in the polyacrylamide gel traps reveals that the majority of particles were made up of two dominant particle sizes. Many individual diatoms and radiolarians were present with ESDs in the 70-120 $\mu \mathrm{m}$ size range. With their dense frustules and skeletons, these small particles were likely sinking quickly, and therefore would have had high abundances in the gels relative to their measured concentrations in the water column. On the large end of the FSD, fecal strands from the Antarctic krill species Euphausia superba dominated the flux and led to high $W_{i, \text { avg }}$ in these size classes. Thus it is likely that these two distinct particle groups sink very rapidly and therefore lead to high $W_{i, \text { avg }}$ in their respective size bins. Previous direct measurements of the sinking velocities of Euphausiid fecal pellets range from 16-862 $\mathrm{m} \mathrm{d}^{-1}$ while marine snow was observed to have a more restricted upper limit with sinking velocities of 16-368 $\mathrm{m} \mathrm{d}^{-1}$ (Turner 2002). Fecal pellets generated by Euphausia superba specimens from our January 2009 cruise had velocities of $200 \mathrm{~m} \mathrm{~d}^{-1}$ as determined by laboratory settling column measurements (D. Steinberg, pers. comm.). Our calculated $W_{i, \text { avg }}$ are consistent with these measurements. In addition, since $W_{i, \text { avg }}$ is the average sinking velocity of all particles in the water column of a given size, we expect these values to be in the middle of the range of sinking velocities measured via direct methods, and this is in fact what we observed.

The subtle variations that exist between the three locations presented in Fig. 3 can be explained by real changes in the actual sinking velocities of individual particles, differences in the assemblages of particles present, or a combination of those two factors. Real changes in the sinking velocities of particles are possible and could occur for a variety of reasons. For example, the excess densities of particles could be different due to diet changes in the krill populations (Bienfeng 1980). Changes in the fractal nature of aggregates could change their excess densities or drag coefficients (Stemmann et al. 2004). Another factor that could alter $W_{i, \text { avg }}$ is differences in the types of particles present for a given size class, or even a shift in their relative abundances. In the case of PS3, the gel trap at $150 \mathrm{~m}$ contained many large aggregates made up of long fecal pellets joined to diatom aggregates. These joint fecal pellet-diatom aggregates were unique to this station and could be the reason why higher sinking velocities of $150 \mathrm{~m} \mathrm{~d}^{-1}$ were observed at this location for these large size classes.

The striking change in the ASVD between the two occupations of PS2 in Marguerite Bay (Fig. 5) illustrates how a seasonal succession in community structure can strongly affect the relationship between the flux and concentration of particles in the water column. Previous studies 
assumed this variability was insignificant and that a single parameterization relating bulk fluxes to CSD measurements was capable of accurately estimating particle flux from measurements of CSD (Guidi et al. 2008). However, our results demonstrate that this approach could introduce large errors if this variability is not properly taken into account.

\section{Interpreting the variability in the ASVD}

We explored how changes in the relative abundances of different particle types with characteristically different sinking velocities can affect the observed ASVD. This was accomplished by constructing a simple model of particle sinking velocities based on Stokes' Law. Noticing that the flux of particles collected in the gel traps consisted primarily of two distinctive particle types, small spherical particles and large cylindrical fecal pellets, we utilized the appropriate permutations of Stokes' Law to describe the sinking velocities of these two particle groups as a function of particle size.

For the spherical particles typical of the small size classes, we used the standard form of Stokes' Law given by

$W_{\text {sphere }}=\frac{2\left(\rho_{p}-\rho_{f}\right) r^{2} g}{9 \mu}$

where $W_{\text {sphere }}$ is the sinking velocity of a solid sphere, $r$ is the particle radius, $g$ is the acceleration of gravity, $\rho_{p}$ and $\rho_{f}$ are the densities of the particle and fluid respectively, and $\mu$ is the dynamic viscosity of the seawater. We utilized a dynamic viscosity typical of WAP waters $\left(1.88 \times 10^{-3} \mathrm{~Pa}\right.$ $\mathrm{s})$, and a particle density, $\rho_{p}$, of $1.25 \mathrm{~g} \mathrm{~cm}^{-3}$ to be representative of the diatomaceous matter of the particles at the smaller end of the size spectrum (Sicko-Goad et al. 1984). This parameterization is plotted as the solid curves in Fig. 6B, D.

The second particle type we considered was cylindrical fecal pellets. We use the semiempirical equation reported by Komar (1980) for cylindrical particles at low Reynolds numbers.

$W_{\text {cylinder }}=\frac{0.079\left(\rho_{p}-\rho_{f}\right) \mathrm{L}^{2} g}{\mu}\left(\frac{\mathrm{L}}{\mathrm{D}}\right)^{-1.664}$ 
We determined an average fecal pellet diameter (D), of $120 \mu \mathrm{m}$ from the gel images. The fecal pellet length (L), was then calculated by dividing the projected particle area for each ESD size bin by D. We used a particle density of $1.174 \mathrm{~g} \mathrm{~cm}^{-3}$, as this was carefully determined for krill fecal pellets produced under a natural diet of diatoms (Bienfang 1980). The dashed curves in Fig. 6B, D show the sinking velocities of krill fecal pellets as a function of ESD. As expected, the cylindrical particles have slower velocities than their spherical counterparts due to the higher drag forces acting upon them. In addition, the sinking velocity of the cylindrical fecal pellets increases more slowly as a function of ESD than that of the spherical particles.

In order to account for the dominance of the spherical type particles in the smaller size classes and the cylindrical fecal pellets in the larger size classes, we varied the relative abundances of the two particle types across the observable size spectrum in a manner that was representative of the particle populations observed in both the January and February occupations of PS2. These inputs of relative particle abundance are described in graphical form in Fig. 6A, C. In addition to the two categories of sinking particles, we included a third neutrally buoyant particle type (sinking velocity equal to zero at all sizes), whose relative abundance was estimated by analyzing the differences between the FSD and the CSD. In the case when there was a high concentration of large particles present in the water column but very few found in the gels, we assumed that there were a large proportion of non-sinking particles. The average sinking velocity was then computed for each size class as the abundance-weighted average of the spherical, cylindrical, and non-sinking particle velocities and plotted as bar graphs in Fig. 6B, D. It is important to note that we use this simple model solely to aid in the interpretation of our experimentally determined ASVD in this particular region. It is formulated in a way that is specific to the observations of particle types that we made along the WAP in 2009 and, as such, we don't recommend its wide or general application as a predictive model of particle flux.

In the model run parameterized to represent the relative abundances present in January, the ASVD came to a local maximum of $120 \mathrm{~m} \mathrm{~d}^{-1}$ at an ESD of $150 \mu \mathrm{m}$, and decreased to slower velocities for particles with an ESD of between 250 and $1000 \mu \mathrm{m}$ (Fig. 6A, B). Between $400 \mu \mathrm{m}$ and $9 \mathrm{~mm}, W_{i, \text { avg }}$ increased due to the increasing velocities of the cylindrical fecal pellets as a function of particle size (Fig. 6B, dotted curve). A comparison of the modeled ASVD in Fig. 6B to the observed ASVD in Fig. 5D reveals similarities in both the magnitude of the velocities and their dependencies on particle size. 
Can this simple model be used to explain the major change we observed in the ASVD at PS2 between January and February? We addressed this question by conducting a second model run, this time without the large cylindrical fecal pellets (Fig. 6C), similar to the conditions observed in February at PS2. As we expect, in the absence of cylindrical fecal pellets, the modeled ASVD drops quickly to very low velocities after peaking at an ESD of $150 \mu \mathrm{m}$ (Fig. 6D), just as we observed during the February occupation of PS2 (Fig. 5H). It is worth noting that without the inclusion of a third non-sinking particle category, the modeled ASVD would continue to increase as a function of increasing size, in accordance with Stokes' Law. The observation that the ASVD dropped to almost zero at the larger size classes in the case of February's occupation of PS2 confirms the presence of significant quantities of very slow sinking or neutrally buoyant particles of those large sizes in the water column.

The results from this simple model suggest that the relative abundances of different particle types coupled with their characteristic sinking velocities can affect the ASVD in a manner that cannot be predicted from a single formulation of Stokes' Law. It is likely that the majority of the variations in the ASVD that we observed in this study were primarily driven by changes in the relative abundances of different types of sinking particles.

These ASVD results are important because several studies have attempted to estimate particle flux from the particle CSD (Guidi et al. 2007; Guidi et al. 2008; Iversen et al. 2010). The framework for these flux estimates is almost always some modeled formulation of Stokes' Law in which the sinking velocity is a function of the particle size with the largest particles sinking


collections of particles found in the water column, the velocities of these particles did not follow the pattern suggested by a single formulation of Stokes' Law. While Stokes' Law is clearly still valid for individual solid spherical particles at low Reynolds numbers, it is likely that variations in the excess density of particles and their drag coefficients result in ASVD that are not easily predictable from measurements of ESD alone. This means that it is important to determine the ASVD through direct measurements such as those presented in this paper in order to accurately estimate particle fluxes from the CSD. In addition, our results show that one general ASVD relationship is not applicable across all regional spatial scales and seasonal time scales in the ocean, and that these paired measurements of flux and concentration need to be made on scales that appropriately capture the variability of the ASVD. 
Another way to approach this question would be to sort particles by type rather than arbitrary size classes. In the case of the WAP, particles could be classified into several categories such as those mentioned above. This would allow us to use Eq. 1 to calculate the average sinking velocity for each particle type or even an ASVD for each particle type. Because we might expect particles of the same type to have similar sinking velocities, it is possible that classifying particles by type would remove some of the observed variability in ASVD that arises due to the presence, absence or variable abundances of these different particle types with their characteristic sinking velocities at various depths, locations, or times. This could potentially increase the range of spatial and temporal scales over which one determination of the ASVD is applicable, making it more useful in calculating particle fluxes from measurements of particle concentration. We are currently developing methods to automatically sort and identify particles in images from the VPR and the polyacrylamide gels in order to explore the utility of particle classification in the determination of average sinking velocities.

Multiplication of the CSD by the ASVD (Eq. 1) determined here could yield highresolution estimates of the FSD. But to convert this number flux into a biogeochemical flux, we would need to know the particle volume flux and carbon content of particles as a function of ESD. Volume flux can be calculated by either assuming all particles are spherical or by using a more sophisticated method that takes into account the shape of the two-dimensional projection of each particle. Converting the volume flux to a carbon flux requires knowledge of carbon content per unit volume of particle. Unfortunately, this parameter is poorly constrained and difficult to determine. Guidi et al. (2008) addressed the problem by fitting a power law relationship for a combined function of particle mass concentration and sinking velocity to bulk fluxes measured in sediment traps. Ebersbach and Trull (2008) relied on literature values of carbon density per particle volume for a few different particle types. Another way to do this would be to deploy in situ pumps with a few different mesh sizes. This would give a carbon concentration per unit volume of seawater as a function of nominal particle size. Comparison of these concentrations with the measured CSD would allow for an estimate of the carbon density of the particles. All of these methods have significant uncertainties and more work is needed to improve our understanding of organic carbon content per particle volume before in situ imaging of particles becomes a valuable tool in estimating sinking carbon fluxes at high resolutions. Similarly, if the volume content of other interesting elements is able to be determined, it would be possible to use 
in situ imaging systems for the estimation of other elemental fluxes such as nitrogen, particulate inorganic carbon, biogenic silica, etc.

The approach presented here represents a new way to quantify the ASVD of marine particulate matter. The results of this paper highlight the fact that the ASVD is variable in space and time and depends on the relative abundances of particles as well as their respective sinking velocities. This variability implies that global relationships between particle concentrations and fluxes or simple theoretical formulations of sinking velocity as function of particle size such as a single parameterization of Stokes' Law are unsuitable for yielding accurate estimates of particle flux from measurements of particle concentration. Instead, the ASVD should be determined frequently in order to best constrain the relationship between particle stocks in the water column and the sinking flux of particulate matter. This approach will aid in the elucidation of the mechanisms that control the flux of particulate matter into the ocean's interior, and will be useful in the validation and testing of models of particle flux.

\section{Acknowledgements}

We thank the principal investigators of the Palmer Long-Term Ecological Research Program (PAL) and the Food For Benthos on the Antarctic Continental Shelf Project (FOODBANCS) for accommodating our science on their respective cruises to the west Antarctic Peninsula in 2009. The captain, crew, and Raytheon Polar Services Company staff aboard the Antarctic Research and Supply Vessel Laurence M. Gould and onshore did an excellent job helping us achieve our sampling objectives in this challenging work environment. We are very grateful to Tom Trull, who first suggested this approach. Scott Gallager, Mick Follows, Phoebe Lam, Phil Boyd, Debbie Steinberg, Dave Siegel, Dave Glover, and Stephanie Owens provided constructive comments and suggestions. James Valdes made possible much of the underwater instrumentation associated with the drifting sediment trap array. Seascan Inc. provided valuable technical support for the Video Plankton Recorder. We thank Adrian Burd, Thomas Kiørboe and an anonymous reviewer for their comments that greatly improved this manuscript during the review process. Funding was provided by the Woods Hole Oceanographic Institution (WHOI) Rinehart Access to the Sea Program, the WHOI Coastal Oceans Institute, WHOI Academic Programs Office, and the National Science Foundation (NSF) Office of Polar Programs for support of PAL, FOODBANCS, and west Antarctic Peninsula Flux projects. A grant from NSF Carbon and Water Program supported the development of these methods. 


\section{References}

Alldredge, A. L., and C. Gotschalk. 1988. In situ settling behavior of marine snow. Limnol. Oceanogr. 33: 339-351.

Alldredge, A. L., T. C. Granata, C. C. Gotschalk, and T. D. Dickey. 1990. The physical strength of marine snow and its implications for particle disaggregation in the ocean. Limnol. Oceanogr. 35:1415-1428.

Armstrong, R. A., M. L. Peterson, C. Lee, and S. G. Wakeham. 2009. Settling velocity spectra and the ballast ratio hypothesis. Deep-Sea Res. II 56: 1470-1478.

Asper, V. L. 1987. Measuring the flux and sinking speed of marine snow aggregates. Deep-Sea Res. 34: 1-17.

Asper, V. L., S. Honjo, and T. H. Orst. 1992. Distribution of transport of marine snow aggregates in the Panama Basin. Deep-Sea Res. 39: 939-952.

Asper, V. L., and W. O. Smith. 2003. Abundance, distribution and sinking rates of aggregates in the Ross Sea, Antarctica. Deep-Sea Res. I 50: 131-150.

Azetsu-Scott, K., and U. Passow. 2004. Ascending marine particles: significance of transparent exopolymer particles (TEP) in the upper ocean. Limnol. Oceanogr. 49: 741-748.

Berelson, W. M. 2002. Particle settling rates increase with depth in the ocean, Deep-Sea Res. II 49: 237-251.

Bienfang, P. K. 1980. Herbivore diet affects fecal pellet settling. Can. J. Fish. Aquat. Sci. 37: $1352-1357$.

Broecker, W., and T. Peng. 1982. Tracers in the Sea. Lamont-Doherty Geol. Obs. Eldigio Press.

Buesseler, K. O., A. N. Antia, M. Chen, S. W. Fowler, W. D. Gardner, O. Gustafsson, K. Harada, A. F. Michaels, M. van der Loeff, and M. Sarin. 2007. An assessment of the use of sediment traps for estimating upper ocean particle fluxes. J. Mar. Res. 65: 345-416.

Davis, C. S., S. M. Gallager, M. Marra, and W. K. Stewart. 1996. Rapid visualization of plankton abundance and taxonomic composition using the Video Plankton Recorder. Deep Sea-

Res. II 43: 1947-1970.

De La Rocha, C. L., N. Nowald, and U. Passow. 2008. Interactions between diatom aggregates, minerals, particulate organic carbon, and dissolved organic matter: Further implications for the ballast hypothesis. Glob. Biogeochem. Cycles 22: GB4005, doi:10.1029/2007GB003156.

Diercks, A. R., and V. L. Asper. 1997. In situ settling speeds of marine snow aggregates below the mixed layer: Black Sea and Gulf of Mexico. Deep-Sea Res. I 44: 385-398.

Ducklow, H., K. Baker, D. G. Martinson, L. B. Quetin, R. M. Ross, R. C. Smith, S. E. Stammerjohn, M. Vernet, and W. Fraser. 2007. Marine pelagic ecosystems: the West Antarctic Peninsula. Philos. Trans. R. Soc., B. 362: 67-94.

Ebersbach, F., and T. Trull. 2008. Sinking particle properties from polyacrylamide gels during the KErguelen Ocean and Plateau compared Study (KEOPS): Zooplankton control of carbon export in an area of persistent natural iron inputs in the Southern Ocean. Limnol. Oceanogr. 53: 212-224.

Fowler, S., and G. Knauer. 1986. Role of large particles in the transport of elements and organic compounds through the oceanic water column. Prog. in Oceanogr. 16: 147-194.

Gardner, W. D. 2000. Sediment trap technology and surface sampling in surface waters, p. 240281. In R. B. Hanson, H. W. Ducklow and J. G. Field [eds.], The changing ocean carbon cycle, a midterm synthesis of the Joint Global Ocean Flux Study. Cambridge Univ. Press.

González, H. E. 1992. Distribution of minipellets around the Antarctic peninsula. Implications fro protistan feeding behaviour. Mar. Ecol. Prog. Ser. 90: 223-236. 
González, R. C., R. E. Woods, and S. L. Eddins. 2004. Digital image processing using MATLAB. Pearson Prentice Hall.

Gorsky, G., N. S. Fisher, and S. W. Fowler. 1984. Biogenic debris from the pelagic tunicate, Oikopleura dioica, and its role in the vertical transport of a transuranium element. Estuar. Coast. Shelf Sci. 18: 13-23.

Guidi, L., L. Stemmann, L. Legendre, M. Picheral, L. Prieur, and G. Gorsky. 2007. Vertical distribution of aggregates $(>110 \mu \mathrm{m})$ and mesoscale activity in the northeastern Atlantic: Effects on the deep vertical export of surface carbon. Limnol. Oceanogr. 52: 7-18.

Guidi, L., G. A. Jackson, L. Stemmann, J. C. Miquel, M. Picheral, and G. Gorsky. 2008. Relationship between particle size distribution and flux in the mesopelagic zone. DeepSea Res. I 55: 1364-1374.

Hansen, J., T. Kiørboe, and A. Alldredge. 1996. Marine snow derived from abandoned larvacean houses: sinking rates, particle content and mechanisms of aggregate formation. MEPS 141: 205-215.

Honjo, S. 1996. Fluxes of particles to the interior of the open oceans, p. 91-113. In V. Ittekkot, P. Schäfer, S. Honjo and P. J. Depetris, [eds.]. Particle Flux in the Ocean. Wiley.

Iversen, M. H., N. Nowald, H. Ploug, G. A. Jackson, and G. Fischer. 2010. High resolution profiles of vertical particulate organic matter export off Cape Blanc, Mauritania: Degradation processes and ballasting effects. Deep-Sea Res. I 57: 771-784.

Jackson, G. A., R. Maffione, D. K. Costello, A. L. Alldredge, B. E. Logan, and H. G. Dam. 1997. Particle size spectra between $1 \mu \mathrm{m}$ and $1 \mathrm{~cm}$ at Monterey Bay determined using multiple instruments. Deep-Sea Res. I 45: 1739-1767.

Jackson, G. A., A. M. Waite, and P. W. Boyd. 2005. Role of algal aggregation in vertical carbon export during SOIREE and in other low biomass environments. Geophys. Res. Letters 32: L13607.

Komar, P. 1980. Settling velocities of circular cylinders at low Reynolds numbers. The Journal of Geology. 88: 327-336.

Lamborg, C., K. O. Buesseler, J. Valdes, C. H. Bertrand, R. Bidigare, S. Manganini, S. Pike, D. Steinberg, T. Trull, and S. Wilson. 2008. The flux of bio-and lithogenic material associated with sinking particles in the mesopelagic twilight zone of the northwest and North Central Pacific Ocean. Deep-Sea Res. II 55: 1540-1563.

Lee, C., M. L. Peterson, S. G. Wakeham, R. A. Armstrong, J. K. Cochran, J. C. Miquel, S. W. Fowler, D. Hirschberg, A. Beck, and J. Xue. 2009. Particulate organic matter and ballast fluxes measured using time-series and settling velocity sediment traps in the northwestern Mediterranean Sea. Deep-Sea Res. II 56: 1420-1436.

Lundsgaard, C. 1995. Use of a high viscosity medium in studies of aggregates, p. 141-152. In S. Floderus, A. S. Heisakanen, M. Oleson and P. Wassman [eds.], Sediment trap studies in the Nordic countries 3. Proceedings of the Symposium on Seasonal Dynamics of Planktonic Ecosystems and Sedimentation in Coastal Nordic Waters. Finnish Environment Agency.

Passow, U., R. F. Shipe, A. Murray, D. K. Pak, M. A. Brzezinski, and A. L. Alldredge. 2001. The origin of transparent exopolymer particles (TEP) and their role in the sedimentation of particulate matter. Continental Shelf Research 21: 327-346.

Peterson, M. L., S. G. Wakeham, C. Lee, M. A. Askea, and J. C. Miquel. 2005. Novel techniques for collection of sinking particles in the ocean and determining their settling rates.

Limnol. Oceanogr.: Methods 3: 520-532. 
Ploug, H., M. H. Iversen, and G. Fischer. 2008. Ballast, sinking velocity, and apparent diffusivity within marine snow and zooplankton fecal pellets: Implications for substrate turnover by attached bacteria. Limnol. Oceanogr. 53: 1878-1886.

Sarmiento, J. L., and N. Gruber. 2006. Ocean biogeochemical dynamics. Princeton Univ. Press.

Shanks, A. L., and J. D. Trent. 1980. Marine snow: sinking rates and potential role in vertical $\mathrm{f}$ lux. Deep-Sea Res. 27: 137-143.

Sicko-Goad, L., C. Schelske, and E. Stoermer. 1984. Estimation of intracellular carbon and silica content of diatoms from natural assemblages using morphometric techniques. Limnol. Oceanogr. 29: 1170-1178.

Silver, M. W. and A. L. Alldredge. 1981. Bathypelagic marine snow: deep-sea algal and detrital community. J. Mar. Res. 39: 501-530.

Stemmann, L., G.A. Jackson, and D. Ianson. 2004. A vertical model of particle size distributions and fluxes in the midwater column that includes biological and physical processes-Part I: model formulation. Deep-Sea Res. I 51: 865-884.

Trull, T., S. G. Bray, K. O. Buesseler, C. H. Lamborg, S. Manganini, C. Moy, and J. Valdes. 2008. In situ measurement of mesopelagic particle sinking rates and the control of carbon transfer to the ocean interior during the Vertical Flux in the Global Ocean (VERTIGO) voyages in the North Pacific. Deep-Sea Res. II 55: 1684-1695.

Turner, J.T. 2002. Zooplankton fecal pellets, marine snow and sinking phytoplankton blooms. Aquat. Microb. Ecol. 27: 57-102.

Volk, T. and M. I. Hoffert. 1985. Ocean carbon pumps-Analysis of relative strengths and efficiencies in ocean-driven atmospheric $\mathrm{CO} 2$ changes, p. 99-110. In The carbon cycle and atmospheric CO2: natural variations archean to present. Geophysical Monograph 32, American Geophysical Union, Wash., D. C.

Waite, A., and S. Nodder. 2001. The effect of in situ iron addition on the sinking rates and export flux of Southern Ocean diatoms. Deep-Sea Res. II 48: 2635-2654.

Walsh, I. D., and W. D. Gardner. 1992. A comparison of aggregate profiles with sediment trap fluxes. Deep-Sea Res. 39: 1817-1834.

Xue, J., and R. A. Armstrong. 2009. An improved "benchmark" method for estimating particle settling velocities from time-series sediment trap fluxes. Deep-Sea Res. II 56: 1479-148 
Table 1. Particles were divided into one of eleven size bins according to their computed equivalent spherical diameter (ESD). These bins are logarithmically spaced and defined by the ESD limits listed in this table.

\begin{tabular}{lll}
\hline ESD Bin & $\begin{array}{l}\text { Lower } \\
\text { limit }(\mu \mathrm{m})\end{array}$ & $\begin{array}{l}\text { Upper limit } \\
(\mu \mathrm{m})\end{array}$ \\
\hline 1 & 45 & 73 \\
2 & 73 & 120 \\
3 & 120 & 195 \\
4 & 195 & 320 \\
5 & 320 & 520 \\
6 & 520 & 850 \\
7 & 850 & 1400 \\
8 & 1400 & 2290 \\
9 & 2290 & 3740 \\
10 & 3740 & 6110 \\
11 & 6110 & 10,000 \\
\hline
\end{tabular}






Figure 1. Simultaneous measurements of particle flux and concentration were conducted at three process study (PS) stations on the continental shelf along the west Antarctic Peninsula from January through March 2009. PS1 and PS2 were each occupied twice during the season, allowing for temporal coverage. 

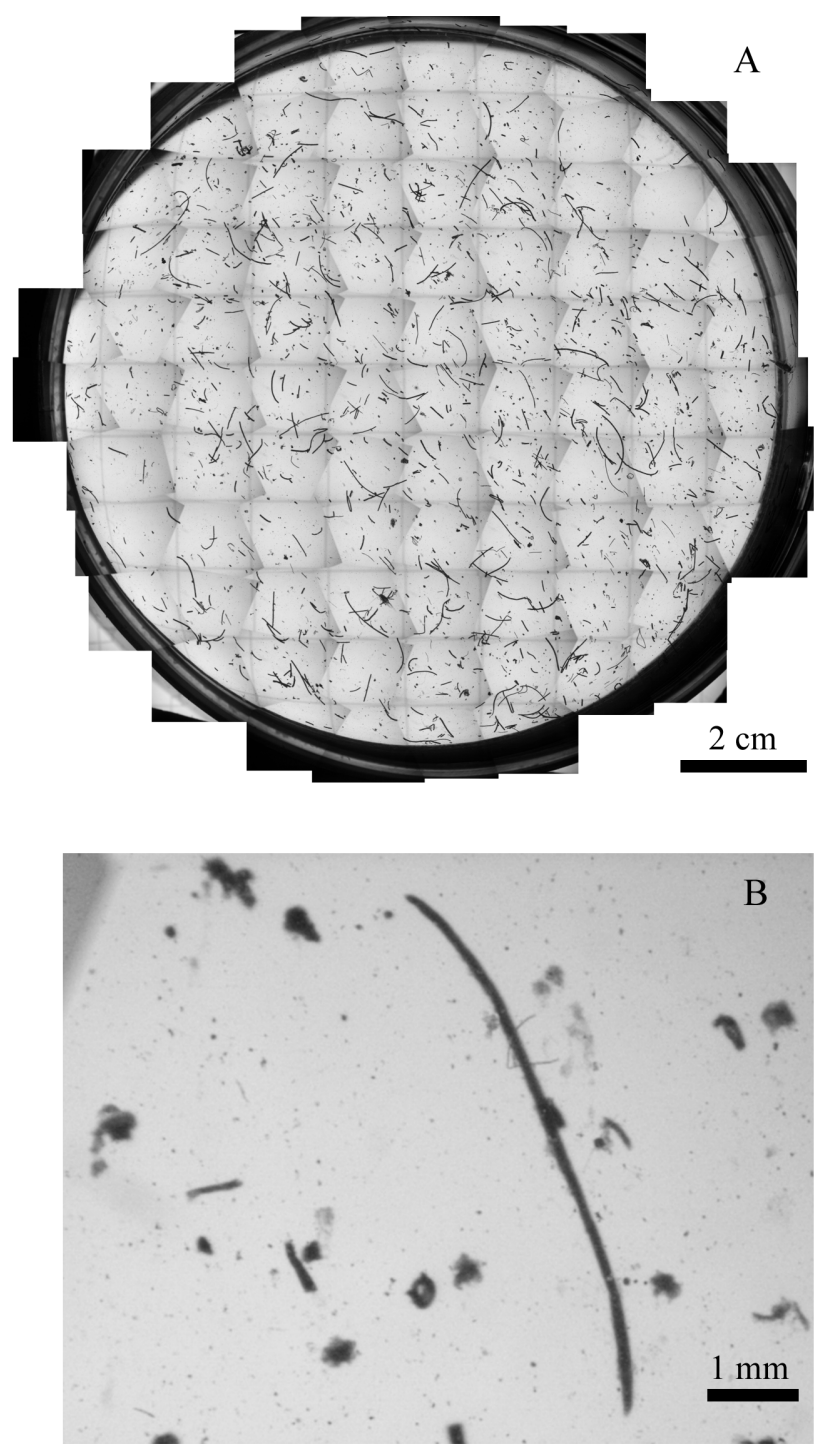

Figure 2. Viscous polyacrylamide gels are placed in the base of drifting cylindrical sediment traps to collect intact sinking particles and preserve their individuality. These gels are systematically photographed with a microscope and analyzed in MATLAB yielding the particle size distribution of the sinking flux. (A) shows an overall image of the gel created by merging 87 photographs. (B) is a detail of the same gel samples showing the range of particle sizes and types. Krill fecal strands and small diatom aggregates dominate the sinking flux. This gel was collected at PS1 on 05-06 March 2009 (a 35.5 hour collection duration) at a depth of $150 \mathrm{~m}$. 



Figure 3. Particle size distributions for three locations along the WAP illustrate the relationship between the $(\mathrm{A}, \mathrm{D}, \mathrm{G})$ particle flux, $(\mathrm{B}, \mathrm{E}, \mathrm{H})$ concentration, and $(\mathrm{C}, \mathrm{F}, \mathrm{I})$ average sinking velocity. The calculated $W_{i, \text { avg }}$ range from about $20 \mathrm{~m} \mathrm{~d}^{-1}$ to about $150 \mathrm{~m} \mathrm{~d}^{-1}$, with the highest velocities for the particles with the smallest and largest ESD collected in the traps. Intermediatesized particles had the lowest velocities. Error bars display the standard deviations for each size bin. Open bars indicate that fewer than six particles were counted in that size bin, and therefore the associated errors are high and difficult to quantify, but we include these data for the additional information they may provide. Two vertical grid lines are used to aid the eye in the alignment of the different size classes. Flux data is from the $150 \mathrm{~m}$ trap at PS1 and PS3, and the $200 \mathrm{~m}$ trap at PS2. CSD are averages from the $50 \mathrm{~m}$ of the water column immediately above the trap. 

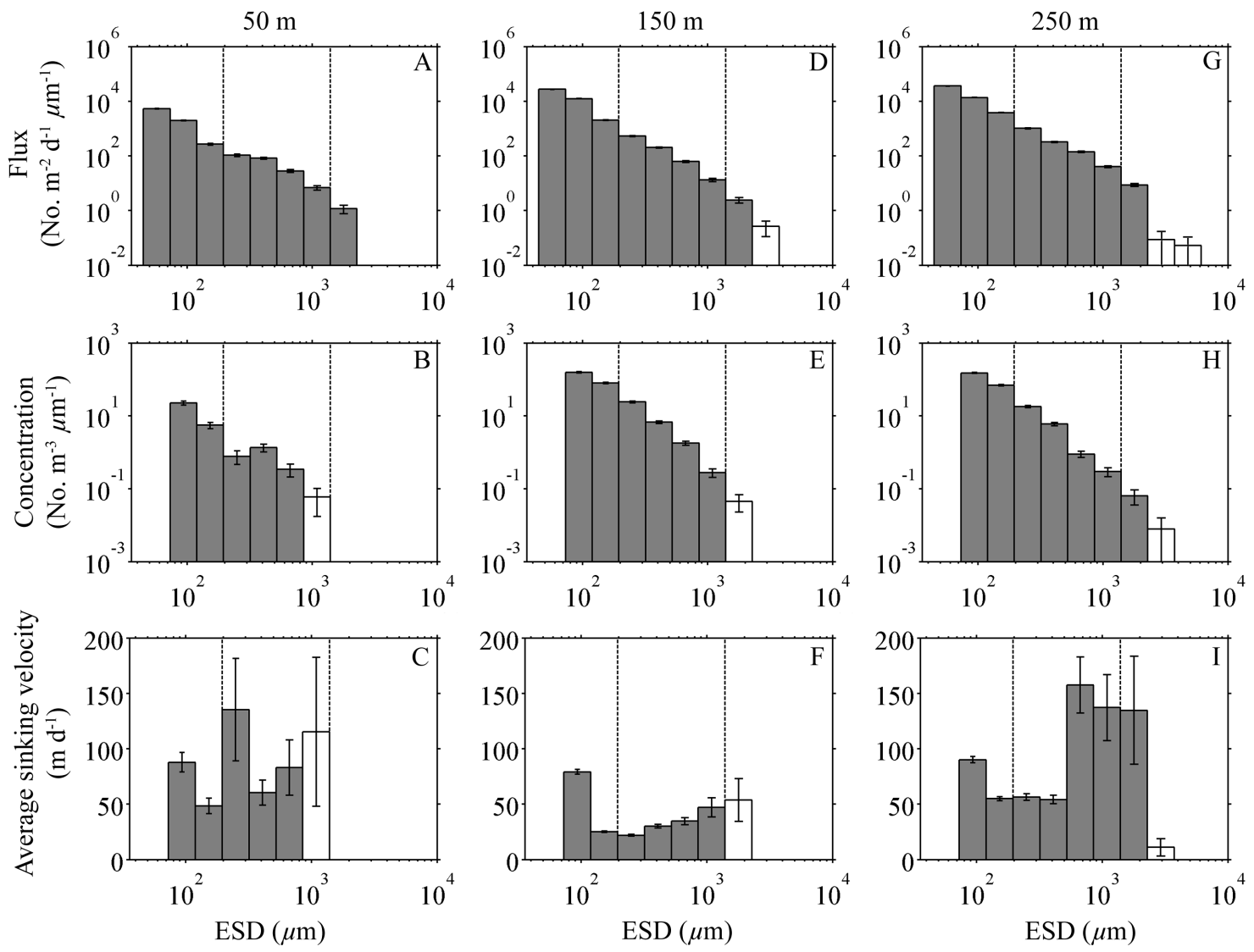

Figure 4. Particle size distributions during the January 2009 occupation of PS1 illustrate the relationship between the $(\mathrm{A}, \mathrm{D}, \mathrm{G})$ particle flux, $(\mathrm{B}, \mathrm{E}, \mathrm{H})$ concentration, and $(\mathrm{C}, \mathrm{F}, \mathrm{I})$ average sinking velocity at (A-C) $50 \mathrm{~m},(\mathrm{D}-\mathrm{F}) 150 \mathrm{~m}$, and (G-I) $250 \mathrm{~m}$ beneath the surface. Open bars indicate less than 6 particles were counted in that size bin in either the flux or concentration. Two vertical grid lines are included to aid the eye in the alignment of the different size classes. 

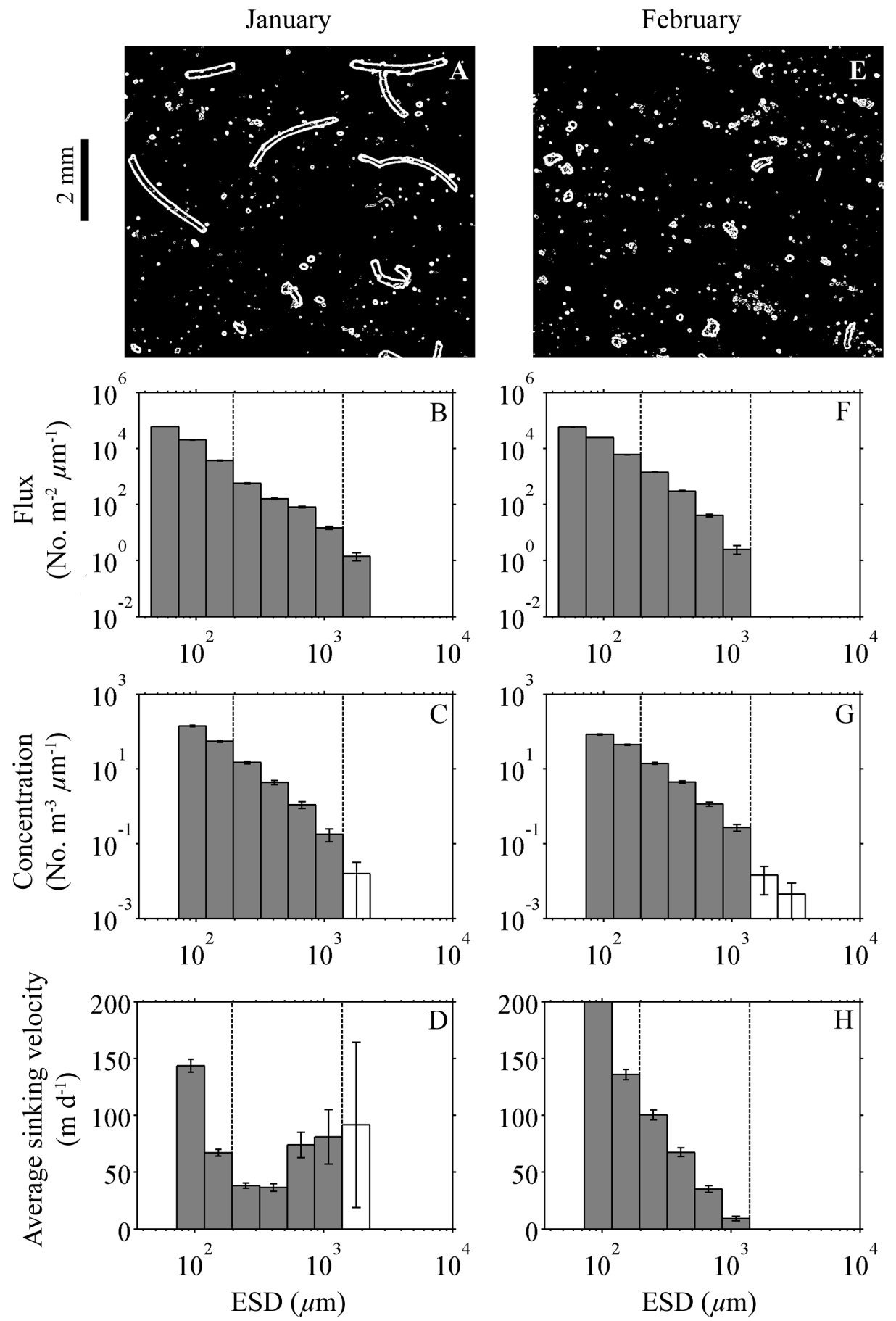

Figure 5. (A) During the first occupation of the PS2 in January, the flux collected in the polyacrylamide gel traps consisted mostly of small spherical particles and large krill fecal strands. (B) In late February, the flux consisted primarily of small aggregates, while the large fecal strands were absent. (B, F) These conditions caused changes in the FSD. (C, G) In addition, the CSD was significantly different between the two months. (D, H) These variations led to substantially different ASVD. Note the $W_{i \text {,avg }}$ of the small size class for panel $\mathrm{F}$ is off scale at $250 \mathrm{~m} \mathrm{~d}^{-1}$. 
January
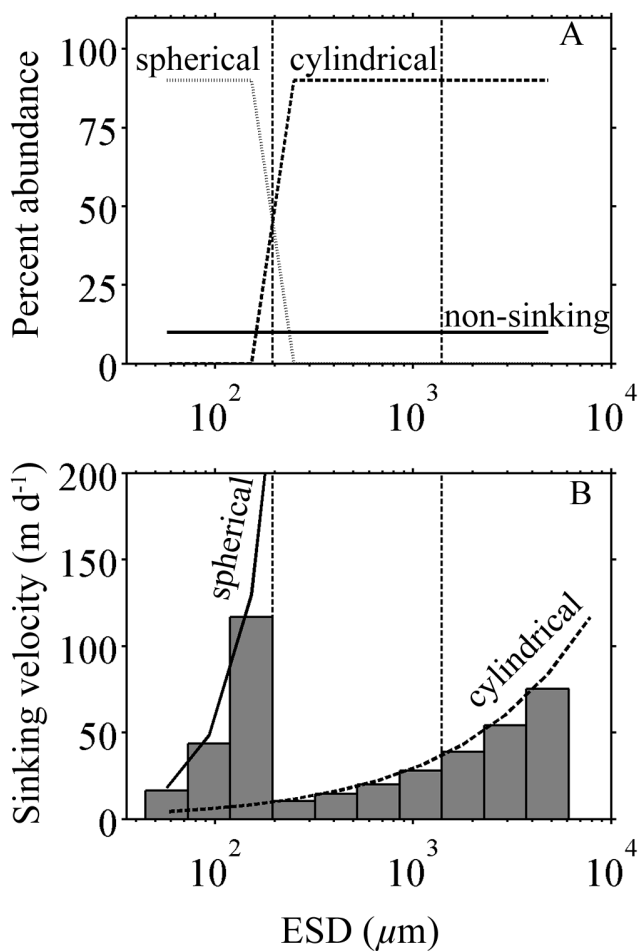

February
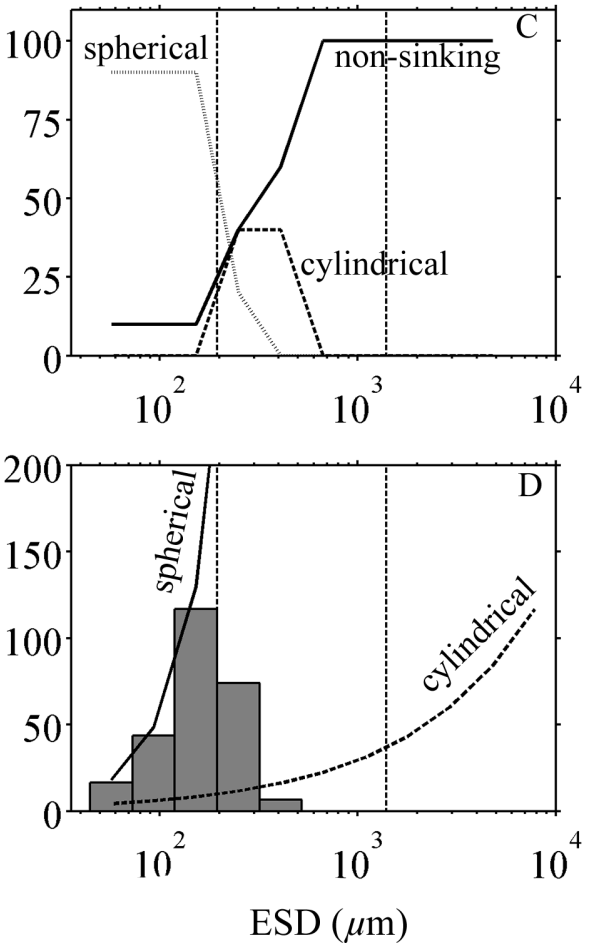

Figure 6. Here we present a simple model to aid in the interpretation of the large variability in the ASVD observed between the two occupations of PS2. The model features three types of particles (small spherical, large cylindrical, and non-sinking particles), each with their own characteristic sinking velocities. (A, C) show the model inputs of relative particle abundances for the three functional groups of particles as a function of ESD. (B, D) show the modified Stokes' sinking velocities for the two sinking particle types (solid and dashed curves), and the ASVD (bars) that would be expected based on the different particle abundance scenarios in panels A and C. (A, B) are representative of the relative particle abundances present at PS2 in January, while (C, D) are representative of conditions during the February occupation of PS2. These results illustrate how the presence or absence of certain particle types in the water column can lead to large variability in the ASVD and how ASVD do not always follow a pattern of increasing sinking velocity as a function of ESD as predicted by single particle type formulations of Stokes' Law. Two vertical grid lines are included to aid the eye in the alignment of the different size classes. 


\section{CHAPTER THREE}

Spatial and temporal variability in particle concentrations and sinking fluxes along the western Antarctic Peninsula 


\section{Introduction}

The waters above the continental shelf of the western Antarctic Peninsula (WAP) sustain a highly productive ecosystem with large blooms of diatoms that occur in the austral spring and summer. This intense production supports large stocks of krill, salps, silverfish, penguins, marine mammals, and seabirds (Fraser and Trivelpiece 1996). These processes also have important biogeochemical consequences, drawing down surface $\mathrm{pCO}_{2}$ concentrations (Carrillo et al. 2004; Montes-Hugo et al. 2010) and exporting sinking particulate matter to depth (Ducklow et al. 2008; Karl et al. 1991). All of this activity is inextricably linked to the physical marine environment, as the seasonal cycle of sea ice and the depth of the mixed layer affect the timing and magnitude of the phytoplankton bloom and the survival success of top predators (Garibotti et al. 2005; Ross et al. 1996; Smith et al. 1995)

Our current understanding of sinking carbon fluxes along the WAP comes primarily from the moored Palmer Long-Term Ecological Research program (PAL) sediment trap record. This conical time series sediment trap has been deployed since 1993 at $150 \mathrm{~m}$ depth beneath the surface and $100 \mathrm{~km}$ northwest of Palmer station on the continental shelf. Particle fluxes along the WAP are highly seasonal, often varying several orders of magnitude between the ice-covered winters and highly productive summers (Ducklow et al. 2008). Krill fecal pellets and diatom aggregates dominate the flux during the summer months in this region (McDonnell and Buesseler 2010). Until very recently, measured export ratios (export flux divided by net primary production) along the WAP were very low $(<4 \%)$ suggesting that bacteria and zooplankton efficiently recycle particulate matter in the euphotic zone or on its transit towards depth. But a recent study with drifting sediment traps and water column profiles of ${ }^{234} \mathrm{Th}$ suggest that particle fluxes are about 20 times larger than those measured by the moored conical trap (Buesseler et al. 2010). Thus, the export ratios are much higher than previously thought, implying more efficient export and only modest reprocessing of particulate matter by resident heterotrophic organisms.

Unfortunately the moored sediment trap only provides data from a single location and depth in a region with large spatial and temporal gradients in physical and biogeochemical parameters. This variability occurs on many scales, due to changes in the annual cycle of solar irradiance, mixing, temperature, sea-ice, and food web processes. With the fixed mooring, it is difficult to assess whether a pulse in the flux is representative of the peninsular region or just the specific location of the trap, and also the variability of fluxes across different spatial scales.

These sampling challenges are not unique to the WAP. Significant effort and 
advancements have been made in recent years to utilize measurements of the particle size distribution to estimate particle fluxes at high spatial and temporal resolutions (Guidi et al. 2008; Iversen et al. 2010).

To understand the biogeochemical effects of particulate sinking and cycling, one critical parameter is the concentration and distribution of particles in the water column. Several methods exist for determining the concentration of particulate matter in seawater. These include transmissometry, in situ imaging, large volume in situ filtration, and filtration of water collected from a CTD rosette. Each method relies on different characteristics of the particles and, therefore, not all of the data are equivalent. Filtration methods enable the determination of the total amount of mass, carbon, nitrogen, or other elements and compounds that are associated with the particulate matter (Knap et al. 1996). The size of the filter cutoff and the type of filter affect the types and sizes of particles collected. In addition, the manner in which these particles are filtered and sampled influences what is collected. High flow rates of water through the filtration membrane and collection of water in Niskin bottles can be destructive for some of the more delicate particles. Unless these filtrations are conducted with multiple filter stages each with a different size filter pore (Bishop et al. 1985), or if it is not possible to determine the size distribution of the particles. Transmissometry has the advantage that it is a simple sensor that can collect data on particle concentrations in real time and is often deployed onboard the CTD or even autonomous vehicles (Bishop and Wood 2008; Bishop and Wood 2009). Prior studies have demonstrated that the percent transmission is very tightly correlated with particulate organic carbon concentration as measured by filtration (Bishop 1999). Thus, transmissometry is a valuable and fast tool for mapping particulate concentration. However, the beam attenuation measurements produced by transmissometers are affected primarily by the more abundant small particles which are likely not as important to the sinking flux as are the rare large particles $>100$ $\mu \mathrm{m}$ in diameter. With the development of digital photography and image processing capabilities, in situ imaging of particles has emerged as a relatively new tool to study particle distributions in the water column. These instruments image particles in a non-destructive manner, are easily deployed in a high-resolution sampling scheme, and are capable of characterizing the particle size distribution (McDonnell and Buesseler 2010; Stemmann et al. 2004).

Particles larger than about $100 \mu \mathrm{m}$ in diameter are important because they represent a vehicle by which organic matter is transported throughout the oceans. To convert measurements of the numerical abundance of particles in the water column into a downward geochemical flux, it 
is necessary to know the sinking velocity of particles and their volume-specific elemental densities. In an important earlier study, Guidi et al. (2008) described the total mass flux ( $F$, mg $\left.\mathrm{m}^{-2} \mathrm{~d}^{-1}\right)$ as an integral over all particle diameters, $d$,

$$
F=\int_{0}^{\infty} n(d) m(d) w(d) \mathrm{d} d
$$

where $n\left(\right.$ No. $\left.\mathrm{m}^{-3} \mu \mathrm{m}^{-1}\right)$ is the number concentration of particle in a given small size range, $m$ $(\mathrm{mg})$ is the particle mass as a function of particle diameter, and $w\left(\mathrm{~m} \mathrm{~d}^{-1}\right)$ is the sinking velocity of the particles, each as a function of particle size, $d$. Without explicit information on the sinking velocities and particle masses, Guidi et al. (2008) used a single power law relationship for their product:

$w m=A d^{b}$

The parameters $A$ and $b$ were determined empirically by finding the best-fit parameters that most accurately predicted the flux from Eqn. 1 when compared to bulk sediment trap collectors from several different locations throughout the global oceans. This approach allowed the use of this globally derived relationship to estimate particle fluxes from high-resolution measurements of the particle size spectrum.

As demonstrated in McDonnell and Buesseler (2010), there is significant variability in the average sinking velocity of marine particles. This variability is significant even on regional and seasonal scales, suggesting that a global relationship is likely not appropriate for the accurate estimation of flux from the particle size distribution at any given site or time. Furthermore, sinking velocity does not often follow a power law relationship with respect to particle size. In some cases, average sinking velocity actually decreases with increasing particle diameter, indicating that a power law relationship for the product of sinking velocity and mass may not be a suitable formulation.

In this chapter, I apply the derived average sinking velocities to transform the concentration size distribution (CSD) as measured by the VPR directly into the flux size distribution (FSD), thereby eliminating the need to parameterize the sinking velocity as a function of particle size. In order to convert to fluxes of geochemical significance, I parameterize a 
relationship between the numeric fluxes and the POC flux by fitting the FSD measured in polyacrylamide gels to the measurements of bulk POC flux in paired sediment trap tubes at the same depth. I then evaluate the distribution of large particles across the WAP and use the above parameterizations to estimate the downward carbon flux at high spatial and temporal resolutions in this region.

\section{Methods}

Cruises

Data were collected during four cruises to the WAP in 2009 and 2010 as listed in Table 1. During the January cruises, sampling efforts were focused on a subset of the PAL grid described in Ducklow et al. (2007). Ship scheduling constraints during the two late summer and early autumn cruises permitted a more limited sampling scheme focused at PS1 and PS2 in Marguerite Bay. Figure 1 displays a map of the WAP study area with the bathymetry, deployment locations, and points of geographical reference.

\section{Determination of large particle concentration from the Video Plankton Recorder}

As described in McDonnell and Buesseler (2010), the Video Plankton Recorder (VPR) was deployed in profiling mode to capture images of large particles in the water column. The total large particle volume was calculated for all particles with an equivalent spherical diameter (ESD) ranging between 70 and $1400 \mu \mathrm{m}$. This was done by taking the ESD of each particle, converting to particle volume with the assumption that the particles were perfectly spherical $\left(\mathrm{V}_{\text {sphere }}=\pi(\mathrm{ESD})^{3} / 6\right)$, then summing these volumes and dividing the sum by the total volume of water imaged by the VPR. This procedure yields a total particle volume concentration in parts per million (ppm).

\section{Measurement of the particulate organic carbon concentration}

The concentration of particulate organic carbon (POC) was determined via filtration of seawater samples from the CTD rosette. Samples were processed by Hugh Ducklow's laboratory at the Marine Biological Laboratory following the protocol outlined in Knap et al. (1996) and these data are available via PAL's online data archive (website url: http://pal.lternet.edu/data/).

\section{Determination of large particle concentration from transmissometry}


The raw $24 \mathrm{~Hz}$ transmissometry data from the CTD was processed by applying a running minimum filter followed by a running maximum filter, each with a window size of 0.42 seconds in order to establish a baseline signal (Briggs 2010). A spike was defined arbitrarily as a transmissometry signal exceeding a $0.06 \%$ difference from the filtered baseline signal. Finally, the transmissometry spike frequency $\left(\mathrm{sec}^{-1}\right)$ was calculated by dividing the number of measured spikes by the duration of time sampled in each $50 \mathrm{~m}$ depth bin. This approach is also similar to Bishop and Wood (2008), except they used a running mean filter to establish the signal baseline, and a different algorithm to identify the occurrence of a spike. The spike frequencies calculated in this study were compared directly to the VPR data gathered within 2 hours of the CTD deployment at the same location. Due to the high variability in the baseline transmission in the upper $100 \mathrm{~m}$, the analysis was restricted to waters below that depth.

\section{Measurement of particle flux}

Particle flux was measured directly with two different types of sediment traps. Both were deployed from a drifting sediment trap array with a wave-isolating float at the surface. Traps were hung at three depths ranging from 50-300 m below the surface. The traps were deployed in collection mode for 36 hours before lids on the traps were closed, and the drifting array recovered aboard the ship.

The first type of sediment trap consisted of a standard cylindrical tube serving as a bulk flux collector. These samples contained $500 \mathrm{~mL}$ of formalin $(0.022 \%)$ poisoned and filtered brine (salinity $\sim 70 \mathrm{psu}$ ) to preserve the collected samples. Once retrieved on board the ship, tubes were allowed to settle for one hour before the overlying water was siphoned off. The brine and particle sample mixture was then drained through a $350-\mu \mathrm{m}$ Nitex screen to remove swimmers. The screened brine suspension was then filtered through a $1.2-\mu \mathrm{m}$ silver membrane filter (Sterlitech), and the particles dried for 24 hours at $50{ }^{\circ} \mathrm{C}$. Due to their large size and aspect ratio, many krill fecal pellets were also retained by the $350 \mu \mathrm{m}$ screen. Swimmers were picked off of the screens under a microscope and the remaining particulate material on the screen was rinsed off and filtered onto a separate silver membrane filter. The filtered samples were analyzed on a CHN analyzer and the screen filtrate and non-swimmer rinse was summed to determine the total flux of particulate carbon intercepted by the trap. A similar method is described in detail in Lamborg et al. (2008). 
The particle flux size distribution (FSD) was determined through the use of a polyacrylamide gel trap at the same depths as the bulk flux collectors described above. This trap had the same cylindrical geometry as the bulk flux collector but was outfitted with a polycarbonate jar that contained $200 \mathrm{~mL}$ of $16 \%$ polyacrylamide and took up the entire area at the base of the trap cylinder. We followed the gel preparation protocol described by F. Ebersbach (personal communication). Upon recovery, samples were allowed to settle for at least 3 hours. After this time, the overlying water was siphoned off out of the trap tube and the polyacrylamide gel was removed from the base of the trap. Some of the overlying water in the gel jar was decanted off, with care taken not to disturb any of the particles at the gel-water interface. The polyacrylamide gels were systematically photographed with a Nikon SMZ-1500 stereomicroscope over its entire area (See Chapter 2 for details). This process yielded about 80 images that were subsequently merged together manually with the photomerge tool in Photoshop (Adobe Creative Suite 2). These large composite images are about 50 Megapixels, and are capable of resolving particles over a large range of sizes ( $\sim 50 \mu \mathrm{m}$ to several $\mathrm{cm}$ in diameter). The large composite image was cropped to remove the edges of the gel jars and then processed with Photoshop's edge detection and threshold algorithms. The result was a binary image that identifies the two-dimensional projected shape and area of each particle and their numeric abundance in the gel per unit area and time of collection. The binary image was processed in MATLAB (see Appendix II) to calculate the FSD (No. $\mathrm{m}^{-2} \mathrm{~d}^{-1} \mu \mathrm{m}^{-1}$ ).

\section{Calculation of particle flux from particle concentration size distributions}

As described in McDonnell and Buesseler (2010), the numeric flux, $\left(F_{i}\right.$, No. $\left.\mathrm{m}^{-2} \mathrm{~d}^{-1} \mu \mathrm{m}^{-1}\right)$ can be calculated from the product of the particle concentration $\left(C_{i}\right.$, No. $\left.\mathrm{m}^{-3} \mu \mathrm{m}^{-1}\right)$ and the average sinking velocity $\left(W_{i, \text { avg }}\right)$ for each size class $i$ :

$F_{i}=C_{i} \times W_{i, \text { avg }}$

Because $W_{i, \text { avg }}$ varies with respect to location, depth, and time (McDonnell and Buesseler 2010), it becomes important to include this variability when estimating the FSD. Because the available ship time limited this study to only 3 deployments of the drifting sediment traps, these three sites were assumed to provide representative estimates of $W_{i, \text { avg }}$ for the latitudinal zones in which they were located. These three latitudinal zones were defined as follows (Fig. 1A): Northern $\left(<67^{\circ} \mathrm{S}\right)$, 
Central (between $67^{\circ} \mathrm{S}$ and $\left.69^{\circ} \mathrm{S}\right)$, and Southern $\left(>69^{\circ} \mathrm{S}\right) . W_{i \text {,avg }}$ determined from the polyacrylamide gels during each drifting array deployment was applied to the depth bins ranging from that specific trap depth upwards to either the depth of the next trap above or $20 \mathrm{~m}$ depth in the case of the most shallow trap. $W_{i, \text { avg }}$ from the deepest trap was also applied downwards in the water column where necessary. I assumed these $W_{i, \text { avg }}$ were valid for the duration of the cruise on which they were measured. The values used are presented in Table 2. The average sinking velocities of particles used in this study were derived from the CSD data from a combination of 2-4 VPR casts conducted during the collection phase of the drifter deployment.

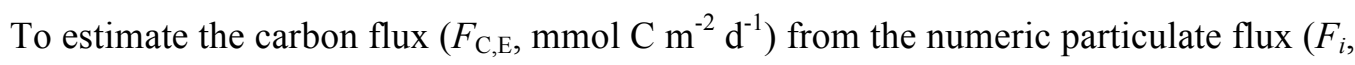
No. $\left.\mathrm{m}^{-2} \mathrm{~d}^{-1} \mu \mathrm{m}^{-1}\right)$, I relied on a power law formulation of carbon content as a function of particle diamter $(d, \mu \mathrm{m})$ similar to that used by Alldredge and Gotschalk (1988):

$F_{\mathrm{C}, \mathrm{E}}=\Sigma\left(F_{i} \cdot \Delta d_{i} \cdot \alpha d^{\beta}\right)$

where $\Delta d_{i}$ is the width $(\mu \mathrm{m})$ of each size bin, $i$. In a manner similar to that of Guidi et al. (2008), the MATLAB function "fminsearch" is employed in order to determine the best fit parameters $\alpha$ and $\beta$ by minimizing the log-transformed differences $\left(\Delta \mathrm{F}_{\mathrm{C}}\right)$ between the estimated carbon flux $\left(\mathrm{F}_{\mathrm{C}, \mathrm{E}}\right)$ derived from the measured gel FSD and the measured sediment trap flux $\left(\mathrm{F}_{\mathrm{C}, \mathrm{T}}\right)$ :

$\Delta \mathrm{F}_{\mathrm{C}}=\Sigma\left(\log \left(\mathrm{F}_{\mathrm{C}, \mathrm{T}}\right)-\log \left(\mathrm{F}_{\mathrm{C}, \mathrm{E}}\right)\right)^{2}$

I used the available carbon flux and gel FSD from LMG0901 and LMG0902 to estimate $\alpha$ and $\beta$. The parameter $\alpha$ is a measure of the bulk carbon density of the particulate material and $\beta$ represents the shape factor where a value of 3 would indicate solid spherical particles. With these parameters, equations 3 and 4 can be used in to arrive at estimates of carbon flux from the CSD and average sinking velocities as applied in the three latitudinal zones (Fig. 1A).

\section{Results and Discussion}

In this section, The large particle volume concentration from the VPR and the POC concentration determined by filtering seawater samples from the Niskin bottles are poorly correlated (Fig. 2) along the WAP. The primary cause for this is the fact that near-surface waters tended to have the highest bottle POC values and bottle POC concentration declined quickly with 
respect to depth below these levels whereas the total particle volume determined by the VPR tended to be smaller at the surface. This suggests that the small carbon-rich particles consisting primarily of living phytoplankton have the largest effect on the POC concentration. In contrast, the large particle concentrations measured by the VPR are typically more abundant in deeper waters where bottle POC concentrations are low. The slightly elevated POC concentrations at the highest measured large particle volumes (Fig. 2) are likely a weak signal of the largest particles influencing the bottle POC concentration. In general, it appears that the particles in the size range quantified by the VPR do not strongly influence the POC concentration and, similarly, most of the bottle POC is from particles with sizes smaller than those detectable by the VPR.

As the percent light transmission measured by optical transmissometers is tightly correlated with bottle POC concentration (Bishop 1999), the relationship between the large particle volume and transmission is very similar to the results presented in Figure 2. However, recent work has suggested that the frequency of sharp spikes in the transmissometry data may be related to the concentration of large particles or zooplankton (Bishop and Wood 2008; Briggs 2010). I found the total large particle volume to be well correlated with the transmissometry spike frequency (Fig. 3) with a Pearson's correlation coefficient $(r)$ of 0.779 . This suggests that both the VPR and the transmissometry spikes are detecting similar sizes of particulate material in the water column. In addition, I also explored the relationship between the numeric concentrations of particles in the different size classes with the transmission spike frequency. These results are presented in Figure 4. The correlation coefficients for these datasets ranged from 0.214 to 0.887 with the best correlation found for the largest size class (1400-2290 $\mu \mathrm{m}$ ) and no significant correlation with the smallest size classes detected by the VPR. The transmissometry spikes, therefore, most likely represent the largest rare particles in the water column. The strongest correlation between the number concentration and the transmissometry spike frequency was found in the largest size class despite the fact that the uncertainty in the numeric concentration is largest for this size class due to their paucity in the water column. Bishop and Wood (2008) found that the transmissometry spike frequency in the North Pacific "looked" similar to zooplankton distributions and did not match well with some measures of particulate concentration from in situ pumps. The results presented here suggest that, at least along the WAP, transmissometry spikes may be a good indicator of large particle concentrations. As the transmissometer is a much more simple instrument to deploy and operate than the VPR, analysis of transmissometry data in this manner could provide a valuable tool for the study of 
large particles in the marine environment. It does have the disadvantage, however, that it is incapable of determining the size distribution of the particles and it is unable to provide information about what type of particles are present, as is possible with imaging systems such as the VPR. That these two methods yield similar results is an encouraging sign that both of these emerging technologies are performing as expected.

Particle fluxes ranged from 2 to $26 \mathrm{mmol} \mathrm{C} \mathrm{m}^{-2} \mathrm{~d}^{-1}$ during the austral summer and early autumn sampling period in 2009 (Fig. 5). Carbon fluxes were larger during the January 2009 cruise than they were in late February and early March when PS1 and PS2 were reoccupied. PS2, located at the mouth of Marguerite Bay, was the site of the largest carbon fluxes in January. One month later, this same site exhibited the lowest fluxes measured during this study. These results demonstrate the strong seasonality in particle flux that occurs in this region.

Interestingly, the fluxes measured by the drifting sediment traps showed no clear patterns with respect to depth. This contrasts with the typical pattern of strong flux attenuation that has been observed in these mesopelagic depth horizons at many locations throughout the global oceans (Buesseler et al. 2007; Martin et al. 1987). I demonstrate in Chapter 5 that this uncommon feature of the WAP is likely due to the relatively high sinking velocities of particles as well as slow rates of microbial breakdown of sinking particulate matter. In many cases, the measured flux actually increased from one depth to another. The causes of these increases are unknown. One possible explanation is a lateral source of particulate matter from the nearby coasts and shallow shelf sills that contributes to the flux magnitude in the deeper traps (DeMaster et al. 1991; Jaeger et al. 1996). Alternatively, zooplankton could be contributing to the observed variability in the signal by what is referred to as the vertical shunt in which they consume particles in the upper layers of the ocean and subsequently defecate at depth (Buesseler and Boyd 2009; Wilson et al. 2008).

The use of the VPR as a profiling instrument provided a unique opportunity to assess both the spatial and temporal variability in particle distributions along the WAP during the austral summers of 2009 and 2010. Figure 6 displays the total particle volume concentration $(73<$ ESD $<1400 \mu \mathrm{m}$ ) as a function of depth at the occupations of PS1, PS2, and PS3 during 2009. The general pattern observed here was an increase in the abundance of particulate matter in these size ranges with respect to depth. Much of this is driven by the distribution of particles in the largest size classes, as they are nearly absent in surface waters but relatively quite common at depths of greater than $150 \mathrm{~m}$. This phenomenon is quite the opposite of what is suggested by the POC 
concentration and beam attenuation profiles from the CTD transmissometer, which, as discussed above, show large abundances in the euphotic zone and decline sharply to background levels by $100 \mathrm{~m}$ (Fig. 2). The VPR concentration profiles of Fig. 6 show some similarities between the measured sediment trap fluxes in Fig. 5, however a close inspection reveals that high particle concentrations do not necessarily imply high fluxes. For example, at PS2 there was very little change in the large particle concentration between the two occupations (Fig. 6). In contrast, the sinking fluxes declined by a factor of about 5 from January until February 2009 (Fig. 5). This discrepancy is reflective of the decline in average sinking velocities between the two months (McDonnell and Buesseler 2010).

How consistent is the relationship between the concentration of particles in the water and the fluxes that result from those particles? I explore this question in Figure 7 where I plot this relationship as derived from a comparison of numeric flux measurements from the gel traps and the numeric particle concentration data from the VPR. Each data point plotted here is a comparison for particles at a given depth and size bin, and therefore the data span about 6 orders of magnitude. Figure 7 demonstrates that the numeric particle concentration may generally be a good predictor of the flux. The exact nature of the relationship here is dependent upon the average sinking velocity for a given size class. This plot would have a constant slope if the sinking velocities were invariant with respect to particle size. It is the departure of the data points from this constant slope relationship that gives the average sinking velocity size distributions their shape as a function of size. In the case of the WAP, both the most abundant and least abundant particles measured with the VPR (the largest and smallest size classes within the VPR's detection limits) have somewhat elevated fluxes. This leads to the generally higher sinking velocities for both the small and large size classes relative to the mid-sized particles as observed in McDonnell and Buesseler (2010). Of important note is that for a given concentration, the observed fluxes do seem to vary by over 1 order of magnitude, especially for the largest, least abundant particles. This is probably a combination of the inherent uncertainties in calculating the concentration of the rare large particles, but also the natural variability in the average sinking velocity for a given size class.

The minimization procedure described above yielded best-fit parameter selections for $\alpha$ and $\beta$. I found $\alpha=3.91 \times 10^{-12} \mathrm{mmol} \mathrm{C} \mu \mathrm{m}^{-\beta}$ and $\beta=2.53$, which when applied to Eqn. 4 produces carbon flux estimates in the units of mmol $\mathrm{C} \mathrm{m}^{-2} \mathrm{~d}^{-1}$ when the FSD is in the units No. $\mathrm{m}^{-}$ ${ }^{2} \mathrm{~d}^{-1} \mu \mathrm{m}^{-1}$ and both $\Delta \mathrm{s}_{i}$ and $d$ are in $\mu \mathrm{m}$. The results of this parameterization are presented in 
Figure 8 and show how the carbon fluxes estimated from the FSD compare to those measured by the sediment traps. Note that three of the data points were excluded from the fitting routine because the gels contained anomalously few particles relative to the carbon fluxes measured in the tubes mounted only inches away on the same arrays. Two of the three excluded data points were from trap samples at $50 \mathrm{~m}$ depth (the January deployments at PS1 and PS2), suggesting that sinking particles at this shallow depth have anomalous carbon contents. This idea is supported by the high POC to particle volume concentrations observed in shallow waters (Fig. 2). The third outlier was from the polyacrylamide gel trap at $200 \mathrm{~m}$ depth at PS2 in January 2009, where this gel had visually fewer particles than the traps $100 \mathrm{~m}$ above and below it, despite a nearly constant flux profile with respect to depth (Fig. 5). Including these three data points biased the fit such that the majority of the data points fell below the 1:1 line, and therefore were omitted. The parameters above led to a Pearson's correlation coefficient of 0.92 when the three outliers were omitted.

The strengths of the approach presented here rest on the use of region and depth-specific sinking velocities quantified through a direct comparison of the FSD and the CSD, as well as region-specific assessments of particle densities. Given the large differences in the average sinking velocities and particle densities observed along the WAP and in the Sargasso Sea (see Chapter 4), this technique offers an improvement over the global assimilation method used by Guidi et al. (2008) to parameterize the carbon flux from measurements of the CSD. Moreover, the separate determination of average sinking velocities and particle densities described here also provides additional insights into the mechanisms of particulate flux to depth at these various sites (see Chapters 4 \& 5).

The relationship between the numeric flux size distribution and the carbon flux discussed above facilitates the investigation of the relative importance of different sized particles to the total downward carbon flux of particulate matter. This fraction, computed as a function of the ESD for each polyacrylamide gel trap, is presented in Figure 9. I found that along the WAP, the carbon flux was dominated by particles with an ESD of 800-2200 $\mu \mathrm{m}$. The notable exception to this occurred during the late-February reoccupation of PS2 marked by the pink lines in Figure 9. At this time, the majority of the carbon flux was delivered in particles with an ESD of between 300 and $500 \mu \mathrm{m}$. This corresponds to the observations that the large krill fecal pellets were largely absent from the flux, and the average sinking velocities were quite low for the larger particles compared to the previous occupation in January. The fact that the majority of the sinking carbon 
flux is a result of rare large particles has important implications for the interpretation of sediment trap data at WAP. This could explain why there exists a large degree of variability from one trap tube to another deployed at the same depth on the same array. If a majority of the flux collected in a trap is the result of only one rare particle, the associated variability from tube to tube would be high.

Now that the full relationship between the CSD and the carbon flux has been established using sediment trap data from the three process stations, the VPR data can be employed to create high-resolution estimates of carbon flux at other sites. Figure 10 shows a detailed comparison between the estimated fluxes and the sediment trap-measured fluxes at the three process study stations. The estimated fluxes from multiple VPR profiles are depicted as separate solid lines in Fig. 10.

In general, the predicted fluxes match those measured typically within a factor of 2 . The estimated fluxes again support the conclusion that particle fluxes along the WAP do not follow a typical Martin-type decline with respect to depth. Some discrepancies between the estimated and measured fluxes do exist. These come in two different forms: 1) variability of the flux estimates around the mean sediment trap flux when fluxes are computed from CSD determined by several different VPR profiles conducted over the duration of trap flux collection, and 2) systematic offsets of flux estimates from the measured trap flux. In the first case, the variability between the VPR-based flux estimates and those measured by sediment traps is to be expected because the two methods assess the flux on different time scales. Fluxes estimated from the VPR measurements of the CSD represent an instantaneous assessment of the particle flux whereas the sediment trap averages the flux over the 36 -hour collection period. This variability provides insight into the true nature of the sinking particle fluxes that may not be captured by sediment traps. The second type of discrepancy between the estimated and measured fluxes (systematic offsets) can arise for two difference reasons. First, in some cases, such as the $100 \mathrm{~m}$ estimates at PS2 during January, the larger particles were so rare in the water column that they were often not detected by the VPR. As a result, although these large particles were found in the sediment traps, their contribution was not included in the FSD estimated from the product of the CSD and $W_{i, \text { avg }}$, and therefore those large size classes did not contribute to the total carbon flux estimates. This scenario led to underestimates of flux relative to those measured by the bulk sediment trap. In an attempt to rectify this discrepancy, I tested the use of a restricted size range of particles for the fit of the FSD to the sediment trap and found that the quality of the fit was highly dependent on the 
inclusion of all the large size classes, and that ignoring them produced a poor fit. One other possible solution that I explored was the extrapolation of the FSD to estimate the numeric flux of the larger particles. When applied to the gel-derived FSD, it led to the overestimation of the particle flux. Ultimately, the size range and total volume sampled by the VPR is an important limitation in the accuracy of the flux estimates. This is especially the case along the WAP because the majority of the carbon flux is from the largest and most scarce particles. The best solution to this problem would be to improve the resolution of the underwater particle cameras used in studies such as this one or to increase the duration of sampling with the VPR. These changes would allow for larger sampling volumes and better quantification of the large particle concentrations while maintaining the ability to resolve the small highly abundant particles. The second reason for underestimated fluxes relative to the bulk sediment trap collectors is the fact that even if the FSD is properly estimated from the CSD and the average sinking velocities, there are a few cases where this FSD will result in anomalously low estimations of carbon flux (crosses in Figure 8). This explains why the estimates of carbon flux at the shallow depths during January at PS1 and PS3 are too low relative to those measured by the bulk sediment traps. With additional trap data, it would be possible to develop separate carbon density parameterizations for different depths and even locations, thereby improving the estimates of carbon flux at these depths. However with only a few measurements of the FSD and carbon flux at these shallow depths, this was not possible within the sampling limitations of the current study. Instead we assumed that carbon densities are uniform with respect to depth and location, which likely introduces some errors into the method.

The results presented in Figure 10 include all of the measured spatial, depth, and temporal variability in the average sinking velocities of the particles. I tested the use of a single depth-averaged and spatially-averaged sinking velocity and found that it led to substantial discrepancies between the estimated and measured fluxes when the analysis was done in a manner similar to Figure 10. This emphasizes the point made in Chapter 2 that it is essential to properly characterize the local variability in the average sinking velocity in order to make reliable estimates of the flux from the CSD. The approach presented here constitutes an important improvement over the globally-averaged methodology of Guidi et al. (2008). However, if variability in the ASVD exists at smaller spatial and temporal scales than were measured in this study, their extrapolation across time periods, depth bins, and latitudinal zones would indeed introduce errors into the estimated fluxes along the WAP. With average sinking velocity data 
only available at a select few locations, depths, and times, there is no way to investigate the potential effect of smaller scale variability.

The VPR profiles conducted along the WAP, especially during the intensive sampling characteristic of the January LTER cruises allow for a detailed look at the distribution of large particles in the region. First, it is important to place this in the context of the seasonal cycle and general pattern of the summer phytoplankton bloom in the region. Level 3 satellite chlorophyll data from MODIS was downloaded from the Ocean Color Website (http://oceancolor.gsfc.nasa.gov/) and monthly average chlorophyll $a$ concentrations were mapped for the WAP from November until March for both the 2008/2009 and 2009/2010 Austral summer seasons (Figure 11). During the 2008/2009 summer, there was a pronounced offshore bloom in November which quickly dissipated but was followed by increased chlorophyll $a$ inshore above the continental shelf with a typical chlorophyll $a$ concentration of around $1 \mathrm{mg} \mathrm{m}^{-3}$. Higher chlorophyll $a$ concentrations of $>3 \mathrm{mg} \mathrm{m}^{-3}$ were only found in the most coastal areas deep inside Marguerite Bay. Along much of the continental shelf, elevated chlorophyll concentrations of 0.3 to $1 \mathrm{mg} \mathrm{m}^{-3}$ persisted into March. The summer of 2009/2010 was markedly different with a stronger $\left(>7 \mathrm{mg} \mathrm{m}^{-3}\right)$ and spatially more extensive bloom developing in Marguerite Bay and south west towards Charcot Island which began January and reached a climax in February. The bloom was also stronger in 2009/2010 in the near shelf and mid-shelf regions further to the north of Marguerite Bay.

The VPR data in Figures 12, 13, and 14 show the concentrations of three different particle size classes during the four WAP cruises. To orient the reader, these multi-panel figures represent a three dimensional map of the continental shelf region off the WAP. North is to the left along lines of constant longitude. The vertical axis represents the depth in meters and is expanded substantially relative to the dimensions of latitude and longitude. The light color overlaid on the surface of the map represents the average satellite derived chlorophyll $a$ concentration for the month of each of the four cruises presented in the four different panels. The colored dots that form a vertical line from the surface represent the concentration of particles in the specified size bin as a function of depth. The open circle is the surface representation of the VPR profile location, to provide reference. It is important to recognize that these plots blend both spatial and temporal variability as the profiles were conducted over the course of about one month of sampling for any given panel. 
During January 2009, the concentrations of small (119 $\leq$ ESD < $195 \mu \mathrm{m}$; Fig. 12), medium $(320 \leq \mathrm{ESD}<520 \mu \mathrm{m}$; Fig. 13), and large $(0.9 \leq \mathrm{ESD}<1.4 \mathrm{~mm}$; Fig. 14) particles often increased from a surface minimum to a mid-water maximum (Figs. 12A, 13A, 14A). In this month, particles concentrations in the $20-50 \mathrm{~m}$ depth bin did not correlate well with the satellite chlorophyll concentration, nor did elevated chlorophyll concentrations correspond to increased particle concentrations at depth. Repeat profiles during LMG0902 (Fig. 12C) showed a decline in small particle concentration from early January until early March at PS1, while they remained relatively constant from mid-January until late February at PS2 (see Fig. 1 for location references). Compared to the January 2009 data, the concentrations of small and medium sized particles in January 2010 were lower over a majority of the sampling region, especially for the small sizes in the subsurface waters (Figs. 12B, 13B). In 2010, maximum particle concentrations were often found near the surface or near the bottom rather than in the middle of the water column. Large particle concentrations were similar or even more abundant in January 2010 (Fig. $14 \mathrm{~A}, \mathrm{~B})$ than they were in the previous year.

The strong chlorophyll bloom that extended from Marguerite Bay to offshore of Charcot Island (the far south) in January 2010 produced increased concentrations of particles in all size classes in the shallow depth bins (Figs. 12B, 13B, 14B). Approximately two months later, these high concentrations persisted in this region (Figs. 12D, 13D, 14D), and this signal had propagated into deeper waters, especially for the large particle size class (Fig. 14D), suggesting export was occurring well into the fall season following this intense and sustained bloom. The chlorophyll bloom that occurred in 2009 had a similar spatial pattern to the 2010 distribution, but was not as intense and had a small effect on the particle distributions.

These particle concentration maps also suggest that there may be a contribution of particles to the water column from horizontal processes such as re-suspension of sediments from the continental shelf or coastal margins. Elevated subsurface concentrations are particularly evident at certain stations nearshore and in submarine canyons that cut deeply into the continental shelf (Figs. 12A, 13A). Examples include the Palmer Deep region south of Anvers Island, the Marguerite Trough offshore of Adelaide Island, and also the Charcot Trench immediately to the north of Charcot Island. Since the particle maximum at these sites occur at and below the sill depth of the continental shelf $(\sim 300 \mathrm{~m})$, they are likely signals caused by horizontal currents that re-suspend particles off of the nearby shelves and margins. Interestingly, these are also known penguin foraging areas for the Adélie penguins that nest in colonies nearby these locations (Fraser 
and Hofmann 2003). However, as the majority of Adélie foraging takes place immediately below the chlorophyll maximum (Kahl et al. 2010) this species is not targeting these deep particle maximums in the canyons.

The concentrations of particles exhibit wide ranging variability of more than an order of magnitude with respect to depth, location, and time of sampling. The spatial scales of variability are broader for the large and medium sized particles. For example, in Fig. 14A, most of the profiles in the entire WAP region follow similar patterns and magnitudes. The following year (Fig. 14B) large particle concentrations were slightly higher and characterized by near-surface maximums. Due to the large and intense bloom in the southern portion of the PAL grid in 2010, particle concentrations were higher here than they were further to the north on the grid (Figs. 12B $\& \mathrm{D}, 13 \mathrm{~B} \& \mathrm{D}, 14 \mathrm{~B} \& \mathrm{D})$. Within both the northern and southern sub regions, particle distributions were relatively uniform.

Assuming the ASVDs and parameters $\alpha$ and $\beta$ determined here are representative across the scales that they are applied, it is possible to calculate particle fluxes from the CSD measurements obtained with the VPR. Figure 15 displays the results of these calculations for both 2009 cruises. These results predict increasing carbon fluxes with respect to depth across much of the PAL grid in January (Fig. 15A). As discussed above, the low numeric abundances of large particles in the near-surface waters often were below the detection limit of the VPR, and so the flux estimates at these depths are likely underestimated. Thus the increase in flux with respect to depth may be overestimated, but this general pattern would still hold true. The magnitude of particle fluxes decreased from January until February and March at the few stations sampled late in the season. This is a sign that the system is transitioning back to the low export regime typical of the fall and winter months in this region. Unlike the patterns of productivity suggested by the satellite chlorophyll data (Fig. 11), several of the offshore stations showed elevated carbon fluxes compared to nearshore stations at similar latitudes (Fig. 15A).

\section{Conclusions}

In situ imaging systems such as the VPR are effective tools for the measurement of the concentrations of large particles at high spatial and temporal resolutions. They allow for improvements in our understanding of the ocean's biological pump. The comparison of the VPR particle abundance data with the transmissometry spike frequencies suggest that transmissometers may also be capable of providing estimates of the large particle concentration. This advancement 
would be very useful since transmissometers are often included as standard equipment on shipboard CTD packages and have been deployed widely and regularly throughout the oceans. By looking at historical transmissometry data from the Palmer LTER along the WAP, for example, it might be possible to quantify how particle abundances and spatial distributions are responding to the rapid climate warming currently taking place along the WAP. However, the unique combination of information provided by the VPR and the polyacrylamide gels cannot be fully replaced by transmissometry or bulk sediment collectors as the VPR and polyacrylamide gels enable a more detailed understanding of the particle types and sizes. One important result from the polyacrylamide gels was the fact that the majority of the carbon flux at WAP can be attributed to large particles with an ESD between 0.8-2.2 $\mathrm{mm}$ with average sinking velocities of a few hundred meters per day.

The results presented here demonstrate that the concentrations of particles vary by over one order of magnitude with respect to location, depth, and time of sampling across the WAP. Even over timescales of one day or spatial scales of several kilometers, this variability can be significant. In this manner, even the drifting sediment traps, which collect particles over a 36hour time span, do not reveal the true degree of variability in the particle concentrations and fluxes. The analysis presented here suggests that biological parameters such as the patterns of chlorophyll $a$ concentration are poor predictors of large particle abundance and flux.

This new approach for estimating flux from the concentration of particles provides an improvement over earlier methods (Guidi et al. 2008; Iversen et al. 2010). By relying on the measured relationships between the flux and concentration at a few locations, I was able to quantify the spatial, temporal and depth variability in the average sinking velocity of marine particles and take this into account when estimating the flux across the WAP region. For perspective, up until now our understanding of particle fluxes along the WAP was restricted to a single time-series sediment trap at a fixed location and depth in the northern outer-shelf region of the WAP. Furthermore, it appears that this bottom-moored conical trap has provided measurements of particle flux that are over an order of magnitude lower than the flux suggested by drifting sediment traps and measurements of the flux proxy ${ }^{234}$ Th that were conducted as part of this study (Buesseler et al. 2010). With this new methodology, this chapter presents estimates of the particle flux from over 30 different locations along the WAP and resolves the flux profile for each $50 \mathrm{~m}$ depth bin at those sites. The results do offer a unique and detailed look at the variability in the flux itself on scales that would be impossible to explore with conventional 
sediment trap methodology. More work will be needed to assess the full variability in the average sinking velocities and particle carbon densities in order to ensure the accuracy of these flux estimates over refined spatial and temporal scales. 


\section{References}

Alldredge, A. L., and C. Gotschalk. 1988. In Situ Settling Behavior of Marine Snow. Limnology and Oceanography 33: 339-351.

Bishop, J., D. Schupack, R. Sherrell, and M. Conte. 1985. A multiple-unit large-volume in-situ filtration system for sampling oceanic particulate matter in mesoscale environments. Mapping Strategies in Chemical Oceanography. Advances in Chemistry Series 209: 155175.

Bishop, J., and T. Wood. 2008. Particulate matter chemistry and dynamics in the twilight zone at VERTIGO ALOHA and K2 sites. Deep Sea Research Part I: Oceanographic Research Papers 55: 1684-1706.

---. 2009. Year-round observations of carbon biomass and flux variability in the Southern Ocean. Global Biogeochemical Cycles 23.

Bishop, J. K. B. 1999. Transmissometer measurement of POC. Deep-Sea Research I 46: 355-371.

Briggs, N. 2010. Analysis of optical spikes reveals dynamics of aggregates in the twilight zone. University of Maine.

Buesseler, K., and P. Boyd. 2009. Shedding light on processes that control particle export and flux attenuation in the twilight zone of the open ocean. Limnol. Oceanogr 54: 1210-1232.

Buesseler, K. O., C. H. Lamborg, P. W. Boyd, P. J. Lam, T. W. Trull, R. R. Bidigare, J. K. B. Bishop, K. L. Casciotti, F. Dehairs, and M. Elskens. 2007. Revisiting Carbon Flux Through the Ocean's Twilight Zone. Science 316: 567.

Buesseler, K. O., A. M. P. McDonnell, O. M. E. Schofield, D. K. Steinberg, and H. W. Ducklow. 2010. High particle export over the continental shelf of the west Antarctic Peninsula. Geophys. Res. Lett.: (In Press).

Carrillo, C., R. Smith, and D. Karl. 2004. Processes regulating oxygen and carbon dioxide in surface waters west of the Antarctic Peninsula. Marine Chemistry 84: 161-179.

DeMaster, D., T. Nelson, S. Harden, and C. Nittrouer. 1991. The cycling and accumulation of biogenic silica and organic carbon in Antarctic deep-sea and continental margin environments. Marine Chemistry 35: 489-502.

Ducklow, H., K. Baker, D. Martinson, L. Quetin, R. Ross, R. Smith, S. Stammerjohn, M. Vernet, and W. Fraser. 2007. Marine pelagic ecosystems: the West Antarctic Peninsula. Philosophical Transactions of the Royal Society B: Biological Sciences 362: 67.

Ducklow, H. W., M. Erickson, J. Kelly, M. Montes-Hugo, C. A. Ribic, R. C. Smith, S. E. Stammerjohn, and D. M. Karl. 2008. Particle export from the upper ocean over the continental shelf of the west Antarctic Peninsula: A long-term record, 1992-2007. Deep Sea Research Part II: Topical Studies in Oceanography 55: 2118-2131.

Fraser, W., and E. Hofmann. 2003. A predator's perspective on causal links between climate change, physical forcing and ecosystem. Mar Ecol Prog Ser 265: 1-15.

Fraser, W., and W. Trivelpiece. 1996. Factors controlling the distribution of seabirds: wintersummer heterogeneity in the distribution of AdÈlie penguin populations. Foundations for ecological research west of the Antarctic Peninsula 70: 257-272.

Garibotti, I., M. Vernet, R. Smith, and M. Ferrario. 2005. Interannual variability in the distribution of the phytoplankton standing stock across the seasonal sea-ice zone west of the Antarctic Peninsula. Journal of Plankton Research 27: 825.

Guidi, L., G. Jackson, L. Stemmann, J. Miquel, M. Picheral, and G. Gorsky. 2008. Relationship between particle size distribution and flux in the mesopelagic zone. Deep-Sea Research Part I. 
Iversen, M. H., N. Nowald, H. Ploug, G. A. Jackson, and G. Fischer. 2010. High resolution profiles of vertical particulate organic matter export off Cape Blanc, Mauritania: Degradation processes and ballasting effects. Deep Sea Research Part I: Oceanographic Research Papers 57: 771-784.

Jaeger, J., C. Nittrouer, D. DeMaster, C. Kelchner, and R. Dunbar. 1996. Lateral transport of settling particles in the Ross Sea and implications for the fate of biogenic material. Journal of Geophysical Research 101: 18479.

Kahl, L., O. Schofield, and W. Fraser. 2010. Autonomous Gliders Reveal Features of the Water Column Associated with Foraging by Adélie Penguins. Integrative and Comparative Biology: 1-10.

Karl, D. M., B. D. Tilbrook, and G. Tien. 1991. Seasonal coupling of organic matter production and particle flux in the western Bransfield Strait, Antartica. Deep Sea Research Part A. Oceanographic Research Papers 38: 1097-1126.

Knap, A., A. Michaels, A. Close, H. Ducklow, and A. Dickson. 1996. Protocols for the Joint Global Ocean Flux Study (JGOFS) core measurements. JGOFS Report 19: 155-162.

Lamborg, C., K. Buesseler, J. Valdes, C. Bertrand, R. Bidigare, S. Manganini, S. Pike, D. Steinberg, T. Trull, and S. Wilson. 2008. The flux of bio-and lithogenic material associated with sinking particles in the mesopelagic 'twilight zone' of the northwest and North Central Pacific Ocean. Deep-Sea Research Part II 55: 1540-1563.

Martin, J. H., G. A. Knauer, D. M. Karl, and W. W. Broenkow. 1987. VERTEX: Carbon cycling in the Northeast Pacific. Deep-Sea Research 34: 267-285.

McDonnell, A. M. P., and K. O. Buesseler. 2010. Variability in the average sinking velocity of marine particles. Limnology and Oceanography 55: 2085-2096.

Montes-Hugo, M., C. Sweeney, S. C. Doney, H. Ducklow, R. Frouin, D. G. Martinson, S. Stammerjohn, and O. Schofield. 2010. Seasonal forcing of summer dissolved inorganic carbon and chlorophyll a on the western shelf of the Antarctic Peninsula. J. Geophys. Res. 115: C03024.

Ross, R., E. Hofmann, and L. Quetin. 1996. Foundations for ecological research west of the Antarctic Peninsula. Amer Geophysical Union.

Smith, R., K. Baker, W. Fraser, E. Hofmann, D. Karl, J. Klinck, L. Quetin, B. Prezelin, R. Ross, and W. Trivelpiece. 1995. The Palmer LTER: A long-term ecological research program at Palmer Station, Antarctica. OCEANOGRAPHY-WASHINGTON DCOCEANOGRAPHY SOCIETY- 8: 77-86.

Stemmann, L., G. A. Jackson, and D. Ianson. 2004. A vertical model of particle size distributions and fluxes in the midwater column that includes biological and physical processes-Part I: model formulation. Deep-Sea Research I 51: 865-884.

Wilson, S., D. Steinberg, and K. Buesseler. 2008. Changes in fecal pellet characteristics with depth as indicators of zooplankton repackaging of particles in the mesopelagic zone of the subtropical and subarctic North Pacific Ocean. Deep Sea Research Part II: Topical Studies in Oceanography 55: 1636-1647. 
Table 1. Cruise dates of this study

$\begin{array}{ccc}\text { Cruise Name } & \text { Start Date } & \text { End Date } \\ \text { LMG0901 } & \text { 28 December 2008 } & \text { 6 February 2009 } \\ \text { LMG0902 } & \text { 16 February 2009 } & \text { 17 March 2009 } \\ \text { LMG1001 } & \text { 28 December 2009 } & \text { 6 February 2010 } \\ \text { NBP1002 } & \text { 16 March 2010 } & \text { 1 May 2010 }\end{array}$


Table 2. Average sinking velocities, $W_{i, \text { avg }}$, used in this study to calculate the numeric fluxes of particles, $F_{i}$, from the concentration size distribution measured by the VPR. These velocities were computed by merging particle concentration data from multiple (2-5) VPR casts conducted during the collection phase of each sediment trap deployment. As a result, they are slightly different from the velocities reported in Chapter 2, and Appendix IV, which only used concentration data from a single VPR cast. Average sinking velocities equal to zero indicate that no particles of that size were collected in the gel. Values of "Inf" means there were particles collected in the flux, however none were detected in the water column concentration by the VPR. The "NaN" values indicate that no particles were detected in either the flux or the concentration.

\begin{tabular}{|c|c|c|c|c|c|c|c|c|c|c|c|}
\hline \multirow[b]{3}{*}{ Date } & \multirow[b]{3}{*}{ Site } & \multirow[b]{3}{*}{$\begin{array}{l}\text { Depth } \\
\text { of } \\
\text { Trap } \\
(\mathrm{m})\end{array}$} & \multicolumn{9}{|c|}{ Average sinking velocity size distribution $\left(\mathrm{m} \mathrm{d}^{-1}\right)$} \\
\hline & & & \multicolumn{6}{|c|}{ Size Bins } & \multirow[b]{2}{*}{ 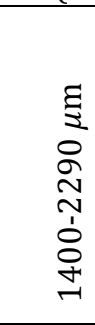 } & \multirow[b]{2}{*}{ 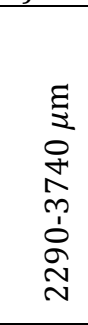 } & \multirow[b]{2}{*}{ 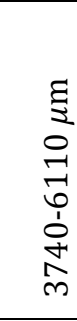 } \\
\hline & & & 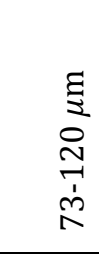 & 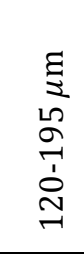 &  & 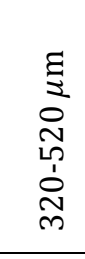 &  & 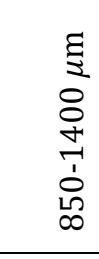 & & & \\
\hline \multirow[t]{3}{*}{ 8-10 Jan } & PS1 & 50 & 168 & 72 & 62 & 67 & 84 & 155 & 342 & $\mathrm{NaN}$ & $\mathrm{NaN}$ \\
\hline & PS1 & 150 & 116 & 38 & 28 & 30 & 34 & 47 & 127 & 201 & $\mathrm{NaN}$ \\
\hline & PS1 & 250 & 122 & 68 & 52 & 51 & 93 & 97 & 78 & 7 & 33 \\
\hline \multirow[t]{3}{*}{ 19-20 Jan } & PS2 & 100 & 171 & 99 & 100 & 76 & 131 & 388 & 2180 & Inf & Inf \\
\hline & PS2 & 200 & 135 & 56 & 29 & 26 & 49 & 38 & 28 & 0 & $\mathrm{NaN}$ \\
\hline & PS2 & 300 & 300 & 135 & 89 & 55 & 63 & 66 & 97 & 114 & 256 \\
\hline \multirow[t]{3}{*}{ 26-27 Jan } & PS3 & 50 & 104 & 116 & 121 & 118 & 495 & 1850 & 253 & $\mathrm{NaN}$ & $\mathrm{NaN}$ \\
\hline & PS3 & 100 & 24 & 25 & 74 & 120 & 265 & 1050 & 1465 & Inf & $\mathrm{NaN}$ \\
\hline & PS3 & 150 & 46 & 31 & 44 & 82 & 77 & 176 & 571 & 272 & 136 \\
\hline \multicolumn{12}{|l|}{$23-25$} \\
\hline \multirow[t]{3}{*}{ Feb } & PS2 & 100 & 305 & 98 & 93 & 78 & 81 & 123 & Inf & $\mathrm{NaN}$ & $\mathrm{NaN}$ \\
\hline & PS2 & 200 & 274 & 118 & 73 & 46 & 25 & 8 & 0 & 0 & $\mathrm{NaN}$ \\
\hline & PS2 & 300 & 249 & 123 & 83 & 66 & 44 & 7 & 5 & 0 & $\mathrm{NaN}$ \\
\hline \multicolumn{12}{|l|}{$5-7$} \\
\hline \multirow{3}{*}{ March } & PS1 & 50 & 2230 & 581 & 80 & 172 & 262 & 1240 & Inf & $\mathrm{NaN}$ & $\mathrm{NaN}$ \\
\hline & PS1 & 150 & 384 & 70 & 49 & 105 & 221 & 1800 & 1550 & 49 & $\mathrm{NaN}$ \\
\hline & PS1 & 250 & 329 & 75 & 38 & 32 & 45 & 262 & Inf & 0 & $\mathrm{NaN}$ \\
\hline
\end{tabular}


(A)

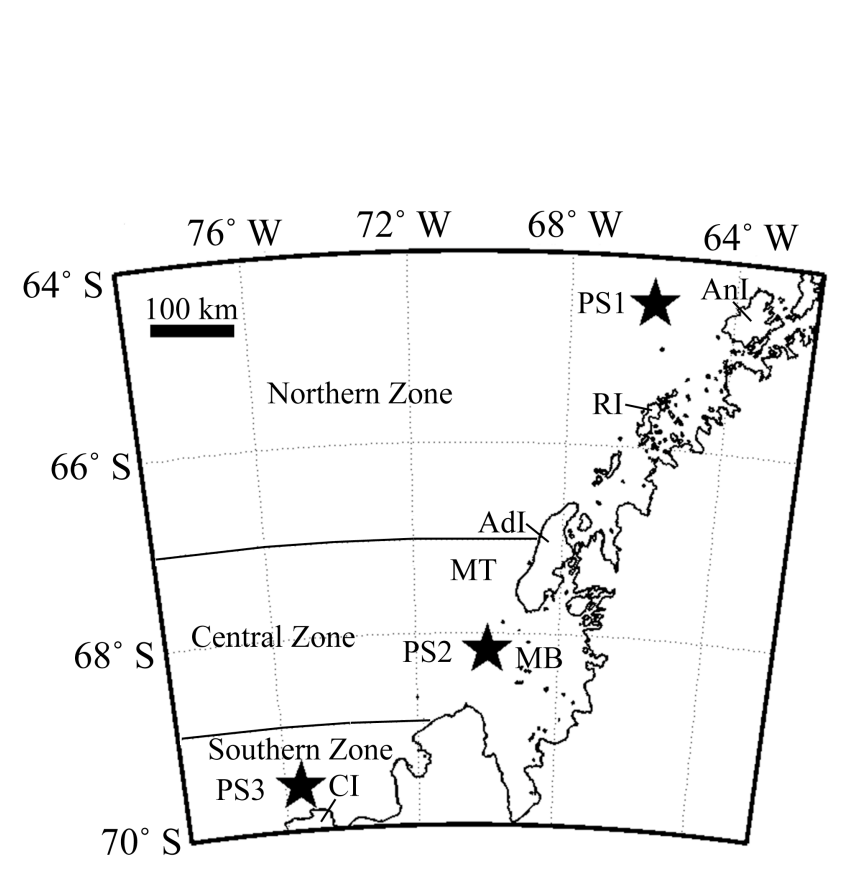

(B)



Figure 1. (A) Map of the WAP study area. The stars indicate the locations of the three process study stations PS1 near Anvers Island (AnI), PS2 at the mouth of Marguerite Bay (MB), and PS3 near Charcot Island (CI). Adelaide Island (AdI) and Renaud Island (RI) are also marked for reference. MT indicates the Marguerite Trough, a deep canyon in the continental shelf that extends $200 \mathrm{~km}$ from the mouth of MB towards the northwest. (B) Bathymetry of the region. Dark grey are bottom depths $<500 \mathrm{~m}$, light grey is $500-1000 \mathrm{~m}$ depths, and white is $>1000 \mathrm{~m}$. The locations of VPR profiles conducted along the LTER sampling grid in January of 2009 are indicated by the red dots. The dark blue dots represent PS1, PS2, and PS3. 


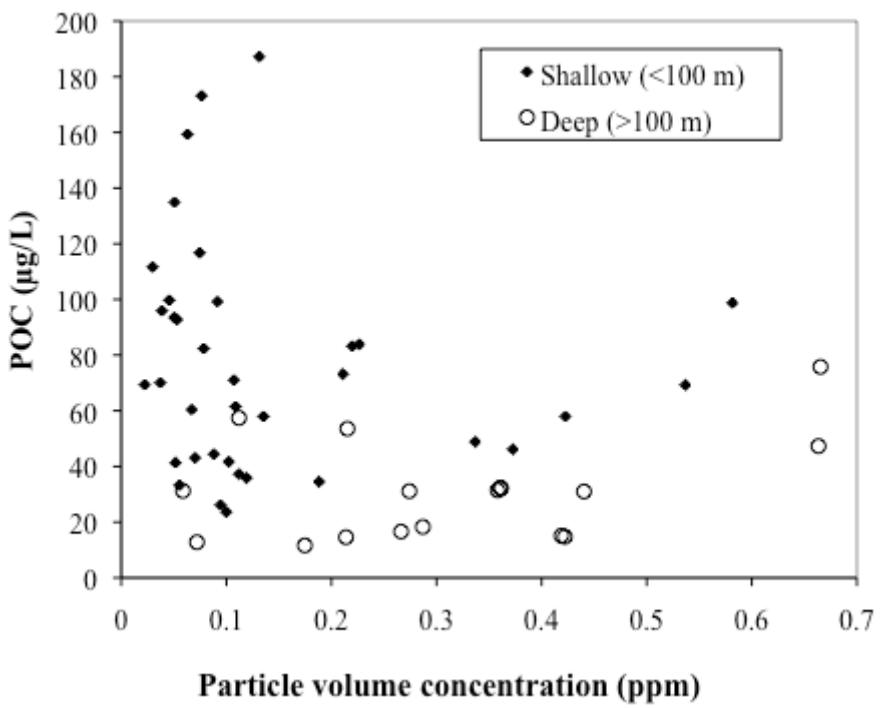

Figure 2. Relationship between particle volume concentration for particles with an ESD between 70 and $1400 \mu \mathrm{m}$ as measured by the VPR and the concentration of particulate organic carbon from filtration of water from the CTD rosette. The data pairs are for matching $50 \mathrm{~m}$ depth bins. 




Figure 3. Relationship of the large particle volume determined from the VPR (ESD between 70 and $1400 \mu \mathrm{m}$ ) vs. the frequency of spikes in the transmissometry data from the CTD. Data pairs are for matching $50 \mathrm{~m}$ depths bins from LMG1001. Data from depths $>100 \mathrm{~m}$ here due to the difficulty in establishing a transmission background level in surface waters. 

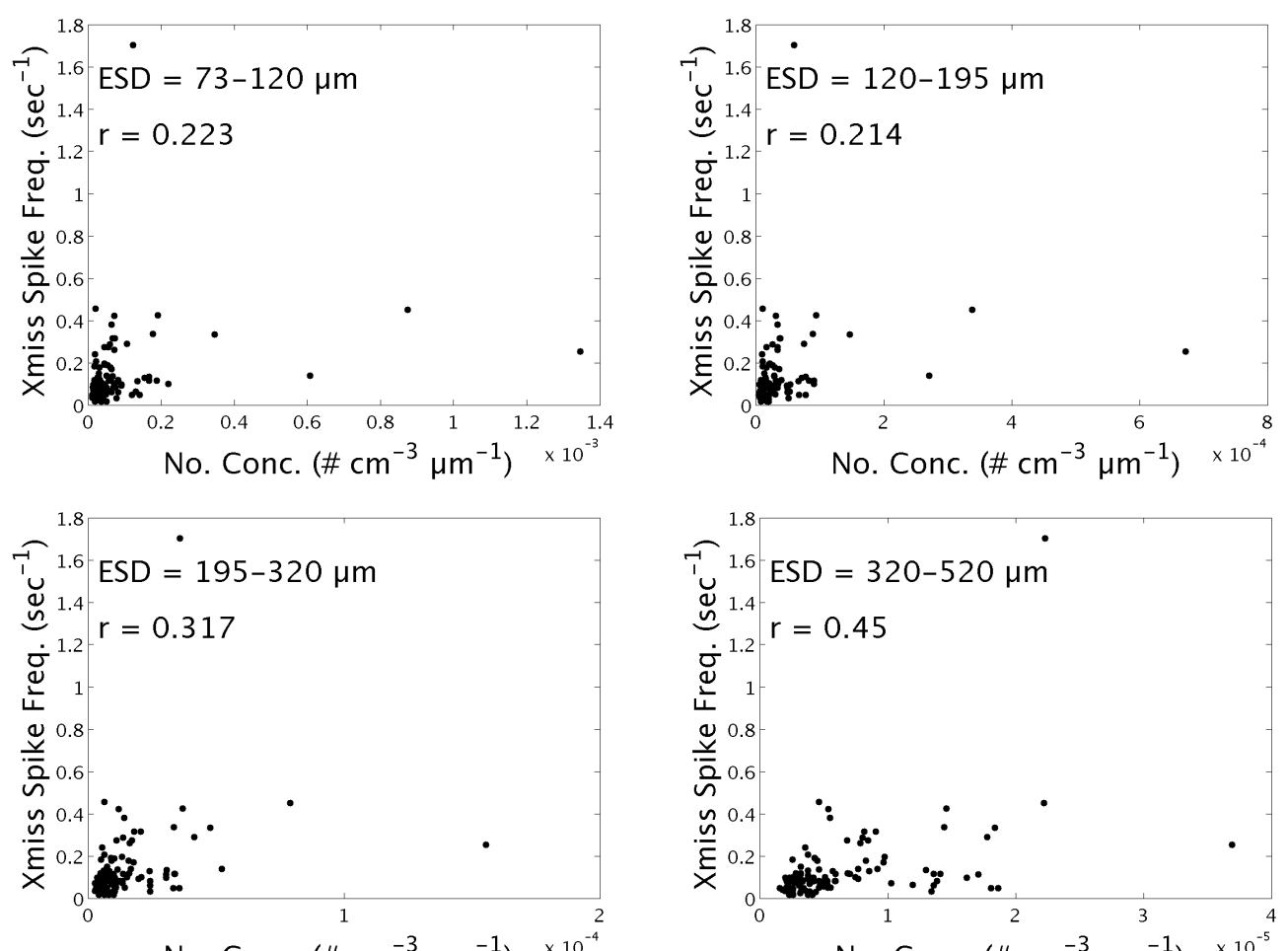

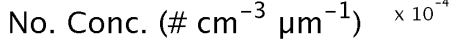
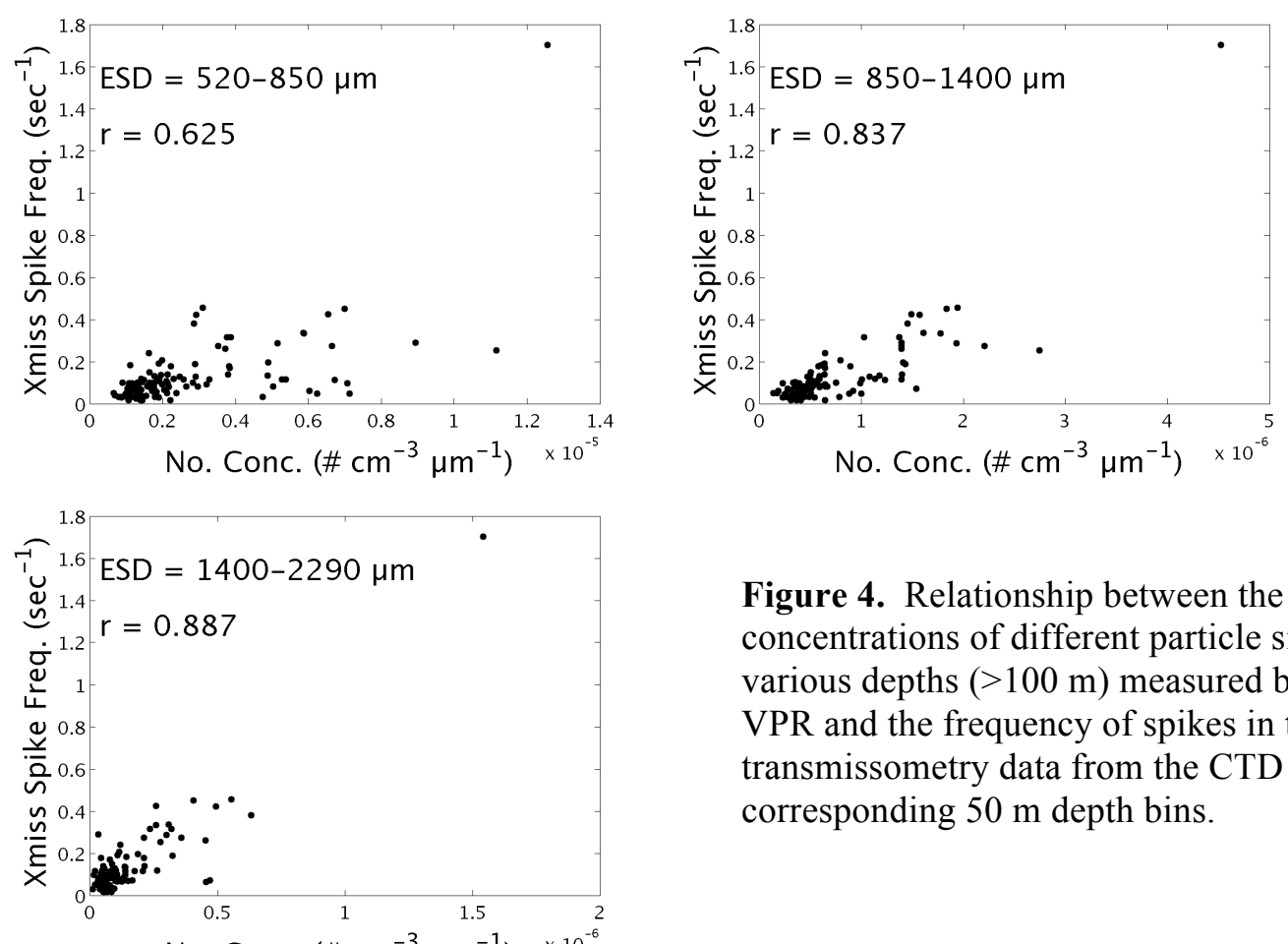

Figure 4. Relationship between the concentrations of different particle sizes at various depths $(>100 \mathrm{~m})$ measured by the VPR and the frequency of spikes in the transmissometry data from the CTD in corresponding $50 \mathrm{~m}$ depth bins.

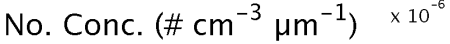



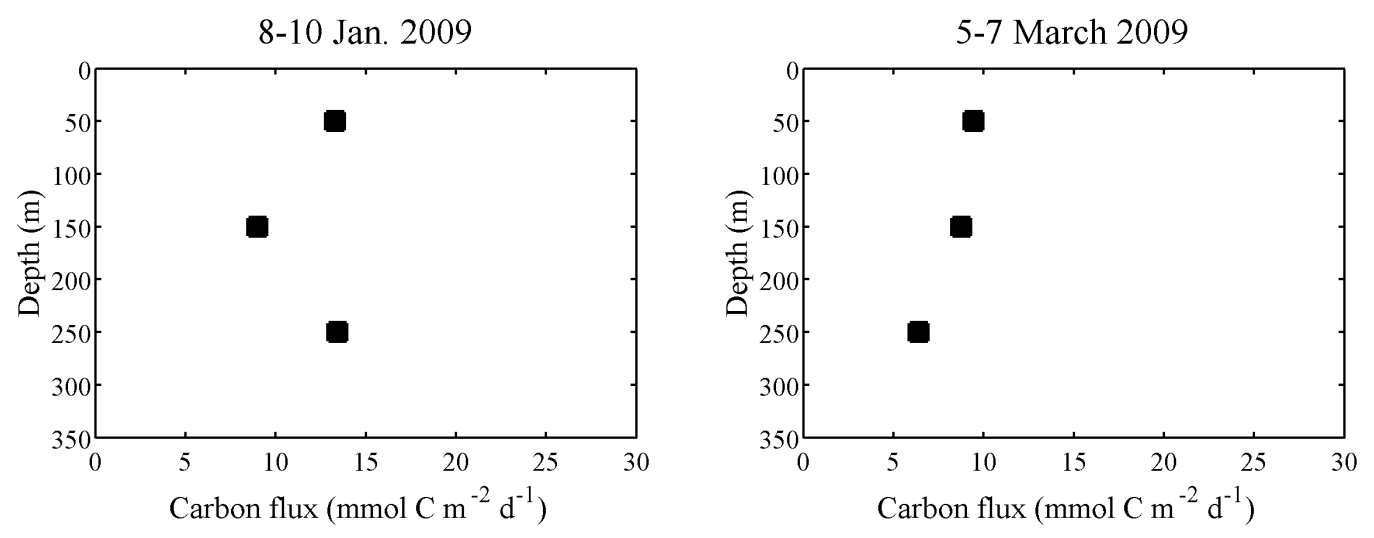

PS2
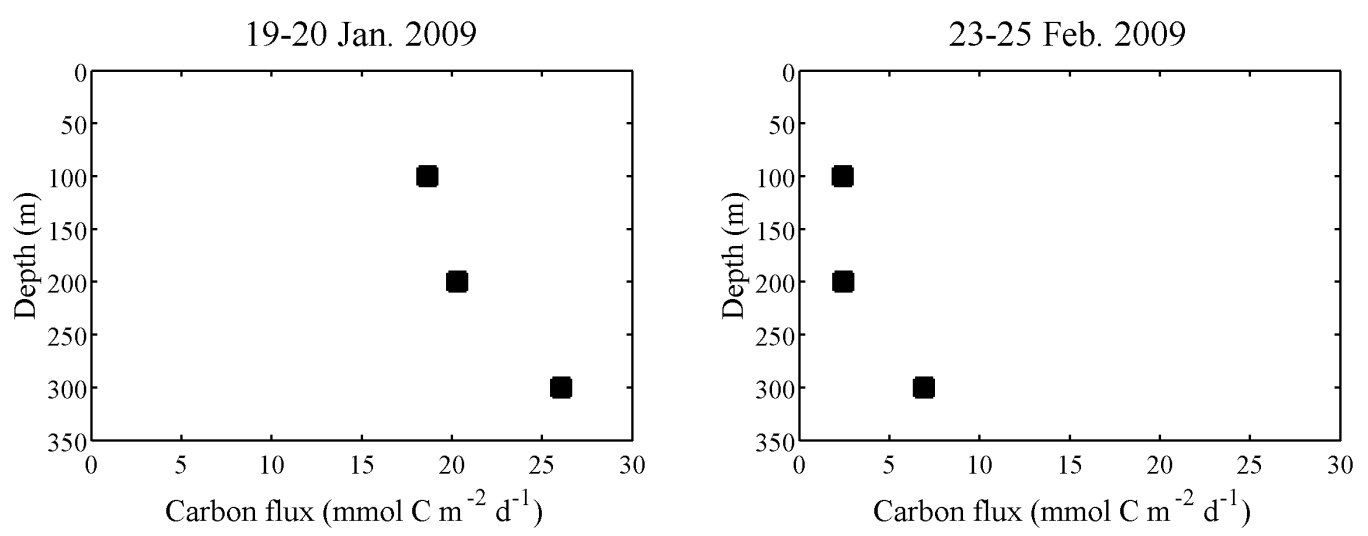

\section{PS3}



Figure 5. Carbon flux as a function of depth as measured by the drifting sediment trap array at PS1, PS2, and PS3 during the austral summer of 2009. PS1 and PS2 were each occupied twice during the season. 
8-10 Jan. 2009

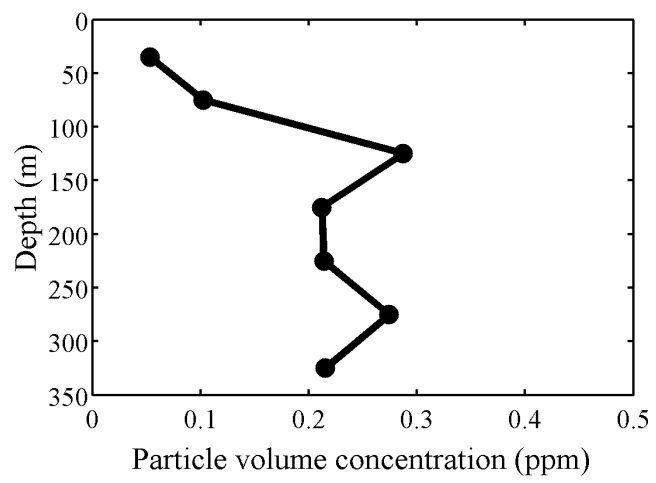

PS2

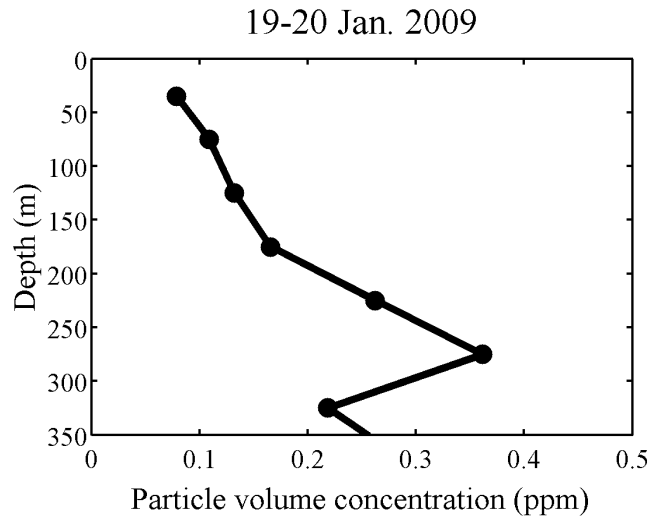

PS3

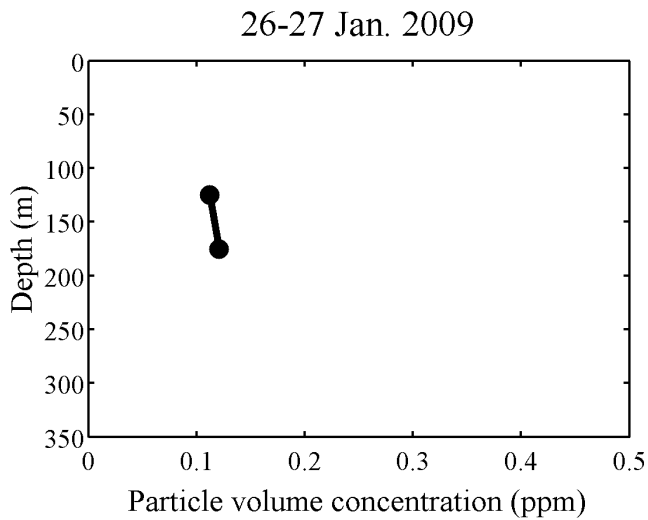

5-7 March 2009



23-25 Feb. 2009

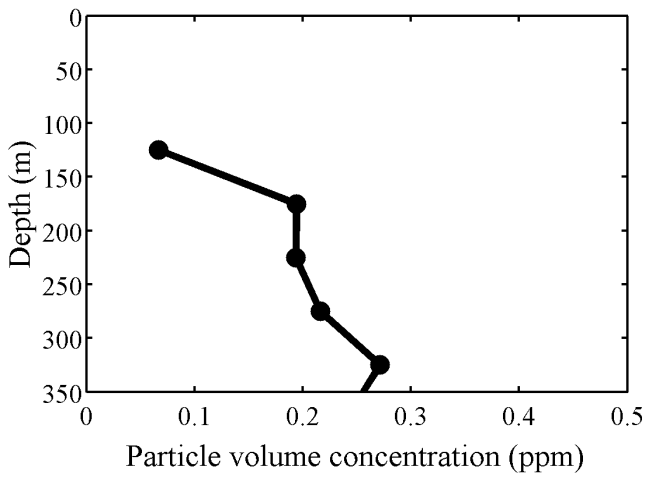

Figure 6. Total particle volume $(73<\mathrm{ESD}<1400 \mu \mathrm{m})$ as a function of depth at the trap sites in 2009. Where no particle volume data is presented in the upper $100 \mathrm{~m}$ of the water column, the total particle volume was unable to be computed because the abundances of the largest particles in this size range were below the detection limit of the VPR due to their paucity. 




Figure 7. The relationship between the numeric concentration of particles in the water column and the fluxes measured in the polyacrylamide gel traps. This plot compares concentrations and fluxes across the size spectrum observable with the VPR.

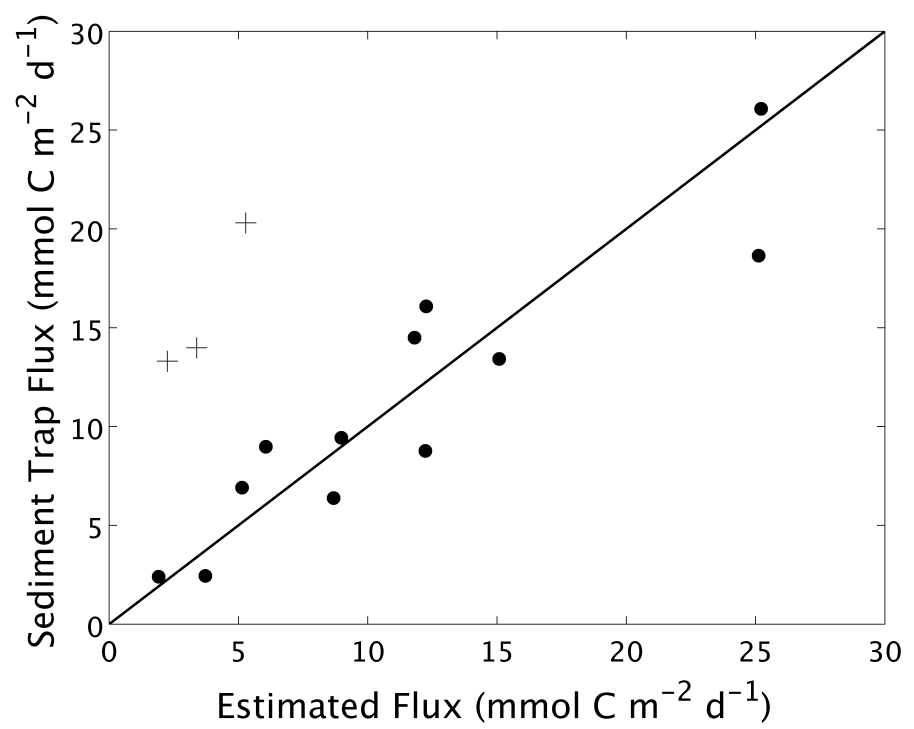

Figure 8. Carbon flux measured from drifting sediment traps plotted vs. the estimated carbon flux derived from the calculations described in the methods section. The three data point marked by a '+' were omitted from the fitting procedure as the fluxes in those gels were anomalously low and would have caused the majority of the points to deviate from the 1:1 solid line in the figure. 


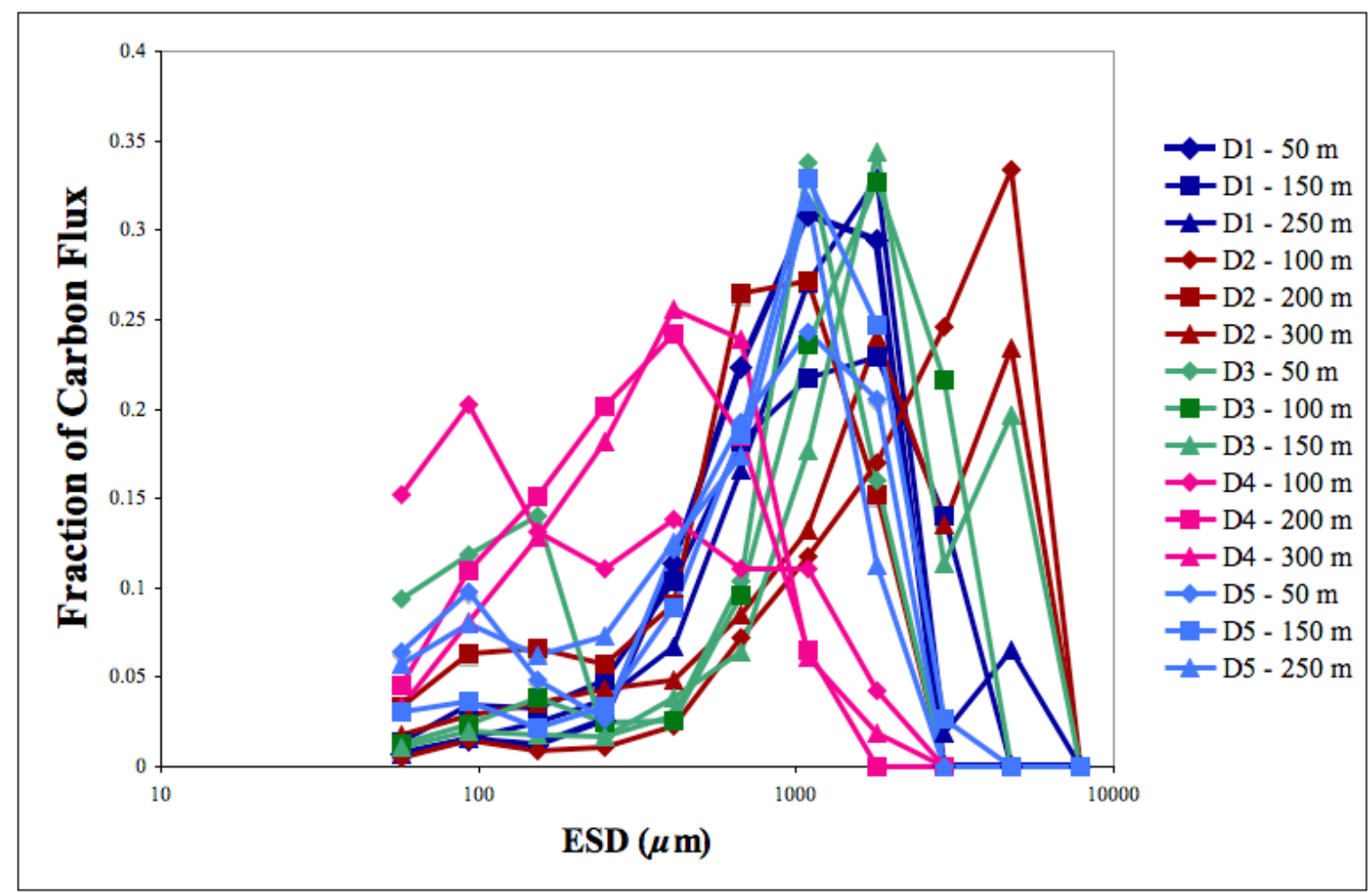

Figure 9. The fraction of the total carbon flux collected in each logarithmically spaced size bin as a function of the equivalent spherical diameter (ESD) for the 2009 WAP deployments. This data is calculated from the flux size distribution of each polyacrylamide gel and the parameterization of carbon content as a function of particle size. The colors represent different deployments of the drifting array and the markers represent the depths specified in the legend. Deployments D1 (dark blue) and D5 (light blue) were conducted at PS1 near Anvers Island. Deployments D2 (dark red) and D4 (pink) were located in Marguerite Bay at PS2. Deployment D3 (green) was conducted near Charcot Island at PS3 in the far south of the study area. 



PS2

19-20 Jan. 2009

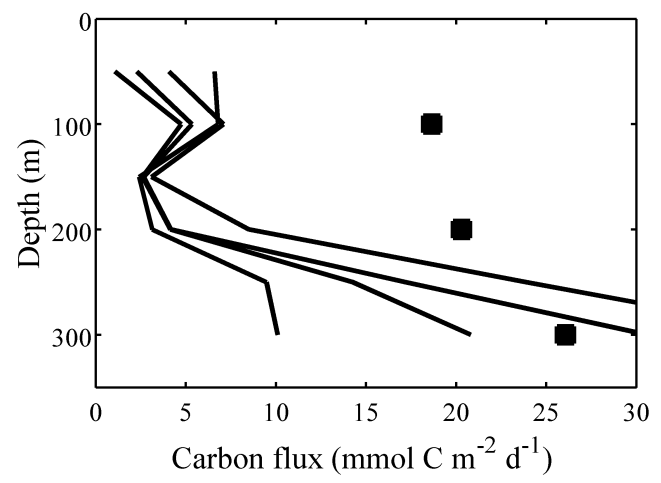

23-25 Feb. 2009

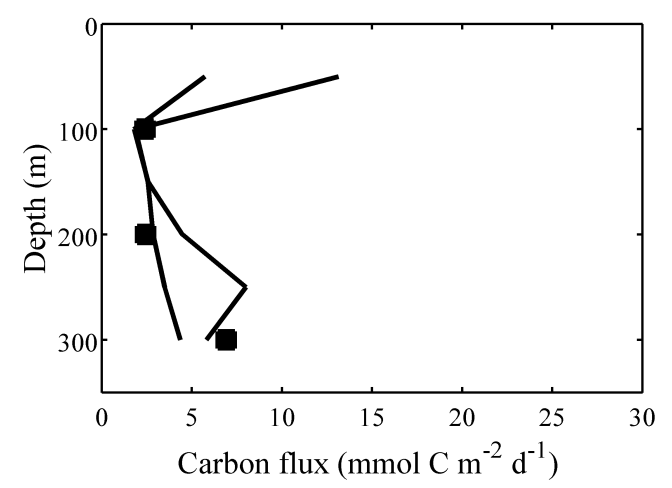

PS3

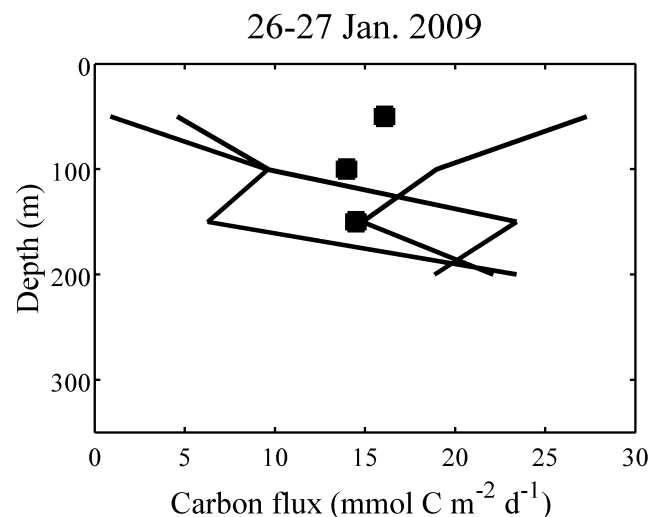

Figure 10. Comparison of carbon flux measured by the drifting sediment trap arrays (squares) to those estimated from the CSD and average sinking velocities (solid lines). Each solid line represents fluxes estimated from different VPR casts conducted during the 36-hour collection phase at the drifting sediment trap site, and gives an indication of the short-term variability in particle concentrations and fluxes during the collection phase. 

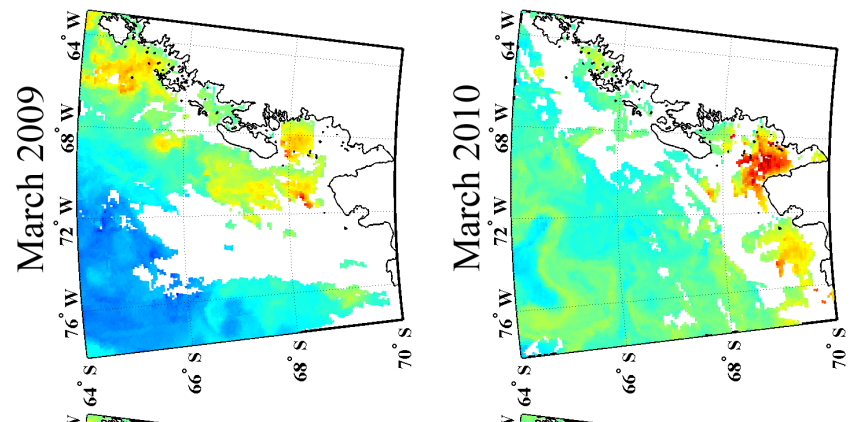

Figure 11. Monthly average Chlorophyll $a$ concentrations from MODIS showing the seasonal progression of the phytoplankton blooms during the austral summers of 2008/2009 and 2009/2010.
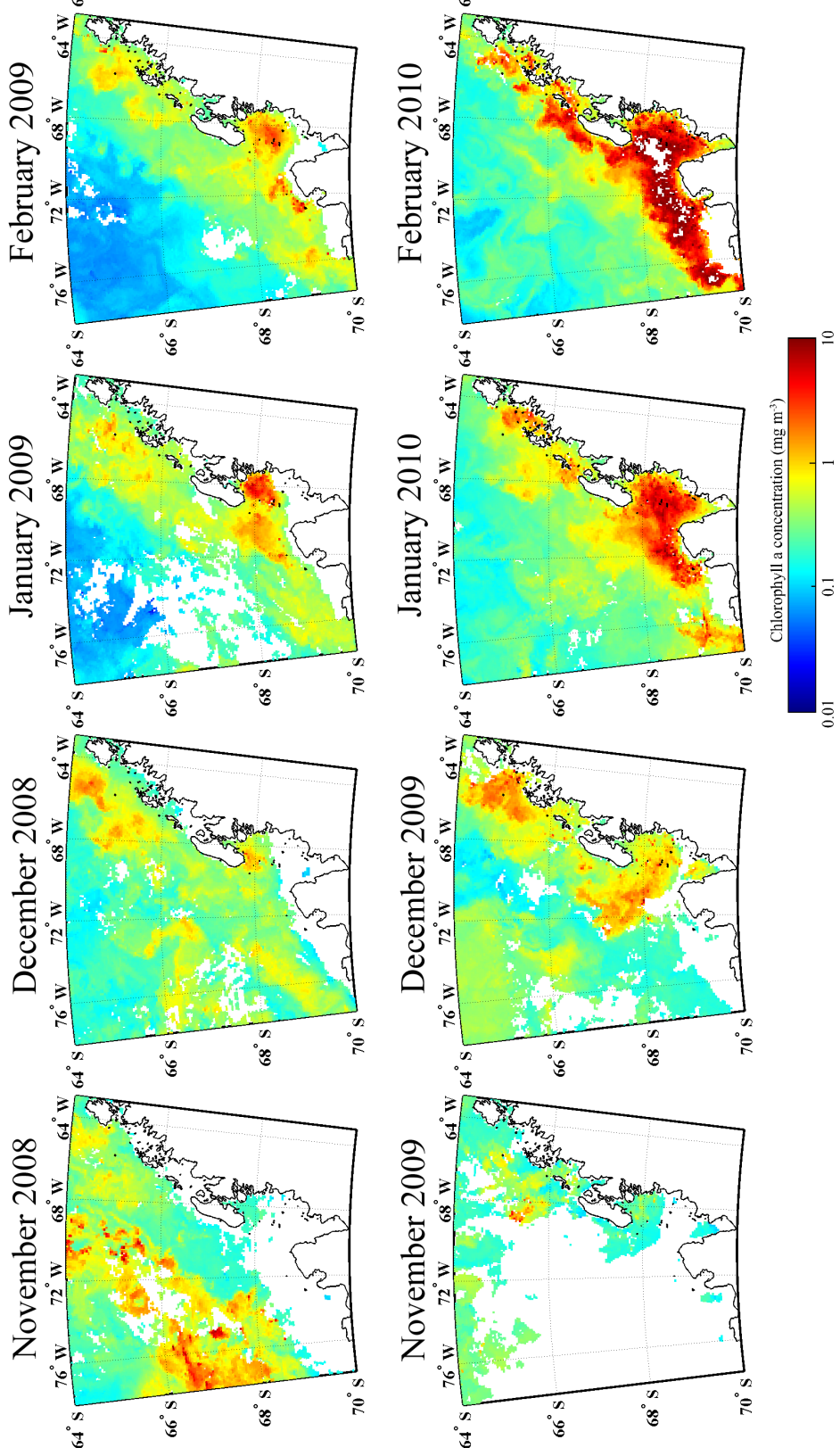
(A) January 2009

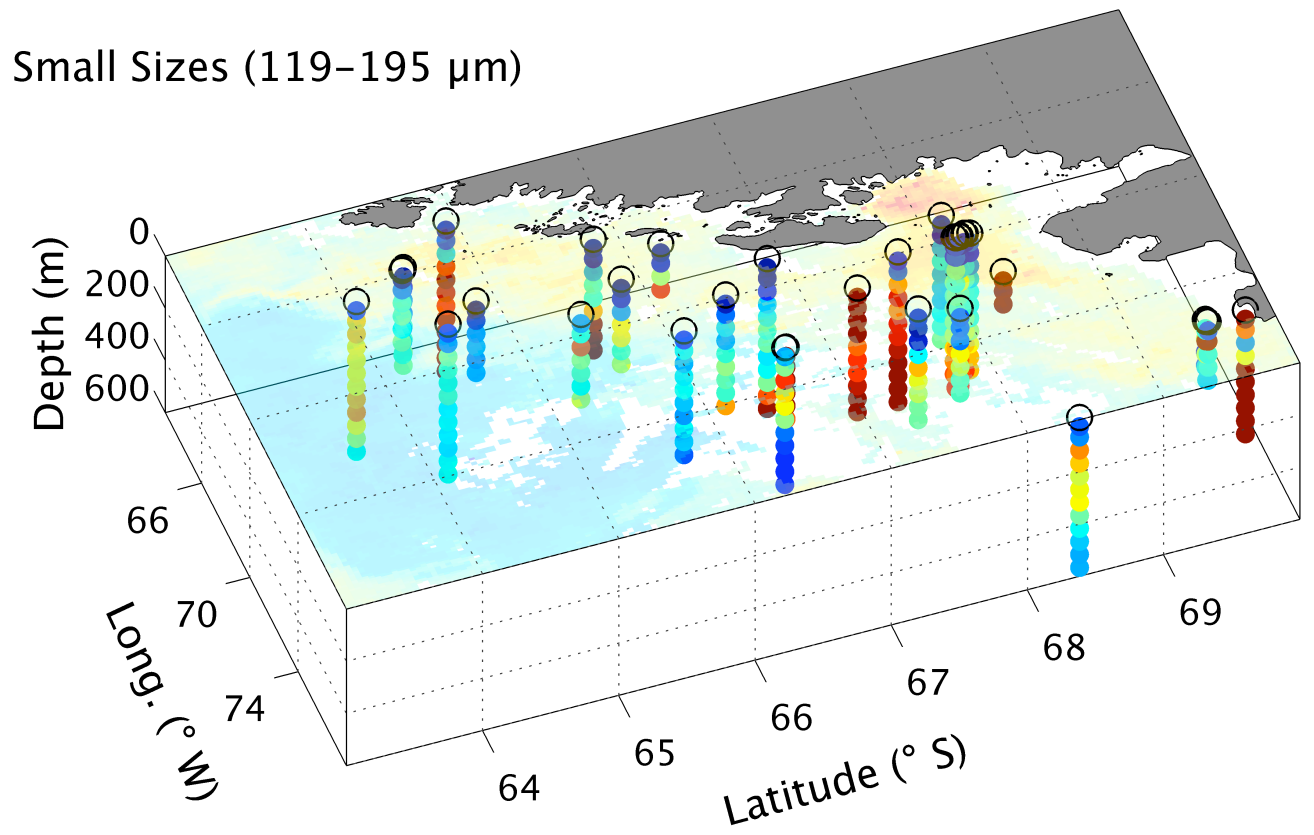

(B) January 2010

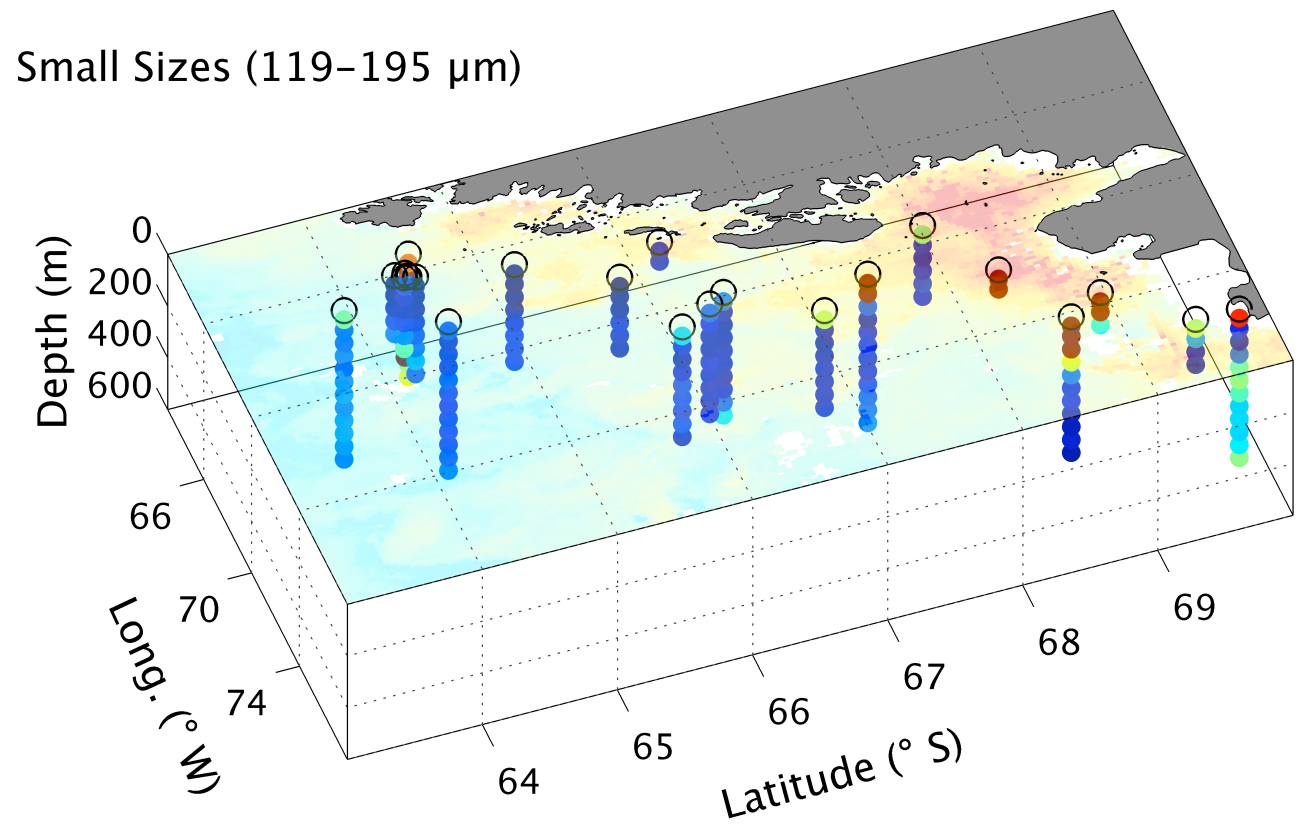

Figure 12. Spatial maps of particle concentration (colored dots) for the small particle size bin $(119 \leq \mathrm{ESD}<195 \mu \mathrm{m})$ for cruises in (A) January 2009, (B) January 2010, (C) February/March 2009, and (D) March/April 2010. Overlaid in faint color on the surface of the map is the monthly averaged chlorophyll a concentration from the MODIS satellite. 
(C) February/March 2009



(D) March/April 2010
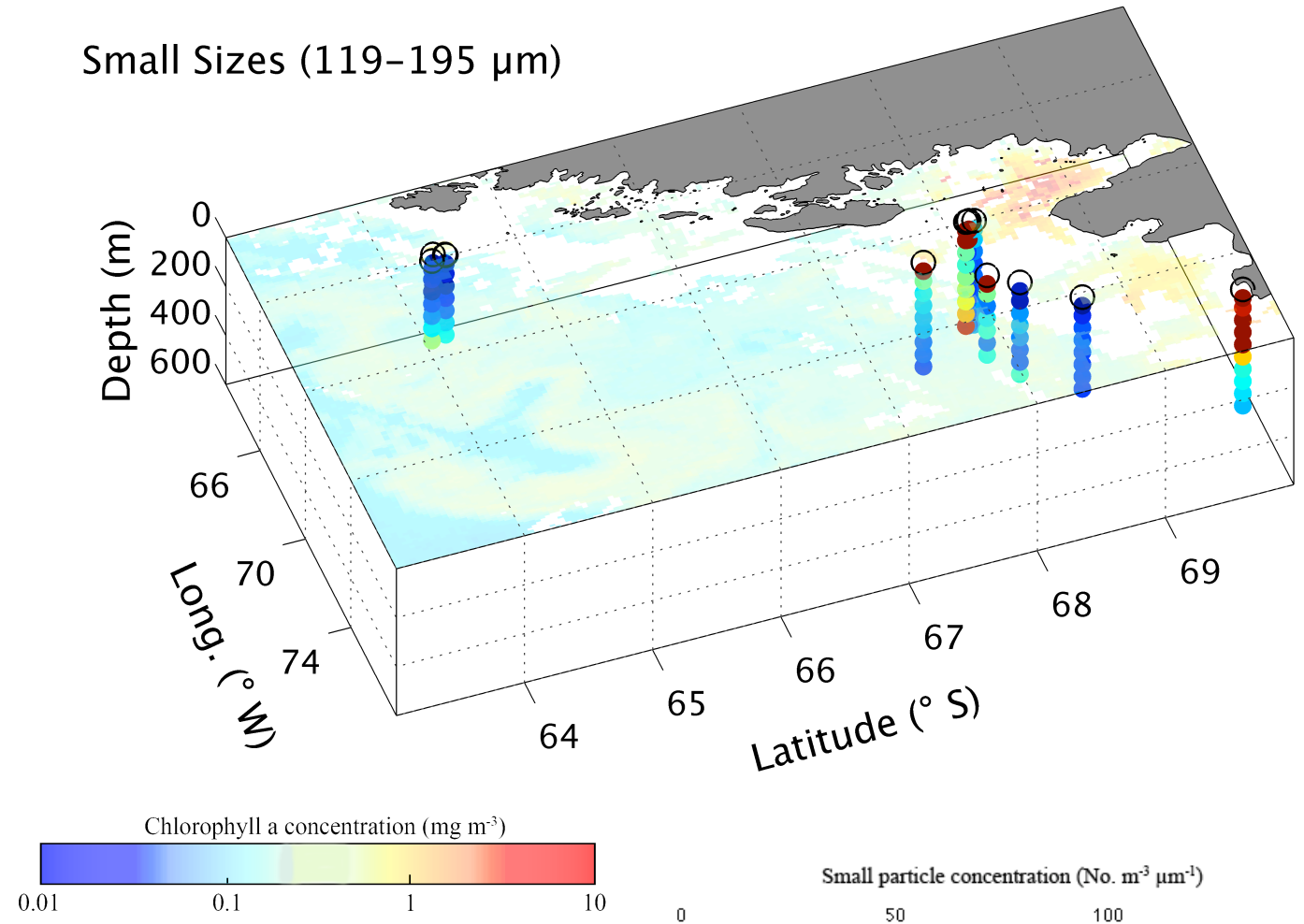

Small particle concentration (No. $\mathrm{m}^{-3} \mu \mathrm{m}^{-1}$ )

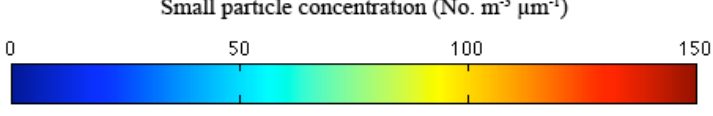


(A) January 2009

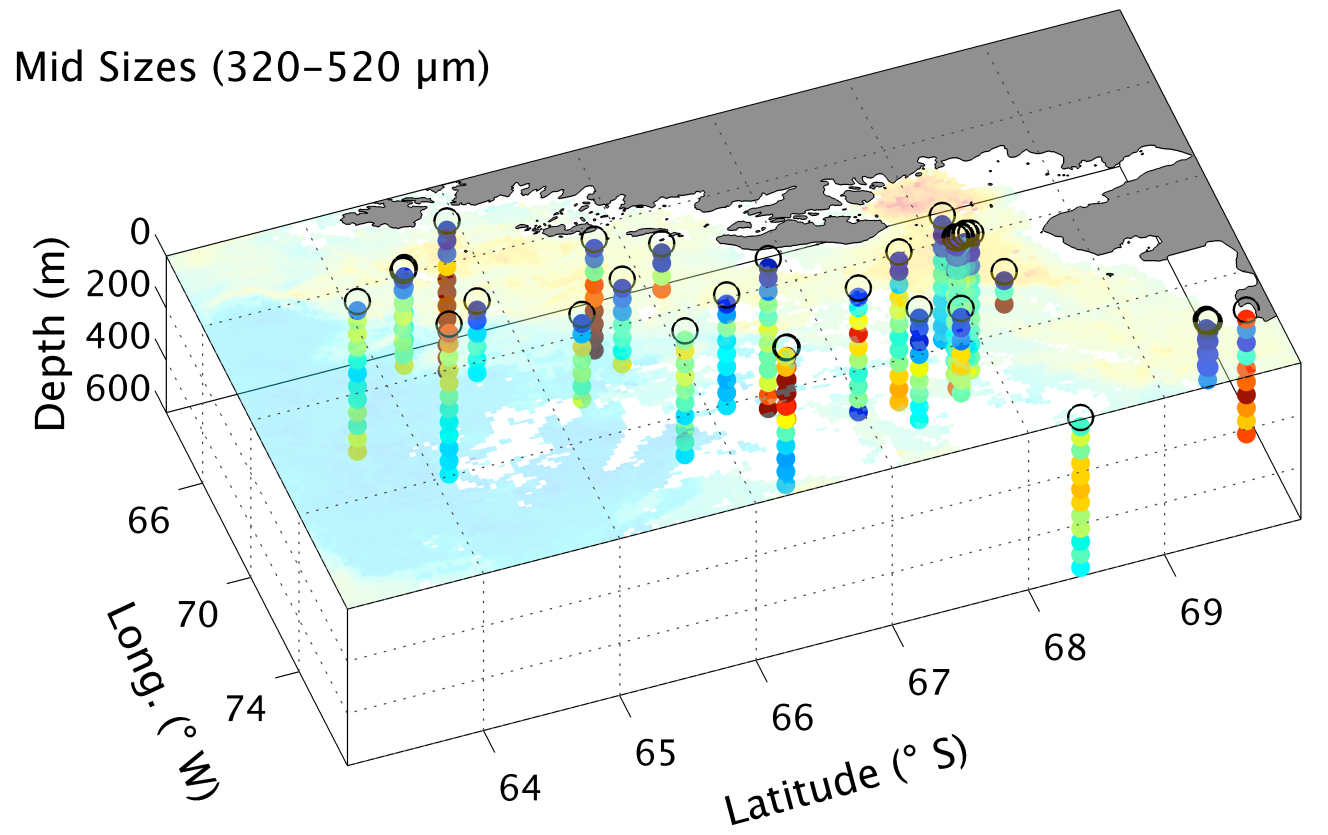

(B) January 2010

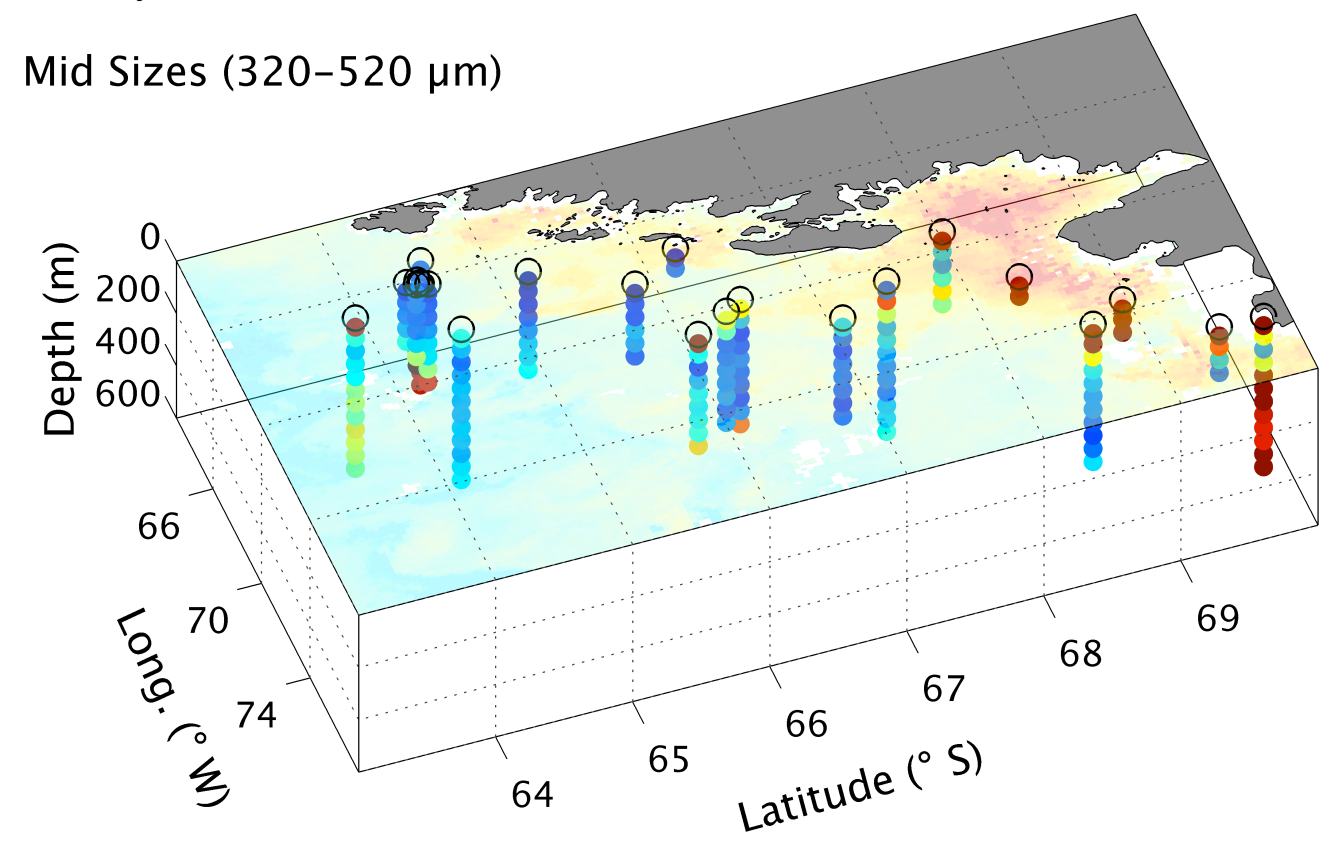

Figure 13. Spatial plots of particle concentration (colored dots) for the medium particle size bin $(320 \leq \mathrm{ESD}<520 \mu \mathrm{m})$ for cruises in (A) January 2009, (B) January 2010, (C) February/March 2009, and (D) March/April 2010. Overlaid in faint color on the surface of the map is the monthly averaged chlorophyll a concentration from the MODIS satellite. 
(C) February/March 2009

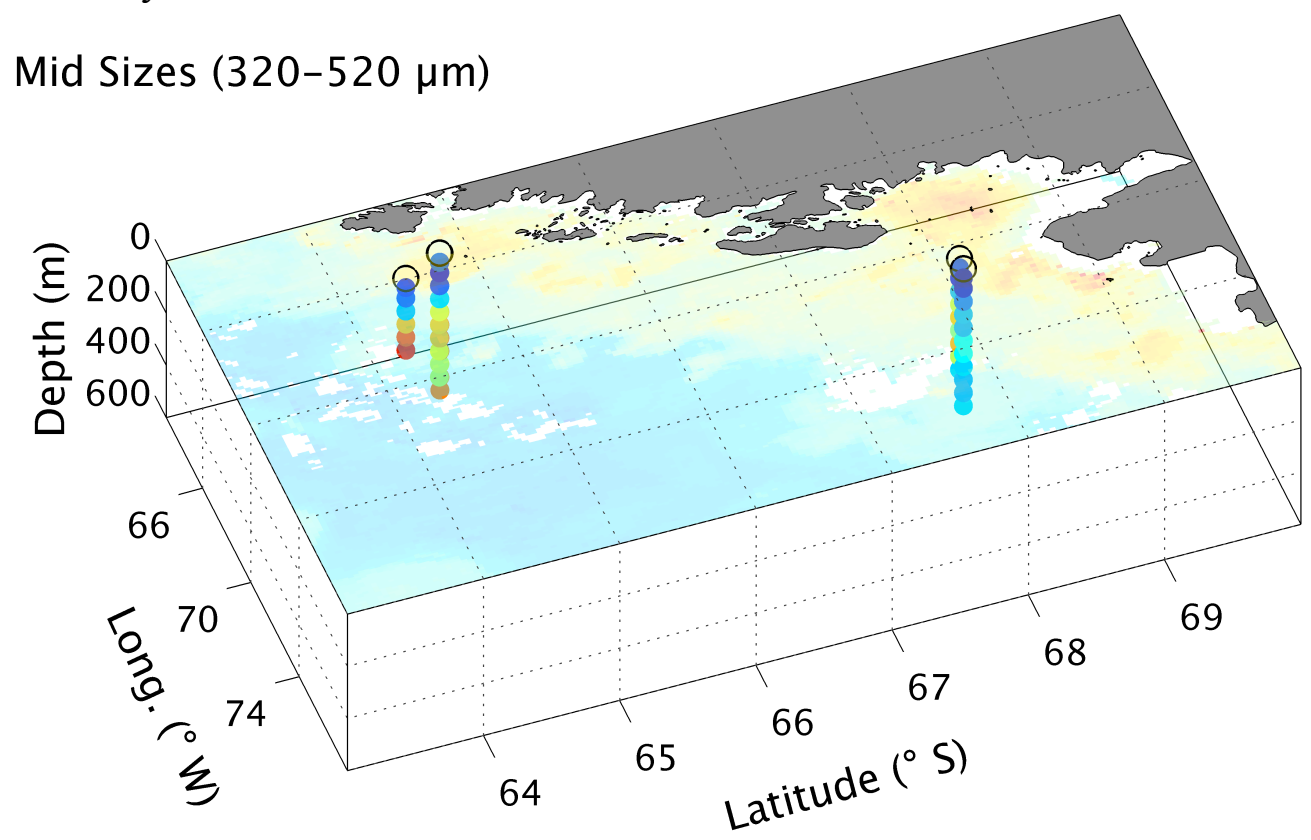

(D) $\quad$ March/April 2010
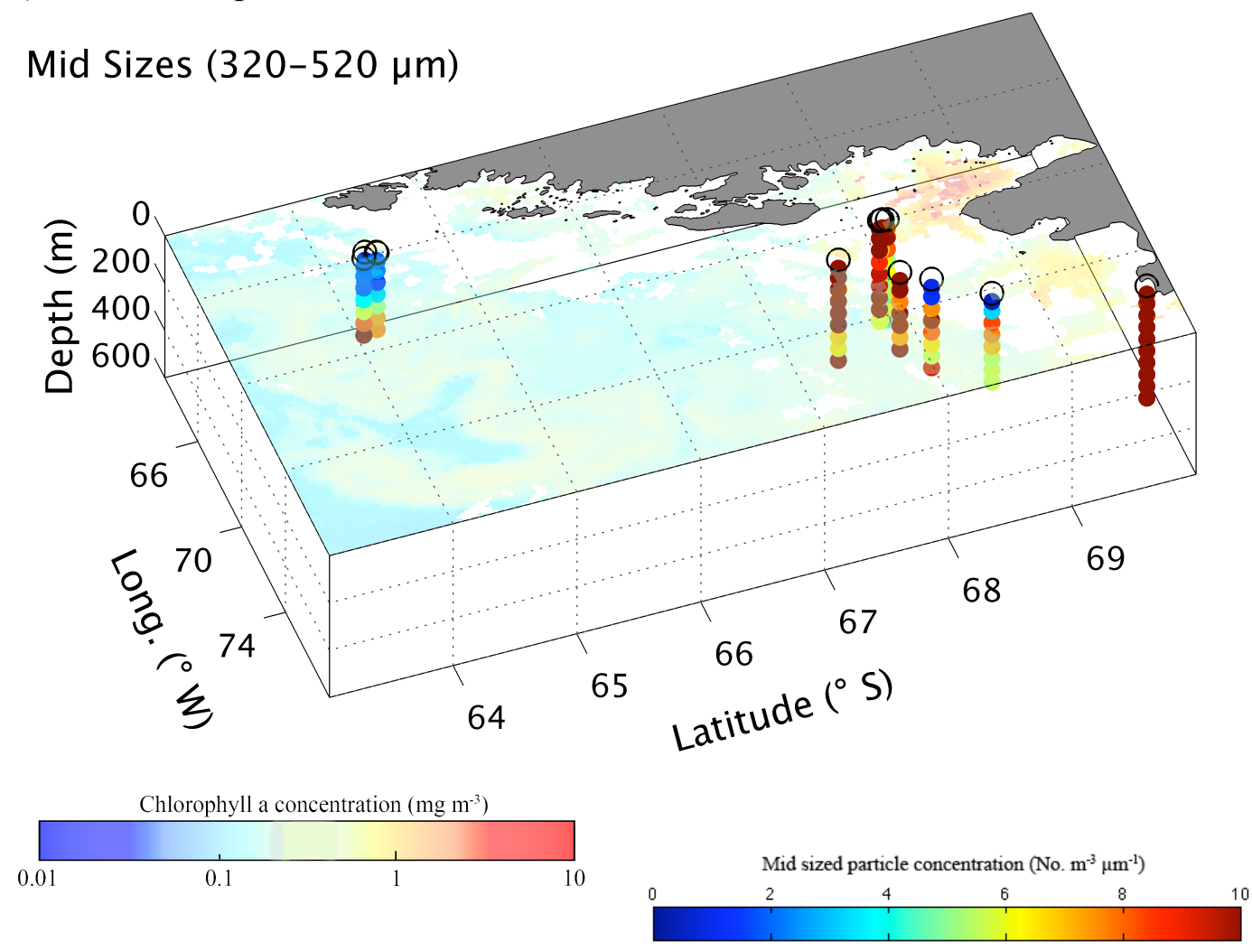
(A) January 2009

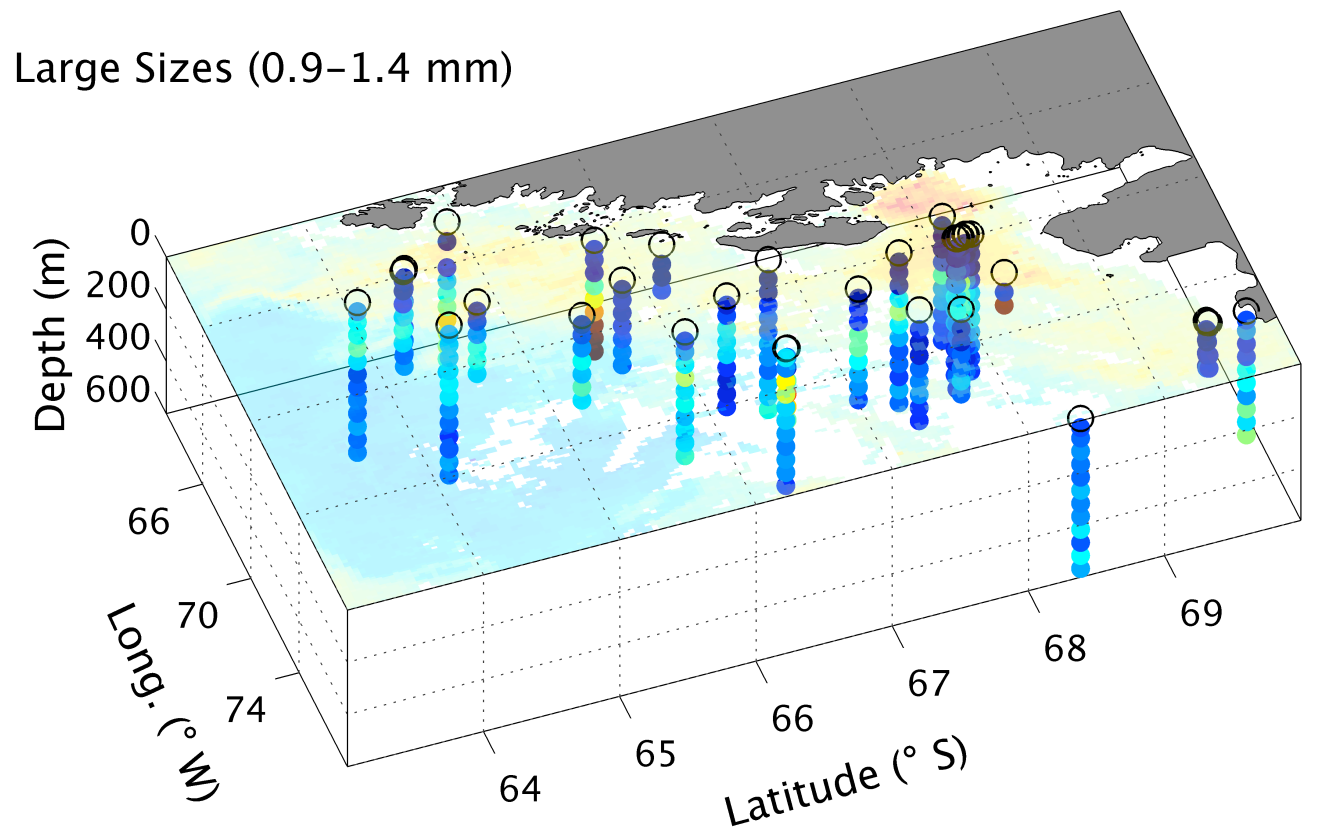

(B) January 2010

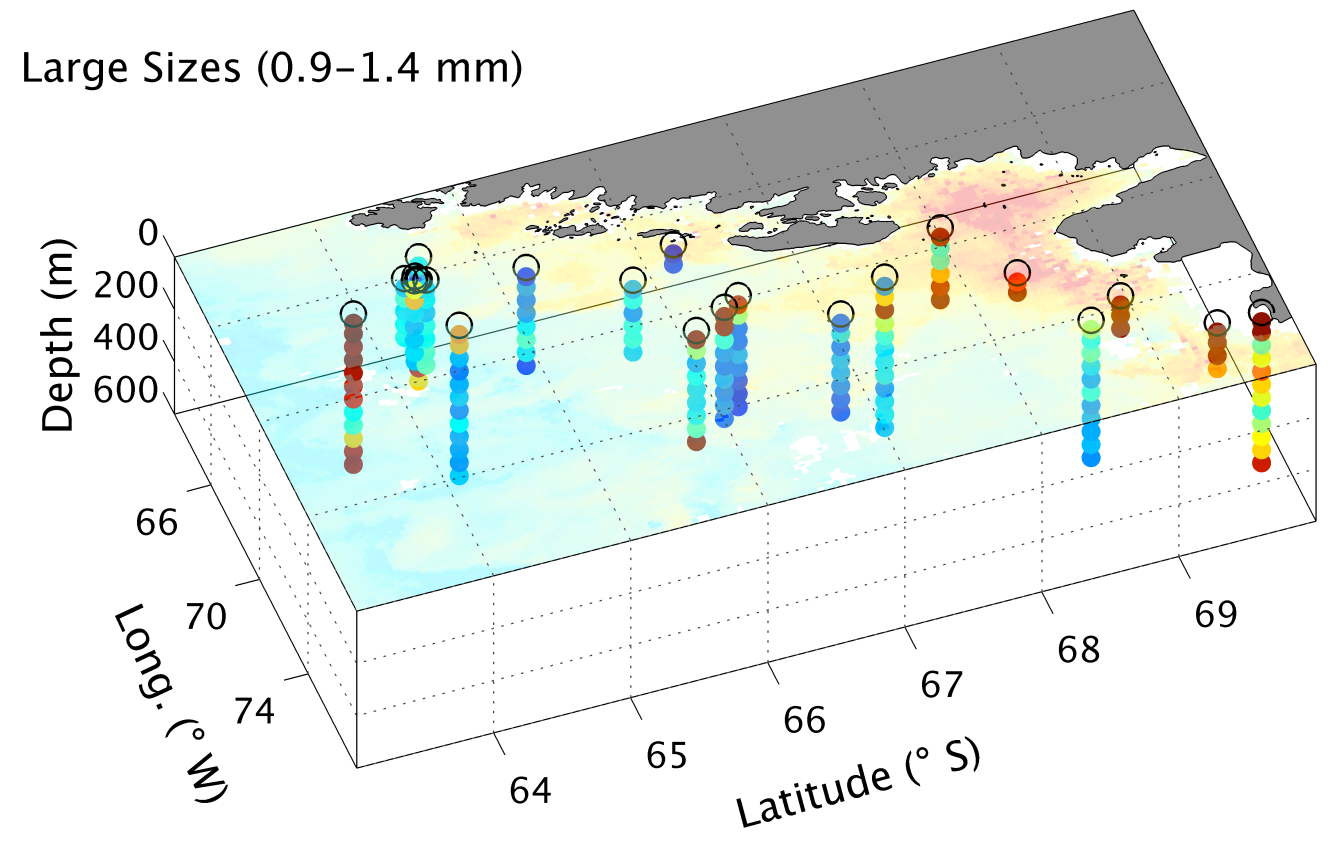

Figure 14. Spatial plots of particle concentration for the large particle size bin $(0.9 \leq \mathrm{ESD}<1.4$ $\mathrm{mm}$ ) for cruises in (A) January 2009, (B) January 2010, (C) February/March 2009, and (D) March/April 2010. Overlaid in faint color on the surface of the map is the monthly averaged chlorophyll a concentration from the MODIS satellite. 
(C) February/March 2009

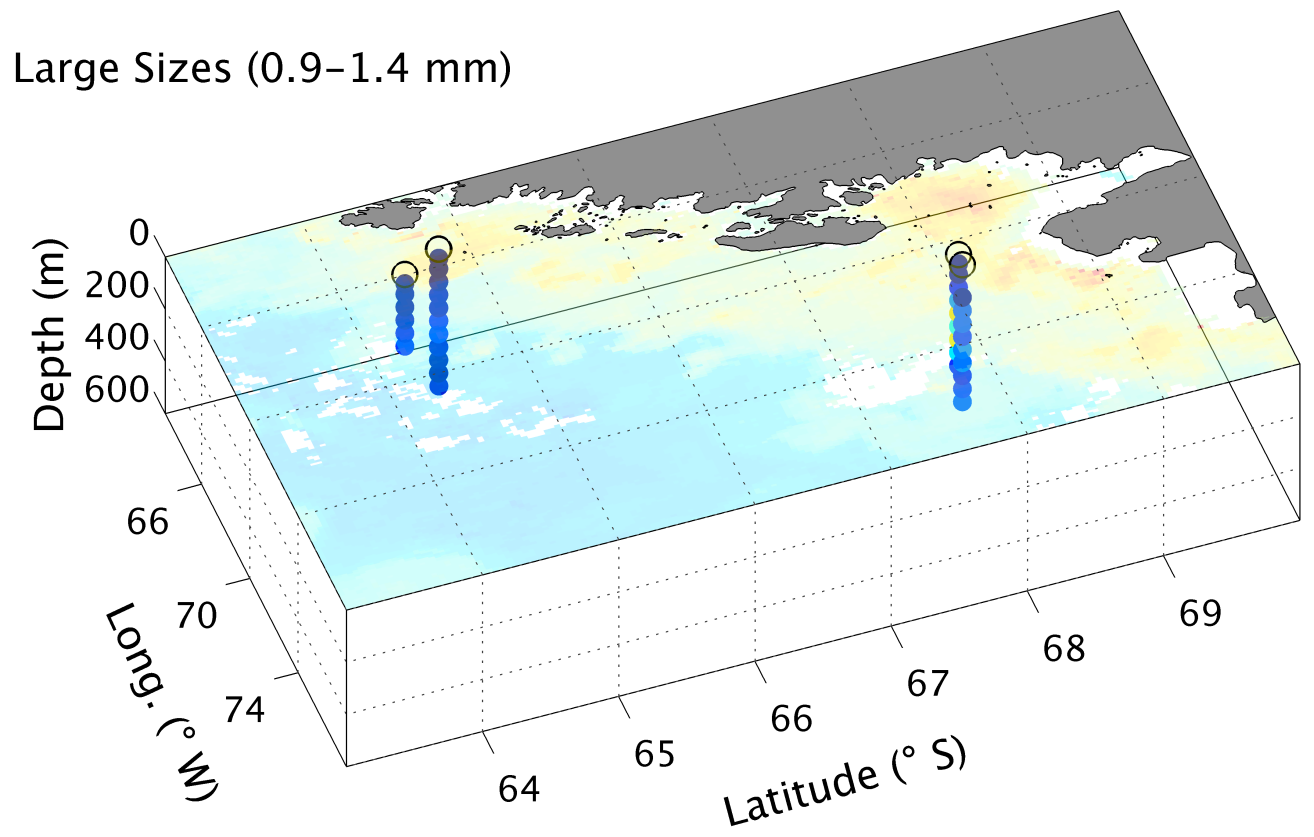

(D) $\operatorname{March} /$ April 2010

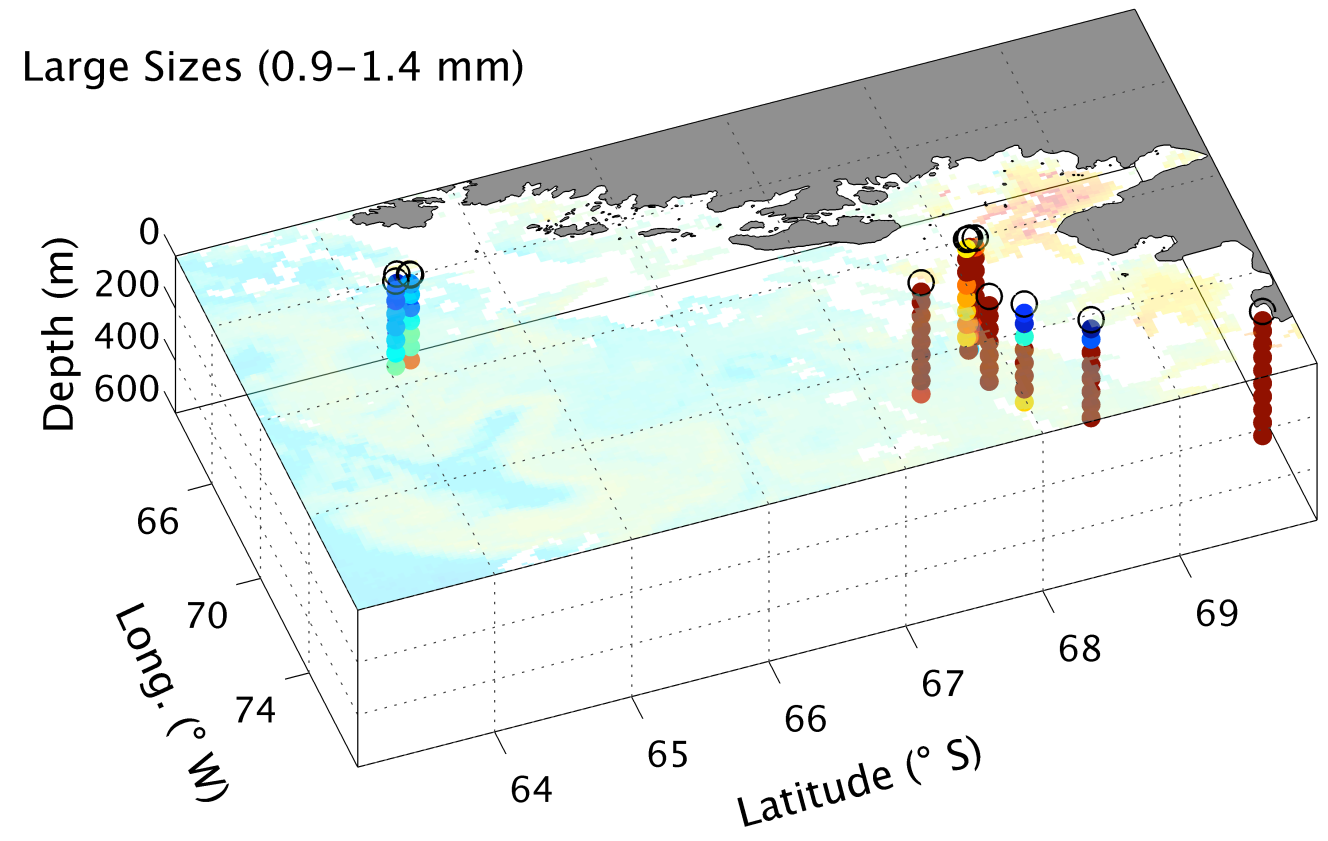

Chlorophyll a concentration $\left(\mathrm{mg} \mathrm{m}^{-3}\right)$
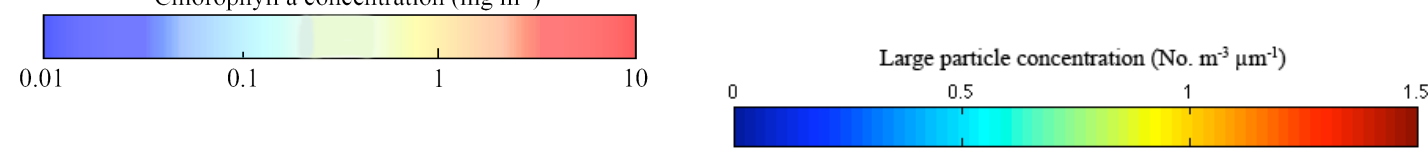
(A) January 2009

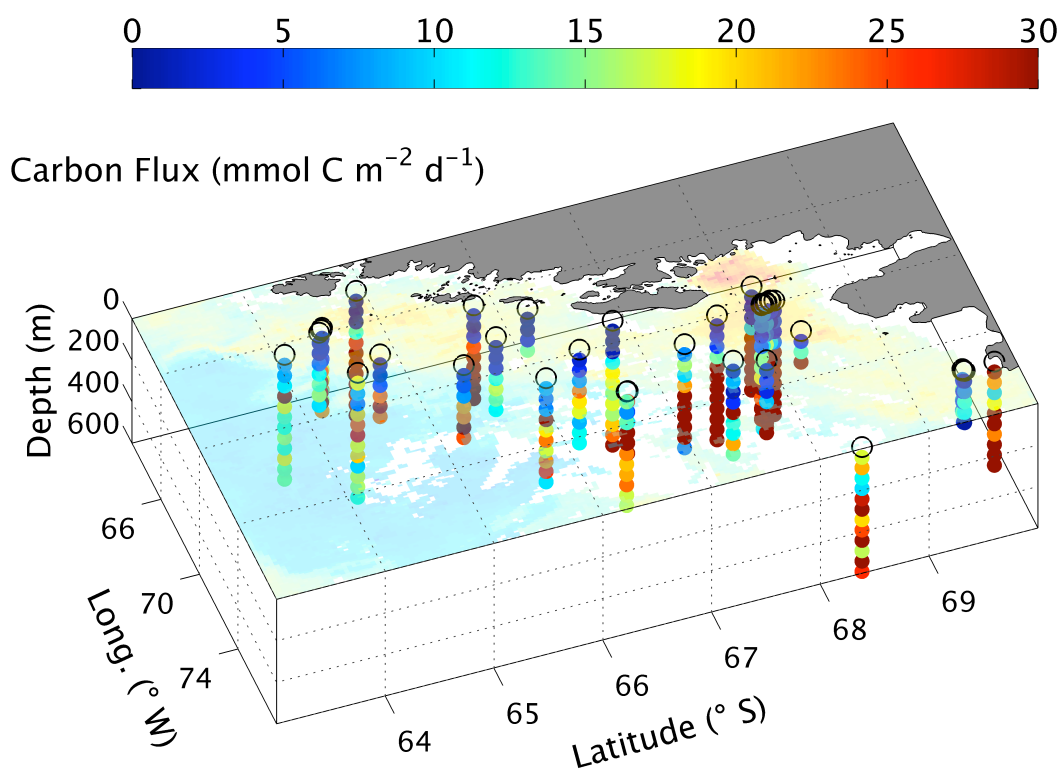

(B) February/March 2009

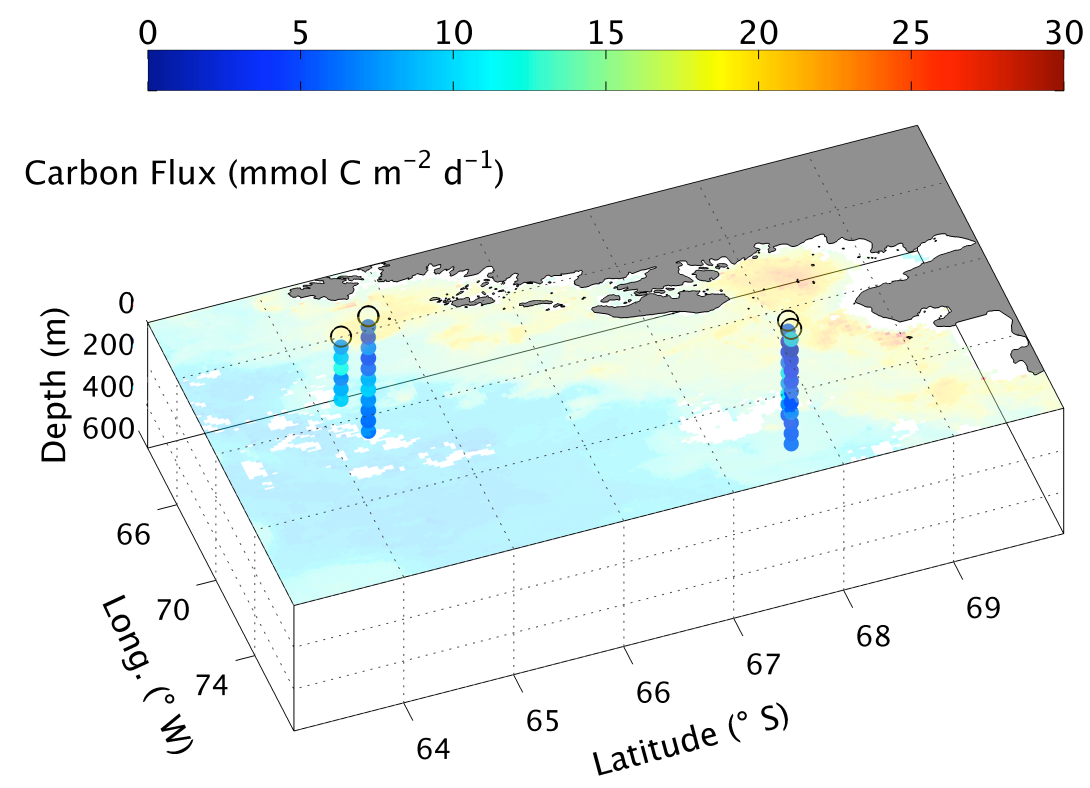

Figure 15. Particulate carbon flux (colored dots) as estimated from CSD profiles obtained from the VPR for cruises in (A) January 2009 and (B) February/March 2009. Overlaid in faint color on the surface of the map is the monthly averaged chlorophyll a concentration from the MODIS satellite. 


\section{CHAPTER FOUR}

Particle concentration, sinking velocity, and flux in the Sargasso Sea 


\section{Introduction}

The subtropical gyres cover almost half of the global oceans and more than a third of the total surface area of the globe. Although these oligotrophic areas are less productive per unit area than other regions of the global oceans, their vast spatial extent means that the subtropics account for approximately 45\% of annual global ocean primary production (Howard and Yoder 1997).

Ocean color data from satellites indicates that these ocean deserts are expanding, likely as a result of ocean warming and increased stratification (Polovina et al. 2008). Because these regions are important to the global carbon cycle, it is essential that we gain an understanding of processes such as primary production, and the export of organic matter in these regions via mixing of dissolved organic carbon (DOC) and the sinking of particulate organic carbon (POC).

Production and export occur on many different spatial and temporal scales in the subtropical gyres. It is clear that mesoscale eddies are important physical structures in the subtropical gyres because they supply nutrients to the base of the euphotic zone (McGillicuddy Jr et al. 2003; Siegel et al. 1999). The effect of these mesoscale processes on sinking particle fluxes is more difficult to ascertain due to the challenges of sampling particle fluxes on these scales. Sediment traps are difficult and time consuming to deploy and, as a result, they cannot easily be deployed in a manner that captures the high spatial variability in these processes that exists throughout the oceans. They also integrate over large collection areas and multi-day collection time periods (Siegel et al. 2008). Another approach to studying particle export fluxes at high spatial resolutions has been the use of the particle reactive radionuclide ${ }^{234} \mathrm{Th}$ (Buesseler et al. 2008). This method integrates over time scales of several days to weeks that make it difficult to quantify the instantaneous rates of particle export in non-steady state conditions. It is also useful primarily as a tracer of export from the upper ocean, and does not provide information about the magnitude of flux with respect to depth throughout the mesopelagic zone where particle attached microbes and resident zooplankton consume and alter the flux of sinking particulate matter.

Mesoscale and submesoscale features could be important pathways of particulate matter export. Sweeney et al. (2003) found that peak fluxes in particle export at the Bermuda Atlantic Time-series (BATS) site often occurred concurrently with the passage of eddies and that the presence of these mesoscale features affected the phytoplankton community composition. Buesseler et al. (2008) found little spatial variability associated with mature eddies at this site, but did observe persistent features such as narrow layers of particle export and remineralization. Recent studies have employed the use of particle camera systems to study the distribution of 
particles on high resolutions grids. In a study in the northeastern Atlantic, Guidi et al. (2007) found large variability in the concentrations of large particles on submesoscales and used it to infer strong variations in the sinking flux of particles across distances smaller than $100 \mathrm{~km}$. This study, however, relied on the assumption that the average sinking velocity of the particles at these locations was invariant in time and space. Given that the average sinking velocities of marine particles are also highly variable (McDonnell and Buesseler 2010), this assumption may not be valid.

In this chapter, I quantify the size distributions of the particle flux and concentration in the Sargasso Sea with an innovative sampling approach that allows for the determination of the average particle sinking velocities in the region. This region of the subtropical North Atlantic Ocean has been part of intensive oceanographic studies over the past several decades through several long-term scientific programs including BATS (Michaels and Knap 1996; Steinberg et al. 2001), the Oceanic Flux Program (Conte et al. 2001), Hydrostation S (Michaels and Knap 1996), and the Bermuda Testbed Mooring (Dickey et al. 2001). This site is characterized by generally low productivity and deep mixing in the winter followed by a brief spring bloom as the hydrography transitions to a thermally stratified and nutrient poor euphotic zone that lasts well into October (Steinberg et al. 2001). During the summer months, primary production rates are low and a subsurface chlorophyll maximum exists near the base of the euphotic zone. A diverse assemblage of phytoplankton inhabit the euphotic zone here, often dominated by prokaryotic picoplankton such as prochlorophytes and cyanobacteria, but with variable contributions from eukaryotic plankton such as prymnesiophytes and pelagophytes (Steinberg et al. 2001). Sinking particle fluxes in the mesopelagic zone have been measured regularly with drifting sediment trap arrays. The peak fluxes are not well correlated with peaks in production, suggesting decoupling between these two processes (Steinberg et al. 2001).

The measurements of the size distributions of the particle flux and concentration presented in this chapter allow for the determination of the average particle sinking velocities as a function of particle size. By fitting the flux size distribution to the bulk carbon fluxes, a parameterization of particle density is derived. This parameterization, along with the computed average sinking velocities, enables the estimation of particle fluxes at spatial resolutions that would be impossible with conventional sediment trap methods. Moreover, this method represents a significant improvement over previous methods of estimating flux from the particle concentration size distribution because it relies on locally determined sinking velocity and 
particle density relationships as opposed to global parameterizations with inherent assumptions of the dependency of sinking velocity on the equivalent spherical diameter of the particles (Guidi et al. 2008).

\section{Methods}

Cruises

These experiments were conducted during cruises in conjunction with the Bermuda Atlantic Time-Series (BATS) $75 \mathrm{~km}$ to the southeast of Bermuda in the Sargasso Sea. Table 1 presents the cruises and drifter deployment information used in this study.

\section{Measurement of the particle concentration size distribution}

The concentration of particles in the water column was measured with the Video Plankton Recorder (VPR), as described in detail in Chapter 2. Briefly, this instrument was operated in profiling mode captured tens of thousands of images per deployment. Image analysis routines in MATLAB (Appendix II) were used to determine the abundances and sizes of particles in the images, and subsequently construct a particle concentration size distribution (CSD). The CSD is calculated as the number of particles in a given equivalent spherical diameter (ESD) size range $\left(\right.$ No. $\left.\mathrm{m}^{-3} \mu \mathrm{m}^{-1}\right)$. I present data from the VPR cast locations and times listed in Table 2.

Any zooplankton caught in the field of view of the VPR would have been counted as particles in this analysis, as they were not identified and removed. Along the WAP, this is was not an issue because after reviewing thousands of images from the instrument, there was virtually no identifiable zooplankton. At BATS, the situation is slightly different, with the presence of zooplankton such as copepods being potentially significant, especially in the upper $200 \mathrm{~m}$ of the water column. To assess the effect of ignoring the contribution of live zooplankton to the calculated particle abundances and average sinking velocities in the BATS region, I compared the concentration of zooplankton collected via nets with 3 different aperture sizes (Deevey 1971) to the concentration of particles observed with the VPR. The results, presented in Table 3, indicate that by not identifying zooplankton and excluding them from the particle concentration analysis, this would introduce overestimates of the particle concentration of at most $2.5 \%$. Because the zooplankton are rare compared to that of passive particles, their contribution is ignored in this study. 


\section{Measurement of particle flux}

Particle flux was measured directly with two different types of sediment traps. Both were deployed from a drifting sediment trap array with a wave-isolating float at the surface. Traps were hung at depths of 200,300, and $500 \mathrm{~m}$ below the surface and deployed in collection mode for 36 hours before lids on the traps were closed, and the drifting array recovered aboard the ship.

The first type of sediment trap consisted of a standard cylindrical tube serving as a bulk flux collector. These samples contained $500 \mathrm{~mL}$ of formalin $(0.022 \%)$ poisoned and filtered brine (salinity 70) to preserve the collected samples. Once retrieved on board the ship, tubes were allowed to settle for one hour before the overlying water was siphoned off. The brine and particle sample mixture was then drained through a $350-\mu \mathrm{m}$ Nitex screen to remove swimmers. The screened brine suspension was then filtered through a $1.2-\mu \mathrm{m}$ silver membrane filter (Sterlitech), and the particles dried for 24 hours at $50{ }^{\circ} \mathrm{C}$. These samples were analyzed on a $\mathrm{CHN}$ analyzer to determine the flux of carbon intercepted by the trap. This method is described in detail in Lamborg et al. (2008).

The particle flux size distribution (FSD) was determined through the use of a polyacrylamide gel trap at the same depths. This trap had the same cylindrical geometry as the bulk sediment trap collection tubes but was outfitted with a polycarbonate jar that contained 200 $\mathrm{mL}$ of $16 \%$ polyacrylamide and took up the entire area at the base of the trap cylinder. We followed the gel preparation protocol described in F. Ebersbach (personal communication). Upon recovery, samples were allowed to settle for at least 3 hours. After this time, the overlying water was siphoned off out of the trap tube and the polyacrylamide gel was removed from the base of the trap. Some of the overlying water in the gel jar was decanted off, with care taken not to disturb any of the particles at the gel-water interface. The polyacrylamide gels were systematically photographed with a with a Nikon SMZ-1500 stereomicroscope over its entire area (See Chapter 2 for details). This process yielded about 80 images that were subsequently merged together manually with the photomerge tool in Photoshop (Adobe Creative Suite 2). These large composite images are about 50 Megapixels, and are capable of resolving particles over a large range of sizes ( $\sim 50 \mu \mathrm{m}$ to several $\mathrm{cm}$ in diameter). The large composite image was cropped to remove the edges of the gel jars and then processed with Photoshop's edge detection and threshold algorithms. The result was a binary image that identifies the two-dimensional projected shape and area of each particle and their numeric abundance in the gel per unit area and time of 
collection. The binary image was processed in MATLAB (see Appendix III) to calculate the flux size distribution (FSD, No. $\mathrm{m}^{-2} \mathrm{~d}^{-1} \mu \mathrm{m}^{-1}$ ).

\section{Calculation of average sinking velocities}

The particle flux $\left(F_{i}\right.$, No. $\left.\mathrm{m}^{-2} \mathrm{~d}^{-1} \mu \mathrm{m}^{-1}\right)$ for each size class, $i$, is related to the concentration of particles in the water column $\left(C_{i}\right.$, No. $\left.\mathrm{m}^{-3} \mu \mathrm{m}^{-1}\right)$ and their average sinking velocities $\left(W_{i, \text { avg }}, \mathrm{m}\right.$ $\left.\mathrm{d}^{-1}\right)$ by the following equation:

$F_{i}=C_{i} \times W_{i, \text { avg }}$

With measurements of the particle FSD and CSD we calculated the average sinking velocity size distribution (ASVD) at each location and time that there were simultaneous measurements of particle flux and concentration. This was done by dividing $F_{i}$ by $C_{i}$ (Eq. 1), giving $W_{i \text {,avg }}$ in units of $\mathrm{m} \mathrm{d}^{-1}$.

\section{Calculation of particle flux from particle concentration size distributions}

Using Equation 1, the numeric flux, $F_{i}$, can be calculated from the product of the particle

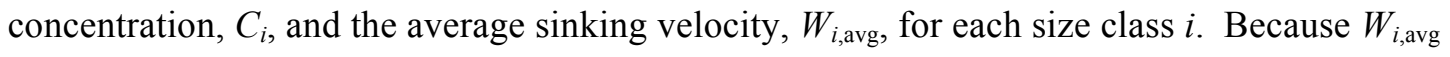
varies with respect to location, depth, and time (McDonnell and Buesseler 2010), it becomes important to include this variability when estimating the FSD. I assumed that the measurements of $W_{i, \text { avg }}$ made here were representative of the depth bins, and deployment time periods in which they were made. $W_{i \text {,avg }}$ determined from the polyacrylamide gels during each drifting array deployment were applied to the depth bins ranging from that specific trap depth upwards to either the depth of the next trap above or $20 \mathrm{~m}$ depth (in the case of the most shallow trap). $W_{i \text {,avg }}$ from the deepest trap was also applied downwards in the water column where necessary. To account for the observed variations of $W_{i, \text { avg }}$ with respect to time, sinking velocities measured from the 2122 September deployments were applied to VPR cast ID numbers TZEX 11 through TZEX 19, while sinking velocities measured during the 25-27 September drifter deployment were applied to the VPR cast ID numbers TZEX 23- TZEX 35 (see Table 2).


No. $\left.\mathrm{m}^{-2} \mathrm{~d}^{-1} \mu \mathrm{m}^{-1}\right)$, I relied on a power law formulation of carbon content as a function of particle diamter $(d, \mu \mathrm{m})$ similar to that used by Alldredge and Gotschalk (1988):

$F_{\mathrm{C}, \mathrm{E}}=\Sigma\left(F_{i} \cdot \Delta d_{i} \cdot \alpha d^{\beta}\right)$ 
where $\Delta d_{i}$ is the width $(\mu \mathrm{m})$ of each size bin, $i$. In a manner similar to that of Guidi et al. (2008), the MATLAB function "fminsearch" is employed in order to determine the best fit parameters $\alpha$ and $\beta$ by minimizing the log-transformed differences $\left(\Delta \mathrm{F}_{\mathrm{C}}\right)$ between the estimated carbon flux $\left(\mathrm{F}_{\mathrm{C}, \mathrm{E}}\right)$ derived from the measured gel FSD and the measured sediment trap flux $\left(\mathrm{F}_{\mathrm{C}, \mathrm{T}}\right)$ :

$\Delta \mathrm{F}_{\mathrm{C}}=\Sigma\left(\log \left(\mathrm{F}_{\mathrm{C}, \mathrm{T}}\right)-\log \left(\mathrm{F}_{\mathrm{C}, \mathrm{E}}\right)\right)^{2}$

I used the available carbon flux and gel FSD from July and September 2009 at BATS to estimate $\alpha$ and $\beta$. With these parameters, Equations 1 and 2 can be used in to arrive at estimates of carbon flux from the CSD.

\section{Results and Discussion}

The flux collected in the polyacrylamide gels consisted primarily of small light colored, and nearly spherical aggregates up to about $1 \mathrm{~mm}$ in diameter (Figure 1). The flux material appeared to be much more heterogeneous than the particles collected in the gels along the WAP (see Chapter 2). This heterogeneity likely reflects the diverse community of plankton that exists in the Sargasso Sea. Large fecal pellets that were common in the WAP region (Chapter 2) were essentially absent from the sinking material collected in the Sargasso Sea.

Figures 2-5 show the flux size distribution (FSD), concentration size distribution (CSD), and average sinking velocity size distributions at multiple depths during four cruises to the BATS site from May until September 2009. These multi-paneled figures show how the relationship between the FSD and the CSD influence the average sinking velocity that is calculated as their quotient. The sinking velocities are also reported in Table 4.

In May 2009 (Figure 2), sinking velocities were the smallest measured at all of the BATS deployments. At $200 \mathrm{~m}$ depth, they ranged from 5-10 $\mathrm{m} \mathrm{d}^{-1}$ with the highest velocities in the smallest size class, and slowly decreasing velocities with respect to ESD (Fig. 2C). At $300 \mathrm{~m}$, the average sinking velocities were about $40 \%$ higher with velocities of $8-13 \mathrm{~m} \mathrm{~d}^{-1}$, except for the largest quantifiable size class, which only measured $3 \mathrm{~m} \mathrm{~d}^{-1}$ (Fig. 2F). Velocities were even higher at 500m (12-29 $\left.\mathrm{m} \mathrm{d}^{-1}\right)$ while displaying a similar pattern of decreasing speed with larger ESD (Fig. 2I). These depth-related changes are primarily a result of declining particle concentrations as a function of depth in all size classes (Fig 2B, E, H) as the FSD changed very 
little from the upper trap to the lower trap (Fig. 2A, D, G). This increase in the average sinking velocity with depth is consistent with other observations (Berelson 2001), however this pattern was not persistent throughout all the deployments, as is discussed below.

During the July 2009 study, the $500 \mathrm{~m}$ data was unavailable because of a failed polyacrylamide gel trap. At the 200 and $300 \mathrm{~m}$ depth traps, sinking velocities were also in the 6$30 \mathrm{~m} \mathrm{~d}^{-1}$ range. The average sinking velocities at $200 \mathrm{~m}$ increased with respect to ESD in the larger size classes quantified (Fig. 3C), however this was not the case at 300m where the two largest size classes had lower velocities (Fig. 3F) than at $200 \mathrm{~m}$. During this month, the FSD and CSD both decreased from 200 to $300 \mathrm{~m}$, and it was the relatively high flux of large particles in the gel at $200 \mathrm{~m}$ that created the difference in sinking velocity between the two depths.

Figure 4 displays the size distributions of flux, concentration, and average sinking velocity for the 21-22 September deployment at the BATS site. This deployment showed mostly similar sinking velocities across all size classes with velocities ranging primarily from $10-25 \mathrm{~m} \mathrm{~d}$ 1. The exception was the smallest size class, which increased in velocity from 35 to $55 \mathrm{~m} \mathrm{~d}^{-1}$ between the 200 and $500 \mathrm{~m}$ depths. Aside from the smallest size class, the average sinking velocities were relatively invariant as a function of ESD. Interestingly, there were several very large particles detected in the water column at all depths (Fig. 4B, E, H), however particles of these sizes were not found in the gel flux.

The final deployment took place on 25-27 September at the PITS site, only 3 days after the previous deployment. I found high average sinking velocities of 135,316 , and $243 \mathrm{~m} \mathrm{~d}^{-1}$ in the smallest size class at 200,300, and $500 \mathrm{~m}$ respectively, and quickly declining velocities as ESD increased (Fig. 5). These velocities are up to 6 times higher than what was measured only several days earlier at the same location. This change is primarily driven by lower concentrations of particles in the smallest size class detected by the VPR during the 25-27 September deployment (Fig. 5B, E, H) when compared to the 21-22 dates (Fig. 5B, E, H). By contrast, the FSDs determined during both September deployments were quite similar to each other (Fig. 4A, D, G and Fig. 5A, D, G). Particles with an ESD of greater than $195 \mu \mathrm{m}$ had average sinking velocities that were similar to those measured during the 21-22 September deployment several days earlier. During the 25-27 September deployment, the average sinking velocity of particles larger than $320 \mu \mathrm{m}$ increased with increasing depth.

The minimization procedure for calculating the best-fit conversion factors between the FSD and the carbon flux yielded the parameters $\alpha=5.50 \times 10^{-13}$ and $\beta=2.93$. These parameters 
were used to convert the gel-derived FSD into an estimated carbon flux, which was then plotted with respect to the carbon flux measured in the standard sediment traps immediately adjacent to each of the polyacrylamide gel traps (Fig. 6). The Pearson's correlation coefficient of this data was 0.78 .

With the restricted number of gel and carbon flux pairs available from the BATS site (7), as well as the limit carbon flux range that the data pairs spanned $\left(1.2-4.2 \mathrm{mmol} \mathrm{C} \mathrm{m}^{-2} \mathrm{~d}^{-1}\right)$ it is likely that this is not an extremely robust parameterization of particle carbon content, however it does provide a useful basis for estimating the particle carbon densities in this type of subtropical environment. This, along with the quantification of average sinking velocities as a function of particle size at several depths and different seasons at BATS, allows for significant improvements in the ability to estimate carbon fluxes from the CSD in the water column. Previous studies used Stokes' Law-type parameterizations of sinking velocity with the assumption that particles of increasing diameter sink faster, which the measurements presented here demonstrate is not always true. In addition, globally derived relationships between the bulk flux and the particle CSD do not take into account regional variability in the density of particles.

The particle density result reported here for the Sargasso Sea differs significantly from what was measured along the WAP (Chapter 3). Table 5 displays the parameters that were derived from fitting multiple polyacrylamide gel flux size distributions to concurrent measurements of bulk carbon flux at each site. In the Sargasso Sea, $\alpha$ was 7 times smaller than the value determined along the WAP. This indicates that on the whole, particles had a lower carbon-density in the subtropical location. The parameter $\beta$ provides information about the fractal dimension of the particles. Perfectly spherical particles would be expected to have a fractal dimension equal to 3 . I calculated a $\beta$ of 2.93 for the BATS site, only slightly smaller than the spherical fractal dimension of 3 . This result fits with the qualitative assessment of flux in the polyacrylamide gel traps that illustrate the fact that most particles captured in the flux are spherical aggregates made up of loosely associated components. In the case of the WAP, particles tended to be densely packed zooplankton fecal pellets or irregularly shaped diatom aggregates. These observations explain their larger $\alpha$ and smaller $\beta$.

The parameters $\alpha$ and $\beta$ also enable the calculation of the contribution of the various particle size classes to the total carbon flux in the Sargasso Sea. Figure 7 shows that a majority of the flux is from particles in the middle of the size range detected here $(200-800 \mu \mathrm{m})$, smaller sizes than those that dominated the particle fluxes at WAP. Particles smaller than this size range do not 
contribute large amounts of carbon to the flux because although they are numerically very abundant, they contain a very small amount of carbon per particle. Conversely, particles larger than $1000 \mu \mathrm{m}$ in ESD contain large amounts of carbon but are so rare in the water column that they do not contribute much to the overall flux. Figure 7 suggests that the size range that is detected by the methods described here likely accounts for the majority of the downward particulate carbon flux collected by the sediment traps. However, the fact that there was a contribution of $3-18 \%$ of the carbon flux in the smallest size class detected (Fig. 7) indicates that improving the resolution of the VPR camera could help with the detection of even smaller particles that may contribute a small fraction of the total carbon flux. At the large end of the particle size spectrum, it is clear that only one or two large particles collected in the trap could have a noticeable effect on the total carbon flux measured in a sediment trap. This finding could help explain the tube to tube variability that is often quantified in adjacent sediment traps.

When these carbon density parameters are paired with the average sinking velocity size distributions determined above, they can be used to calculate an estimate of the flux from the particle CSD measured by the VPR. Figure 8 displays a comparison of fluxes estimated in this manner to what was measured by the standard bulk sediment trap collectors during 3 deployments at the BATS site. The estimated fluxes (solid line) show relatively high fluxes above $200 \mathrm{~m}$, but at the depths of the traps, the estimates fit the measurements very well. This is to be expected, as these three examples were the locations used to determine the relationship between the particle flux and the CSD. The fact that they do match well confirms that this method is effective at least in the locations where we have measured the average sinking velocity size distribution. Where the estimated carbon flux does not match the flux measured in the adjacent bulk sediment trap collector, it is primarily due to the nature of the misfit from the 1:1 line in Figure 6. One other source of error is when the conversion from CSD to FSD in Equation 1 does not produce an estimated FSD identical to what was measured in the gels. This occurs occasionally in the larger ESD size bins when for a given size, no particles are counted with the VPR but they are quantified in the gel FSD. The effect is that when calculating the carbon content from the estimated FSD, that size bin does not contribute carbon to the total flux, and therefore the estimated carbon flux is lower than what would be estimated from the full gel size distribution as presented in Figure 6. In the case of BATS, this has only happened in a couple of cases because, as is evident from Figures 2-5, the largest particles were most often detected by the VPR rather than the polyacrylamide gels. 
Because carbon fluxes were not quantified in the upper $150 \mathrm{~m}$ of the water column, it is impossible to verify whether or not the predicted velocities at these depths are accurate. If they are indeed lower than the estimates suggests, it would imply that either 1) the average sinking velocities of particles in that depth range are lower than what was measured at the 150-200 m depths, or 2) that there is a different carbon density relationship for particles in the upper water column.

To look at the spatial variability of particle concentration, 22 profiles were conducted with the VPR in the BATS region during September 2009. These results are presented in Figure 9, where the three different panels display the concentrations of small, mid-sized, and large particles. The concentration at a specific depth and location is indicated by the color of the dot. The open circles are the surface location of the vertical profile on the map. Across all the size classes, the concentration of particles decreases rapidly from a maximum in the first depth bin $(20-50 \mathrm{~m})$ to levels about a factor of 10 lower by $200-250 \mathrm{~m}$. The spatial variability in the upper depth bins was significant, ranging by a factor of 2-3 for all three size classes presented here. These variations took place over spatial scales as short as about $20 \mathrm{~km}$. Variations in the surface followed similar patterns for both the small and mid-sized particles, but sometimes the large particle distributions deviated from these general patterns. This indicates that different populations of particles exist at different sites and that slope and shape of the particle size distribution varies across the sampling area.

The sinking particle flux was estimated on the high-resolution spatial grid from the VPR profiles conducted from 21-28 September (Figure 10). This approach provides a look at the variability in fluxes that is not possible to quantify with conventional sediment traps. Over the upper $100 \mathrm{~m}$, the estimated fluxes were high, typically about $10 \mathrm{mmol} \mathrm{C} \mathrm{m}^{-2} \mathrm{~d}^{-1}$ but up to 30 mmol C m $\mathrm{d}^{-2}$ in a few cases (Figure 11). In the mesopelagic zone at depths of 200 to $600 \mathrm{~m}$, fluxes ranged from about $1-4 \mathrm{mmol} \mathrm{C} \mathrm{m} \mathrm{d}^{-1}$. Many of the profiles only went to a depth of 250 $\mathrm{m}$, so extrapolation of flux attenuation to depths below this was not possible in these cases. Where deeper profiles were available, they generally showed fluxes remaining constant or slightly decreasing to at about 2-3 $\mathrm{mmol} \mathrm{C} \mathrm{m}^{-2} \mathrm{~d}^{-1}$.

In a few of the estimated flux profiles (such as the four profiles up the western edge of the study region), there was somewhat of a discontinuity between the 200 and $250 \mathrm{~m}$ flux with the $250 \mathrm{~m}$ flux being about $1 \mathrm{mmol} \mathrm{C} \mathrm{m}^{-2} \mathrm{~d}^{-1}$ higher than the flux at $200 \mathrm{~m}$. Features like this are due to the use of average sinking velocities over discrete depth horizons, and since the average 
sinking velocity increased from 200 to $250 \mathrm{~m}$ (Fig. 5C, F), the calculated flux reflects this change. Because irregularly increasing fluxes like this are not often observed in the oceans, it suggests that the average sinking velocities may not be perfectly valid across the entire $100 \times 100 \mathrm{~km}$ study area. In addition, the observed average sinking velocity size distributions are at least slightly different each time they are measured (Figs. 2-5), suggesting that average sinking velocities vary on spatial scales smaller than we have sampled here with the drifting sediment traps. Still, this approach of using a locally determined average sinking velocity size distribution is vastly superior to the use of a generalized global relationship based on assumptions about the functionality of sinking velocity with respect to particle size.

In Figure 11, the envelope of estimated fluxes is visible. From 100 to $200 \mathrm{~m}$ below the surface, the estimated fluxes are quite consistent during the 9-day sampling period across the spatial grid. This is consistent with the fluxes measured by the drifting sediment traps that saw little difference between the two late-September deployments. While different particle sinking velocity size distributions were applied to concentration profiles taken during the first and second half of this cruise, the resulting estimates of fluxes in the upper $200 \mathrm{~m}$ remained quite similar. Below $200 \mathrm{~m}$ it is difficult to determine if the use of different average sinking velocities led to a departure in the flux estimates because during the first half of the cruise, most VPR profiles were only conducted down to about $300 \mathrm{~m}$. At $300 \mathrm{~m}$ it does appear that the profiles from the second half of the cruise (red curves) were about twice as high as those calculated during the first half (blue curves). The few deep VPR profiles that were available from the second half of the cruise produced estimated carbon fluxes that ranged from $2.5-4.5 \mathrm{mmol} \mathrm{C} \mathrm{m}^{-2} \mathrm{~d}^{-1}$. This is slightly higher than the deep fluxes measured with the sediment traps nearby. Either the sinking velocities determined in the 25-27 September drifter deployment, particularly at 300 and $500 \mathrm{~m}$, are different from the actual average particle sinking velocities of the populations of particles observed with the VPR from 26-28 September at nearby locations, or the VPR is capturing higher fluxes in these deep profiles that were not observed with the sediment traps.

The VPR-based estimates of flux indicate that a large amount of flux attenuation occurs in the upper $200 \mathrm{~m}$ of the water column at the BATS site (Fig. 11). This is consistent with some other studies that show substantial flux attenuation just below the bottom of the euphotic zone (Buesseler and Boyd 2009; Maiti et al. 2010). Insights from imaging techniques such as those described here and the use of Thorium-234 as a tracer of particle flux and remineralization in the upper water column (Maiti et al. 2010) can provide new information about the important flux 
processes occurring in the depth ranges and just below the euphotic zone where it is difficult to use conventional sediment traps.

\section{Conclusions}

This study provides new insights into the nature of sinking particle fluxes in the Sargasso Sea and highlights some of the strengths and limitations of estimating particle fluxes at high spatial and temporal resolutions from measurements of the particle concentration size distribution and the average sinking velocities. Particle sinking velocities are important rates that play a critical role in determining the average depth of particle penetration into the dark waters of the oceans interior. At BATS, the average particle sinking velocities ranged from a few $\mathrm{m} \mathrm{d}^{-1}$ to a couple hundred $\mathrm{m} \mathrm{d}^{-1}$ in a few cases. Contrary to what is predicted by a simple parameterization of Stokes' Law, the fastest sinking velocities were found for the smallest particles $(\sim 100 \mu \mathrm{m}$ ESD) detectable by the VPR and polyacrylamide gel traps and decreased with increasing particle size up to the upper detection limit of a few millimeters. In general, these velocities are much slower than those found in Chapter 2 for particles along the western Antarctic Peninsula. This feature is due to the difference in particle types between the two locations with the WAP particle populations dominated by quickly sinking diatom aggregates and krill fecal pellets whereas in the Sargasso Sea, a more diverse assemblage of porous aggregates were observed. These differences were also reflected in the best-fit parameters determined for the relationships between the flux size distribution and the carbon flux, indicating different fractal geometries and particle densities. This relationship is a critical component needed to estimate fluxes from in situ camera profiles. More work is needed to understand what controls this relationship and how it might vary even on small spatial and temporal scales. Particles with an ESD between 200 and $800 \mu$ m dominated the carbon flux in the Sargasso Sea, smaller than the particles most important to the flux along the WAP. Because this size range falls near the middle of the particle sizes that are detectable by the VPR, more success was had estimating carbon fluxes from measurements of the CSD in the Sargasso Sea than compared to Chapter 3 where the same exercise was conducted at the WAP. Along the WAP, larger particles dominated the flux and due to their paucity in the water column, it was more difficult to quantify their concentration precisely, which in several cases led to the underestimation of flux. This problem was not nearly as pronounced in the Sargasso Sea.

The data presented here show that there is substantial variability in the concentrations, fluxes, and sinking velocities of particles on small spatial and temporal scales. At this point, the 
causes of these variations are not well understood. Physical factors such as the local circulation and turbulence likely play a role, while variability in primary production, community structure and succession, and zooplankton feeding, swimming and migratory behavior are also important. 


\section{References}

Alldredge, A. L., and C. Gotschalk. 1988. In Situ Settling Behavior of Marine Snow. Limnology and Oceanography 33: 339-351.

Berelson, W. M. 2001. The flux of particulate organic carbon into the ocean interior: A comparison of four US JGOFS regional studies. Oceanography 14: 59-67.

Buesseler, K., and P. Boyd. 2009. Shedding light on processes that control particle export and flux attenuation in the twilight zone of the open ocean. Limnol. Oceanogr 54: 1210-1232.

Buesseler, K. O., C. Lamborg, P. Cai, R. Escoube, R. Johnson, S. Pike, P. Masque, D. McGillicuddy, and E. Verdeny. 2008. Particle fluxes associated with mesoscale eddies in the Sargasso Sea. Deep Sea Res., Part II 55: 1426-1444.

Conte, M. H., N. Ralph, and E. H. Ross. 2001. Seasonal and interannual variability in deep ocean particle fluxes at the Oceanic Flux Program (OFP)/Bermuda Atlantic Time Series (BATS) site in the western Sargasso Sea near Bermuda. Deep Sea Research Part II: Topical Studies in Oceanography 48: 1471-1505.

Deevey, G. 1971. The annual cycle in quantity and composition of the zooplankton of the Sargasso Sea off Bermuda. I. The upper 500 m. Limnology and Oceanography 16: 219240.

Dickey, T., S. Zedler, X. Yu, S. Doney, D. Frye, H. Jannasch, D. Manov, D. Sigurdson, J. McNeil, and L. Dobeck. 2001. Physical and biogeochemical variability from hours to years at the Bermuda Testbed Mooring site: June 1994-March 1998. Deep Sea Research Part II: Topical Studies in Oceanography 48: 2105-2140.

Guidi, L., G. Jackson, L. Stemmann, J. Miquel, M. Picheral, and G. Gorsky. 2008. Relationship between particle size distribution and flux in the mesopelagic zone. Deep-Sea Research Part I.

Guidi, L., L. Stemmann, L. Legendre, M. Picheral, L. Prieur, and G. Gorsky. 2007. Vertical distribution of aggregates $(>110 \mu \mathrm{m})$ and mesoscale activity in the northeastern Atlantic: Effects on the deep vertical export of surface carbon. Limnol. Oceanogr. 52: 7-18.

Howard, K., and J. Yoder. 1997. Contribution of the subtropical Oceans to global primary production, p. 157-167. Elsevier.

Lamborg, C., K. Buesseler, J. Valdes, C. Bertrand, R. Bidigare, S. Manganini, S. Pike, D. Steinberg, T. Trull, and S. Wilson. 2008. The flux of bio-and lithogenic material associated with sinking particles in the mesopelagic 'twilight zone' of the northwest and North Central Pacific Ocean. Deep-Sea Research Part II 55: 1540-1563.

Maiti, K., C. Benitez-Nelson, and K. Buesseler. 2010. Insights into particle formation and remineralization using the short-lived radionuclide, Thoruim-234. Geophysical Research Letters 37: L15608.

McDonnell, A. M. P., and K. O. Buesseler. 2010. Variability in the average sinking velocity of marine particles. Limnology and Oceanography 55: 2085-2096.

McGillicuddy Jr, D. J., L. A. Anderson, S. C. Doney, and M. E. Maltrud. 2003. Eddy-driven sources and sinks of nutrients in the upper ocean: Results from a 0.1 resolution model of the North Atlantic. Global Biogeochem. Cycles 17: 1035.

Michaels, A., and A. Knap. 1996. Overview of the US JGOFS Bermuda Atlantic Time-series Study and the Hydrostation S program. Deep Sea Research Part II: Topical Studies in Oceanography 43: 157-198.

Polovina, J., E. Howell, and M. Abecassis. 2008. Oceanís least productive waters are expanding. Geophys. Res. Lett 35: 1-5. 
Siegel, D., E. Fields, and K. Buesseler. 2008. A bottom-up view of the biological pump: modeling source funnels above ocean sediment traps. Deep Sea Research Part I: Oceanographic Research Papers 55: 108-127.

Siegel, D., D. McGillicuddy, and E. Fields. 1999. Mesoscale eddies, satellite altimetry, and new production in the Sargasso Sea. Journal of Geophysical Research 104: 359.

Steinberg, D. K., C. A. Carlson, N. R. Bates, R. J. Johnson, A. F. Michaels, and A. H. Knap. 2001. Overview of the US JGOFS Bermuda Atlantic Time-series Study(BATS): a decade-scale look at ocean biology and biogeochemistry. Deep-Sea Research(Part II, Topical Studies in Oceanography) 48: 1405-1447.

Sweeney, E., D. McGillicuddy, and K. Buesseler. 2003. Biogeochemical impacts due to mesoscale eddy activity in the Sargasso Sea as measured at the Bermuda Atlantic Timeseries Study (BATS). Deep Sea Research Part II: Topical Studies in Oceanography 50: 3017-3039. 
Table 1. Description of drifting trap deployments in the Sargasso Sea during 2009.

\begin{tabular}{|c|c|c|c|c|c|}
\hline Cruise Name & $\begin{array}{l}\text { Drifter } \\
\text { Deployment } \\
\text { Location }\end{array}$ & $\begin{array}{l}\text { Drifter } \\
\text { Deployment } \\
\text { Date }\end{array}$ & $\begin{array}{l}\text { Drifter } \\
\text { Recovery } \\
\text { Location }\end{array}$ & $\begin{array}{l}\text { Drifter } \\
\text { Recovery } \\
\text { Time }\end{array}$ & $\begin{array}{l}\text { Collection } \\
\text { Duration } \\
\text { (days) }\end{array}$ \\
\hline May BATS & $\begin{array}{l}31^{\circ} 35.02^{\prime} \mathrm{N} \\
64^{\circ} 09.60^{\prime} \mathrm{W}\end{array}$ & $\begin{array}{l}\text { 15 May } 2009 \\
03: 18\end{array}$ & $\begin{array}{l}31^{\circ} 45.96^{\prime} \mathrm{N} \\
64^{\circ} 22.03, \mathrm{~W}\end{array}$ & $\begin{array}{l}18 \text { May } \\
200902: 45\end{array}$ & 1.46 \\
\hline July BATS & $\begin{array}{l}31^{\circ} 32.91^{\prime} \mathrm{N} \\
64^{\circ} 09.94^{\prime} \mathrm{W}\end{array}$ & $\begin{array}{l}\text { 14 July } 2009 \\
03: 14\end{array}$ & $\begin{array}{l}31^{\circ} 21.06^{\prime} \mathrm{N} \\
64^{\circ} 12.18^{\prime} \mathrm{W}\end{array}$ & $\begin{array}{l}17 \text { July } \\
200902: 11\end{array}$ & 1.52 \\
\hline $\begin{array}{l}\text { September } \\
\text { TZEX }\end{array}$ & $\begin{array}{l}31^{\circ} 34.93^{\prime} \mathrm{N} \\
64^{\circ} 09.97^{\prime} \mathrm{W}\end{array}$ & $\begin{array}{l}\text { 21 Sept. } 2009 \\
\text { 09:23 }\end{array}$ & $\begin{array}{l}31^{\circ} 14.80^{\prime} \mathrm{N} \\
63^{\circ} 35.90^{\prime} \mathrm{W}\end{array}$ & $\begin{array}{l}24 \text { Sept. } \\
200900: 15\end{array}$ & 1.48 \\
\hline $\begin{array}{l}\text { September } \\
\text { TZEX }\end{array}$ & $\begin{array}{l}31^{\circ} 35.24^{\prime} \mathrm{N} \\
64^{\circ} 08.40^{\prime} \mathrm{W}\end{array}$ & $\begin{array}{l}\text { 25 Sept. } 2009 \\
13: 40\end{array}$ & $\begin{array}{l}31^{\circ} 14.08^{\prime} \mathrm{N} \\
63^{\circ} 43.62^{\prime} \mathrm{W}\end{array}$ & $\begin{array}{l}28 \text { Sept. } \\
2009 \text { 02:02 }\end{array}$ & 1.51 \\
\hline
\end{tabular}

Table 2. Locations and times of VPR deployments conducted in September 2009 as part of this study on the spatio-temporal variability in particle concentrations and fluxes.

\begin{tabular}{|c|c|c|c|c|c|c|}
\hline \multirow{2}{*}{$\frac{\text { Cast ID }}{\text { TZEX } 11}$} & \multicolumn{2}{|c|}{ Latitude (N) } & \multicolumn{2}{|c|}{ Longitude (W) } & \multirow{2}{*}{$\begin{array}{c}\begin{array}{c}\text { Date (Sept. } \\
\text { 2009) }\end{array} \\
24\end{array}$} & \multirow{2}{*}{$\begin{array}{r}\begin{array}{r}\text { Time } \\
\text { (local) }\end{array} \\
2: 50\end{array}$} \\
\hline & $31^{\circ}$ & 16.911 & $63^{\circ}$ & 34.677 & & \\
\hline TZEX 12 & $31^{\circ}$ & 24.612 & $63^{\circ}$ & 29.434 & 24 & $5: 20$ \\
\hline TZEX 13 & $31^{\circ}$ & 31.785 & $63^{\circ}$ & 32.667 & 24 & $10: 30$ \\
\hline TZEX 14 & $31^{\circ}$ & 33.399 & $63^{\circ}$ & 35.578 & 24 & $13: 15$ \\
\hline TZEX 15 & $31^{\circ}$ & 45.664 & $63^{\circ}$ & 41.437 & 24 & $15: 54$ \\
\hline TZEX 16 & $31^{\circ}$ & 56.844 & $63^{\circ}$ & 51.33 & 24 & $18: 30$ \\
\hline TZEX 17 & $31^{\circ}$ & 51.108 & $63^{\circ}$ & 58.632 & 24 & $21: 50$ \\
\hline TZEX 18 & $31^{\circ}$ & 47.526 & $64^{\circ}$ & 3.12 & 25 & 0:01 \\
\hline TZEX 19 & $31^{\circ}$ & 44.21 & $64^{\circ}$ & 5.629 & 25 & $2: 15$ \\
\hline TZEX 23 & $31^{\circ}$ & 31.766 & $63^{\circ}$ & 56.09 & 26 & $11: 05$ \\
\hline TZEX 24 & $31^{\circ}$ & 29.19 & $63^{\circ}$ & 52.799 & 26 & $20: 40$ \\
\hline TZEX 25 & $31^{\circ}$ & 21.05 & $63^{\circ}$ & 46.9 & 27 & $10: 55$ \\
\hline TZEX 26 & $31^{\circ}$ & 21.032 & $64^{\circ}$ & 1.391 & 28 & $7: 25$ \\
\hline TZEX 27 & $31^{\circ}$ & 26.58 & $64^{\circ}$ & 2.295 & 28 & $9: 35$ \\
\hline TZEX 28 & $31^{\circ}$ & 32.12 & $64^{\circ}$ & 5.51 & 28 & $11: 45$ \\
\hline TZEX 29 & $31^{\circ}$ & 36.174 & $64^{\circ}$ & 6.93 & 28 & $13: 30$ \\
\hline TZEX 30 & $31^{\circ}$ & 40.128 & $64^{\circ}$ & 9.774 & 28 & $15: 27$ \\
\hline TZEX 31 & $31^{\circ}$ & 35.028 & $64^{\circ}$ & 34.038 & 28 & $18: 38$ \\
\hline TZEX 32 & $31^{\circ}$ & 41.532 & $64^{\circ}$ & 33.738 & 28 & $20: 28$ \\
\hline TZEX 33 & $31^{\circ}$ & 51.6 & $64^{\circ}$ & 32.244 & 28 & $22: 02$ \\
\hline TZEX 34 & $31^{\circ}$ & 51.656 & $64^{\circ}$ & 31.667 & 29 & 0:05 \\
\hline TZEX 35 & $31^{\circ}$ & 58.077 & $64^{\circ}$ & 31.292 & 29 & $1: 30$ \\
\hline
\end{tabular}


Table 3. A comparison of the numeric concentrations of zooplankton as determined by net tows and the total particle concentrations measured by the VPR for the BATS region. The final column is the expected error in the VPR concentration estimated that is introduced by neglecting to exclude live zooplankton from the particle counts.

\begin{tabular}{|c|c|c|c|c|}
\hline $\begin{array}{c}\text { Net aperture } \\
(\mu \mathrm{m})\end{array}$ & $\begin{array}{c}\text { Zooplankton } \\
\text { concentration* } \\
\left(\text { No. m}^{-3}\right)\end{array}$ & $\begin{array}{c}\text { VPR size } \\
\text { cutoff }(\mu \mathrm{m})\end{array}$ & $\begin{array}{c}\text { Total particle } \\
\text { concentration } \\
\left(\mathrm{No} \mathrm{m}^{-3}\right)\end{array}$ & Error (\%) \\
\hline 366 & 33 & 320 & $3.15 \times 10^{3}$ & 1.0 \\
\hline 203 & 140 & 120 & $6.75 \times 10^{3}$ & 2.1 \\
\hline 76 & 615 & 73 & $2.43 \times 10^{4}$ & 2.5 \\
\hline
\end{tabular}

* number of individuals per cubic meter from net tows with the specified apertures as reported by Deevey (1971) for Station S (32 $\left.10^{\prime} \mathrm{N}, 64^{\circ} 30^{\prime} \mathrm{W}\right), 24 \mathrm{~km}$ to the southeast of Bermuda.

${ }^{\sharp}$ Calculated as the sum of all the particles larger than the listed VPR size cutoff divided by the total volume of water sampled by the VPR. This value is an average for all the VPR profiles conducted at BATS in 2009. 
Table 4. Average sinking velocities, $W_{i, \text { avg }}$, used in this study to calculate the numeric fluxes of particles, $F_{i}$, from the concentration size distribution measured by the VPR. These velocities were computed by merging particle concentration data from multiple VPR casts conducted during the collection phase of each sediment trap deployment. Average sinking velocities equal to zero indicate that no particles of that size were collected in the gel. Values of "Inf" means there were particles collected in the flux, however none were detected in the water column concentration by the VPR. The "NaN" values indicate that no particles were detected in either the flux or the concentration.

\begin{tabular}{|c|c|c|c|c|c|c|c|c|c|c|c|}
\hline \multirow[t]{2}{*}{$\begin{array}{l}\text { Dates } \\
(2009) \\
\end{array}$} & \multirow[t]{2}{*}{$\begin{array}{l}\text { Depth } \\
\text { (m) }\end{array}$} & \multicolumn{10}{|c|}{ Average sinking velocity distribution $\left(\mathrm{m} \mathrm{d}^{-1}\right)$} \\
\hline & & $\begin{array}{c}\underset{\Xi}{\Sigma} \\
\stackrel{2}{2} \\
\stackrel{1}{n}\end{array}$ & 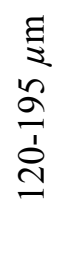 & 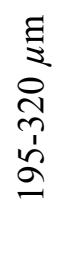 & 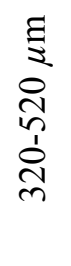 &  & 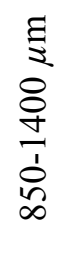 & 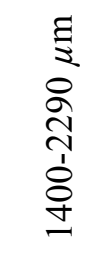 & 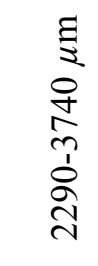 & 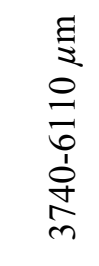 & $\begin{array}{l}\xi \\
8 \\
8 \\
8 \\
0 \\
1 \\
0 \\
\overline{0}\end{array}$ \\
\hline \multirow[t]{3}{*}{ 15-16 May } & 200 & 10 & 9 & 7 & 5 & 5 & 7 & 0 & $\mathrm{NaN}$ & 0 & $\mathrm{NaN}$ \\
\hline & 300 & 13 & 11 & 10 & 8 & 3 & 0 & 0 & $\mathrm{NaN}$ & $\mathrm{NaN}$ & $\mathrm{NaN}$ \\
\hline & 500 & 13 & 11 & 10 & 8 & 3 & 0 & 0 & $\mathrm{NaN}$ & $\mathrm{NaN}$ & $\mathrm{NaN}$ \\
\hline \multirow[t]{2}{*}{ 14-15 July } & 200 & 16 & 8 & 6 & 10 & 15 & 29 & 0 & $\mathrm{NaN}$ & $\mathrm{NaN}$ & $\mathrm{NaN}$ \\
\hline & 300 & 19 & 9 & 8 & 10 & 8 & 3 & 0 & $\mathrm{NaN}$ & $\mathrm{NaN}$ & $\mathrm{NaN}$ \\
\hline \multirow[t]{3}{*}{ 21-22 Sept. } & 200 & 36 & 16 & 15 & 17 & 6 & 17 & 0 & 0 & $\mathrm{NaN}$ & $\mathrm{NaN}$ \\
\hline & 300 & 45 & 23 & 18 & 22 & 13 & 12 & Inf & $\mathrm{NaN}$ & 0 & $\mathrm{NaN}$ \\
\hline & 500 & 54 & 16 & 10 & 14 & 16 & 25 & $\mathrm{NaN}$ & 0 & 0 & $\mathrm{NaN}$ \\
\hline \multirow[t]{3}{*}{ 25-27 Sept. } & 200 & 135 & 55 & 32 & 17 & 6 & 4 & 0 & 0 & $\mathrm{NaN}$ & $\mathrm{NaN}$ \\
\hline & 300 & 316 & 92 & 44 & 35 & 19 & 15 & $\operatorname{Inf}$ & 0 & $\mathrm{NaN}$ & $\mathrm{NaN}$ \\
\hline & 500 & 243 & 84 & 43 & 28 & 16 & 32 & 32 & $\mathrm{NaN}$ & $\mathrm{NaN}$ & $\mathrm{NaN}$ \\
\hline
\end{tabular}

Table 5. Best-fit parameters for the power-law relationship calculated for the relationship between the numeric flux size distribution and the carbon flux.

\begin{tabular}{lcc}
\hline Location & $\boldsymbol{\alpha}$ & $\boldsymbol{\beta}$ \\
\hline Sargasso Sea & $5.50 \times 10^{-13}$ & 2.93 \\
Western Antarctic Peninsula & $3.91 \times 10^{-12}$ & 2.53 \\
\hline
\end{tabular}




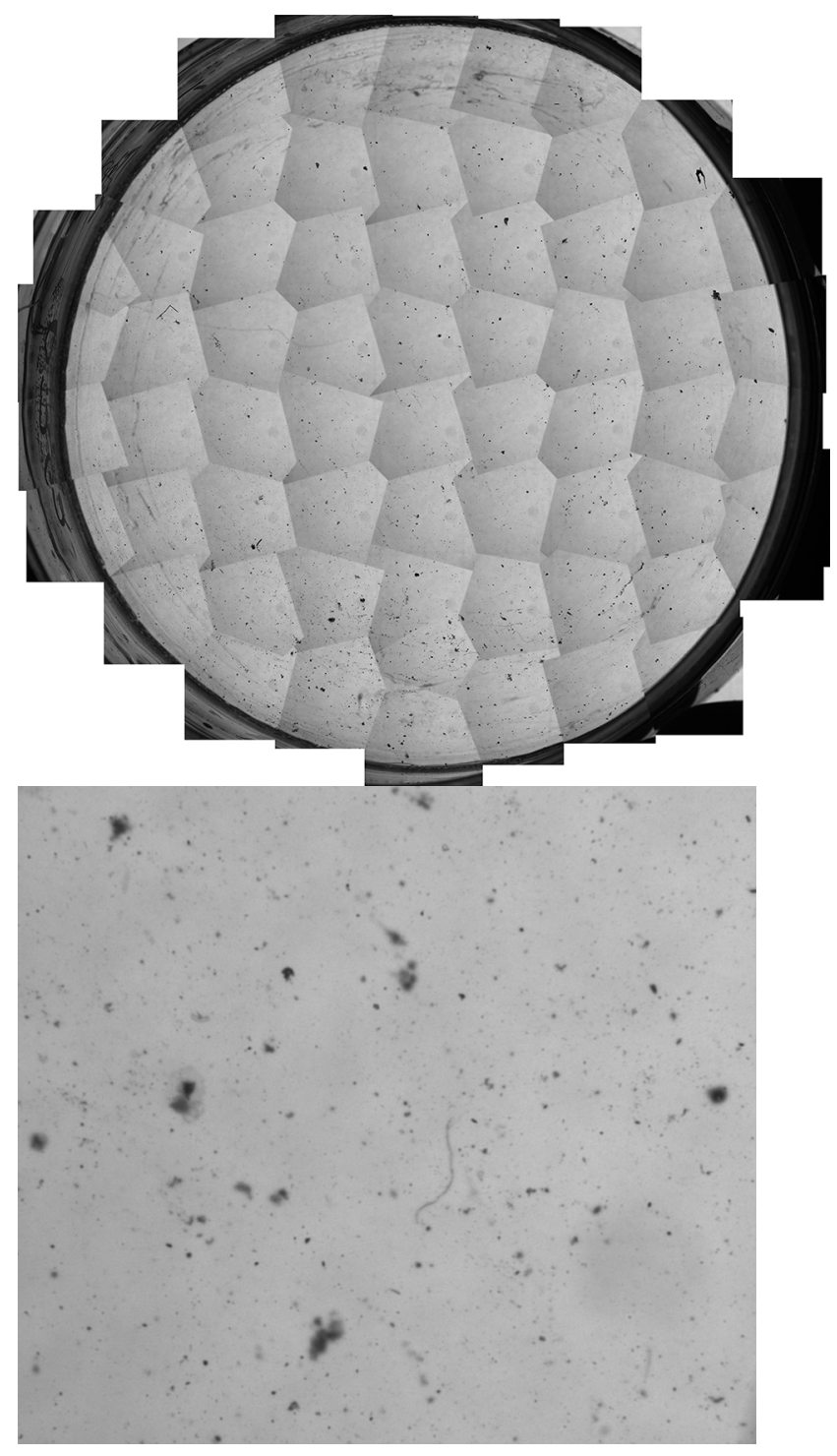

Figure 1. Photographs of a polyacrylamide gel deployed at $300 \mathrm{~m}$ depth at the BATS site on 2527 September 2009. The top panel shows the merged image containing about 70 microscopic photographs of the gel. The gel has an $11 \mathrm{~cm}$ diameter. Below, a close-up of a $1 \times 1 \mathrm{~cm}$ section of the gel, showing the distribution of particles collected in the flux. 

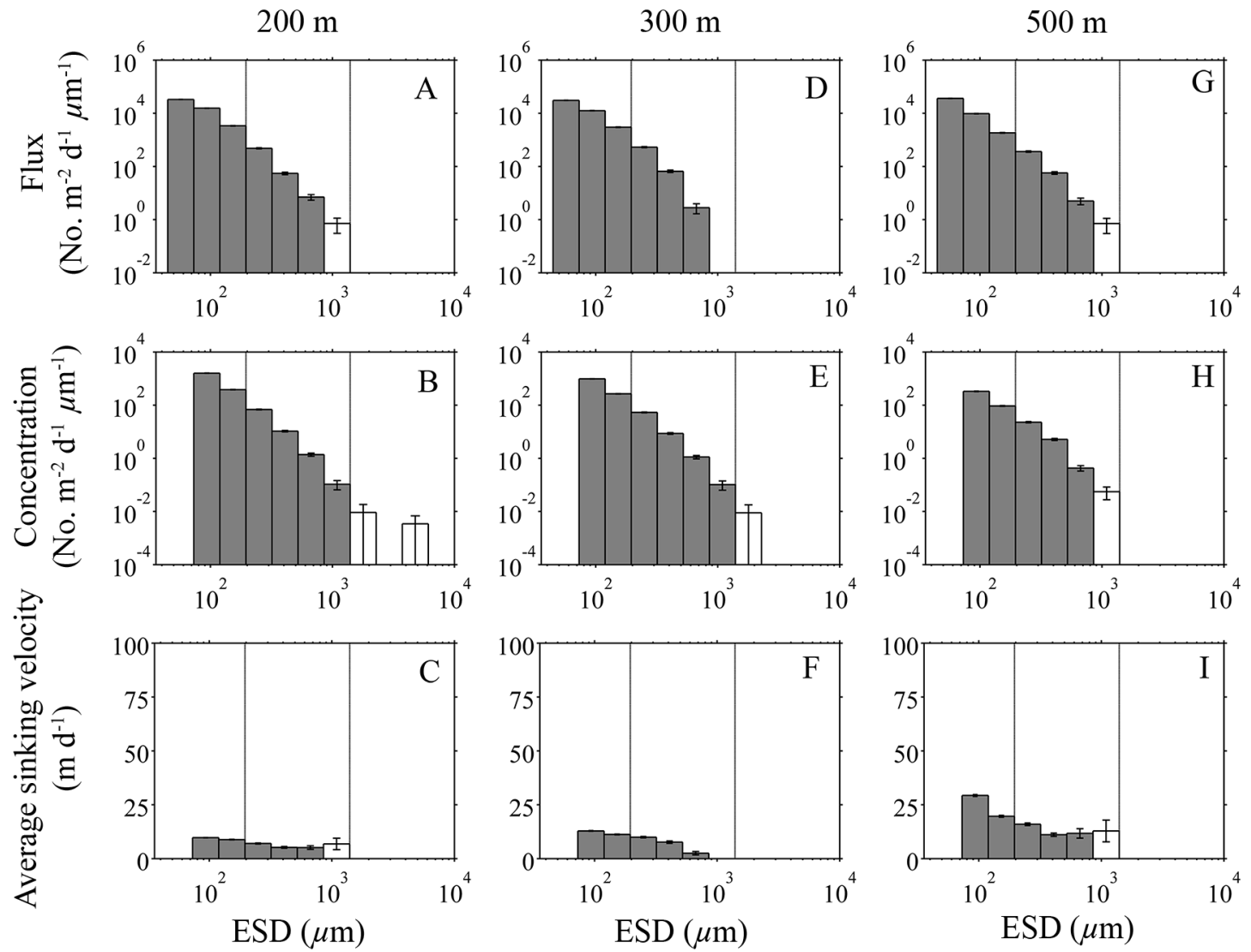

Figure 2. Particle size distributions as a function of particle equivalent spherical diameter (ESD) at the BATS site during May 2009 at (A-C) $200 \mathrm{~m}$, (D-F) $300 \mathrm{~m}$, and (G-H) $500 \mathrm{~m}$ depths. Panels A, D, and $G$ represent the numeric flux size distribution determined from polyacrylamide gel traps. The concentration size distributions (B, E, H) were derived from VPR profile data and represent the average concentration in the $50 \mathrm{~m}$ of water immediately above the designated trap depth. The average sinking velocities are derived as the quotient of the flux and concentration size distributions. The vertical grid lines located at ESDs of 195 and $1400 \mu \mathrm{m}$ are used to aid the eye in the alignment of the different size classes. Open bars indicate that fewer than six particles were counted in that size bin and therefore the associated errors are high and difficult to quantify. 
$200 \mathrm{~m}$
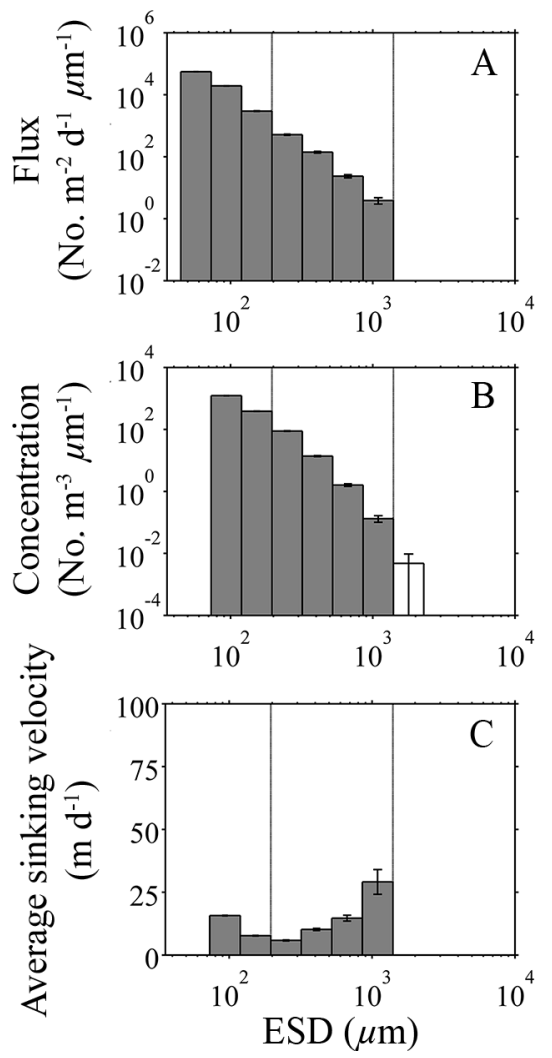

$300 \mathrm{~m}$
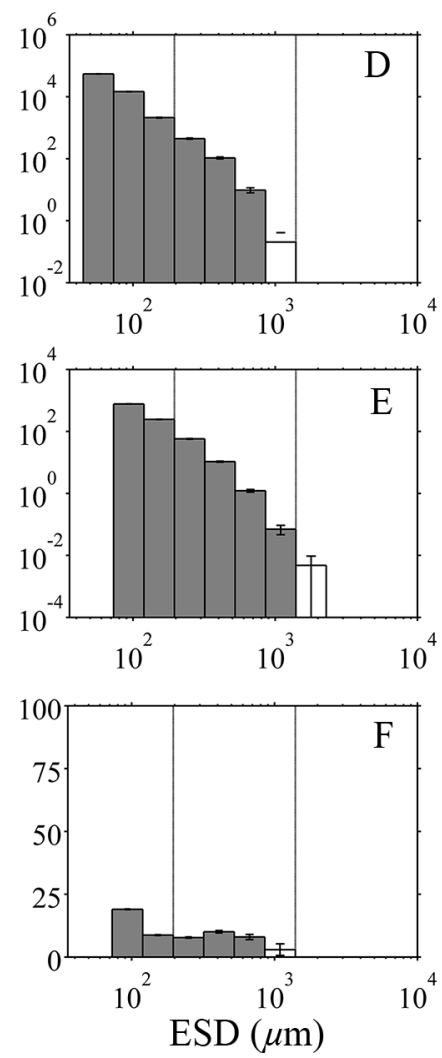

Figure 3. Particle size distributions as a function of particle equivalent spherical diameter (ESD) at the BATS site during July 2009 at (A-C) $200 \mathrm{~m}$ and (D-E) $300 \mathrm{~m}$ depths. Panels A and D represent the numeric flux size distribution determined from polyacrylamide gel traps. The concentration size distributions $(\mathrm{B}, \mathrm{E})$ were derived from VPR profile data and represent the average concentration in the $50 \mathrm{~m}$ of water immediately above the designated trap depth. The average sinking velocities are derived as the quotient of the flux and concentration size distributions. The vertical grid lines located at ESDs of 195 and $1400 \mu \mathrm{m}$ are used to aid the eye in the alignment of the different size classes. Open bars indicate that fewer than six particles were counted in that size bin and therefore the associated errors are high and difficult to quantify. 

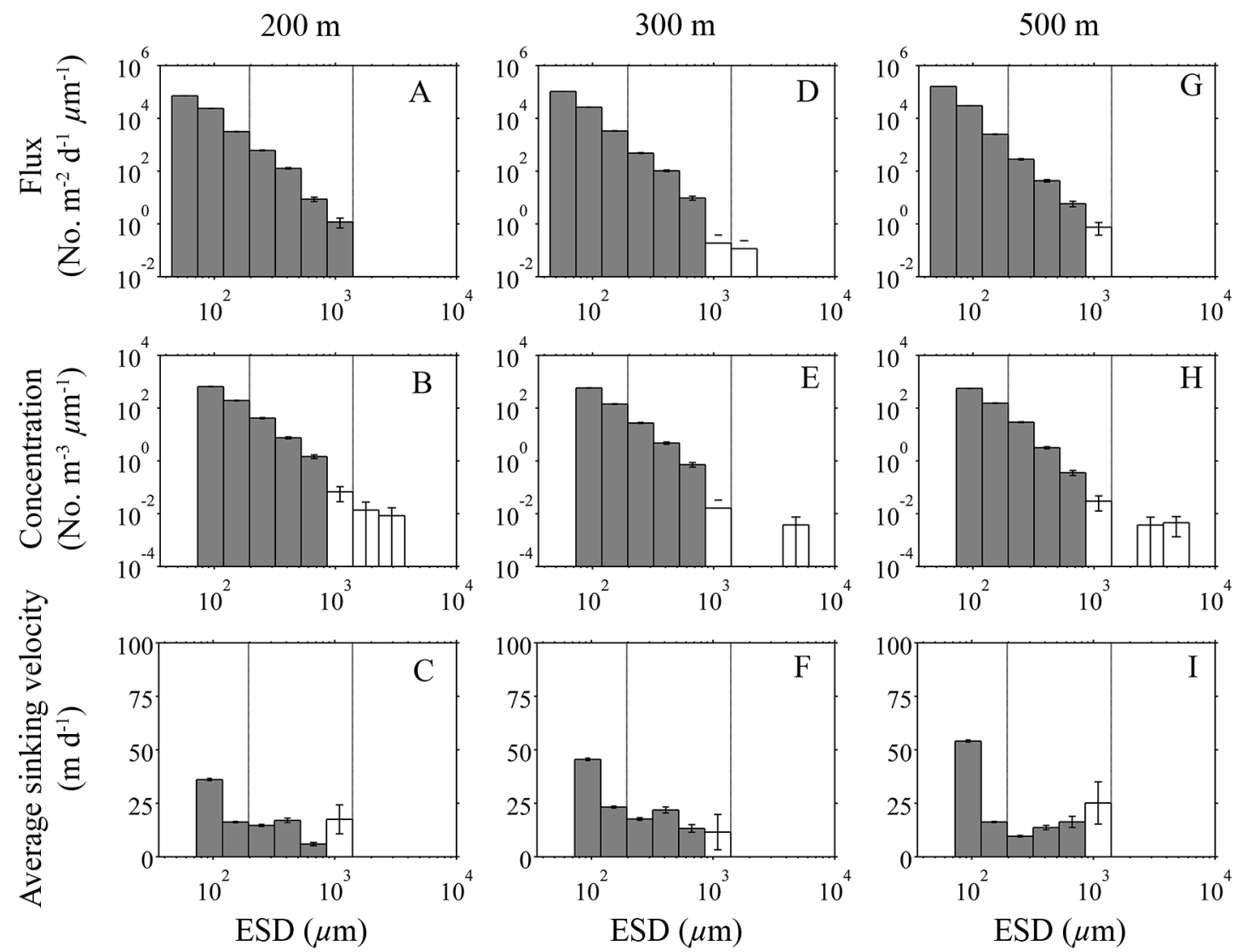

Figure 4. Particle size distributions as a function of particle equivalent spherical diameter (ESD) at the BATS site during the 21-22 September trap deployment at (A-C) $200 \mathrm{~m}$, (D-F) $300 \mathrm{~m}$, and (G-H) $500 \mathrm{~m}$ depths. Panels A, D, and G represent the numeric flux size distribution determined from polyacrylamide gel traps. The concentration size distributions $(\mathrm{B}, \mathrm{E}, \mathrm{H})$ were derived from VPR profile data and represent the average concentration in the $50 \mathrm{~m}$ of water immediately above the designated trap depth. The average sinking velocities are derived as the quotient of the flux and concentration size distributions. The vertical grid lines located at ESDs of 195 and $1400 \mu \mathrm{m}$ are used to aid the eye in the alignment of the different size classes. Open bars indicate that fewer than six particles were counted in that size bin and therefore the associated errors are high and difficult to quantify. 

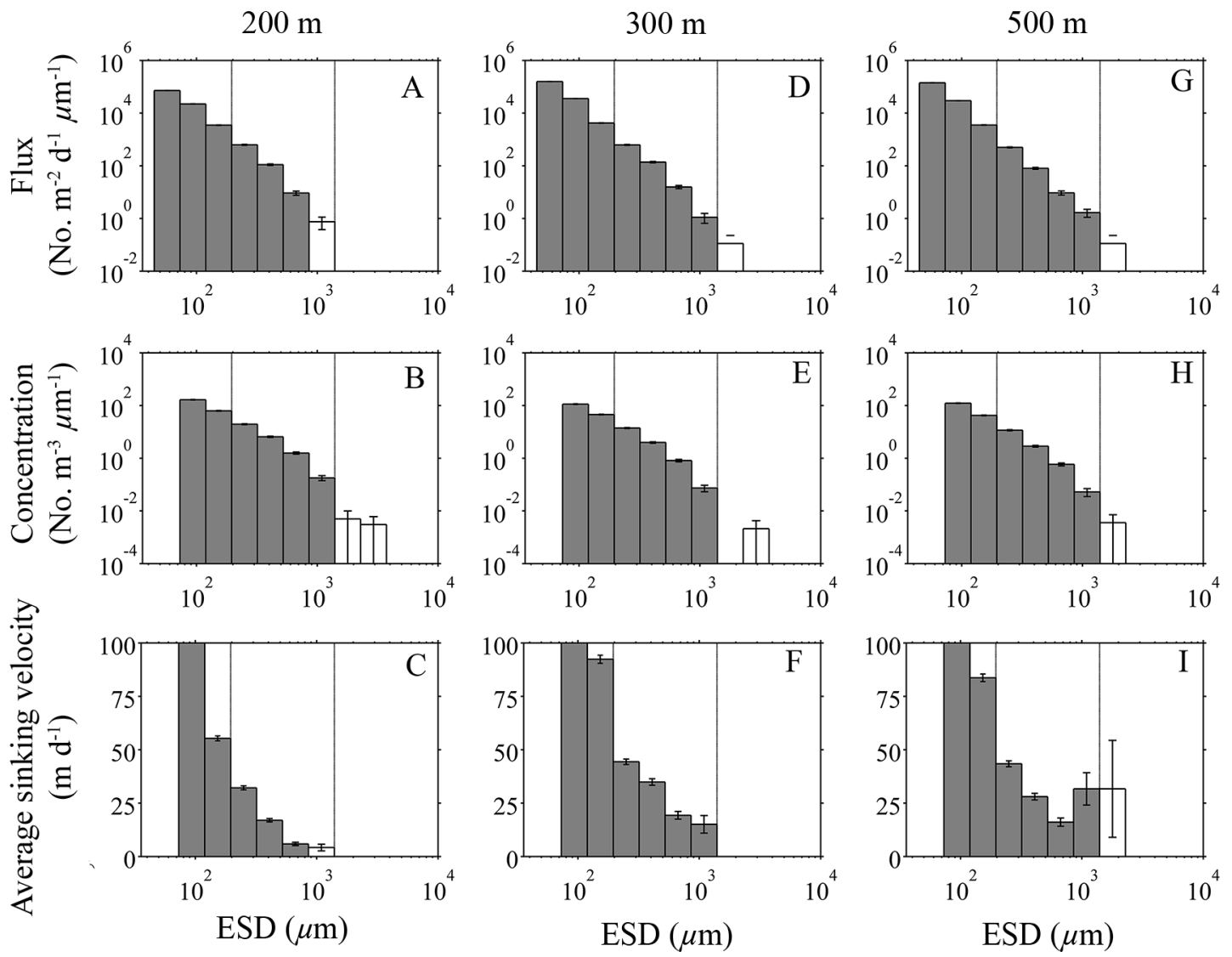

Figure 5. Particle size distributions as a function of particle equivalent spherical diameter (ESD) at the BATS site during the 25-27 September trap deployment at (A-C) $200 \mathrm{~m}$, (D-F) $300 \mathrm{~m}$, and (G-H) $500 \mathrm{~m}$ depths. Panels A, D, and G represent the numeric flux size distribution determined from polyacrylamide gel traps. The concentration size distributions $(\mathrm{B}, \mathrm{E}, \mathrm{H})$ were derived from VPR profile data and represent the average concentration in the $50 \mathrm{~m}$ of water immediately above the designated trap depth. The average sinking velocities are derived as the quotient of the flux and concentration size distributions. The vertical grid lines located at ESDs of 195 and $1400 \mu \mathrm{m}$ are used to aid the eye in the alignment of the different size classes. Open bars indicate that fewer than six particles were counted in that size bin and therefore the associated errors are high and difficult to quantify. 




Figure 6. Comparison of the carbon flux estimated from the gel flux size distribution and the carbon fluxes measured by the drifting sediment trap arrays at BATS. The estimated fluxes were derived from the least squares comparison in Equation 3 which produced the best fit parameters $\alpha$ $=5.50 \times 10^{-13}$ and $\beta=2.928$. Data is from the 2009 deployments on 14-15 July, 21-22

September, and 25-27 September at the BATS site. Carbon flux data from May 2009 is missing so these data points could not be included in this plot.

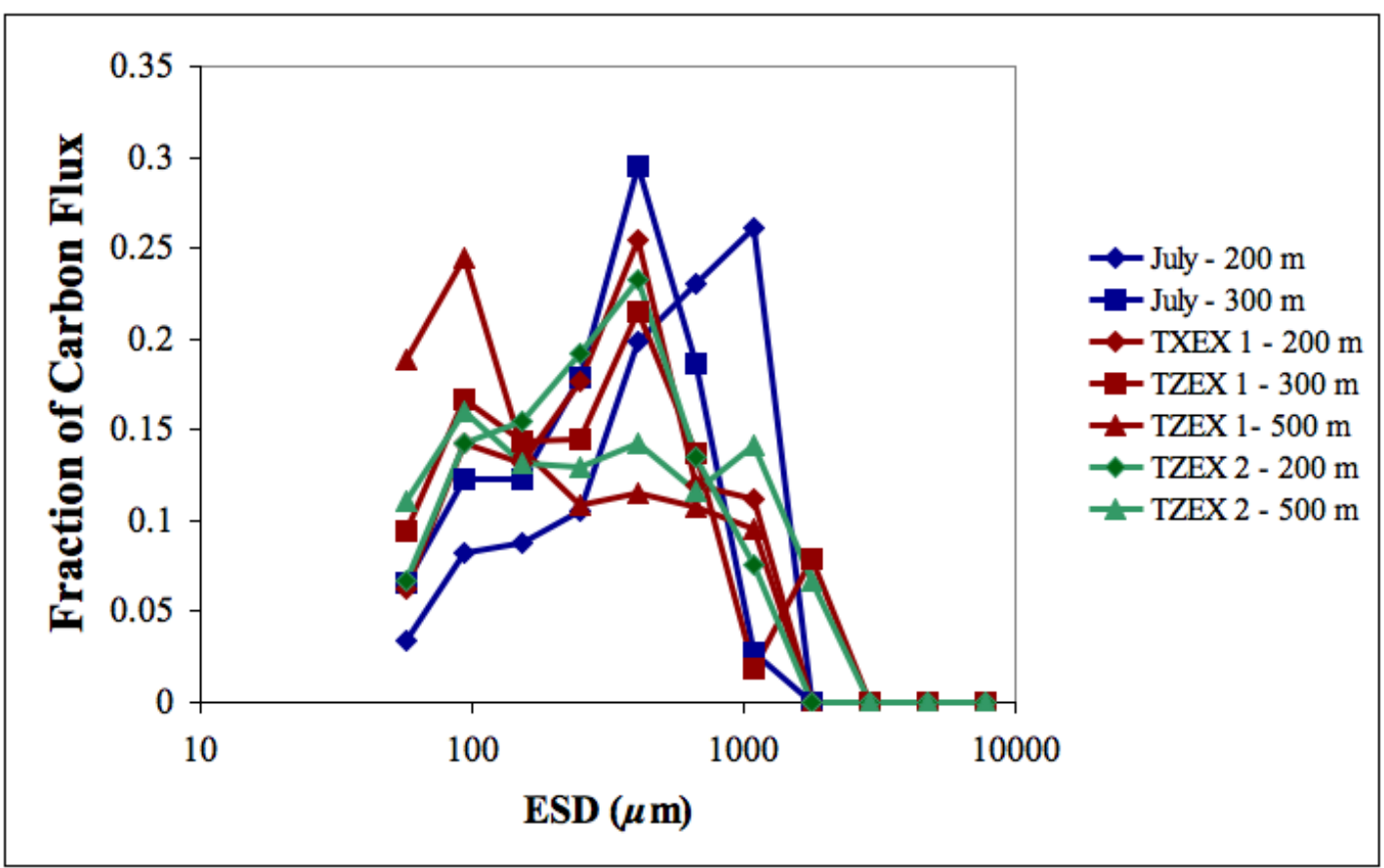

Figure 7. The fraction of the total carbon flux collected in each logarithmically spaced size bin as a function of the equivalent spherical diameter (ESD) for the 2009 Sargasso Sea deployments. This data is calculated from the flux size distribution of each polyacrylamide gel and the parameterization of carbon content as a function of particle size. The colors represent different deployments of the drifting array and the markers represent the depths specified in the legend. 

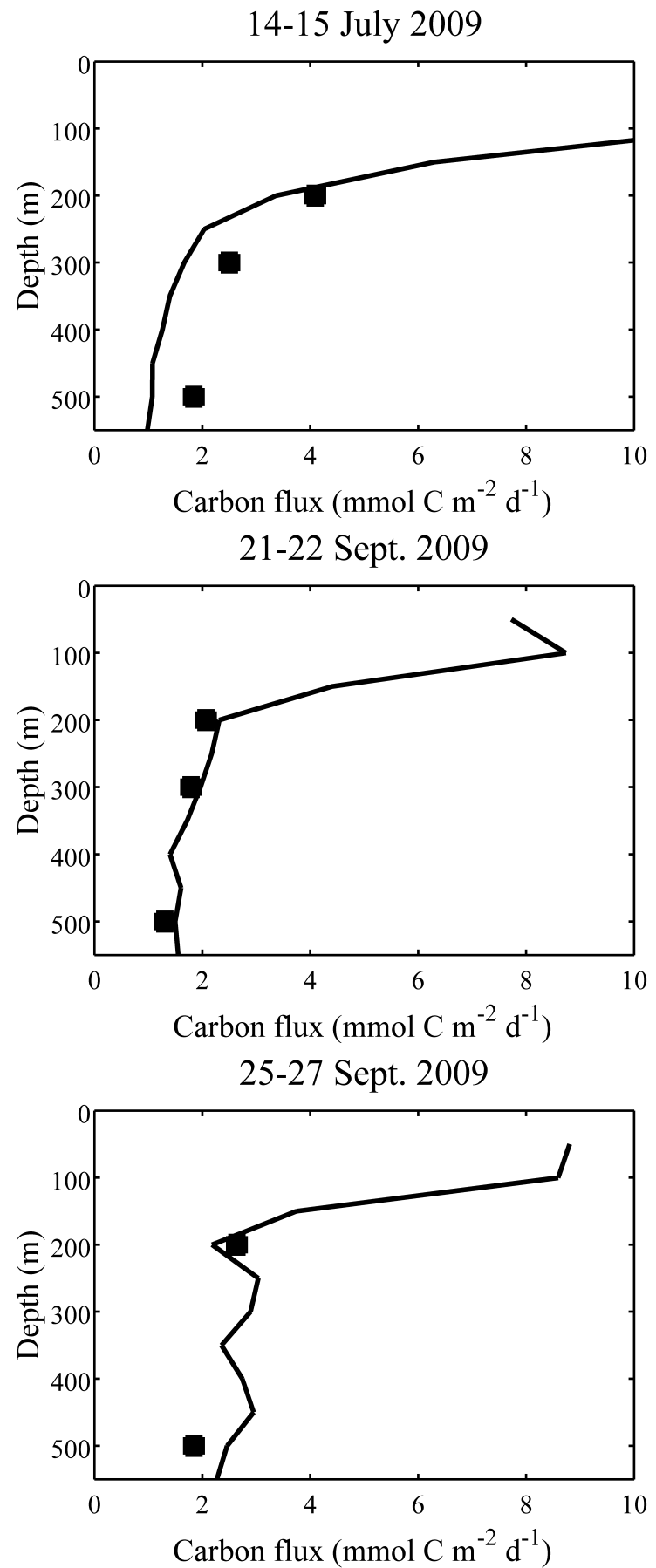

Figure 8. Sinking carbon fluxes as measured by the drifting sediment trap arrays (squares) and estimated from the concentration size distribution measured by the VPR (solid lines). 
(A)

Small particle concentration $(120<\mathrm{ESD}<195 \mu \mathrm{m})$

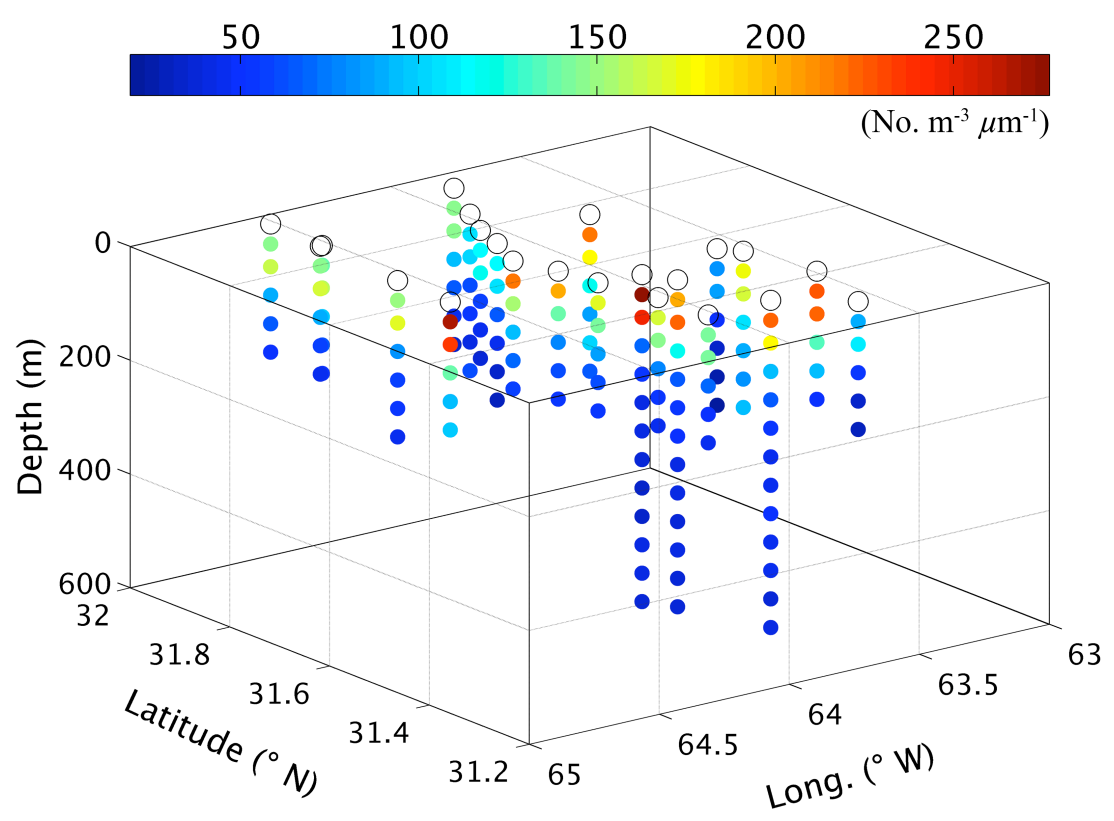

(B)

Mid-sized particle concentration $(320<$ ESD $<520 \mu \mathrm{m})$

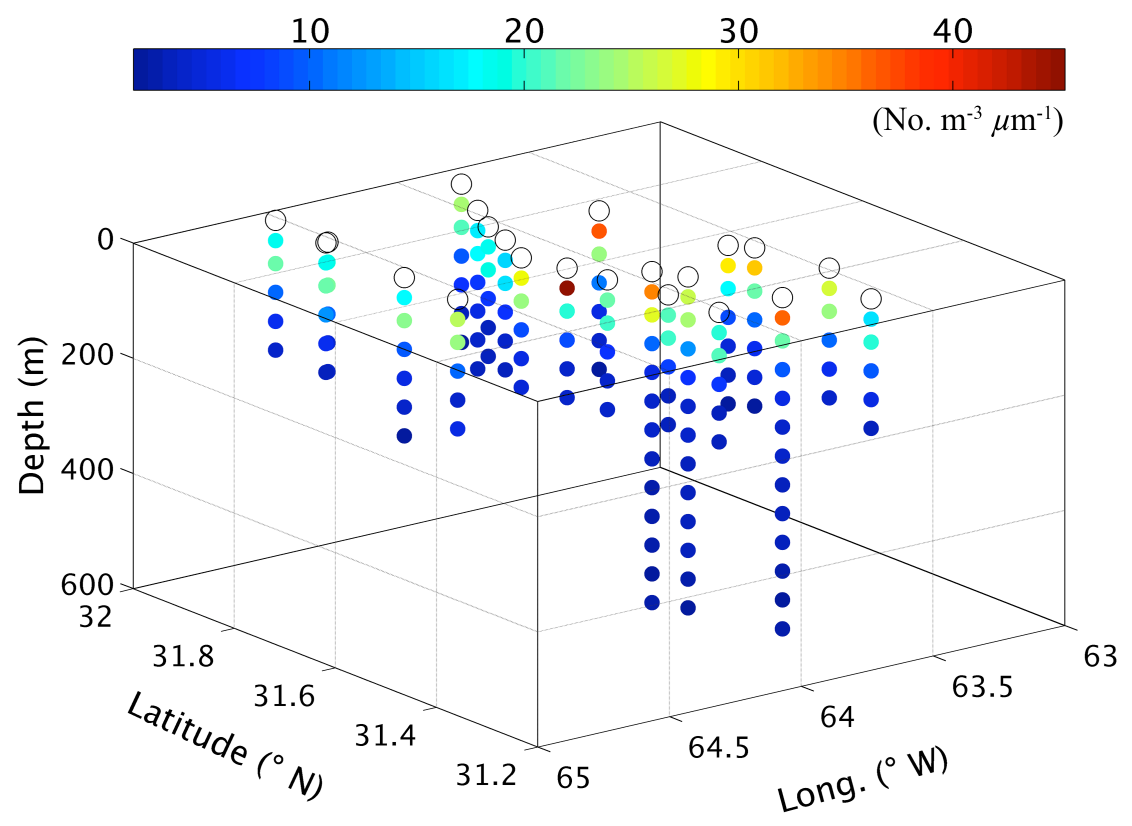


(C)

Large particle concentration $(850<\mathrm{ESD}<1400 \mu \mathrm{m})$

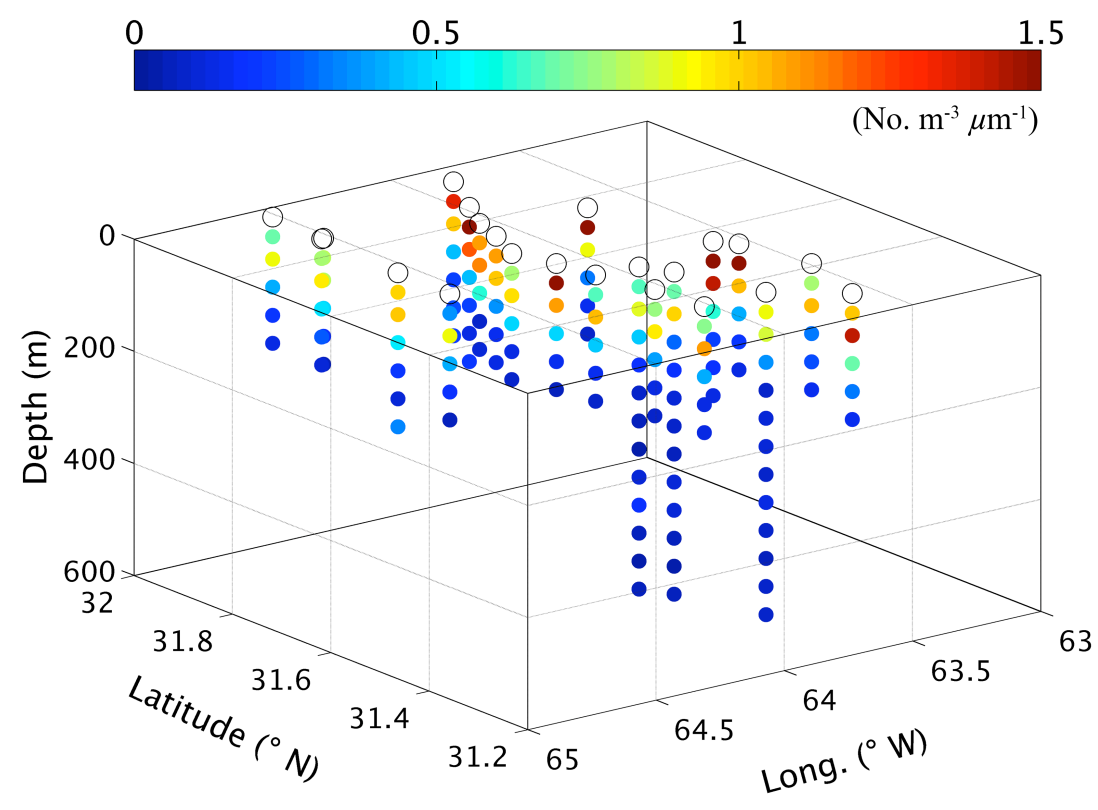

Figure 9. Particle concentrations plotted as a function of location and depth measured from 21-28 September in the BATS region to the southeast of Bermuda. The open circles represent the surface location of the vertical VPR deployment and the color of the dots below the circles denote the concentration of (A) small, (B) mid-sized, and (C) large particles in the 50-m depth bins beneath the surface. North is along lines of constant longitude to the upper left in the figures. 
Sinking Particle Flux (mmol $\left.\mathrm{C} \mathrm{m}^{-2} \mathrm{~d}^{-1}\right)$

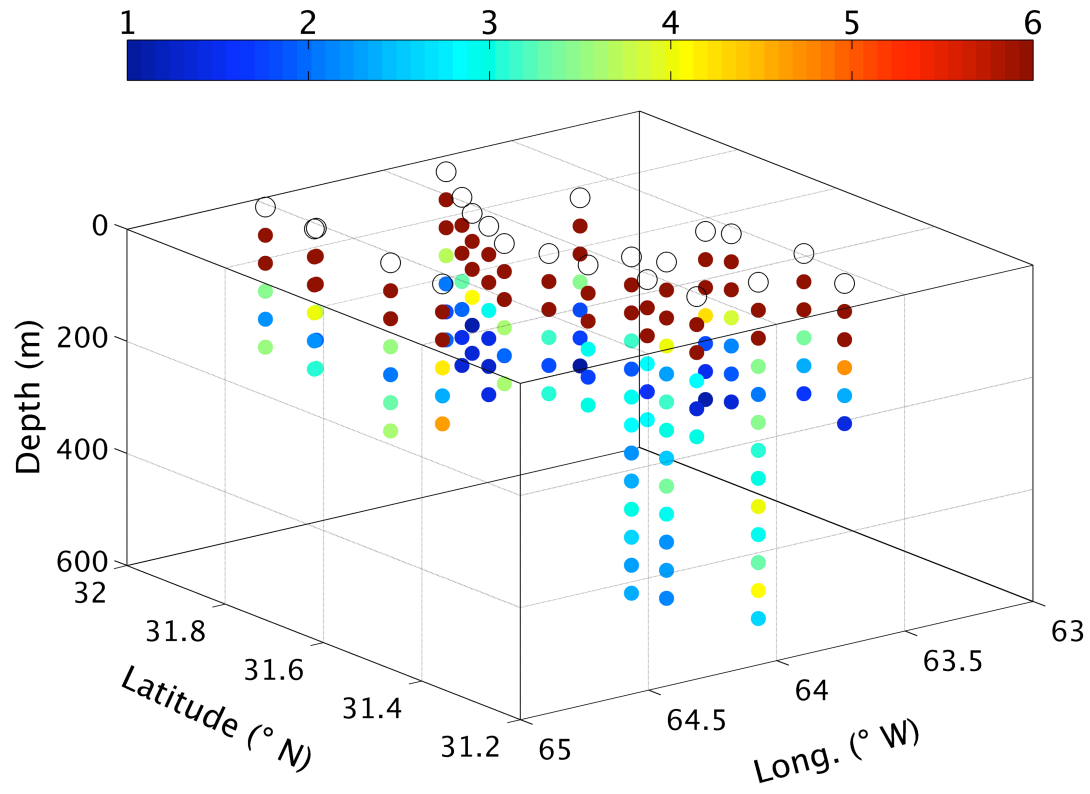

Figure 10. Sinking particle flux estimated from measurements of particle concentration, the average sinking velocity size distribution, and the relationship between the numeric flux size distribution and the carbon flux. Measurements were made from 21-28 September in the BATS region to the southeast of Bermuda.

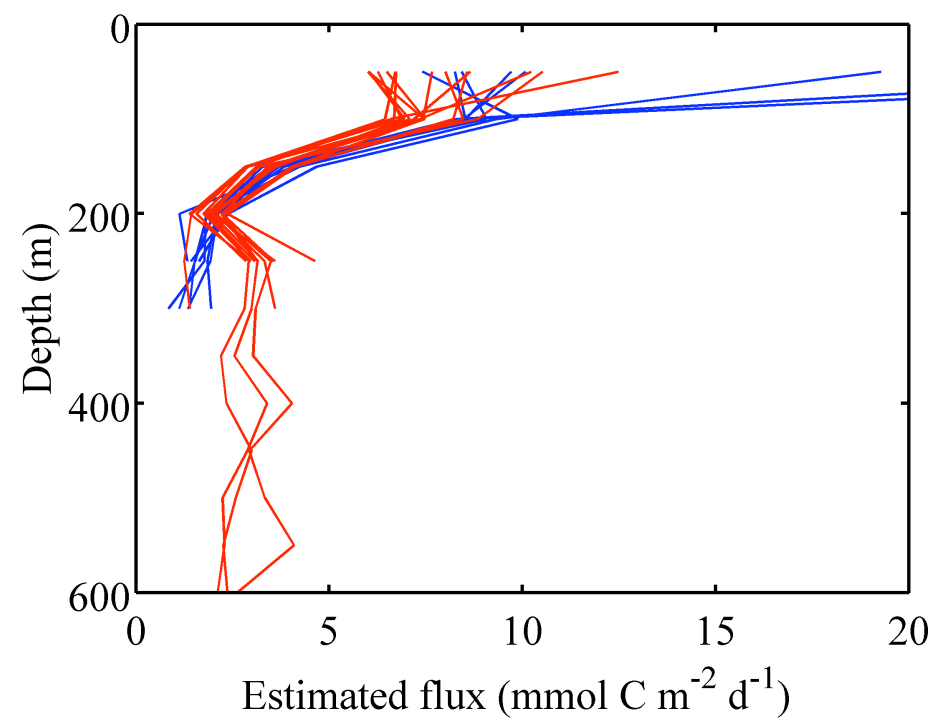

Figure 11. Estimated sinking particle flux profiles for the BATS region. The blue flux profiles were computed using VPR profiles conducted from 21-25 September and average sinking velocities determined from the 21-22 September 2009 deployment of the drifting sediment trap array. The red profiles were computed from VPR profiles conducted from 26-28 September with average sinking velocities from the 25-27 September drifter deployment. 


\section{Chapter Five}

Sinking velocities and microbial respiration control the attenuation of particle flux through the ocean's twilight zone 


\section{Introduction}

Particles sinking from the euphotic zone transport carbon and other elements into the ocean's interior in a process known as the "biological pump" (Volk and Hoffert 1985). This downward flux of particulate organic matter (POM) typically declines sharply with respect to depth due to solubilization and respiration by particle attached microbes as well as the consumption or fragmentation of POM by zooplankton. Modeling studies suggest that variations in the depth at which sinking POM is remineralized can have a substantial impact on the air-sea balance of carbon dioxide (Kwon et al. 2009). Measurements of particle fluxes and inverse modeling studies indicate that this remineralization depth varies significantly with respect to location and time (Berelson 2001; Buesseler and Boyd 2009; Buesseler et al. 2007; Howard et al. 2006), however the physical and ecological controls on this remineralization depth are poorly understood and difficult to measure.

Conceptually, it is the balance between particle sinking velocities and the rates of particle destruction that sets the remineralization depth. These parameters, in turn, are affected by a variety of environmental variables and ecosystem properties. Factors such as ambient temperature, particle composition and structure, and community structure are thought to play a significant role in controlling sinking velocities and rates of particle destruction.

Marine particles, especially marine snow aggregates, are hot spots of microbial activity in the oceans (Alldredge and Gotschalk 1990; Azam and Long 2001; Simon et al. 1990). The abundances of bacteria and other heterotrophic microbes associated with marine particles are up to several orders of magnitude higher than in the surrounding seawater (Simon et al. 2002). The magnitude of these processes has been an issue of considerable debate, with some early studies concluding that marine snow is a relatively poor site for the active remineralization of organic matter, and, therefore, microbial degradation of sinking aggregates should be a minor factor in the attenuation of particle fluxes with depth (Alldredge and Youngbluth 1985; Ducklow et al. 1982; Karl et al. 1988). Other studies found quite the opposite, however, calculating that POM could be broken down on short timescales of hours to days (Ploug and Grossart 2000; Ploug et al. 1999; Smith et al. 1992). Whether or not this range in microbial rates is a result of the inherent variability of respiration in the oceans, or simply a difference in methodological approaches remains unclear. In fact, many of these studies were done under laboratory conditions with laboratory-grown aggregates and may be difficult to compare to the oceanographic process of flux attenuation. 
The techniques for estimating the effects of microbial respiration associated with sinking particles vary. Some studies have employed thymidine incorporation measurements to assess the bacterial production rates (Chin-Leo and Kirchman 1988; Ploug and Grossart 1999). However, this approach takes into account production by both free-living and attached bacteria. Relating these measurements to the remineralization of particulate matter is difficult because it requires the use of several poorly constrained conversion factors such as the relative abundances of free-living vs. particle attached microbes, as well as bacterial growth efficiencies (Burd et al. 2010).

Microelectrodes have also been used to probe oxygen gradients in the diffusive boundary layer surrounding particles (Ploug 2001). Theoretical calculations are then made to determine the total oxygen consumption rates of the particle-attached microbes. Some of these studies have been conducted in flow through systems that emulate the fluid regime that would be experienced if the particle were sinking through the water column (Ploug and Jørgensen 1999).

In this study, I address the question of how microbial respiration rates associated with sinking particles and the average sinking velocities of particles in the water column affect the attenuation of particle flux through the mesopelagic zone. This is accomplished with an in situ particle incubation chamber and determinations of the relationship between particle flux and concentration, both of which constitute novel approaches to the study of these processes. These experimentally determined rates are compared to the attenuation of particle flux as measured by sediment traps deployed at multiple depths. The results from the subtropical Sargasso Sea and the productive continental shelf system of the western Antarctic Peninsula (WAP) provide endmember examples of the direct effect that sinking velocities and microbial activity have on the efficiency of the ocean's biological carbon pump.

\section{Methods}

The microbial respiration rates of particle-attached microbes were measured with RESPIRE traps (Fig. 1) and described in detail in Boyd et al. (In Prep.). These devices were deployed from a drifting sediment trap array that isolates the instruments from surface wave motion with the use of an elastic bungee (Lamborg et al. 2008). Up to three of these instruments were deployed simultaneously on the drifting array at a depth just below the base of the euphotic zone. Prior to deployment, the traps were filled with $0.2-\mu \mathrm{m}$ filtered seawater from the depth of the planned deployment. In the case of the September 2009 deployments at BATS, an underwater CTD pump flushed the incubation chamber with an excess (approximately $5 \mathrm{~L}$ ) of 
ambient seawater. The RESPIRE traps operated in two modes: the collection phase and the incubation phase. During the collection phase, sinking particles entered the opening of the trap and settled onto an indented rotating sphere (IRS) machined out of solid PVC (Peterson et al. 1993) and designed to exclude swimmers from the collection chamber below. One of the RESPIRE traps was covered with a $10-\mu$ m nylon mesh to exclude sinking particles for operation as an experimental control. An external controller rotated the IRS for 50 seconds (approximately 1 complete rotation, depending on the battery voltage available) every 10 minutes, thereby transferring any particles collected on top of the IRS into a $1.34 \mathrm{~L}$ incubation chamber below. Particles settled onto the flat base plate of the RESPIRE trap's incubation chamber (also solid PVC). The walls of the chamber were constructed of transparent acrylic tubing (1/8-inch thickness). After a collection period of approximately 36 hours, the incubation phase began with the closure of the trap lid and the cessation IRS rotation. This prevented additional particles from entering the chamber and also isolated the incubation chamber from fluid exchange with ambient waters. An Optode (Aanderaa Data Instruments, model 3830) measured the concentration of dissolved oxygen in the incubation chamber once every two minutes. The Optodes were factory calibrated. Unlike typical oxygen electrodes, they rely on dynamic luminescence quenching by molecular oxygen, and do not consume the analyte. At the end of the incubation phase, the array was recovered aboard the research vessel.

To quantify the flux collected in the RESPIRE traps, two CLAP traps (Lamborg et al. 2008) were deployed on the same instrument frame and programmed to close at the end of the RESPIRE particle collection phase. Formalin-poisoned brine $(500 \mathrm{~mL}$, Salinity $70 \%$, 0.02\% formalin) was added to the base of these CLAP tubes to prevent microbial breakdown of the samples and allow for an accurate measurement of the sinking particulate carbon fluxes. The RESPIRE and CLAP traps have the same size opening and baffle at the top of the trap but with the IRS near the base of the RESPIRE traps, they do have different aspect ratios. CLAP traps were used as a measure of carbon flux because with the flat base plate of the RESPIRE and enclosed nature of the incubation chamber, the complete removal of the particulate matter for the quantification of flux proved difficult.

During the deployments, data from the Optode were logged on the underwater controller unit. The oxygen consumption rates $\left(\mathrm{mol} \mathrm{L}^{-1} \mathrm{~d}^{-1}\right)$ inside both the particle collecting and particle excluding control RESPIRE traps ( $r_{\text {exp }}$ and $r_{\text {control }}$, respectively) were determined by linear regression of the oxygen concentration in the chamber as a function of incubation time. From 
these rates, a carbon specific remineralization rate, $R_{C}\left(d^{-1}\right)$ was calculated with the following equation

$$
\mathrm{R}_{\mathrm{C}}=\frac{\left(r_{\text {exp }}-r_{\text {control }}\right) \mathrm{V}_{\text {inc }} v_{\mathrm{C}: \mathrm{O}_{2}}}{\mathrm{n}_{\mathrm{C}}}
$$

where $\mathrm{V}_{\text {inc }}$ is the volume of the incubation chamber $(1.34 \mathrm{~L}), v_{\mathrm{C}: \mathrm{O}_{2}}=117 / 170$ is the stoichiometric ratio of organic carbon to oxygen for organic matter remineralized at depth (Anderson and Sarmiento 1994), and $\mathrm{n}_{\mathrm{C}}$ is the number of moles of carbon accumulated in the traps during the collection phase, as determined with the CLAP traps. $\mathrm{R}_{\mathrm{C}}$ is therefore the fraction of sinking particulate carbon that is remineralized over the course of one day. Several studies have confirmed that carbon-specific remineralization rates are independent of aggregate size (Iversen et al. 2010; Ploug and Grossart 2000; Ploug et al. 1999), providing justification for the normalization of oxygen consumption rates to the total amount of carbon collected in the traps.

The average sinking velocity of particles between $100 \mu \mathrm{m}$ and about $6 \mathrm{~mm}$ was calculated by combining measurements of the particle flux size distribution (FSD) and the particle concentration size distribution (CSD) as described in detail in McDonnell \& Buesseler (2010). The particle FSD was determined by the deployment of polyacrylamide gel traps and subsequent microscopic photography and image analysis. CSD was measured by conducting vertical profiles with the Video Plankton Recorder. For each size class, the flux was divided by the concentration, giving an average sinking velocity $W_{i, \text { avg }}$ in $\mathrm{m} \mathrm{d}^{-1}$. From this average sinking velocity distribution (ASVD), an average sinking velocity was calculated for all particles in the measurable size range ( $W_{\text {avg }}$ ) by weighting the ASVD by the volume flux distribution.

The average sinking velocity and the carbon specific remineralization rate can then be combined to calculate a microbial length scale of remineralization $\left(\mathrm{L}_{\text {remin }}\right)$ by the following equation

$$
\mathrm{L}_{\mathrm{remin}}=\mathrm{W}_{\mathrm{avg}} / \mathrm{R}_{\mathrm{C}}
$$

where $\mathrm{L}_{\text {remin }}$ (in meters) represents the e-folding length scale by which the flux is attenuated with respect to depth. Assuming a constant fraction of the POM is remineralized per meter of depth, the flux can be written as a function of the flux $\left(F_{0}\right)$ measured at the upper trap depth $\left(z_{0}\right)$ and the calculated value of $\mathrm{L}_{\text {remin }}$ (Volk and Hoffert 1985). 


$$
F=F_{0} \exp ^{-\left(z-z_{0}\right) / \mathrm{L}_{\text {remin }}}
$$

These experiments were conducted in two contrasting oceanic environments. Data from 5 deployments at the Bermuda Atlantic Time-Series site $\left(31^{\circ} 40^{\prime} \mathrm{N}, 64^{\circ} 10^{\prime} \mathrm{W}\right)$ in the Sargasso Sea are presented here. This region of the subtropical North Atlantic Ocean has been part of intensive oceanographic studies over the past several decades through several long-term scientific programs including BATS (Michaels and Knap 1996; Steinberg et al. 2001b), the Oceanic Flux Program (Conte et al. 2001), Hydrostation S (Michaels and Knap 1996), and the Bermuda Testbed Mooring (Dickey et al. 2001). This site is characterized by generally low productivity and deep mixing in the winter followed by a brief spring bloom as the hydrography transitions to a thermally stratified and nutrient poor euphotic zone that lasts well into October (Steinberg et al. 2001a). During the summer months, primary production rates are low and a subsurface chlorophyll maximum exists near the base of the euphotic zone. A diverse assemblage of phytoplankton inhabit the euphotic zone here, often dominated by prokaryotic picoplankton such as prochlorophytes and cyanobacteria, but with variable contributions from eukaryotic plankton such as prymnesiophytes and pelagophytes (Steinberg et al. 2001a). Sinking particle fluxes in the mesopelagic zone have been measured regularly with drifting sediment trap arrays. The peak fluxes are not significantly correlated with peaks in production, suggesting decoupling between these two processes.

The second site is located in the Southern Ocean along the west Antarctic Peninsula (WAP). These experiments were conducted at two locations along the WAP: the LTER Trap Site (64'29.3'S, 65'57.6'W) $130 \mathrm{~km}$ offshore in the midshelf region, and at the head of Marguerite Bay further to the south $\left(68^{\circ} 10.5^{\prime} \mathrm{S}, 69^{\circ} 59.8^{\prime} \mathrm{W}\right)$. The WAP is a highly productive ecosystem with large blooms of diatoms that occur in the spring and summer. This intense production supports large stocks of krill, salps, silverfish, penguins, and marine mammals (Fraser and Trivelpiece 1996). It is the site of the Palmer Long Term Ecological Research study (PAL) and other studies that provide an oceanographic context to the measurements presented here. Particle fluxes along the WAP are highly seasonal, often varying over an order of magnitude between the ice-covered winters and highly productive summers (Ducklow et al. 2008). Krill fecal pellets and diatom aggregates dominate the flux during the summer months in this region (McDonnell and Buesseler 2010). Up until very recently, measured export ratios along the WAP were very low (< 
$4 \%$ ) suggesting that bacteria and zooplankton efficiently recycle particulate matter in the euphotic zone or on its transit towards depth (Ducklow et al. 2008). But a recent study with drifting sediment traps and water column profiles of ${ }^{234} \mathrm{Th}$ suggest that particle fluxes are about 20 times larger than those measured by the moored conical trap (Buesseler et al. 2010). Thus, the export ratios are likely to be significantly higher than previously thought and this implies efficient export and only modest reprocessing of particulate matter by resident heterotrophic organisms. Due to its remote location and the difficult working conditions, relatively little is known about the dynamics of particle flux and attenuation at this site.

\section{Results}

Only a subset of all the RESPIRE deployments was utilized in this analysis. In early deployments of the instrument in 2008 and 2009, several experimental challenges were encountered. In particular, some accumulation of mineral oil in the incubation chamber was noticed on some occasions when it leaked from the motor housing through the IRS shaft seal. An additional ring seal was added between the incubation chamber and the motor housing in 2009 to prevent this leakage. In some deployments, sustained increases in the measured oxygen concentrations were encountered. After replacing a porous printed IRS with the solid IRS machined out of PVC, this problem was ameliorated.

I defined four experimental criteria for the inclusion of a particular experiment in this analysis. They are as follows:

1. Successful parallel use of a $10 \mu \mathrm{m}$ mesh-covered control RESPIRE trap

2. No known mechanical problems with the IRS rotation

3. No observed accumulation of mineral oil in the incubation chamber from a leaky motor housing

4. Lack of severely spiking or sustained rising oxygen concentrations in the incubation chamber

These criteria narrowed the results to five experiments conducted at the BATS site (Fig. 2) and three experiments along the WAP (Fig. 3). The results show the changes in oxygen that occurred in the incubation chambers during the first six hours of the incubation phase. The divergence between the particle excluding control (shaded lines) and the particle collecting incubators (solid lines) can be attributed to the microbial respiration associated with the sinking particles, as the mesh cover is the only difference between the two configurations. The BATS deployments (Fig. 
2) showed a divergence of $1-10 \mu \mathrm{M}$ over the course of the six-hour incubation. Incubations along the WAP showed no significant divergence from the particle-excluding control (Fig. 3).

In addition to the signal imparted by the particle attached microbes, oxygen concentrations seemed to fluctuate throughout the incubations. The Optode also documented slight temperature fluctuations that oscillated in antiphase with the fluctuations in oxygen. Since the Optode uses the sensor temperature as an input for empirically calculating the dissolved oxygen concentration from an optical measurement of dynamic luminescence quenching by molecular oxygen, these variations could be due to the short period variations in temperature. The fluctuations seem to be mimicked in separate RESPIRE instruments on the same array, suggesting that ambient perturbations simultaneously affect all the instruments at the same depth.

Carbon specific remineralization rates were calculated from this oxygen data (see Methods) and are reported in Table 1. The errors for $\mathrm{R}_{\mathrm{C}}$ were calculated by propagation of error assuming that the tube to tube variability in flux collected was $19 \%$ and using the average uncertainties in the slopes of the oxygen time courses derived from 6 replicate measurements of the oxygen respiration rates $\left(0.03 \mu \mathrm{M} \mathrm{h}^{-1}\right)$. At BATS, $\mathrm{R}_{\mathrm{C}}$ ranged from $0.18 \mathrm{~d}^{-1}$ to $1.1 \mathrm{~d}^{-1}$ with an average value of $0.5 \mathrm{~d}^{-1}$. The respiration rates of particle-attached microbes were essentially undetectable for all three deployments along the WAP. This is despite the fact that the amount of material caught in the traps was typically higher at WAP compared to BATS and therefore the oxygen decline in the chambers might have been expected to be larger at WAP if $\mathrm{R}_{C}$ was similar to what was measured at BATS. In the case of the three WAP deployments, the oxygen drawdown in the particle-excluding controls were actually slightly higher than those that collected sinking particles however, the difference is below the detection limit of $0.03 \mu \mathrm{M} \mathrm{h}^{-1}$ determined from analysis of replicate incubations at the same depth, time, and location. Inspection of the polyacrylamide gels deployed along the WAP revealed no change in the quality or structural integrity of material caught at different depths. This supports the conclusion that microbial activity had a negligible effect on these particles during their rapid transit to depth.

The flux-weighted average sinking velocities ranged from 13-90 $\mathrm{m} \mathrm{d}^{-1}$ (average $49 \mathrm{~m} \mathrm{~d}^{-1}$ ) at BATS (Table 1). Particles sank much more quickly along the WAP, ranging from 91-620 $\mathrm{m} \mathrm{d}^{-}$ ${ }^{1}$ with an average of $274 \mathrm{~m} \mathrm{~d}^{-1}$. The variability in the average sinking velocities between deployments at the BATS site appears to be primarily driven by changes in the water column particle concentration. In July 2009 , when the average sinking velocity was at its lowest (13 $\mathrm{m} \mathrm{d}^{-}$ ${ }^{1}$ ), the particle concentrations in all size were the highest observed at this site, while the flux size 
distribution was very similar to that observed in other deployments. At the WAP, the difference in average sinking velocities at the LTER trap site was due to differences in both the particle concentration and flux.

The high velocities observed in the WAP are likely because the flux is dominated by quickly sinking diatom aggregates and krill fecal pellets (McDonnell and Buesseler 2010). In contrast, the particles collected in the polyacrylamide gel traps at BATS were mostly small, loosely associated aggregates. In addition, water column particle concentrations were actually higher at BATS than they were in the WAP despite the fact that the flux was lower at the former. This implies that many of the particles in the water column are either sinking very slowly or not at all.

The differences in particle sinking velocities and microbial respiration rates have significant implications for the sequestration of carbon in the subsurface ocean. At BATS, the combination of low sinking velocities and high carbon specific remineralization rates leads to estimated microbial remineralization length scales that averaged $98 \mathrm{~m}$ and ranged from 26-355 m (Table 1). By contrast, with no detectable microbial respiration of POM at WAP, this site has essentially infinite microbial remineralization length scales. This means that there would be no attenuation of flux with respect to depth as a result of microbial activity.

The carbon-specific remineralization rate was also measured at various depths. Figure 4A shows the results from an experiment with 3 RESPIRE traps each deployed at different depths $(150,300$, and $500 \mathrm{~m})$ at the BATS site in April 2008. On an absolute basis, the decline in dissolved oxygen concentration in the incubation chamber decreased most rapidly in the shallow trap, and progressively decreasing respiration rates were detected in deeper traps. In this deployment configuration, all three RESPIRE traps were located at different depths, and therefore there were no RESPIRE instruments available to operate as controls. In this case, the average oxygen decline in the mesh-covered controls at the BATS site was used (Fig. 4A, gray line). When the oxygen consumption rates were normalized to the amount of carbon collected in the adjacent CLAP traps, the carbon-specific respiration rates decreased only slightly between the $150 \mathrm{~m}$ trap and the 300 trap, while the rate at $500 \mathrm{~m}$ was only $34 \%$ as strong as the rate measured at $150 \mathrm{~m}$ (Fig. 4B).

Equation 3 was used to model the fluxes as a function of depth. Starting with the measured trap flux at $200 \mathrm{~m}$, the flux was computed incrementally down through the water column at $1 \mathrm{~m}$ intervals using Equation 3 and an $\mathrm{L}_{\text {remin }}$ scaled as a function of depth according to 
the solid lines in Figure 4B. $\mathrm{F}_{0}$ and $z_{0}$ was adjusted at each iteration to the newly computed flux and its depth such that $z-z_{0}$ was always equal to 1 . Figure 5 shows the measured sediment trap fluxes at BATS plotted along with the flux attenuation profiles as computed with the model. In addition to the computed microbial remineralization length scales, I calculated the remineralization length scales suggested by the sediment trap profiles (Table 1, last column). In three of the four of the BATS deployments, the remineralization model predicted microbial remineralization length scales 4-10 times shorter than those measured by sediment traps. The 1012 September study predicted the 300 and $500 \mathrm{~m}$ fluxes within $10 \%$.

Flux measurements and modeled fluxes for the WAP are reported in Fig. 6. Sediment trap measurements in this region show no clear decrease in flux with respect to depth as is widely observed elsewhere in the ocean. In some cases, carbon fluxes even increased at depth. This lack of flux attenuation agrees with what would be predicted from these measurements of particle attached microbial activity and average sinking velocities. The modeled fluxes are unchanged with respect to depth because the microbial respiration rates determined with the RESPIRE traps were undetectable.

\section{Discussion}

These results suggest that the rates of microbial activity associated with sinking particulate matter are highly variable throughout the oceans. The two study sites of BATS and WAP offer a clear example of how this process can range from the dominant factor that controls the particle flux attenuation to one that has no detectable effect. These large differences are likely due to several factors. First, subsurface water temperatures along the WAP are characteristic of the Upper Circumpolar Deep Water that intrudes onto the continental shelf at temperatures only a few degrees above freezing (Ducklow et al. 2007). These low absolute temperatures retard the metabolic activity of microbes. Assuming a $\mathrm{Q}_{10}$ of 2.0, microbial growth and respiration rates would be expected to be about 4 times slower at WAP compared to those in the relatively warm mesopelagic waters at BATS. Scaling the BATS rates down by a factor of four would account for a majority of the observed differences between the two sites. However, even in this scenario, a small amount of particle-associated microbial respiration should have been detected at WAP $\left(\sim 0.13 \mathrm{~d}^{-1}\right)$.

The fact that all of the measurements made at WAP were below detection limits despite the larger absolute flux of sinking particulate matter (Table 1) suggests that factors other than 
temperature control of respiration rates may be important. Hansen et al. (1996) found that fecal pellets formed from a diet of diatoms were more recalcitrant to microbial degradation than those formed from nanoflagellate or dinoflagellate diets due to the more robust mechanical structure of the fecal matter. Fecal pellets and diatom aggregates collected in sediment traps at different depths at WAP were also in similar structural condition, implying that there was little degradation of this material on its transit through the water column. A pronounced peritrophic membrane that encases the partially digested diatomaceous material also enhances the resistance of the krill fecal pellets to microbial colonization and decomposition (Turner and Ferrante 1979). Furthermore, the opal matrix associated with the diatomaceous particulate matter could serve to protect the labile organic carbon from microbial breakdown (Armstrong et al. 2001; Mayer 1994), thereby retarding these rates along the WAP.

Even if the respiration rates measured at WAP were equal to what was measured at BATS, its affect on the attenuation of flux would be minimal due to the high sinking velocities at WAP. With bathymetry along the WAP shelf averaging only $430 \mathrm{~m}$, most of the sinking particles will reach the shelf sediments before microbial activity can consume a significant proportion of the substrates. In fact, this delivery of large fluxes of POM to the WAP sea floor during the summer months supports a rich benthos throughout the year (Mincks et al. 2005). Interestingly, these findings that microbial remineralization rates are higher at BATS than they are at WAP differs from the suggestions of previous authors that high latitude remineralization rates are higher due to more labile planktonic particles in these regions (Arístegui et al. 2005; Francois et al. 2002).

In addition to the differences between two contrasting sites, the data from BATS also suggest that these rates can vary significantly even at a particular site. In two successive deployments only days apart in late September of 2009, the carbon-specific respiration rate varied by a factor of 5 and was primarily due to differences in $\left(r_{\exp }-r_{\text {control }}\right)$ term rather than the amount of flux collected in the traps (Table 1). This suggests that the ecological processes occurring in the mesopelagic zone are at least as variable as what is observed in the euphotic zone. Although the drifting sediment trap arrays were deployed at the same location, the water parcel that they are associated with moves tens of kilometers over the course of the three-day deployment. When the array is redeployed several days later, the deployment location was likely to be associated with a different water mass. Thus, it is certainly possible that the community structure, heterotrophic activity, and particle properties differ between deployments, especially given the fact that 
biological process of production, grazer activity and carbon flux can vary on spatial scales that are smaller than those associated with physical processes (Siegel 2008). While the magnitudes of the carbon specific remineralization rates from the 21-23 September deployment to the 25-27 September deployment were different by a factor of five, the microbial remineralization length scale only changed by a factor of two because the differences in carbon specific remineralization rates were offset by a tripling of the flux weighted average sinking velocity. The trap-derived remineralization length scales were also similar (527 vs. $633 \mathrm{~m}$, Table 1) despite the observed differences in the carbon specific remineralization rates.

Another possible explanation for the large variability in $\mathrm{R}_{\mathrm{C}}$ could be methodological artifacts. As discussed above, the errors reported in Table 1 are calculated using the average uncertainty in both the magnitude of the trap flux and the average uncertainty in the slope of the oxygen concentration as a function of time. Unfortunately because only 3 RESPIRE instruments were available for deployment, multiple experimental replicates were difficult to obtain. The few duplicates that we did obtain indicated only a small amount of variability in the oxygen consumption rates. It is possible that the true variability in respiration rates is larger than this because the criteria defined above resulted in the exclusion of several incubation outliers. If this is indeed the case, there may be methodological artifacts associated with the RESPIRE traps that could account for some of the large variability measured with these traps. Despite the possibility of this large variability in replicates, the general pattern of high particle associated respiration rates at BATS relative to the WAP remains clear and reproducible. It is less clear how these rates vary on small spatial and temporal scales within each region.

The reduction in particle-attached microbial activity as a function of depth has been observed in at least one other study (Karl et al. 1988). As POC is consumed, only the more refractory components are left behind (Armstrong et al. 2001), and the microbial rates decline without an abundance of labile material. The observed reduction in respiration rates as reported in Fig. 4 is stronger than would be expected from the effect of colder water temperatures at the deeper trap depths. If a $\mathrm{Q}_{10}$ of 2.0 is applied to the temperature difference of the typical $2^{\circ} \mathrm{C}$ between 150 and $500 \mathrm{~m}$, the respiration rate at $500 \mathrm{~m}$ would be expected to be only about $20 \%$ slower than it is as $150 \mathrm{~m}$. Thus, other processes such as the quality of the particulate matter must play a role.

Although the effect of slower microbial respiration rates at the deeper depths was taken into account in the modeled profiles of Fig. 5, it had little effect on their shape or the degree to 
which they underestimated the measured sediment trap fluxes. Instead, the $\mathrm{L}_{\text {remin }}$ calculated at the trap depth was the dominant parameter setting the steep decline in predicted flux immediately below the upper trap depth. There are several possible explanations for why the modeled flux profiles using the $\mathrm{L}_{\text {remin }}$ calculated here might predict smaller fluxes than what was measured by the deeper traps. In order for the modeled length scales to match those measured by the sediment traps, it would require a 4-10 fold increase in the average sinking velocities, a decrease of similar magnitude in the carbon specific remineralization rates, or some intermediate combination of the two.

One possibility is that the drifting sediment traps underestimate fluxes in the shallow traps due to poor collection efficiencies. Several previous studies that utilized particle reactive radio nuclides have found that shallow traps are prone to under collection of sinking fluxes (Buesseler 1991; Buesseler et al. 2000). This type of bias would reduce the initial (shallow) flux of the model and lead to the underestimation of the modeled deep fluxes, as was observed. Furthermore, it would also lead to low estimates of the average sinking velocity which would also shorten the $\mathrm{L}_{\text {remin }}$ and lead to the prediction that fluxes would attenuate more quickly than the actual flux attenuation.

Recent studies have shown that microbes communicate with each other through signaling molecules in a process known as quorum sensing (Hmelo and Van Mooy 2009). Given the enclosed nature of the incubation chambers, it is also possible that the concentrations of labile substrates and QS signaling molecules could accumulate to levels that induce QS behavior and lead to artificially high measured rates of microbial activity. Furthermore, in this experimental design, there is a temporal disconnect of 0-36 hours between the collection of particles in the chamber and the measurement of the associated microbial respiration rates. If microbial activity changes with respect to time, the measured rates could be different from those actually occurring on the particles at the depth it is measured. Turley and Stutt (Turley and Stutt 2000) found that cell-specific microbial activity did vary over the first several days after particle collection, so this artifact may play a role in biasing the rate measurements.

Diel vertical migration of zooplankton could create a vertical shunt of particulate matter from the euphotic zone or other upper layers into the mesopelagic zone (Boyd et al. 1999). This would bypass the typical settling and decomposition pathway described in this simple microbial length scale model, and lead to fluxes in the deep traps that would be larger than expected from 
the high measured rates of microbial activity. The vertical shunt could even possibly account for the sporadic increases in particle flux that were observed along the WAP.

In the case of the WAP, particle-attached microbial respiration rates were below the detection level of the RESPIRE traps. Since these rates were undetectable at WAP, and the average sinking velocities high, the result is a modeled carbon flux profile that is constant with respect to depth. The fluxes measured in the traps at WAP were quantitatively larger than those at BATS, however, there was no clear pattern of flux versus depth at WAP. Discrepancies between the modeled profiles and measured fluxes at the WAP can be due to similar factors as experienced at BATS. The unique continental shelf environment of the WAP also raises the possibility of flux variability at different depths due to inputs from lateral advection of particles from shallow waters adjacent to the trap sites.

Because the average sinking velocities are derived from the relationship of the particle FSD and CSD, suspended and very slowly sinking particles affect the velocities reported here. As a result, the average velocities are slower than the actual settling velocities of many of the particles collected in the traps. This may bias the calculated $\mathrm{L}_{\text {remin }}$ in a manner that would suggest more rapid attenuation of particle flux, as was observed here. For example, if $90 \%$ of the particles in the water column were actually suspended or very slowly sinking rather than quickly sinking particles, the actual velocity of the particles collected in the trap would be a factor of 10 larger than the average sinking velocities used here to calculate $\mathrm{L}_{\text {remin }}$. However, a recent study in the subtropical N. Atlantic Ocean found that $>60 \%$ of POC flux is from slowly settling particles with velocities ranging from $0.7-11 \mathrm{~m} \mathrm{~d}^{-1}$ (Alonso-Gonzalez et al. 2010), demonstrating the importance of including this class of particles in the calculations of $\mathrm{L}_{\text {remin }}$.

Sinking velocity is also important because it determines the rate at which flux feeders can scavenge sinking particles from the water column. Large fluxes due to rapidly sinking particles would create an ideal feeding environment for flux feeding zooplankton. In the case of the WAP, fluxes were large and yet very little flux attenuation was observed with respect to depth.

Therefore, flux feeders must not be an important factor at this location.

The results presented here are consistent with prior studies of calculated remineralization length scales. Buesseler and Boyd (2009) compiled estimates of bacterial production rates (based on the thymidine incorporation method (Fuhrman and Azam 1982)) from four open ocean sites. They found an average $\mathrm{L}_{\text {remin }}$ of $500 \mathrm{~m}$, an intermediate value between to the two extreme end members of BATS and WAP. A recent study found that for laboratory produced aggregates, 
$\mathrm{L}_{\text {remin }}$ ranged from 330-500 m (Iversen and Ploug 2010). $\mathrm{L}_{\text {remin }}$ ranging from 50 to 20,000 m were reported by Iversen et al. (2010) as determined by laboratory experiments and analysis of particle abundances determined by in situ camera systems as a function of depth.

The discussion above focuses on explaining why the $\mathrm{L}_{\text {remin }}$ quantified was often shorter than the $\mathrm{L}_{\text {remin }}$ computed from flux profiles derived from sediment trap measurements. Conversely, some aspects of this methodology suggest that the computed remineralization length scale might actually be longer than those observed in the sediment trap fluxes. Since this was not the case, it is unlikely that these factors have a significant effect on the estimation of the remineralization length scale, but I discuss them below because they are important facts to consider in the interpretation of the RESPIRE data.

Firstly, because the RESPIRE traps only measure the respiration of particle attached microbes, these length scale calculations do not take into account the effects of zooplankton destruction of particles through swimming, or the consumption of particles at depth (Buesseler and Boyd 2009; Wilson et al. 2008). These processes are thought to be significant in many places throughout the oceans (Steinberg et al. 2008), and their effect would be to shorted the actual remineralization length scale relative to what would be measured by the RESPIRE traps.

Secondly, the lack of ambient fluid motion that the particles experience inside the RESPIRE trap could possibly lead to an underestimation of the carbon-specific remineralization rates. In these RESPIRE experiments, the particles settle onto the base plate of the incubation chamber and therefore are no longer in a state of perpetual sinking through the water column. Several studies have shown that the flow of seawater around sinking particles creates a microenvironment with an accelerated mass transfer between an aggregate and its surroundings (Kiørboe et al. 2001; Ploug 2001). The reduction in mass transfer of oxygen towards the particle in the RESPIRE traps may cause an underestimation of respiration rates if particle-attached microbes become oxygen limited while sitting on a surface and without the ambient fluid flow induced by sinking (Ploug and Jørgensen 1999). However, diffusion limitation of biological processes occurs only when the biological demand for oxygen at the surface of the aggregate exceeds the flux through the diffusive boundary layer. Iversen et al. (2010) found that even in stagnant conditions, the $\mathrm{O}_{2}$ concentration within the aggregates that they tested was $>90 \mu \mathrm{M}$ and therefore respiration was not diffusion limited. The rates measured at the BATS site were substantial, however, and suggested more rapid flux attenuation than actually observed. 
Finally, it is important to note that the RESPIRE traps do not account for the dissolution of dissolved organic matter that may be taking place via the ectoenzyme hydrolysis of POM (Smith et al. 1992). However, given the configuration of the instrument and the way it concentrates sinking particles in an enclosed volume of water, it is likely that DOC concentrations in the chamber are elevated above ambient levels. This could drive an increased activity of non-particle attached microbes in the water of the incubation chamber. In this manner, the values reported here would account for some of the solubilization processes if this DOC was subsequently respired by the microbes metabolizing the DOC released from the particles in the incubation chamber. Another consideration is the use of a fixed Redfield ratio for the respiration of this particulate organic matter. This assumes that the POC is fully converted into carbon dioxide, nitrate, and phosphate. If this reaction is incomplete, and the Redfield stoichiometric quantity of oxygen is not fully consumed, the POC consumption rate may be underestimated.

Despite the challenges of interpreting the RESPIRE results, the primary advantage of this instrument is that the incubations are conducted at in situ pressures and temperatures. As changes in pressure and temperature are known to affect microbial respiration and growth rates (Bartlett 2002), this type of approach could provide more realistic estimates of in situ respiration rates than those conducted as shipboard or laboratory experiments. Laboratory and shipboard experimentation does have the advantage of more sophisticated sampling techniques such as the use of microelectrodes and flow-through incubation chambers that allow for the maintenance of fluid flow around sinking particles. However, the incorporation of some of these advanced laboratory sampling schemes into in situ instrumentation would pose an immense technical challenge.

\section{Conclusions}

These results illustrate how particle-associated microbial activity and particle sinking velocities vary substantially between the subtropical Sargasso Sea and the polar/subpolar seas above the continental shelf of the WAP. The effect of temperature on microbial respiration rates was not sufficient to explain the magnitude of the differences between sites. This suggests that other factors such as the recalcitrant nature of the zooplankton fecal pellets and diatom aggregates along the WAP may play a role in inhibiting the effect of particle-attached microbial degradation on the sinking flux of particulate organic carbon. Moreover, the average sinking velocities of particles at the WAP were about five times faster than those measured in the Sargasso Sea. The 
average sinking velocities at WAP were fast enough to transport particles from the surface waters down to the sea floor on the continental shelf in a matter of only a couple of days, whereas the majority of particles in the Sargasso Sea would take over one week to reach the $500 \mathrm{~m}$ depth horizon, giving particle attached microbes more of an opportunity to consume and solubilize the sinking flux. These variations lead to clear distinctions in the efficiency of the biological pump at these two sites through their control on the length scale of remineralization. The combined measurements of the average sinking velocities and the carbon specific remineralization rates predict a much shorter $\mathrm{L}_{\text {remin }}$ than those measured by the drifting sediment traps at BATS in three of the four cases. This result was surprising given the fact that many of the potential biases of the RESPIRE trap methodology would likely lead to an overestimate of $\mathrm{L}_{\text {remin. }}$. This highlights the possible importance of the vertical shunt of carbon due to active vertical migration by zooplankton, accelerated microbial activity through quorum sensing, or the presence of significant proportions of slowly or non-sinking particulate matter in the water column.

These results provide an important new mechanistic view of the ocean's biological pump and one that is an essential step towards understanding how these systems modulate the global carbon cycle and how they might respond to and feedback into the changing climate. 


\section{References}

Alldredge, A. L., and C. C. Gotschalk. 1990. The relative contribution of marine snow of different origins to biological processes in coastal waters. Cont. Shelf Res 10: 41-58.

Alldredge, A. L., and M. J. Youngbluth. 1985. The significance of macroscopic aggregates(marine snow) as sites for heterotrophic bacterial production in the mesopelagic zone of the Subtropical Atlantic. Deep-Sea Research 32: 1445-1456.

Alonso-Gonzalez, I. J., J. Aristegui, C. Lee, A. Sanchez-Vidal, A. Calafat, J. Fabres, P. Sangr·, P. Masque, A. Hernandez-Guerra, and V. Benitez-Barrios. 2010. Role of slowly settling particles in the ocean carbon cycle. Geophys. Res. Lett. 37: L13608.

Anderson, L. A., and J. L. Sarmiento. 1994. Redfield ratios of remineralization determined by nutrient data analysis. Global Biogeochem. Cycles 8: 65-80.

Arístegui, J., S. Agustì, J. Middelburg, and C. Duarte. 2005. Respiration in the mesopelagic and bathypelagic zones of the ocean. Respiration in aquatic ecosystems: 181-205.

Armstrong, R. A., C. Lee, J. I. Hedges, S. Honjo, and S. G. Wakeham. 2001. A new, mechanistic model for organic carbon fluxes in the ocean based on the quantitative association of POC with ballast minerals. Deep-Sea Research II 2: 219-236.

Azam, F., and R. Long. 2001. Sea snow microcosms. Nature 414: 495-498.

Bartlett, D. H. 2002. Pressure effects on in vivo microbial processes. Biochimica et Biophysica Acta (BBA) - Protein Structure and Molecular Enzymology 1595: 367-381.

Berelson, W. 2001. The flux of particulate organic carbon into the ocean interior: a comparison of four US JGOFS regional studies. OCEANOGRAPHY-WASHINGTON DCOCEANOGRAPHY SOCIETY- 14: 59-67.

Boyd, P., M. Gall, and A. McDonnell. In Prep. RESPIRE (REspiration of Sinking Particles In the subsuRface ocEan) a joint particle interceptor and in situ incubator. . Limnology and Oceanography Methods.

Boyd, P., N. Sherry, J. Berges, J. Bishop, S. Calvert, M. Charette, S. Giovannoni, R. Goldblatt, P. Harrison, and S. Moran. 1999. Transformations of biogenic particulates from the pelagic to the deep ocean realm. Deep Sea Research Part II: Topical Studies in Oceanography 46: 2761-2792.

Buesseler, K. 1991. Do upper-ocean sediment traps provide an accurate record of particle flux? Nature 353: 420-423.

Buesseler, K., and P. Boyd. 2009. Shedding light on processes that control particle export and flux attenuation in the twilight zone of the open ocean. Limnol. Oceanogr 54: 1210-1232.

Buesseler, K. O., C. H. Lamborg, P. W. Boyd, P. J. Lam, T. W. Trull, R. R. Bidigare, J. K. B. Bishop, K. L. Casciotti, F. Dehairs, and M. Elskens. 2007. Revisiting Carbon Flux Through the Ocean's Twilight Zone. Science 316: 567.

Buesseler, K. O., A. M. P. McDonnell, O. M. E. Schofield, D. K. Steinberg, and H. W. Ducklow. 2010. High particle export over the continental shelf of the west Antarctic Peninsula. Geophys. Res. Lett.: (In Press).

Buesseler, K. O., D. K. Steinberg, A. F. Michaels, R. J. Johnson, J. E. Andrews, J. R. Valdes, and J. F. Price. 2000. A comparison of the quantity and composition of material caught in a neutrally buoyant versus surface-tethered sediment trap. Deep-Sea Research I 47: 277294.

Burd, A., D. Hansell, D. Steinberg, T. Anderson, J. ArÌstegui, F. Baltar, S. BeauprÈ, K. Buesseler, F. DeHairs, and G. Jackson. 2010. Assessing the apparent imbalance between geochemical and biochemical indicators of meso-and bathypelagic biological activity: 
What the@ \$! is wrong with present calculations of carbon budgets? Deep Sea Research Part II: Topical Studies in Oceanography 57: 1557-1571.

Chin-Leo, G., and D. L. Kirchman. 1988. Estimating Bacterial Production in Marine Waters from the Simultaneous Incorporation of Thymidine and Leucine. Applied and Environmental Microbiology 54: 1934-1939.

Conte, M. H., N. Ralph, and E. H. Ross. 2001. Seasonal and interannual variability in deep ocean particle fluxes at the Oceanic Flux Program (OFP)/Bermuda Atlantic Time Series (BATS) site in the western Sargasso Sea near Bermuda. Deep Sea Research Part II: Topical Studies in Oceanography 48: 1471-1505.

Dickey, T., S. Zedler, X. Yu, S. Doney, D. Frye, H. Jannasch, D. Manov, D. Sigurdson, J. McNeil, and L. Dobeck. 2001. Physical and biogeochemical variability from hours to years at the Bermuda Testbed Mooring site: June 1994-March 1998. Deep Sea Research Part II: Topical Studies in Oceanography 48: 2105-2140.

Ducklow, H., K. Baker, D. Martinson, L. Quetin, R. Ross, R. Smith, S. Stammerjohn, M. Vernet, and W. Fraser. 2007. Marine pelagic ecosystems: the West Antarctic Peninsula. Philosophical Transactions of the Royal Society B: Biological Sciences 362: 67.

Ducklow, H., M. Erickson, J. Kelly, R. C. Smith, S. E. Stammerjohn, M. Vernet, and D. M. Karl. 2008. Particle export from the upper ocean over the continental shelf of the west Antarctic Peninsula. Deep-Sea Research Part II 55 (accepted).

Ducklow, H. W., D. L. Kirchman, and G. T. Rowe. 1982. Production and Vertical Flux of Attached Bacteria in the Hudson River Plume of the New York Bight as Studied with Floating Sediment Traps. Applied and Environmental Microbiology 43: 769-776.

Francois, R., S. Honjo, R. Krishfield, and S. Manganini. 2002. Factors controlling the flux of organic carbon to the bathypelagic zone of the ocean. Global Biogeochemical Cycles 16: 1087.

Fraser, W., and W. Trivelpiece. 1996. Factors controlling the distribution of seabirds: wintersummer heterogeneity in the distribution of AdĖlie penguin populations. Foundations for ecological research west of the Antarctic Peninsula 70: 257-272.

Fuhrman, J. A., and F. Azam. 1982. Thymidine incorporation as a measure of heterotrophic bacterioplankton production in marine surface waters: Evaluation and field results. Marine Biology 66: 109-120.

Hansen, B., F. L. Fotel, N. J. Jensen, and S. D. Madsen. 1996. Bacteria associated with a marine planktonic copepod in culture. II. Degradation of fecal pellets produced on a diatom, a nanoflagellate or a dinoflagellate diet. J. Plankton Res. 18: 275-288.

Hmelo, L., and B. Van Mooy. 2009. Kinetic constraints on acylated homoserine lactone-based quorum sensing in marine environments. Aquat. Microb. Ecol 54: 127-133.

Howard, M. T., A. M. E. Winguth, C. Klaas, and E. Maier-Reimer. 2006. Sensitivity of ocean carbon tracer distributions to particulate organic flux parameterizations. Global Biogeochemical Cycles 20.

Iversen, M., and H. Ploug. 2010. Ballast minerals and the sinking carbon flux in the ocean: Carbon-specific respiration rates and sinking velocities of macroscopic organic aggregates (marine snow). BIogeosciences Discussion 7: 3335-3364.

Iversen, M. H., N. Nowald, H. Ploug, G. A. Jackson, and G. Fischer. 2010. High resolution profiles of vertical particulate organic matter export off Cape Blanc, Mauritania: Degradation processes and ballasting effects. Deep Sea Research Part I: Oceanographic Research Papers 57: 771-784.

Karl, D. M., G. A. Knauer, and J. H. Martin. 1988. Downward flux of particulate organic matter in the ocean: a particle decomposition paradox. Nature 332: 438-441. 
Kiørboe, T., H. Ploug, and U. H. Thygesen. 2001. Fluid motion and solute distribution around sinking aggregates. I. Small-scale fluxes and heterogeneity of nutrients in the pelagic environment. Marine Ecology Progress Series 211: 1-13.

Kwon, E. Y., F. Primeau, and J. L. Sarmiento. 2009. The impact of remineralization depth on the air-sea carbon balance. Nature Geosci 2: 630-635.

Lamborg, C., K. Buesseler, J. Valdes, C. Bertrand, R. Bidigare, S. Manganini, S. Pike, D. Steinberg, T. Trull, and S. Wilson. 2008. The flux of bio-and lithogenic material associated with sinking particles in the mesopelagic 'twilight zone' of the northwest and North Central Pacific Ocean. Deep-Sea Research Part II 55: 1540-1563.

Mayer, L. 1994. Surface area control of organic carbon accumulation in continental shelf sediments. Geochimica et Cosmochimica Acta 58: 1271-1284.

McDonnell, A. M. P., and K. O. Buesseler. 2010. Variability in the average sinking velocity of marine particles. Limnology and Oceanography 55: 2085-2096.

Michaels, A., and A. Knap. 1996. Overview of the US JGOFS Bermuda Atlantic Time-series Study and the Hydrostation S program. Deep Sea Research Part II: Topical Studies in Oceanography 43: 157-198.

Mincks, S., C. Smith, and D. DeMaster. 2005. Persistence of labile organic matter and microbial biomass in Antarctic shelf sediments: evidence of a sediment food bank. Marine Ecology Progress Series 300: 3-19.

Peterson, M., P. Hernes, D. Thoreson, J. Hedges, C. Lee, and S. Wakeham. 1993. Field evaluation of a valved sediment trap. Limnology and Oceanography 38: 1741-1761.

Ploug, H. 2001. Small-Scale Oxygen Fluxes and Remineralization in Sinking Aggregates. Limnology and Oceanography 46: 1624-1631.

Ploug, H., and H. Grossart. 1999. Bacterial production and respiration in suspended aggregates- a matter of the incubation method. Aquatic Microbial Ecology 20: 21-29.

Ploug, H., and H. P. Grossart. 2000. Bacterial Growth and Grazing on Diatom Aggregates: Respiratory Carbon Turnover as a Function of Aggregate Size and Sinking Velocity. Limnology and Oceanography 45: 1467-1475.

Ploug, H., H. P. Grossart, F. Azam, and B. B. Joergensen. 1999. Photosynthesis, respiration, and carbon turnover in sinking marine snow from surface waters of Southern California Bight: implications for the carbon cycle in the ocean. Marine Ecology Progress Series 179: $1-11$.

Ploug, H., and B. Jørgensen. 1999. A net-jet flow system for mass transfer and microsensor studies of sinking aggregates. Marine Ecology Progress Series 176: 279.

Siegel, D. 2008. Satellite and in situ observations of the bio-optical signatures of two mesoscale eddies in the Sargasso Sea. Deep Sea Research Part II: Topical Studies in Oceanography 55: $1218-1230$.

Simon, M., A. L. Alldredge, and F. Azam. 1990. Bacterial carbon dynamics on marine snow. Mar. Ecol. Prog. Ser 65: 205-211.

Simon, M., H. Grossart, B. Schweitzer, and H. Ploug. 2002. Microbial ecology of organic aggregates in aquatic ecosystems. Aquatic Microbial Ecology 28: 175-211.

Smith, D. C., M. Simon, A. L. Alldredge, and F. Azam. 1992. Intense hydrolytic enzyme activity on marine aggregates and implications for rapid particle dissolution. Nature 359: 139142.

Steinberg, D., B. Van Mooy, K. Buesseler, P. Boyd, T. Kobari, and D. Karl. 2008. Bacterial vs. zooplankton control of sinking particle flux in the ocean's twilight zone. Limnology and Oceanography 53: 1327-1338. 
Steinberg, D. K., C. A. Carlson, N. R. Bates, R. J. Johnson, A. F. Michaels, and A. H. Knap. 2001a. Overview of the US JGOFS Bermuda Atlantic Time-series Study (BATS): a decade-scale look at ocean biology and biogeochemistry. Deep Sea Research Part II: Topical Studies in Oceanography 48: 1405-1447.

---. 2001b. Overview of the US JGOFS Bermuda Atlantic Time-series Study(BATS): a decadescale look at ocean biology and biogeochemistry. Deep-Sea Research(Part II, Topical Studies in Oceanography) 48: 1405-1447.

Turley, C., and E. Stutt. 2000. Depth-related cell-specific bacterial leucine incorporation rates on particles and its biogeochemical significance in the Northwest Mediterranean. Limnology and Oceanography 45: 419-425.

Turner, J., and J. Ferrante. 1979. Zooplankton fecal pellets in aquatic ecosystems. BioScience 29: 670-677.

Volk, T., and M. I. Hoffert. 1985. Ocean carbon pumps-Analysis of relative strengths and efficiencies in ocean-driven atmospheric $\mathrm{CO} 2$ changes. IN: The carbon cycle and atmospheric CO2: Natural variations archean to present; Proceedings of the Chapman Conference on Natural Variations in Carbon Dioxide and the Carbon Cycle, Tarpon Springs, FL, January 9-13, 1984 (A86-39426 18-46). Washington, DC, American Geophysical Union, 1985, p. 99-110.

Wilson, S., D. Steinberg, and K. Buesseler. 2008. Changes in fecal pellet characteristics with depth as indicators of zooplankton repackaging of particles in the mesopelagic zone of the subtropical and subarctic North Pacific Ocean. Deep Sea Research Part II: Topical Studies in Oceanography 55: 1636-1647. 
Table 1. Comparison of carbon-specific remineralization rates and flux weighted average sinking velocities by deployment at BATS and the WAP. The remineralization length scale is computed by dividing the flux-weighted average sinking velocities by the carbon specific remineralization rates. While the trap-based remineralization length scales are the lengths required to optimally fit the sediment trap flux data.

\begin{tabular}{|c|c|c|c|c|c|c|c|c|c|c|c|c|c|}
\hline \multirow{2}{*}{$\frac{\text { Dates }}{12-14 \text { Nov. } 2008}$} & \multirow{2}{*}{$\begin{array}{l}\begin{array}{l}\text { Depth } \\
\text { (m) }\end{array} \\
150\end{array}$} & \multirow{2}{*}{$\begin{array}{l}\text { Locatio } \\
\text { n } \\
\text { BATS }\end{array}$} & \multirow[t]{2}{*}{$\begin{array}{l}\text { C resp. } \\
\text { rate } \\
(\boldsymbol{\mu m o l} \\
\left.\mathbf{C ~ d}^{-1}\right)^{1} \\
9\end{array}$} & \multirow[t]{2}{*}{$\begin{array}{l}\text { C } \\
\text { collected } \\
\text { in trap } \\
(\boldsymbol{\mu m o l ~ C )}\end{array}$} & \multicolumn{3}{|c|}{$\begin{array}{l}\text { Carbon specific } \\
\text { remin. Rate, } R_{C} \\
\left(d^{-1}\right)\end{array}$} & \multicolumn{3}{|c|}{$\begin{array}{l}\text { Flux weighted } \\
\text { average sinking } \\
\text { velocity, } W_{\text {avg }}(\mathrm{m} \\
\left.\mathrm{d}^{-1}\right)\end{array}$} & \multicolumn{2}{|c|}{$\begin{array}{l}\text { Remin. } \\
\text { Length Scale, } \\
\mathbf{L}_{\text {remin }}(\mathbf{m}) \\
\end{array}$} & \multirow[t]{2}{*}{$\begin{array}{l}\text { Trap- } \\
\text { based } \\
\text { remin. } \\
\text { length } \\
\text { scale }(\mathrm{m}) \\
\end{array}$} \\
\hline & & & & & 0.52 & \pm & 0.10 & & & & & & \\
\hline 14-16 July 2009 & 200 & BATS & 35 & 70 & 0.49 & \pm & 0.09 & 13 & \pm & 0.9 & 26 & \pm 5 & 250 \\
\hline 10-12 Sept. 2009 & 200 & BATS & 16 & 63 & 0.25 & \pm & 0.05 & 90 & \pm & 3.9 & 355 & $\pm \quad 70$ & 293 \\
\hline 21-23 Sept. 2009 & 200 & BATS & 6 & 35 & 0.18 & \pm & 0.04 & 23 & \pm & 0.9 & 127 & $\pm \quad 28$ & 527 \\
\hline \multirow[t]{2}{*}{ 25-27 Sept. 2009} & 200 & BATS & 48 & 45 & 1.07 & \pm & 0.20 & 71 & \pm & 2.3 & 66 & $\pm \quad 13$ & 633 \\
\hline & & $\begin{array}{r}\text { Avg. } \\
\text { BATS }\end{array}$ & 23 & 46 & 0.50 & \pm & 0.35 & 49 & \pm & 37 & 98 & $\pm \quad 100$ & \\
\hline 8-10 Jan. 2009 & 50 & PS1 & BDL & 291 & BDL & & & 91 & \pm & 20 & & $\operatorname{Inf}$ & \\
\hline 23-25 Feb. 2009 & 100 & PS2 & BDL & 37 & BDL & & & 112 & \pm & 21 & & Inf & \\
\hline \multirow[t]{2}{*}{ 5-7 March 2009} & 50 & PS1 & BDL & 158 & BDL & & & 620 & \pm & 244 & & $\operatorname{Inf}$ & \\
\hline & & $\begin{array}{r}\text { Avg. } \\
\text { WAP }\end{array}$ & BDL & 162 & BDL & & & 274 & \pm & 300 & & $\operatorname{Inf}$ & \\
\hline
\end{tabular}

\footnotetext{
${ }^{1}$ Calculated as $\left(r_{\text {exp }}-r_{\text {control }}\right) \mathrm{V}_{\text {inc }} v_{\mathrm{C}: 02}$, which is the numerator of Equation 1
} 




Figure 1. Schematic drawing of the RESPIRE apparatus used to incubate sinking particles and measure the rates of particle-attached microbial respiration. 
12-14 Nov. 2008
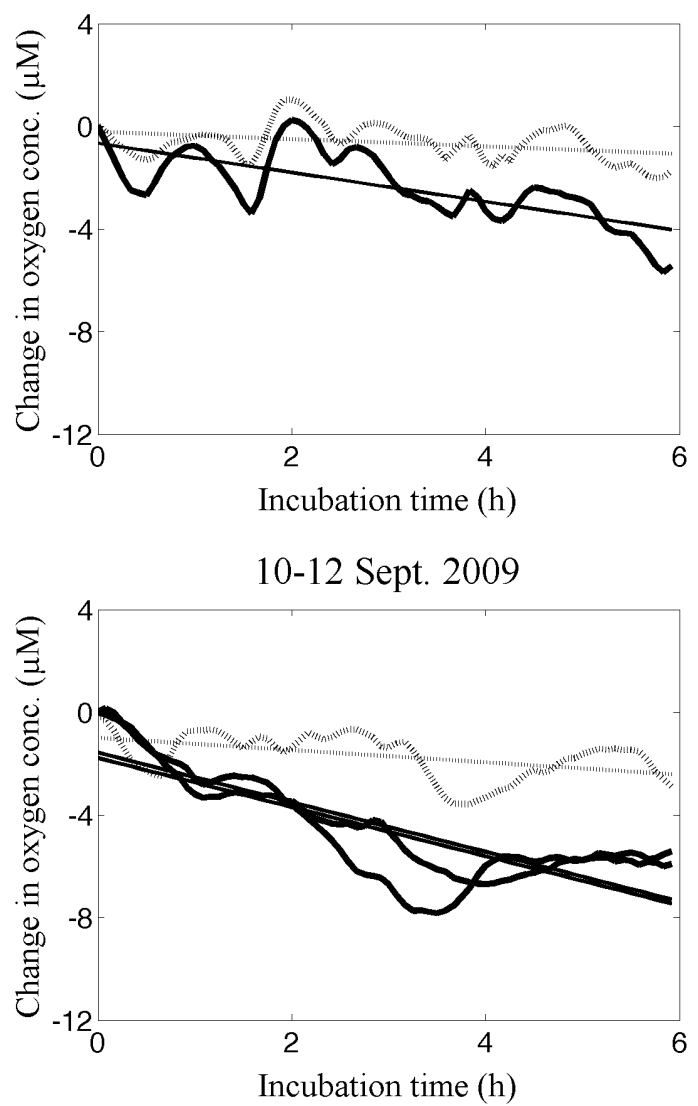

25-27 Sept. 2009

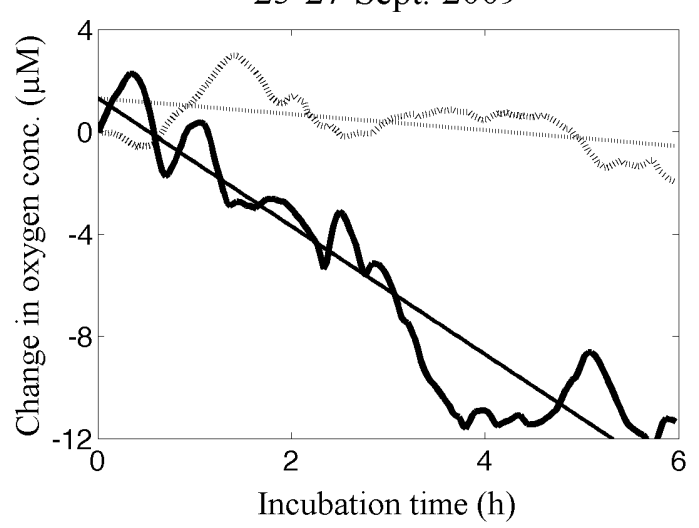

14-16 July 2009



21-23 Sept. 2009

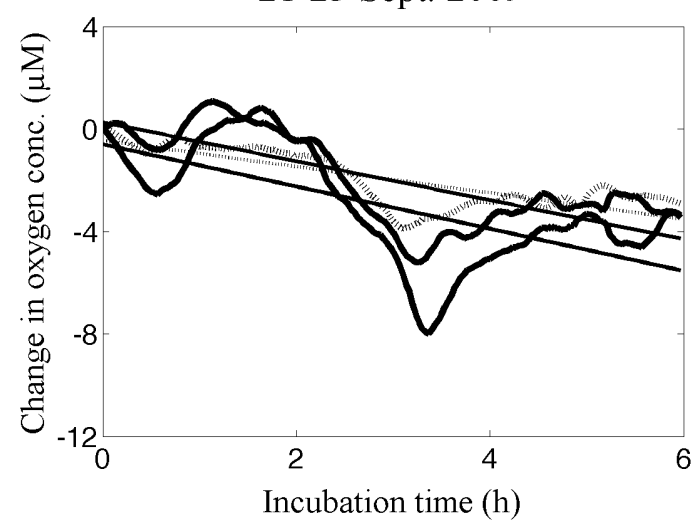

Figure 2. Selected results from RESPIRE experiments conducted at the BATS site. Plotted are the changes in oxygen concentrations that occurred during the incubation phases of the experiments. The gray lines indicate the oxygen changes in the $10 \mu \mathrm{m}$ mesh-covered (particle excluding) control. The solid lines are the oxygen changes in the particle collecting RESPIRE traps. 
8-10 Jan. 2009

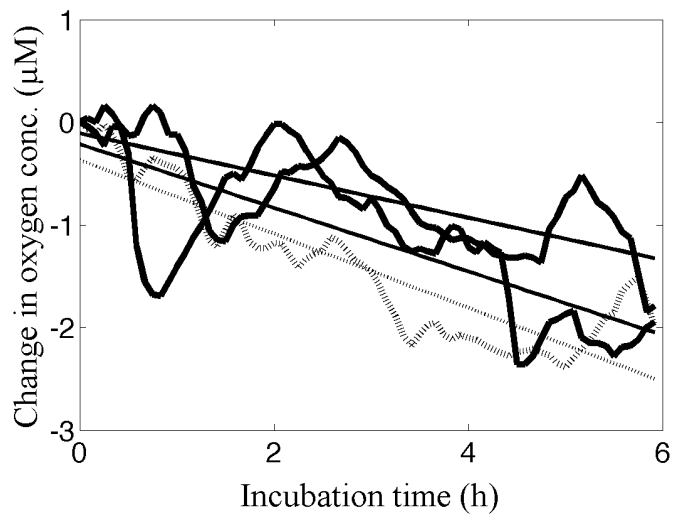

5-7 March 2009

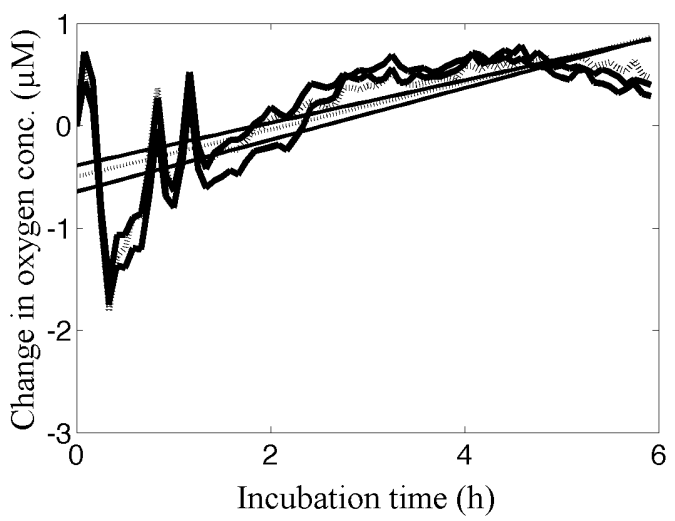

23-25 Feb. 2009

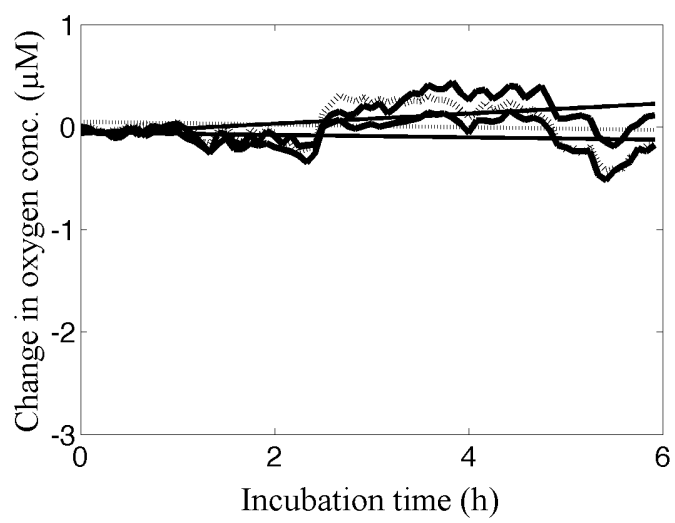

Figure 3. Selected results from RESPIRE experiments conducted along the WAP. Plotted are the changes in oxygen concentrations that occurred during the incubation phases of the experiments. The shaded lines indicate the oxygen changes in the $10 \mu \mathrm{m}$ mesh-covered (particle excluding) control. The solid lines are the oxygen changes in the particle collecting RESPIRE traps. The January and March deployments took place at the PAL trap site, while the February deployment was conducted at the mouth of Marguerite Bay. Note the vertical scale is greatly enlarged relative to those in Figure 2. 
(A)

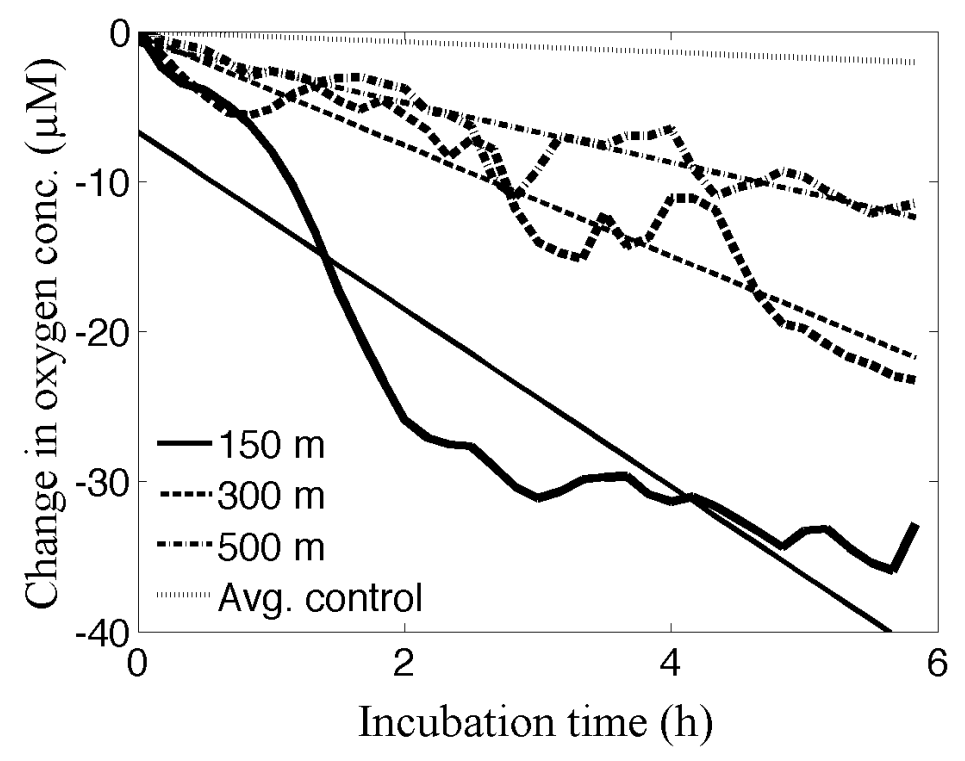

(B)

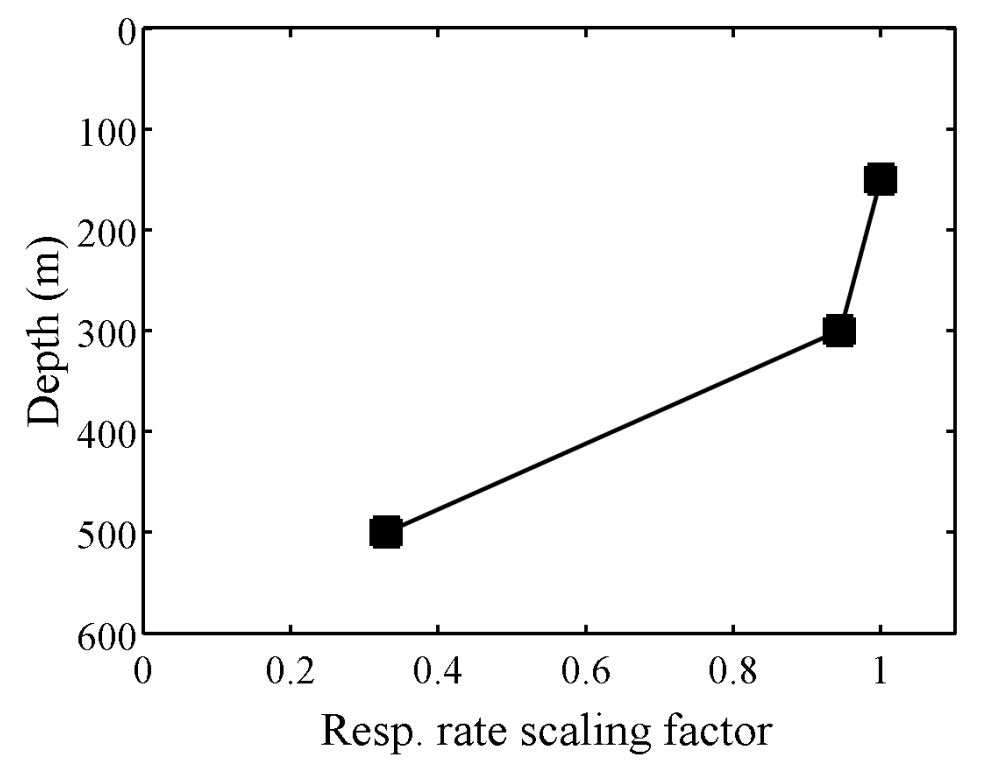

Figure 4. (A) Oxygen drawdown in RESPIRE traps deployed at 3 depths throughout the mesopelagic zone at the BATS station in April 2008. (B) The ratio of the carbon-specific respiration rates relative to the rate measured at the upper $150 \mathrm{~m}$ trap depth at BATS (solid boxes). The solid lines are the linearly interpolated scaling factor that was used to compute the model fluxes in Figure 5. 



Figure 5. Particulate carbon fluxes plotted as a function of depth for both the BATS sites. These squares represent the measurements made with drifting sediment traps. The curves plot the flux attenuation profiles modeled from measurements of the flux weighted average sinking velocities and carbon specific microbial respiration rates. 



Figure 6. Carbon fluxes plotted versus depth for the three deployments along the WAP (squares). The solid curve represents the attenuation of flux that would be expected from the combined average sinking velocities and carbon specific microbial respiration rates measured in this study. In this case, since microbial respiration rates were undetectable, the predicted flux was constant with respect to depth. 


\section{Chapter SiX}

\section{Conclusions and future directions}




\section{Summary of findings}

In this thesis, I addressed some of the unknown rates and attributes important to the ocean's biological pump. This was accomplished by utilizing new instruments and methods to quantify and describe the key properties of particle concentrations, size distributions, fluxes, and the rates of particle attached microbial respiration. The results from multiple research cruises along the Western Antarctic Peninsula (WAP) and the Sargasso Sea provided two contrasting case studies that elucidate the function of the biological pump.

By comparing the particle size distribution of the flux and concentration, I was able to calculate the average sinking velocities of particles as a function of their equivalent spherical diameter. This methodology is a powerful new approach that enabled the assessment of the spatial and temporal variability of average particle sinking velocities. I found that particle sinking velocities were often significantly faster along the WAP compared to those in the Sargasso Sea. This is likely due to the difference in the nature of the particles present at each site. Along the WAP, fluxes were dominated by rapidly sinking krill fecal pellets and diatom aggregates, whereas in the Sargasso Sea, the particles consisted primarily of small heterogeneous marine snow aggregates with slow sinking velocities. The magnitudes of the sinking velocities here were especially dependent upon presence of krill fecal pellets. The disappearance of this particle type during a repeat occupation of one station in Marguerite Bay resulted in a sharp decline in the average sinking velocities, especially for the larger size classes. Moreover, the average sinking velocity did not follow a pattern of increasing velocities for the larger particles, a result contrary to what would be predicted from a simple formulation of Stokes' Law. Because many ocean biogeochemical models work in terms of particle concentrations, average sinking velocities such as those presented here are crucial to converting those stocks into fluxes. From an observational point of view, it is much easier to measure the concentration size distribution of particles than it is to measure the flux, so knowledge of the average sinking velocities are useful for converting these concentrations to fluxes.

Drifting sediment traps were deployed to assess both the bulk particle flux and the size distribution of the particle flux via image analysis of particles collected in polyacrylamide gel traps. In the Sargasso Sea, particle fluxes ranged from about 1-5 mmol C m $\mathrm{m}^{-2} \mathrm{~d}^{-1}$ and attenuated steadily between 200 and $500 \mathrm{~mm}$ depth. Along the WAP, fluxes were 2-26 $\mathrm{mmol} \mathrm{C} \mathrm{m}^{-2} \mathrm{~d}^{-1}$ and showed no consistent pattern of declining particle flux with respect to depth. I derived a best-fit fractal correlation between the flux size distribution and the total carbon flux for both the WAP 
and the Sargasso Sea and found them to be remarkably different. The parameters derived from this exercise provided information on the fractal dimension of the particles and their carbon density. The use of this relationship and the computed average sinking velocities enabled the estimation of particle flux from measurements of the particle concentration size distribution. This approach offers greatly improved spatial and temporal resolutions when compared to traditional sediment trap methods for measuring the downward flux of particulate matter. Maps of particle concentrations and flux from both WAP and the Sargasso Sea reveal a high degree of variability over short distances, depths and times.

Finally, I deployed specialized in situ incubation chambers (RESPIRE traps) to assess the respiration rates of microbes attached to sinking particles. In the Sargasso Sea, the carbon specific remineralization rate of sinking particulate matter ranged from 0.2 to $1.1 \mathrm{~d}^{-1}$, while along the WAP, these rates were very slow and below the detection limit of the instruments. These differences could be partially due to the lower temperatures and therefore retarded rates of microbial activity along the WAP, however the temperature difference between the two sites is not enough to account for the large differences. The tightly packed fecal pellets and the mineralprotected carbon of the diatom aggregates of the WAP are likely another mechanism that slows remineralization rates at WAP vs. BATS. The high microbial respiration rates and slow sinking velocities in the Sargasso Sea resulted in the strong attenuation of the flux with respect to depth, whereas the rapid sinking velocities and slow microbial degradation rates of the WAP resulted in nearly constant fluxes with respect to depth.

\section{Future directions}

The findings of this thesis offer new insights into the dynamics of the ocean's biological pump. At the same time, they also raise new questions and open new doors to further research on the subject.

The observed variability in the average sinking velocity was an important finding but because the measured sinking velocities were quite different between deployments, locations, and depths, it is highly likely that the measurements presented here do not capture the full variability of sinking velocities with respect to time and place. Further work is needed to determine the relationship between the particle size distribution of the flux and concentrations and establish the factors that influence these relationships. Based on the findings of this thesis, I expect that further work into the identification, categorization, and quantitative description of particles captured via 
in situ imagery will be useful for deriving a mechanistic understanding of the factors that influence the average sinking velocity. The assumption here is that particles of a given type and size will have predictable sinking velocities. If this proves to be true, it could explain the observed variability in the average sinking velocities and possibly enable the prediction of the average sinking velocities by simply assessing the types and sizes of particles in the water column. Once these relationships are determined, this approach would avoid the necessity of deploying many sediment traps for the purpose of comparing the size distributions of the flux and concentration, instead allowing for an emphasis on the sampling of the particle distributions with underwater particle cameras.

Advances in digital image technology and underwater instrumentation over the past decade have made possible many aspects of this thesis. But the current technology still only provides limited information about the ocean's biological pump. Particle sizes and abundances in the ocean span several orders of magnitude. As a result, one of central challenges to the accurate quantification of the particle concentration size distribution is the competing concerns of enumerating and identifying the smallest particles while imaging a large enough volume to detect the abundances of the largest and most rare particles. Current instruments must compromise either the size range of particles sampled or the accuracy of the measured concentration of large particles. The way to push the limits of particle detection would be to incorporate the use of high definition cameras and hardware assisted image analysis. This would allow for large image volumes while still capturing the smallest particles important to particle flux. The increase in resolution would significantly increase the computational and storage burden of the image analysis, but this could be ameliorated by conducting the image processing with custom computer boards in real time aboard the instrument. It is also crucial that oceanographers find ways to increase the sampling density of measurements such as underwater particle camera data. This can be accomplished by merging imaging technology with existing sampling platforms such as the standard CTD package aboard research vessels. This approach would reduce the necessity for additional ship time. Incorporation of underwater particle cameras with robotic technology such as autonomous gliders, floats and profiling moorings would dramatically increase our observational capabilities and undoubtedly provide new insights into the workings of the ocean's biological pump.

The spatial maps of particle concentration, flux, and sinking velocity presented in this thesis provide important insights into the nature of particle processes in the ocean. Further work 
will be required to elucidate the causes and mechanisms of this variability. At this point, the linkages between particle flux processes and primary production, community structure, community succession, zooplankton patchiness, and physical features in the ocean are still poorly understood. It is this level of understanding that will be necessary to predict the effect of global change on the ocean's biological pump and determine how this process will act as a feedback mechanism on the pace and nature of these complex changes. 


\section{APPENDIX I \\ High particle export over the continental shelf of the west Antarctic Peninsula}

Ken O. Buesseler ${ }^{1}$, Andrew M. P. McDonnell ${ }^{1}$, Oscar M.E. Schofield ${ }^{2}$, Deborah K. Steinberg ${ }^{3}$, and Hugh W. Ducklow ${ }^{4}$

This manuscript is reproduced here by permission of the American Geophysical Union and the consent of the co-authors.

Citation: Buesseler, K. O., A. M. P. McDonnell, O. M. E. Schofield, D. K. Steinberg, and H. W. Ducklow (2010), High particle export over the continental shelf of the west Antarctic Peninsula, Geophys. Res. Lett., 37, L22606, doi:10.1029/2010GL045448.

\footnotetext{
${ }^{1}$ Woods Hole Oceanographic Institution, Woods Hole MA 02543

${ }^{2}$ Institute of Marine and Coastal Sciences, Rutgers University, New Brunswick, NJ 08901

${ }^{3}$ Virginia Institute of Marine Science, Gloucester Pt, VA 23062

${ }^{4}$ The Ecosystems Center, Marine Biological Laboratory, Woods Hole, MA 02543
} 


\begin{abstract}
Drifting cylindrical traps and the flux proxy ${ }^{234} \mathrm{Th}$ indicate more than an order of magnitude higher sinking fluxes of particulate carbon and ${ }^{234} \mathrm{Th}$ in January 2009 than measured by a time-series conical trap used regularly on the shelf of the west Antarctic Peninsula (WAP). The higher fluxes measured in this study have several implications for our understanding of the WAP ecosystem. Larger sinking fluxes result in a revised export efficiency of at least $10 \%$ (C flux/net primary production) and a requisite lower regeneration efficiency in surface waters. High fluxes also result in a large supply of sinking organic matter to support subsurface and benthic food webs on the continental shelf. These new findings call into question the magnitude of seasonal and interannual variability in particle flux and reaffirm the difficulty of using moored conical traps as a quantitative flux collector in shallow waters.
\end{abstract}

\title{
Introduction
}

The coastal zone and sea-ice margins of Antarctica exhibit high and variable rates of primary production [Vernet et al., 2008]. This high production is important as the base of a food web for top predators [Knox, 2006], for its support of a rich benthos [Smith et al., 2006], and for balancing a microbial demand for labile organic matter [Ducklow et al., 2006]. In order to determine this region's role in the global carbon cycle and the Antarctic marine food web, it is necessary to make accurate measurements of particulate carbon (PC) fluxes. Unfortunately, the study of PC fluxes off Antarctica is complicated by its remote location, harsh conditions, sea ice, export variability in space and time, and by the limited tools we have to study the transfer of organic matter produced in the euphotic zone to the seafloor. Given these substantial impediments, few measurements of sinking PC fluxes have been made in this region and, as a result, the fate of the WAP's high phytoplankton production is poorly understood and quantified.

Our present view of the WAP's biogeochemical function, variability, and ongoing changes is derived in large part from the Palmer Long-Term Ecological Research Project (PAL) which has provided a detailed time-series of observations of the marine ecosystem since 1990 [Ducklow, 2008]. As part of this program, sinking PC fluxes have been measured at $170 \mathrm{~m}$ depth with the use of a bottom-moored time-series sediment trap. These measurements have revealed the extreme seasonality of the $\mathrm{C}$ cycle at this location, with $\mathrm{PC}$ fluxes varying four orders of magnitude between the ice-covered winters and the moderately productive summers. The peak of the annual flux is also now occurring about 40 days later in the season than it did at the beginning 
of the record. Curiously, however, the mean annual flux derived from the PAL trap suggests an extremely low annual export ratio (e-ratio = trap flux/net primary productivity) averaging $<4 \%$ between 1992-2007 [Ducklow et al., 2008]. These e-ratios are much lower than what would be expected from a high-latitude ecosystem like the WAP, which is dominated by quickly-sinking diatom aggregates and krill fecal pellets [McDonnell and Buesseler, 2010]. This low e-ratio severely complicates our understanding and interpretation of the ecosystem function and carbon cycling along the WAP [e.g. Ducklow et al., 2008]. With the rapid warming [Vaughan et al., 2003] and associated changes in ecosystem structure and function [Montes-Hugo et al., 2008] that are already being observed in this sensitive region, it is imperative that we resolve export fluxes.

In this study, we present a new set of upper ocean particle flux measurements collected during a singular intercomparison opportunity conducted in January 2009 along the WAP. We conducted three independent measurements of particle flux using two trap designs as well as the particle flux proxy, thorium-234. Our results suggest that PC fluxes are more than an order of magnitude larger than those determined by the ongoing and multidecadal measurements of flux from a moored time-series sediment trap at this site. While the data are from a single set of observations in the WAP, we discuss how these new estimates have significant implications for our understanding of the magnitude, efficacy and function of the biological pump in this region.

\section{Methods}

Three independent methods were used to quantify sinking particle fluxes at $64^{\circ} 30^{\prime} \mathrm{S}$ latitude, $66^{\circ} 00^{\prime} \mathrm{W}$ longitude, $130 \mathrm{~km}$ off shore on the continental shelf of the WAP. The first method was a moored conical shaped time-series trap (PARFLUX Mark 78H, 21 sample cup, McLane Research Lab) that has been deployed annually as part of PAL since 1992 [Ducklow et al., 2008]. Sample cups were filled with buffered brine and formalin as a preservative and swimmers were removed under a microscope. The moored trap at $170 \mathrm{~m}$ (350 m water depth) was recovered January 10, 2009 after a one year deployment and ${ }^{234} \mathrm{Th}$ was analyzed immediately at sea on 1/8th splits of the 5 most recent sampling cups (programmed for 6-8 day intervals during peak flux periods, December 6, 2008 - January 10, 2009). These splits were later analyzed for PC as described below for the drifting traps. A parallel set of sample splits was analyzed for organic carbon after acid fuming to remove carbonate.

The second method was a surface-tethered, drifting cylindrical trap array deployed at the same site for 1.5 days between January 8-10, 2009 following Lamborg et al. [2008]. Trap tubes 
were deployed at $150 \mathrm{~m}$ with brine and formalin, and swimmers were removed under a microscope. Sample analyses for ${ }^{234} \mathrm{Th}$ on both traps were performed as described in Lamborg et al. [2008]. Carbon analyses at the Woods Hole Oceanographic Institution (WHOI) did not include acid fuming, however these should be equivalent to fumed samples since carbonate was $<2 \%$ of total PC at $500 \mathrm{~m}$ in a nearby trap [Planques, et al., 2002] and expected to be even less in shallow traps. Thus, we use PC to refer to both moored trap POC and drifting trap C fluxes, reported here in units of $\mathrm{mmol} \mathrm{C} \mathrm{m}^{-2} \mathrm{~d}^{-1}$.

The third method relied on the particle-reactive and naturally occurring radionuclide, thorium-234 (half-life 24.1 days), which has been widely used as a particle flux proxy [Waples et al., 2006]. In general, lower ${ }^{234} \mathrm{Th}$ activities relative to its conservative parent, ${ }^{238} \mathrm{U}$, indicate a higher export flux of particles. Total ${ }^{234}$ Th samples (4 L) were collected with the CTD/Rosette and analyzed via methods described in Pike et al. [2005]. Uranium-238 is determined by its constant relationship with salinity [Rutgers van der Loeff et al., 2006]. The flux of ${ }^{234} \mathrm{Th}$ is determined by a simple 1-D steady-state model [Savoye et al., 2006]. In 2009, we measured total

${ }^{234} \mathrm{Th}$ at 10 depths in the upper $250 \mathrm{~m}$ in profiles collected within $1 \mathrm{~km}$ of the drifting trap site on January 8, 9, and 11, 2009 and report fluxes from those profiles calculated at $150 \mathrm{~m}$ in units of $\mathrm{dpm} \mathrm{m} \mathrm{m}^{-2} \mathrm{~d}^{-1}$

We also use the ${ }^{234}$ Th flux approach to determine PC fluxes by multiplying the ${ }^{234} \mathrm{Th}$ flux by the $\mathrm{C} /{ }^{234} \mathrm{Th}$ ratio on particles [Buesseler et al., 2006]. The $\mathrm{C} /{ }^{234} \mathrm{Th}$ ratio was determined here on three different sets of samples: the two trap systems and also particles collected via a large volume in-situ pumping system at $150 \mathrm{~m}$ on January 9 th. That system filtered approximately 1000 liters sequentially through a $53 \mu \mathrm{m}$ and $10 \mu \mathrm{m}$ screen (142 mm diameter), which were then processed for ${ }^{234} \mathrm{Th}$ and $\mathrm{PC}$, identical to the drifting trap samples.

\section{Results}

Particle fluxes measured with the moored trap indicate substantially lower flux than measured by the drifting trap and as calculated from ${ }^{234} \mathrm{Th}$ profiles (Figure 1). On average, the moored trap fluxes are a factor of 30 lower than the drifting trap fluxes for both $\mathrm{PC}$ and ${ }^{234} \mathrm{Th}$ (Table 1). The low flux in the moored trap cannot be attributed to an anomalously low flux in the last moored trap cup (January 3-10), as the fluxes were similarly low in all of the 5 cups between December 6 - January 10 (Table 1). For the drifting trap, replicate tubes agreed within 13\% for fluxes of both PC $\left(8.2 \mathrm{mmol} \mathrm{C} \mathrm{m}^{-2} \mathrm{~d}^{-1}\right)$ and ${ }^{234} \mathrm{Th}\left(2600 \mathrm{dpm} \mathrm{m}^{-2} \mathrm{~d}^{-1}\right)$. 
The estimate of ${ }^{234} \mathrm{Th}$ fluxes derived from the total ${ }^{234} \mathrm{Th}$ profiles $\left(1640 \mathrm{dpm} \mathrm{m} \mathrm{m}^{-2}\right)$ are in closer agreement with the drifting trap and on average about 20 times greater than the moored trap (Figure 1). The variability in ${ }^{234} \mathrm{Th}$ flux predicted from each of the three different profiles is small $( \pm 23 \%)$. PC fluxes can be calculated from the ${ }^{234} \mathrm{Th}$ flux derived from the water column data and an estimate of the $\mathrm{C} /{ }^{234} \mathrm{Th}$ ratio of sinking particles. We measured a similar $\mathrm{C} /{ }^{234} \mathrm{Th}$ ratio

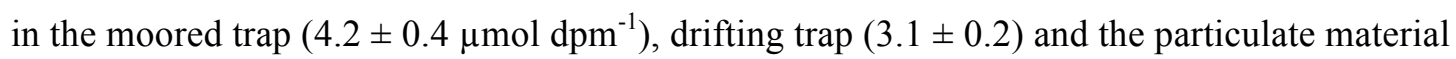
collected via in situ pumps screens as the $>53 \mu \mathrm{m}(3.6 \pm 0.1)$ or $10-53 \mu \mathrm{m}$ size fractions $(3.2 \pm$ 0.1 ). No matter which ratio is used, the PC flux thus calculated is 18 to 25 times greater than found in the moored trap, indicating a similar PC collection bias as found for the two trap comparison.

\section{Discussion}

Two decades ago Karl et al. [1991] stated: "Very little is known about the immediate fate of the Antarctic phytoplankton production". Despite some progress, our understanding of upper ocean export in the Antarctic remains limited not only because of the remote location and harsh sampling conditions, but also as we show here, due to important methodological issues. Time-series moored conical sediment traps are ideal for capturing the seasonal pattern of sedimentation in the deep sea and allow unattended sampling during ice-covered periods. However, biases in applying these traps as quantitative collectors in the upper ocean need to be considered [Gardner, 2000; Buesseler et al., 2007]. This applies not just to the WAP, but also to other polar coastal waters and shelves, and in general to other upper-ocean settings.

The (20-30x) higher PC and ${ }^{234} \mathrm{Th}$ flux in the surface-tethered drifting trap relative to the moored trap is supported by three water column profiles of ${ }^{234} \mathrm{Th}$ at the same site. These measurements result in computed ${ }^{234} \mathrm{Th}$ fluxes that are also more than an order of magnitude higher than in the moored trap. While the comparison between sediment trap ${ }^{234} \mathrm{Th}$ fluxes and fluxes estimated from a model of water column ${ }^{234} \mathrm{Th}$ data has its limitations [Buesseler et al., 2009; Cochran et al., 2009; Savoye et al., 2006], a difference this large is hard to interpret other than as a large under-collection bias by the moored trap.

Unfortunately, there are no other trap data for direct comparison from this site during its 17-year operation, but we can compare to a site $25 \mathrm{~km}$ away, where ${ }^{234} \mathrm{Th}$ fluxes at the seafloor derived from sediment inventories during different seasons and years were 400 to $2600 \mathrm{dpm} \mathrm{m}^{-2}$ $\mathrm{d}^{-1}$ [McClintic, et al., 2008]. Fluxes of $<100 \mathrm{dpm} \mathrm{m}^{-2} \mathrm{~d}^{-1}$ as seen in all 5 cups of our moored trap 
do not match this sedimentary data. Although several hundreds of kilometers to the northeast and in more protected and coastal waters, two previous studies also deployed drifting cylindrical traps in the Gerlach and Bransfield Straits, and thus permit a generalized comparison to the fluxes we measured at the PAL trap site. The first study in 1986 found fluxes of 4 to $>30 \mathrm{mmol} \mathrm{C} \mathrm{m}^{-2} \mathrm{~d}^{-1}$ at $100 \mathrm{~m}$ in December through March [Karl et al., 1991]. Another group in 1995 measured 10-60


more than an order of magnitude higher than the PAL moored trap, and even several-fold higher than our drifting traps that are further offshore.

We know from other studies that there are multiple reasons why conical traps may undercollect sediment fluxes [Buesseler et al., 2007]. First among the possible causes is trap hydrodynamics, whereby horizontal flow over the trap mouth makes these traps susceptible to collection biases due to resuspension of material before it reaches the trap cup. This is a greater concern in conical than cylindrical sediment traps [Gardner, 2000] and in the upper ocean in general where currents are faster. These hydrodynamic effects are difficult to separate from other possible collection biases, such as solubilization or loss of particulate material after collection, which is greater in longer deployments and at shallower depths [Antia, 2005]. Another factor that may contribute to lower fluxes is consumption of detrital particles by zooplankton feeding along the walls of a conical trap.

The significance of the higher fluxes to the WAP ecosystem is profound for many reasons. First, one measure of the strength of the biological pump is the export efficiency, or ratio of flux to primary production. Our export ratio in January at $150 \mathrm{~m}$ is $10 \%$ for the drifting trap (Table 1). In contrast, the moored trap would indicate an e-ratio in January 2009 of $0.3 \%$ which seems unreasonably low for a site dominated by a short food chain with large diatoms and krill. Using a one-month lag between peak productivity and export, Ducklow et al. [2008] calculated eratios for the moored trap ranging from $0.3 \%$ to $2.6 \%$ between 1992-2007 (with one exception of $28 \%$ in $2002 / 2003$ when primary production was extremely low). Such a low export ratio is equivalent or lower than seen in oligotrophic settings such as the Bermuda Atlantic Time-series Study site [Steinberg et al., 2001].

We believe that the higher e-ratios as seen in the drifting trap and as derived from ${ }^{234} \mathrm{Th}$ during January 2009 are more likely to be characteristic of this WAP region. In fact, our e-ratios may be an underestimate of the seasonal average because they are a snapshot of conditions prior to expected peak flux periods. Anadón et al. [2002] estimate a regional PC e-ratio of $26 \%$ at 60 
$\mathrm{m}$ but that was only for the short Dec./Jan. growth season. E-ratios derived from ${ }^{234} \mathrm{Th}$ profiles for the Ross Sea were 25-70\% during the summer of 1996/1997 [Cochran et al., 2000] and are higher at high latitude sites in general [Buesseler, 1998]. While our new estimate of an e-ratio of $10 \%$ is substantially larger than suggested by the moored sediment trap, it still implies that there is substantial recycling component to the foodweb of the upper ocean at WAP, an idea that is consistent with inverse model results of Ducklow et al. [2006].

Higher fluxes measured at depth in the WAP also imply less PC attenuation and recycling in surface waters, and more energy to support subsurface and benthic food webs. Although the moored trap sampled flux at only one depth, the low fluxes imply significant recycling of PC as it settles to the sea floor. There is some support for the idea that sites of high seasonality in flux have low export/high attenuation [Lutz et al., 2007]. However, with our new data, we must question that assumption at the PAL site and possibly for our broader understanding of the Southern Ocean, since many of the traps used in the Southern Ocean are moored conical traps in waters $<1000 \mathrm{~m}$ (for example, 16 of 24 used by Lutz et al.). Looking in more detail at one example, in the Ross Sea, the flux of PC at 200 m estimated by a seasonal C budget exceeded the PC flux measured by a moored conical sediment trap by a factor of 6.6 [Sweeney et al., 2000]. Additionally, seasonal ${ }^{234} \mathrm{Th}$ data, indicated more than 10 times lower fluxes in the moored trap during peak summer flux periods [Cochran et al., 2000]. This was also supported by annual budgets of the longer-lived ${ }^{230} \mathrm{Th}$ and ${ }^{231} \mathrm{~Pa}$ isotopes which indicated at least a factor of 3-6 higher export than the moored trap, and possibly by as much as an order of magnitude [Fleisher and Anderson, 2003]. Thus, low export efficiency assigned to these high latitude sites using shallow moored conical trap data would be in error.

A final implication of higher particle fluxes in the WAP is that it calls into question the variability in flux, and the fundamental causes thereof, as measured by the moored time-series trap. This is important, as Antarctic PC fluxes in general are thought to be characterized by extreme seasonality and large interannual variability in particle flux (e.g. Wefer et al., 1988). In the moored PAL trap, on average $85 \%$ of the flux is caught in the one-month period between late December and January, and total annual fluxes range from 13 to $413 \mathrm{mmol} \mathrm{C} \mathrm{m}^{-2} \mathrm{a}^{-1}$ between 1993 and 2006 [Ducklow et al., 2008]. Our data suggests that these summer fluxes could be even higher, though we can't necessarily extrapolate to winter conditions. That the moored trap shows seasonality is not surprising, as ultimately if total particle stocks in the water column are low, such as under ice conditions, then material caught in the trap will be low, and vice-versa during 
bloom conditions. The similarity in $\mathrm{C} /{ }^{234} \mathrm{Th}$ ratios mentioned above and $\mathrm{C} / \mathrm{N}$ (data not shown) between the drifting and moored traps, as well as microscopic analysis of trap material (a dominance of krill fecal pellets in both traps) give some confidence that the quality of the material in the moored trap is not dramatically different, i.e., sorting is not apparent. However, we should be cautious about the certainty in the magnitude of the highest peak and lowest flux conditions as well as interannual variability in fluxes, until we understand more about the root causes of these potential biases.

\section{Conclusion}

In this study, for the first time, two additional upper ocean particle flux methods, namely drifting cylindrical traps and the flux proxy ${ }^{234} \mathrm{Th}$, were used to show more than an order of magnitude higher fluxes for both $\mathrm{PC}$ and ${ }^{234} \mathrm{Th}$ at $150 \mathrm{~m}$ compared to a moored time-series trap at the same WAP site. The implications of a stronger and more efficient biological pump are important, including a higher organic matter source to subsurface and benthic ecosystems. This is consistent with a short food chain and high $\mathrm{C}$ fluxes associated with blooms of large diatoms and fecal pellet production by krill characteristic of the WAP and many polar blooms. We expect that the highly periodic seasonal pattern in flux seen in the existing time-series trap data will hold, with extremely low fluxes under ice-covered conditions, though the magnitude of these fluxes and the interannual variability are difficult to quantify.

To answer the question from Karl et al. [1991] regarding the fate of Antarctic phytoplankton production, we still need much better quantitative estimates of year-round export fluxes combined with new ecological and biogeochemical process studies, to determine the mechanisms that control the biological pump within the euphotic zone and especially the waters immediately below where the variability in flux attenuation between sites is greatest [Buesseler and Boyd, 2009]. Fortunately, alternatives to moored conical traps do exist for use in the mesopelagic and upper ocean, including moored time-series cylindrical designs that should be less susceptible to hydrodynamic biases [Cochran et al., 2009; Peterson et al., 1993]. Also, as shown here, short deployments of drifting traps, or better yet, use of untethered, neutrally buoyant sediment traps [Buesseler et al., 2007; Lamborg et al., 2008] can reduce even further collection biases due to flow around traps.

Ultimately, the use of multiple methods (different traps designs, in-situ tracers, particle cameras and biogeochemical flux models) will be needed to both confirm the sedimentary fluxes 
and resolve the mechanisms that control flux in the WAP and other sites. Only with a mechanistic understanding of particle export will we be able to predict the consequences of global warming, changing ice dynamics, and plankton community shifts on the strength of the biological pump, and hence the impact of climate change on $\mathrm{C}$ sequestration, nutrient recycling, and food supply to top predators and benthic communities along these productive margins of the Antarctic.

\section{Acknowledgements}

We thank our colleagues in the Palmer LTER and FOODBANCS projects, as well as the captain, crew, and RPSC staff aboard the LM Gould. We are grateful to Steve Pike, Steve Manganini, Matthew Erikson, Dave DeMaster, Brian Pointer and the WHOI ICPMS facility for assistance. We appreciate the comments of GRL editors and two reviewers. Funding was provided by the WHOI Rinehart Access to the Sea program, the WHOI Coastal Oceans Institute, WHOI Academic Programs Office, and most significantly, from the NSF Office of Polar Programs for the PAL-LTER (OPP 0823101), FOODBANCS and WAP Flux projects (OPP 0838866).

\section{References}

Anadón, R., et al. (2002), Vertical biogenic particle flux during Austral summer in the Antarctic Peninsula area, Deep Sea Research Part II: Topical Studies in Oceanography, 49(4-5), 883-901. Antia, A. N. (2005), Particle-associated dissolved elemental fluxes: revising the stochiometry of mixed layer export, Biogeosciences Discussions, 2, 275-302.

Buesseler, K. O. (1998), The decoupling of production and particulate export in the surface ocean, Global Biogeochemical Cycles, 12(2), 297-310.

Buesseler, K. O., et al. (2006), An assessment of particulate organic carbon to thorium-234 ratios in the ocean and their impact on the application of ${ }^{234} \mathrm{Th}$ as a POC flux proxy., Marine Chemistry, 100, 213-233.

Buesseler, K. O., et al. (2007), An assessment of the use of sediment traps for estimating upper ocean particle fluxes, Journal of Marine Research, 65(3), 345-416.

Buesseler, K. O., and P. W. Boyd (2009), Shedding light on processes that control particle export and flux attenuation in the twilight zone, Limnology and Oceanography, 54(4), 1210-1232. Buesseler, K. O., et al. (2009), Thorium-234 as a tracer of spatial, temporal and vertical variability in particle flux in the North Pacific, Deep-Sea Research Part I, 56, 1143-1167. 
Cochran, J. K., et al. (2000), Short-lived thorium isotopes $\left({ }^{234} \mathrm{Th},{ }^{228} \mathrm{Th}\right)$ as indicators of POC export and particle cycling in the Ross Sea, Southern Ocean, Deep-Sea Research II, 47(15-16), 3451-3490.

Cochran, J. K., et al. (2009), Time-series measurements of ${ }^{234} \mathrm{Th}$ in water column and sediment trap samples from the northwestern Mediterranean Sea, Deep sea Research II, 56, 1487-1501.

Ducklow, H. W., et al. (2006), Water-column processes in the West Antarctic Peninsula and the Ross Sea: Interannual variations and foodweb structure, Deep Sea Research Part II: Topical Studies in Oceanography, 53(8-10), 834-852.

Ducklow, H. W. (2008), Long-term studies of the marine ecosystem along the west Antarctic Peninsula, Deep Sea Research II, 55(18-19), 1945-1948.

Ducklow, H. W., et al. (2008), Particle export from the upper ocean over the continental shelf of the west Antarctic Peninsula: A long-term record, 1992-2006., Deep Sea Research Part II, 55, 2118-2131.

Fleisher, M. Q., and R. F. Anderson (2003), Assessing the collection efficiency of Ross Sea sediment traps using ${ }^{230} \mathrm{Th}$ and ${ }^{231} \mathrm{~Pa}$, Deep Sea Research Part II: Topical Studies in Oceanography, 50(3-4), 693-712.

Gardner, W. D. (2000), Sediment Trap Technology and Sampling in Surface Waters, in The Changing Ocean Carbon Cycle: A Midterm Synthesis of the Joint Global Ocean Flux Study, edited by R. B. Hanson, et al., pp. 240-281.

Karl, D. M., et al. (1991), Seasonal Coupling of Organic-Matter Production and Particle-Flux in the Western Bransfield Strait, Antarctica, Deep-Sea Research Part A-Oceanographic Research Papers, 38(8-9), 1097-1126.

Knox, G. A. (2006), The Biology of the Southern Ocean, 604 pp., CRC Press, Boca Raton, FL. Lamborg, C. H., et al. (2008), The Flux of Bio- and Lithogenic Material Associated with Sinking Particles in the Mesopelagic "Twilight Zone" of the Northwest and North Central Pacific Ocean, Deep-Sea Research II, 55(14-15), 1540-1563.

Lutz, M. J., et al. (2007), Seasonal rhythms of net primary production and particulate organic carbon flux to depth describe the efficiency of biological pump in the global ocean, J. Geophys. Res, 112 .

McClintic, M. A., et al. (2008), Testing the FOODBANCS hypothesis: Seasonal variations in near-bottom particle flux, bioturbation intensity, and deposit feeding based on ${ }^{234} \mathrm{Th}$ measurements, Deep sea Research II, 55, 2425-2437. 
McDonnell, A. M. P. and K. O. Buesseler (2010), Variability in the average sinking velocity of marine particles, Limnology and Oceanography, 55(5), 2085-2096.

Montes-Hugo, M. A., et al. (2008), Variability on phytoplankton size structure in the Western Antarctic Peninsula (1997-2006), Deep Sea Research Part II: Topical Studies in Oceanography, submitted.

Peterson, M. L., et al. (1993), Field evaluation of a valved sediment trap designed to minimize collection of swimming animals, Limnology and Oceanography, 38(8), 1741-1761.

Pike, S., et al. (2005), Quantification of ${ }^{234}$ Th recovery in small volume sea water samples by inductively coupled plasma mass spectrometry, Journal of Radioanalytical and Nuclear Chemistry, 263(2), 355-360.

Planques, A., et al. (2002), Annual evolution of downward particle fluxes in the Western Bransfield Strait (Antarctica) during the FRUELA project, Deep sea Research II, 49, 903-920.

Rutgers van der Loeff, M., et al. (2006), A review of present techniques and methodological advances in analyzing ${ }^{234} \mathrm{Th}$ in aquatic systems. , Marine Chemistry, 100, 190-212.

Savoye, N., et al. (2006), ${ }^{234}$ Th sorption and export models in the water column: a review, Marine Chemistry, 100, 234-249.

Smith, C. R., et al. (2006), A synthesis of bentho-pelagic coupling on the Antarctic shelf: Food banks, ecosystem inertia and global climate change, Deep Sea Research Part II: Topical Studies in Oceanography, 53(8-10), 875-894.

Steinberg, D. K., et al. (2001), Overview of the US JGOFS Bermuda Atlantic Time-series Study (BATS): a decade-scale look at ocean biology and biogeochemistry., Deep-Sea Research II, 48(89), 1405-1448.

Sweeney, C., et al. (2000), Biogeochemical regimes, net community production and carbon export in the Ross Sea, Antarctica, Deep-Sea Research II, 47(15-16), 3369-3394.

Vaughan, D. G., et al. (2003), Recent rapid regional climate warming on the Antarctic Peninsula, Climatic Change, 60(3), 243-274.

Vernet, M., et al. (2008), Primary Production within the Sea Ice Zone west of the Antarctic Peninsula: I -- Sea Ice, Summer Mixed Layer and Irradiance, Deep Sea Research II, 55(18-19), 2068-2085.

Waples, J. T., et al. (2006), An introduction to the application and future use of ${ }^{234} \mathrm{Th}$ in aquatic systems, Marine Chemistry, 100(3-4), 166-189. 
Wefer, G., et al. (1988), Seasonal particle flux in the Bransfield Strait, Antarctica, Deep-Sea Research, 35, 891-898. 

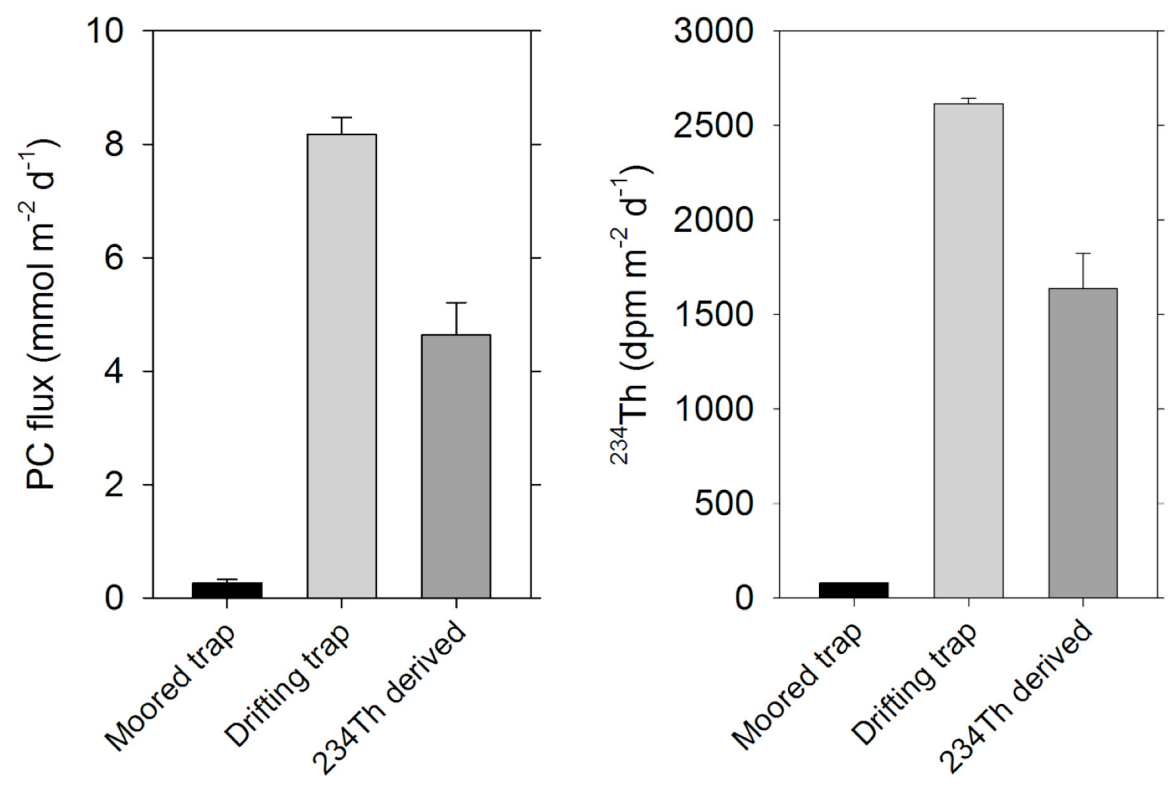

Figure 1. Comparison of average particulate sinking fluxes of PC (left) and ${ }^{234} \mathrm{Th}$ (right) during January 2009 as estimated by a moored time-series trap, a drifting cylindrical trap and as derived from the water column distribution of ${ }^{234} \mathrm{Th}$. Data in Table 1. 
APPENDIX II

Calibration of the video plankton recorder 
The Video Plankton Recorder (VPR) is the underwater microscope used in this thesis to determine the concentration size distributions of particles in the water column. The VPR images particles in an undisturbed volume of water between the camera and strobe housings of the instrument (Figure 1). The 1 Megapixel color digital camera looks towards a masked ring strobe producing a dark field image. Any particle that is present in the imaged volume of the instrument scatters the light from the strobe forward into the camera.

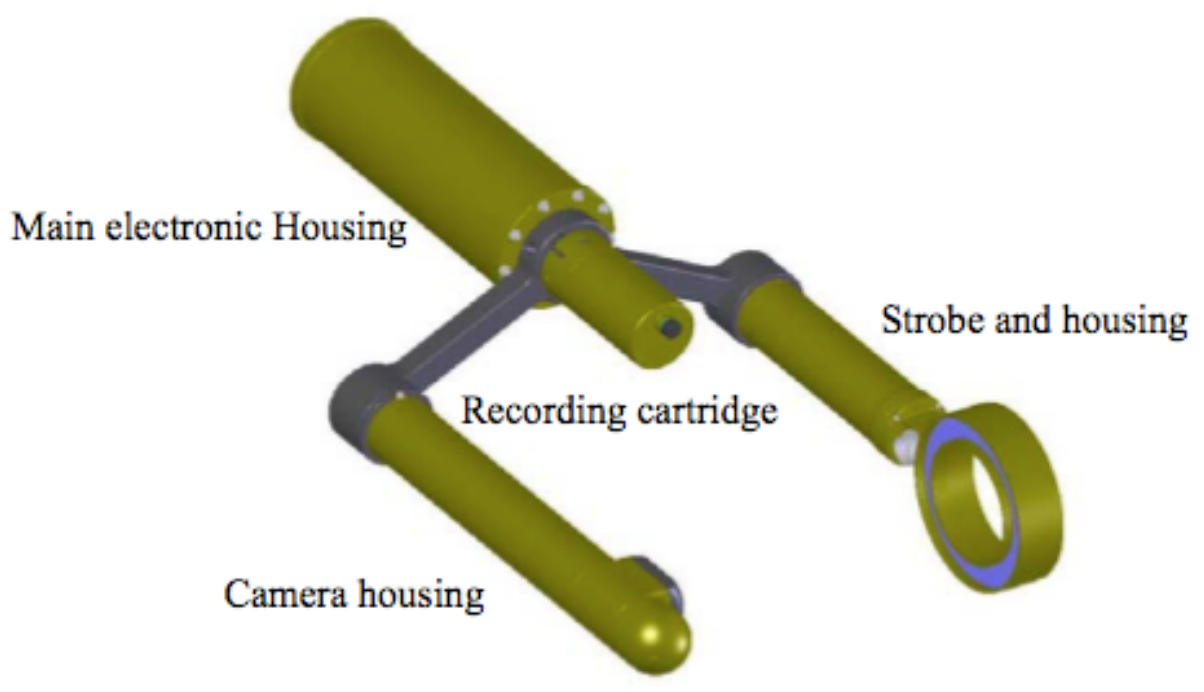

Figure 1. Schematic of the different components of the Video Plankton Recorder (provided by Seascan, Inc.).

We used zoom setting 'S2' on the VPR which produces a field of view of 2.14 by 2.15 $\mathrm{cm}$. To determine the image volume of each VPR photograph, it is necessary to determine the depth of field. The depth of field was calibrated by submerging the VPR in a tank of natural seawater in the laboratory. A thin transparent polycarbonate plate with many small holes (1.5 $\mathrm{mm}$ diameter) drilled at regular intervals $(3 \mathrm{~mm})$ was moved through the imaging area on a mechanical stage at a known speed $\left(1.8 \mathrm{~mm} \mathrm{~s}^{-1}\right)$. The timestamps of each image were used to calculate the distance of the target from an arbitrary zero point. Each image from this calibration procedure was processed as usual with a grayscale threshold of 0.1 (see Matlab code at the end of 
this Appendix). Each hole on the target that is within the image volume produces a round particle-like ROI in the captured images. In this manner, the number of large ROIs with an equivalent spherical diameter larger than $500 \mu \mathrm{m}$ was plotted as a function of the target distance (Figures 2 and 3). As the target enters the image volume, the number of large ROI's quickly increases until it reaches a plateau where most of the holes are visible in the frame. The average number of ROIs in this plateau region was computed as the median full-frame ROI limit (MFRL). The start and end of the VPR's image volume was defined as the position of the target where half of the MFRL ROIs were detected. The difference between these distances is the depth of field of the image volume. The image volume was then computed by multiplying $2.14 \mathrm{~cm}$ by $2.15 \mathrm{~cm}$ by the depth of field, yielding a volume in cubic centimeters.

In the manner described above, two separate calibrations of the VPR were done on 11 March, 2009. On this date the iris setting on the VPR was also changed to produce brighter images of the particles in the water column. One calibration, Calibration A, was conducted before changing this setting. The results from Calibration A apply to measurements taken with the VPR before 11 March 2009, while the results from Calibration B apply to data collected with the VPR after the change in the iris setting. The depth of field results are presented in Table 1.

Table 1. Calibrated image volumes for the VPR.

\begin{tabular}{|c|c|c|c|}
\hline Calibration Name & Applicable Dates & Depth of Field (cm) & Image Volume (cm $\mathbf{c m}^{\mathbf{3}}$ \\
\hline Calibration A & Before 11 March, 2009 & 13.41 & 61.7 \\
\hline Calibration B & After 11 March, 2009 & 17.30 & 79.6 \\
\hline
\end{tabular}

In addition to the metric of depth of field, it is also necessary to determine the ratio of pixels per millimeter in the image plane for an accurate description of particle sizes. The distance (in pixels) between the centroids of adjacent ROIs was divided by the known distance (in $\mu \mathrm{m}$ ) between the holes in the polycarbonate target in order to calculate the ratio of pixels per millimeter in the image plane. We found that throughout the image volume, this ratio varied from 43 to 51 pixels $\mathrm{mm}^{-1}$ with a larger ratio at the end of the depth of field closest to the camera. This variability introduces some errors into the determination of each particle's size, but this error is likely to be distributed in a Gaussian manner around the average value of 47 pixels $\mathrm{mm}^{-1}$. Variation of the parameters used in the image analysis routines can also affect the results achieved. We explored a variety of different image processing parameters for the VPR images via manual tuning and subsequent evaluation and verification of the processed images. 


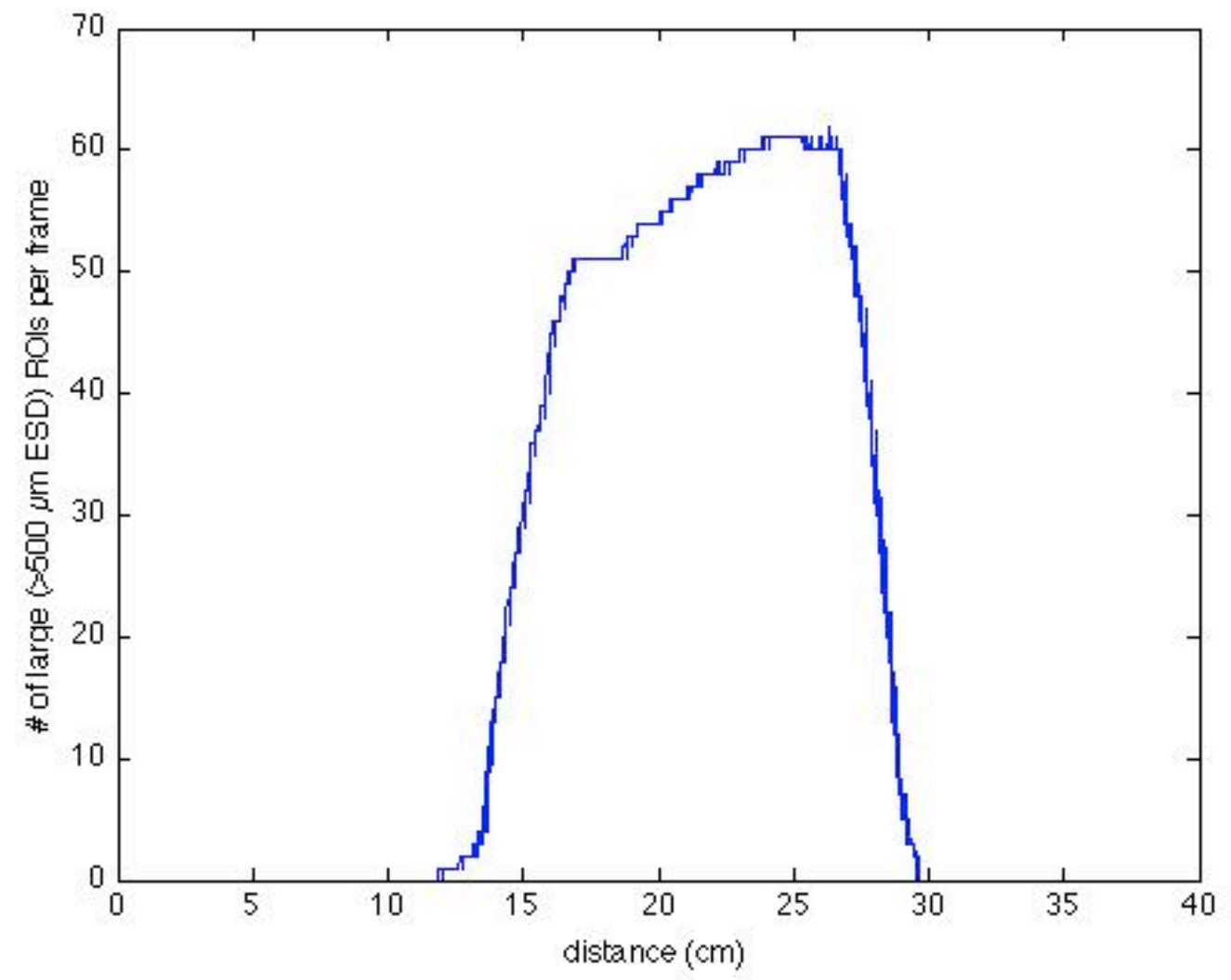

Figure 2. Plot of the number of large Regions of Interest $(>500 \mu \mathrm{m})$ as a function of the target distance (arbitrary zero point) for Calibration A. The median full frame ROI limit for this calibration was 56 ROIs. The distances at which half of these 56 ROIs were detected (28 ROIs) occurred at $14.94 \mathrm{~cm}$ and $28.35 \mathrm{~cm}$ which resulted in a computed depth of field of $13.41 \mathrm{~cm}$ for Calibration A. 




Figure 3. Plot of the number of large Regions of Interest $(>500 \mu \mathrm{m})$ as a function of the target distance (arbitrary zero point) for Calibration B. The median full frame ROI limit for this calibration was 64 ROIs. The distances at which half of these 64 ROIs were detected (32 ROIs) occurred at $14.58 \mathrm{~cm}$ and $31.88 \mathrm{~cm}$ which resulted in a computed depth of field of $17.30 \mathrm{~cm}$ for Calibration B.









\% Create size bins

diameter_bins $=\mathrm{cm} 2 \mathrm{microm} *$ logspace $($ smallend, largeend, $\mathrm{n}) ;$ \% in $\mu \mathrm{m}$ bin_width $=\operatorname{diff}($ diameter_bins);

bin_counts $=$ zeros $(\mathrm{n}-1, \mathrm{n}$ t timebins $)$;

\% depth_img_count=zeros $(\overline{1}$, ( length $($ depth_bins $)-1))$;

for $i=1:(n-\overline{1})$

junkk1 $1=\log \operatorname{space}(\log 10($ diameter_bins $(i)), \log 10($ diameter_bins $(i+1))$

$, 3)$;

end

bin_center $(i)=j u n k k 1(2)$;

scrsz $=\operatorname{get}\left(0,{ }^{\prime}\right.$ ScreenSize');

cd (rootpath)

o Look for all days in cast folder

readdirday $=$ [rootpath ' $\mathrm{d} *$ '] ;

sdirday $=\operatorname{dir}($ strcat (readdirday)); $\%$ retreives structure of

files and folders in readdir

dirdaylist $=$ strvcat $($ sdirday $\cdot$ name $) ;$ creates vertical character array of file and folder names

[numdirday rows] = size(dirdaylist); $\%$

disp([ 'Found ' mat2str(numdirday) ' day folders in '

mat2str(rootpath) ]);

$\%$

for $i=1$ :numdirday ofor each day folder

\% Look for all hour ctd files in day folder

\% $i$

readdirhr $=$ [rootpath dirdaylist(i,:) '/h*ctd.dat'];

sdirhr $=\operatorname{dir}($ strcat $($ readdirhr $)) ; \quad$ o retreives structure of

files and folders in readdir

dirhrlist $=$ strvcat $($ sdirhr $\cdot$ name $) ; \circ$ creates vertical

character array of file and folder names

[numdirhr rows] = size(dirhrlist); $\%$

disp([ 'Found ' mat2str(numdirhr) ' hourly CTD files in '

mat2str(rootpath) mat2str(dirdaylist( $i,:))])$;

- Load all CTD data into one matrix

for $j=1$ :numdirhr $\%$ for each hour cdt.dat file

$\% j$

fid $=$ fopen $([$ rootpath dirdaylist $(i,:)$ '/'

$\operatorname{dirhrlist}(j,:)])$;

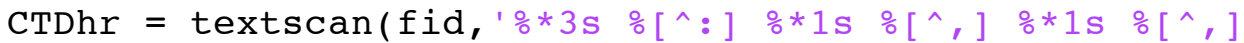

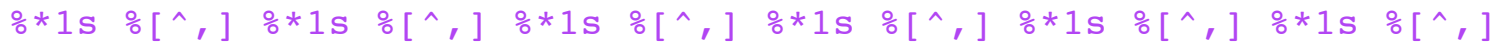

$\%$ (s $\% \mathrm{~s} ')$;

fclose(fid);

for $k=1: 10 \%$ for each column of the ctd.dat file

CTDdathr_t=str2double $(\operatorname{CTDhr}\{\mathrm{k}\}) ; \%$ Convert strings to 


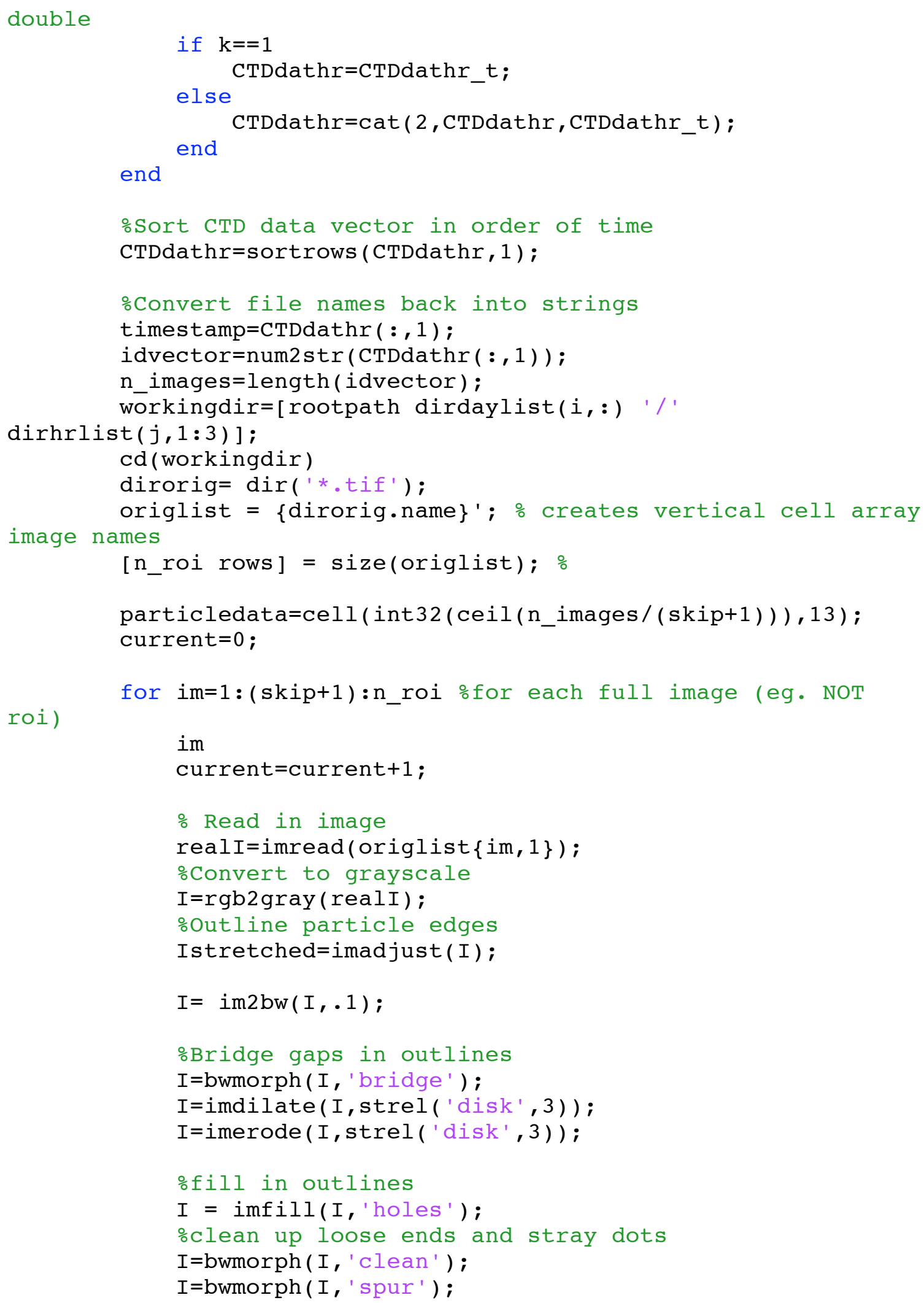


olabel each particle blob

[ Ilab, num ] =bwlabel ( I );

\% Saves every 50th image and the processed result

for pcount $=1$ : length (ex_roi_im)

if im=eex_roi_im(pcount)

I2 = reali ;

imwrite(I2, [outpath '/' ...

$\mathrm{I} 3=\mathrm{I}$;

num2str((pcount)) '.tif'],'tif')

imwrite(I3, [outpath '/' ...

num2str((pcount)) 'binary.tif'], 'tif')

end

end

\% Compute Paticle Areas (square $\mu \mathrm{m}$ )

areas 1 = regionprops (Ilab, 'Area');

$\operatorname{areas} 2=\operatorname{cel} 12 \operatorname{mat}\left(\operatorname{struct} 2 \operatorname{cel} 1(\operatorname{areas} 1)^{\prime}\right)$;

allareas_per_frame=areas $2 . *($ cmperpixel $) \wedge 2 * \mathrm{~cm} 2 \mathrm{microm}{ }^{\wedge} 2$; $\%$ convert to area in square $\mu \mathrm{m}$

particledata $\{$ current, 1$\}=$ allareas_per_frame;

\% Compute Equivalent Spherical Diameters $(\mu \mathrm{m})$

alldiam_per_frame $=$ sqrt $\left(4 * a l l a r e a s \_p e r \_f r a m e . / p i\right)$;

particledata $\{$ current, 2$\}=$ alldiam_per_frame;

\% Compute Paticle Perimeters ( $\mu \mathrm{m})$

Perim = regionprops (Ilab, 'Perimeter');

Perim2 = cell2mat (struct2cell (Perim)');

allperim_per_frame=Perim2.*(cmperpixel)*cm2microm;

oconvert to length in $\mu \mathrm{m}$

particledata $\{$ current, 3$\}=$ allperim_per_frame;

clear Perim Perim2 areas2 areas1

oAssocitate particle information with CTD metadata

for allmeta=4:13 \%Changed from 3:12, to make space

for perimeter data

particledata $\{$ current, allmeta $\}=$

CTDdathr(im,allmeta-3); ochanged from allmeta-2 to make space for perimeter data

end

end

if $j==1$

particledata_c=particledata;

else 


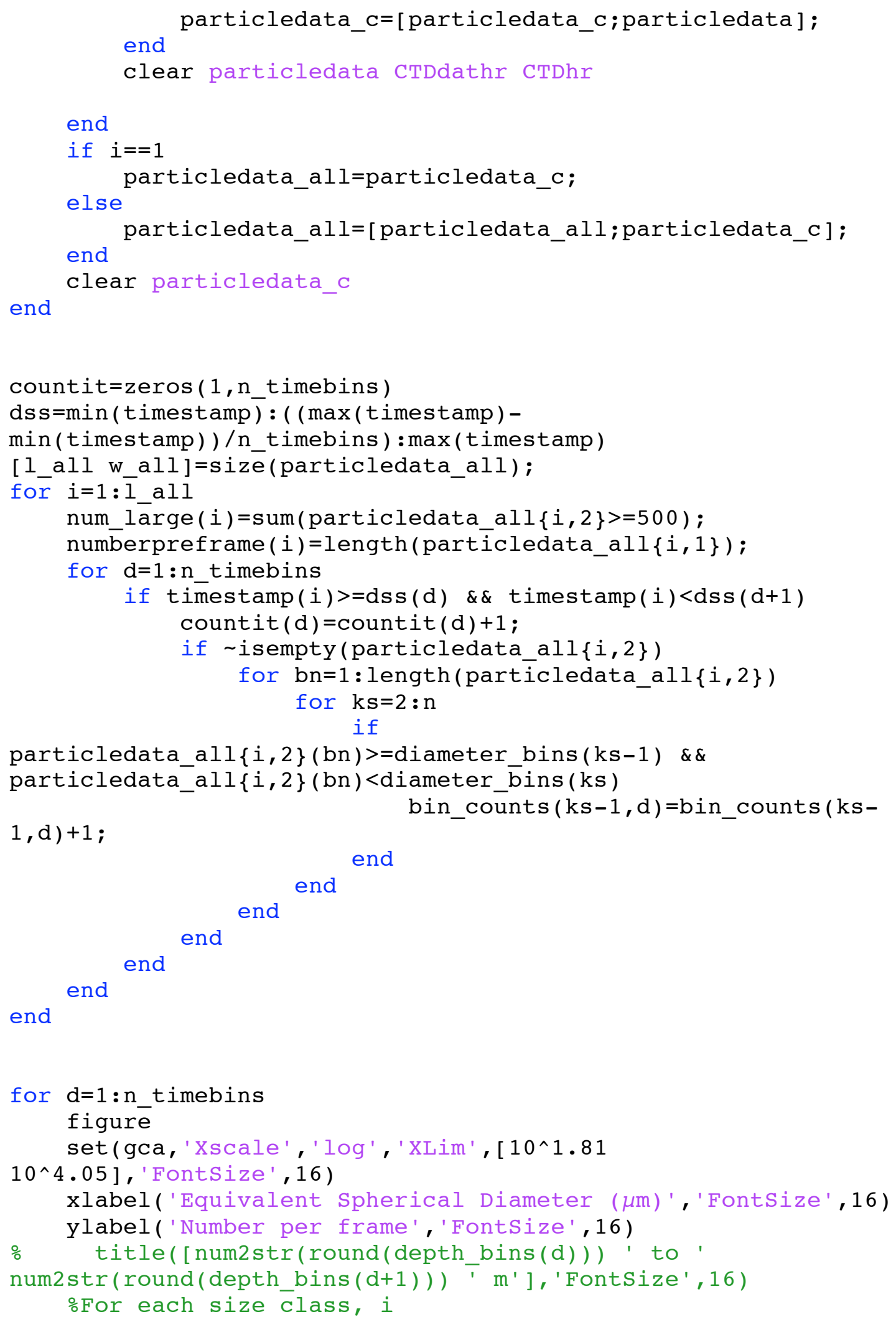




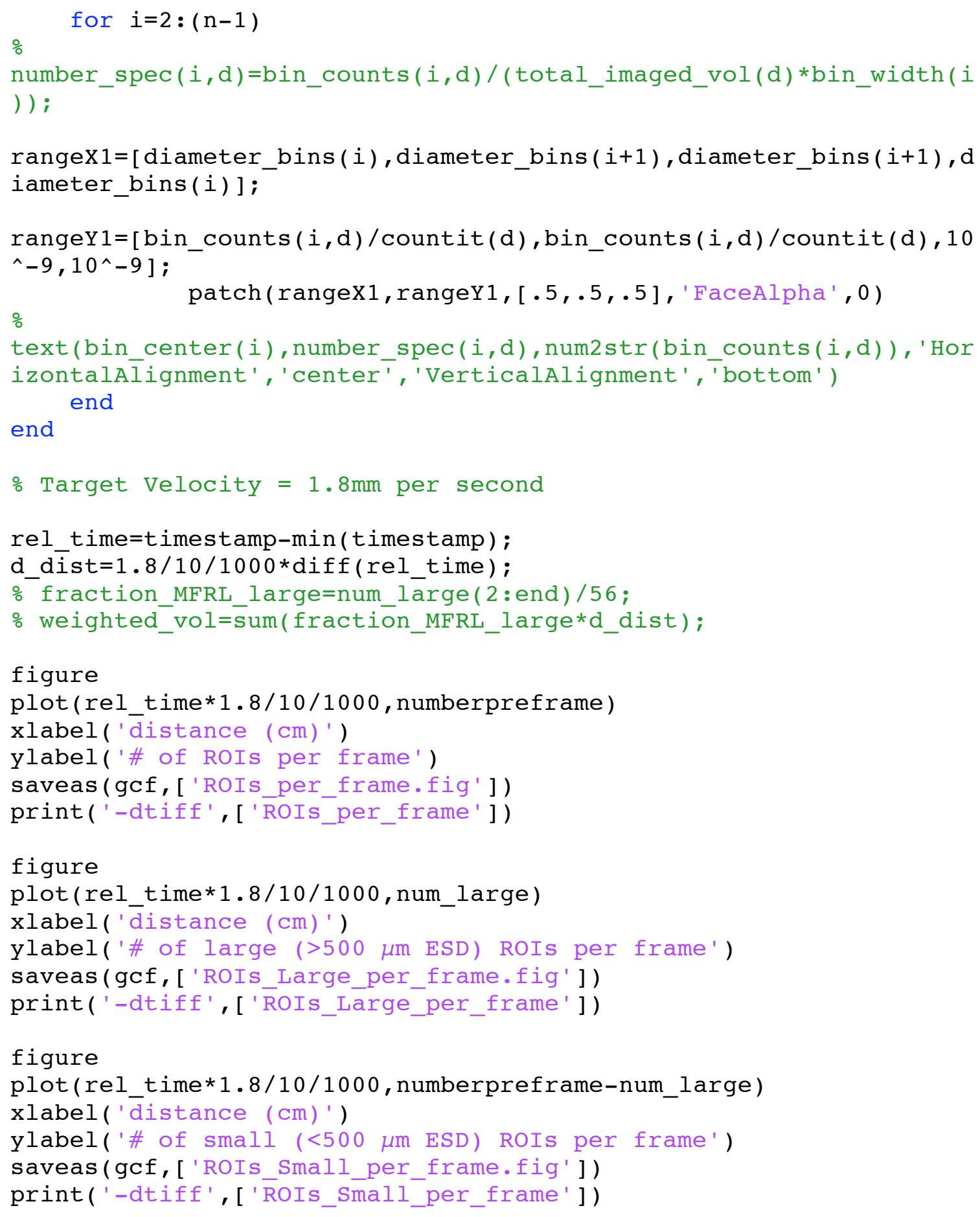




\section{APPENDIX III}

MATLAB code for processing and analyzing images from the Video Plankton Recorder 
\%VPR_full_process_current.m

\% Written by Andrew M. P. McDonnell

oversion $10 / 31 / 2010$

\% This MATLAB script takes the VPR images exported from the Autodeck

\% application and analyzes them to compute the concentration size

o distribution of particles in the water column.

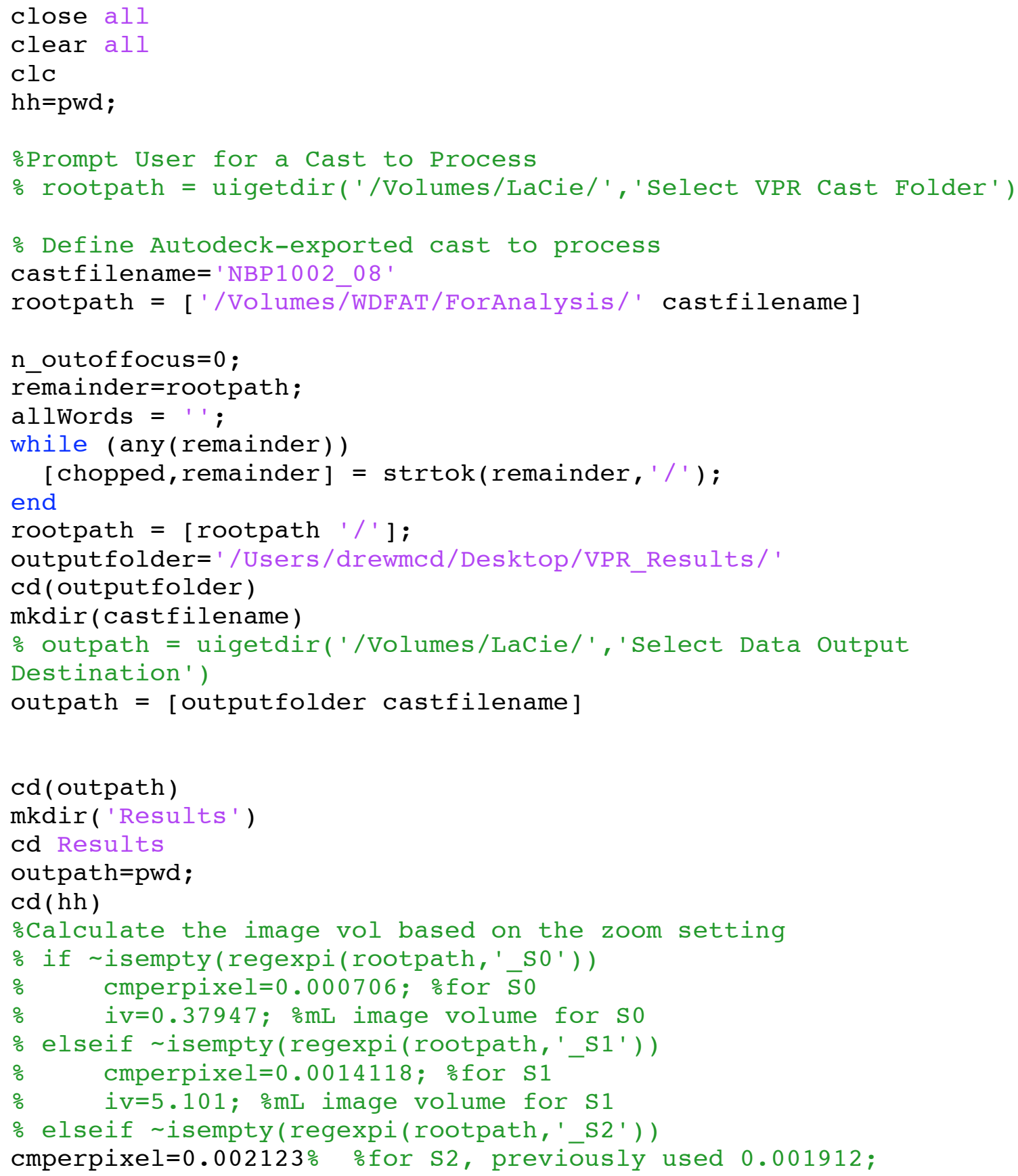


\% depthoffield=13.41 \%cm based off of May_2009_Post_Antarctic_VPR_Cal_S2, VPRCalibrationResultsandNotes.docx depthoffield=17.3 \% $\mathrm{cm}$ based off of May_2009_Pre_Bermuda_VPR_Cal_s2,

VPRCalibrationnesults̄andN̄otes.docx

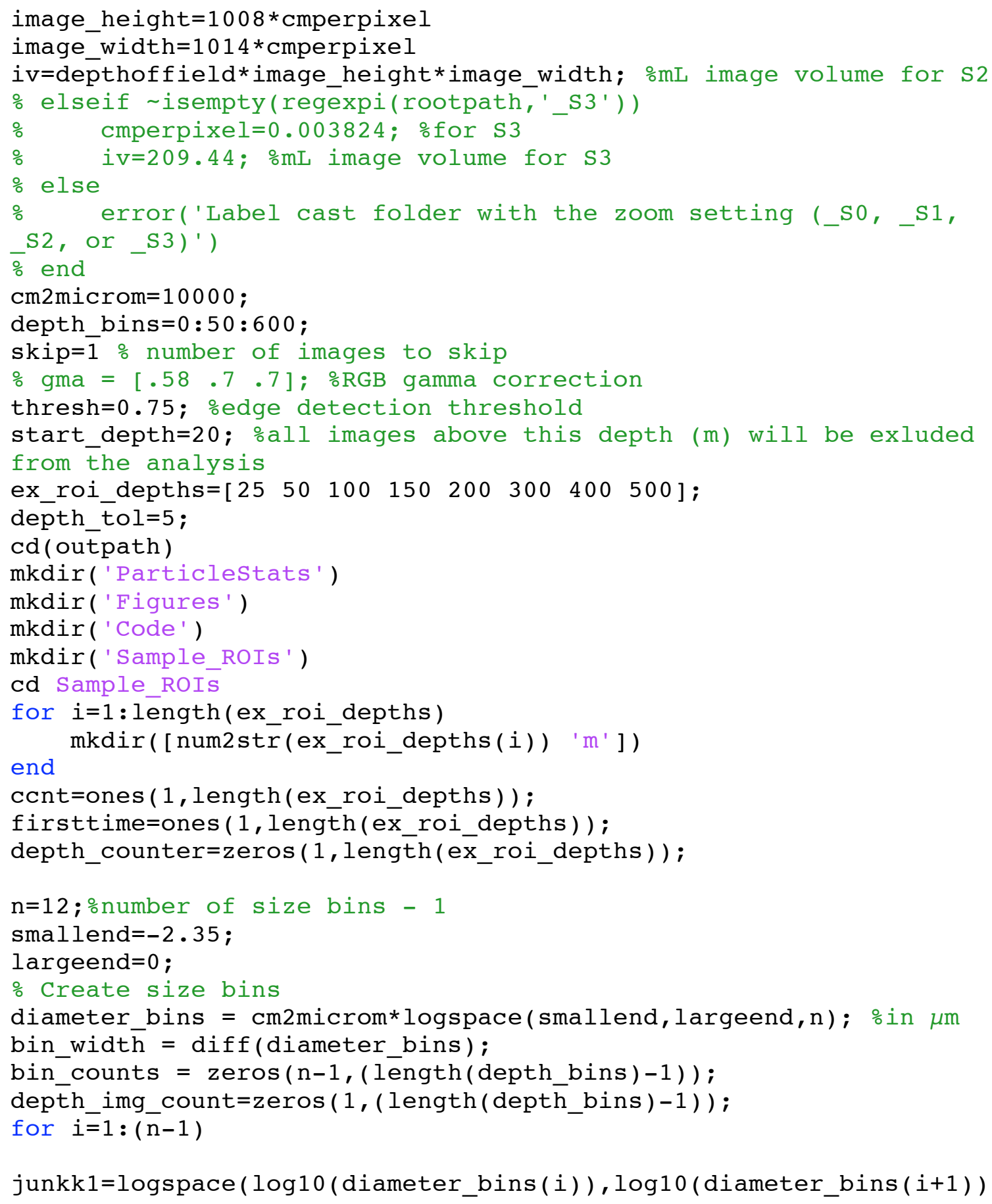




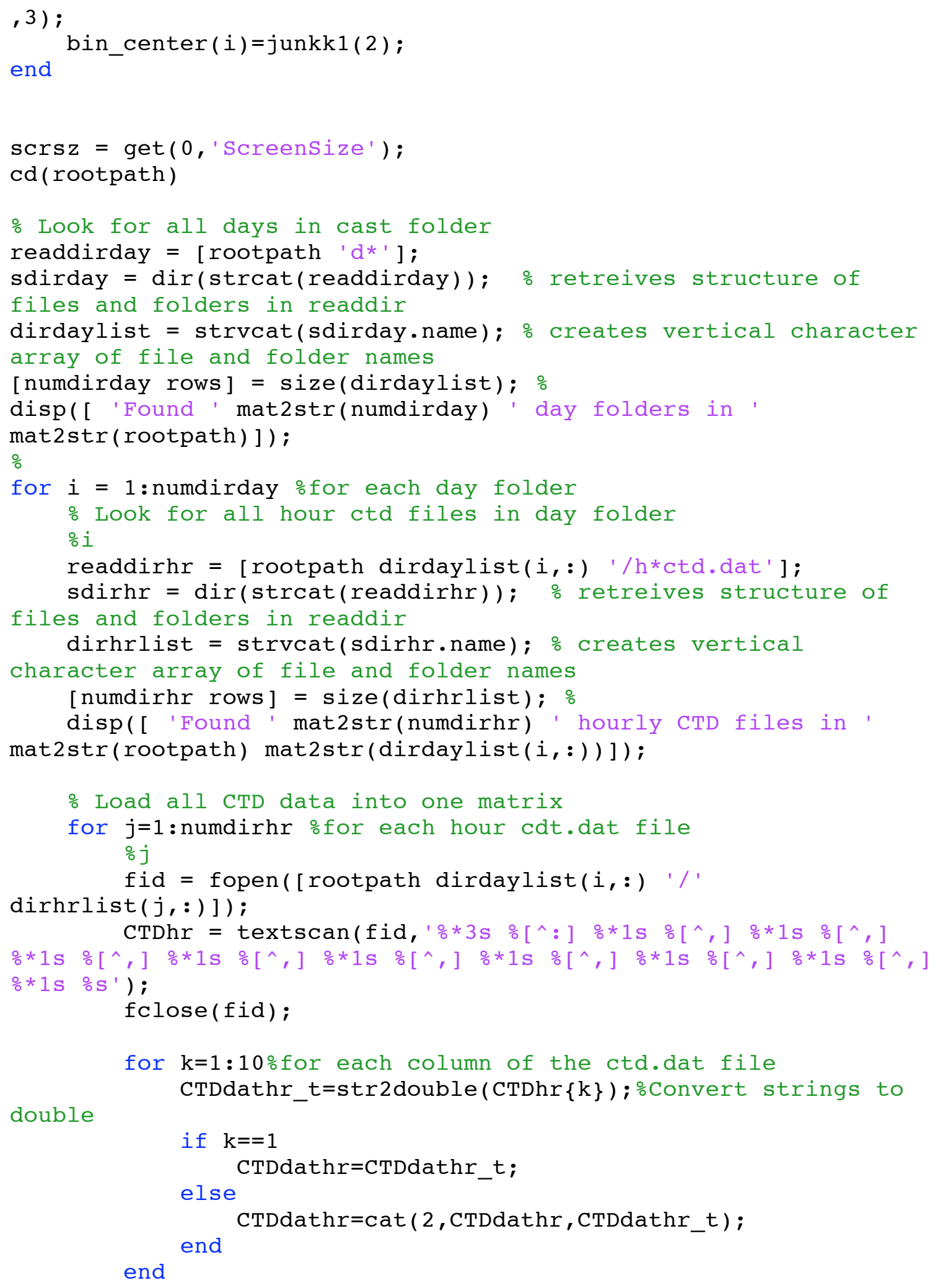









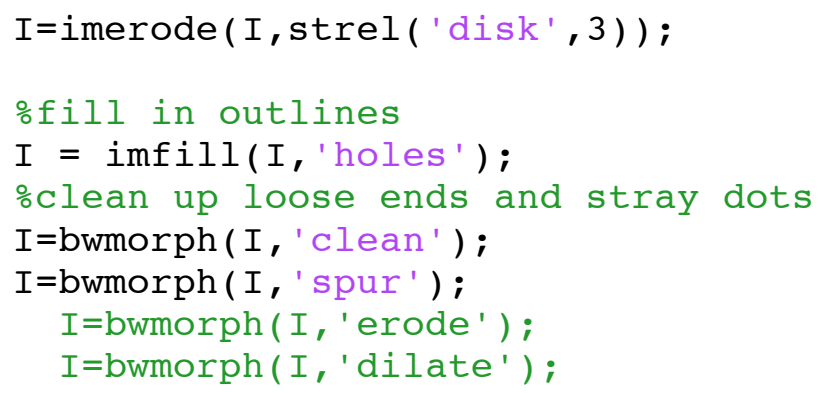

\%label each particle blob

[ Ilab, num ] =bwlabel ( I ) ;

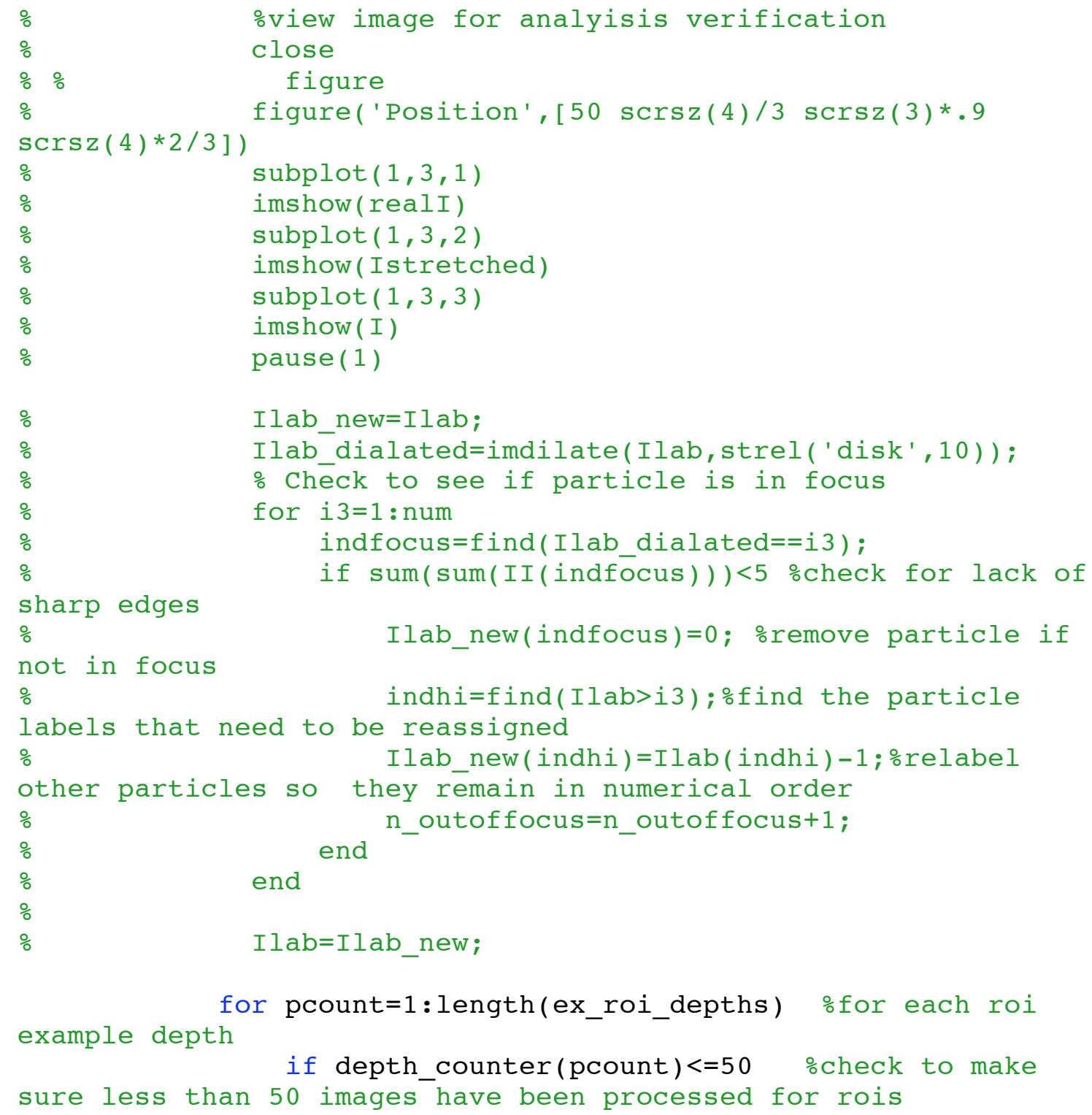


if depth> (ex_roi_depths (pcount)-depth_tol) \&\& depth $<$ (ex_roi_depths (pcount) + depth_tol $)$ numberrois $=\max (\max (\mathrm{Ilab}))$; if numberrois $>0$

for nrois $=1$ : numberrois; [hity hitx] =find (Ilab==nrois) ; if length(hity) $>=10$ $x \max =\max ($ hitx $)$; $\operatorname{xmin}=\min ($ hitx $)$; $y \max =\max ($ hity $)$; ymin=min (hity);

I2 = imcrop (realI, [ (xmin-10)

$(y \min -10)(x \max -x \min +20)(y \max -y \min +20)]) ;$ imwrite(I2, [outpath

'/Sample_ROIs/' [num2str(ex_roi_depths(pcount)) 'm/'] num2str(ex_roi_depths (pcount)) '_m_'...

'.tif'],'tif' ) num2str (ccnt (pcount))

$(y \min -10)(x \max -x \min +20)(y \max -y \min +20)])$; I3 $=\operatorname{imcrop}(I,[(x \min -10)$

imwrite(I3, [outpath

'/Sample_ROIs/' [num2str(ex_roi_depths(pcount)) 'm/'] num2str(ex_roi_depths (pcount $))$ '_m_...

'binary.tif'], 'tif' )

num2str ( ccnt (pcount))



\% Compute Paticle Areas (square $\mu \mathrm{m}$ )

areas 1 = regionprops (Ilab, 'Area');

$\operatorname{areas} 2=\operatorname{cel} 12 \operatorname{mat}\left(\operatorname{struct} 2 \operatorname{cel} 1(\operatorname{areas} 1)^{\prime}\right)$;

allareas_per_frame=areas $2 . *($ cmperpixel $) \wedge 2 * \mathrm{~cm} 2 \mathrm{microm}{ }^{\wedge} 2$; $\%$ convert to area in square $\mu \mathrm{m}$

particledata $\{$ current, 1$\}=$ allareas_per_frame;

o Compute Equivalent Spherical Diameters ( $\mu \mathrm{m})$

alldiam_per_frame $=$ sqrt $\left(4 * a l l a r e a s \_p e r \_f r a m e . / p i\right) ;$ particledata $\{$ current, 2$\}=$ alldiam_per_frame; 


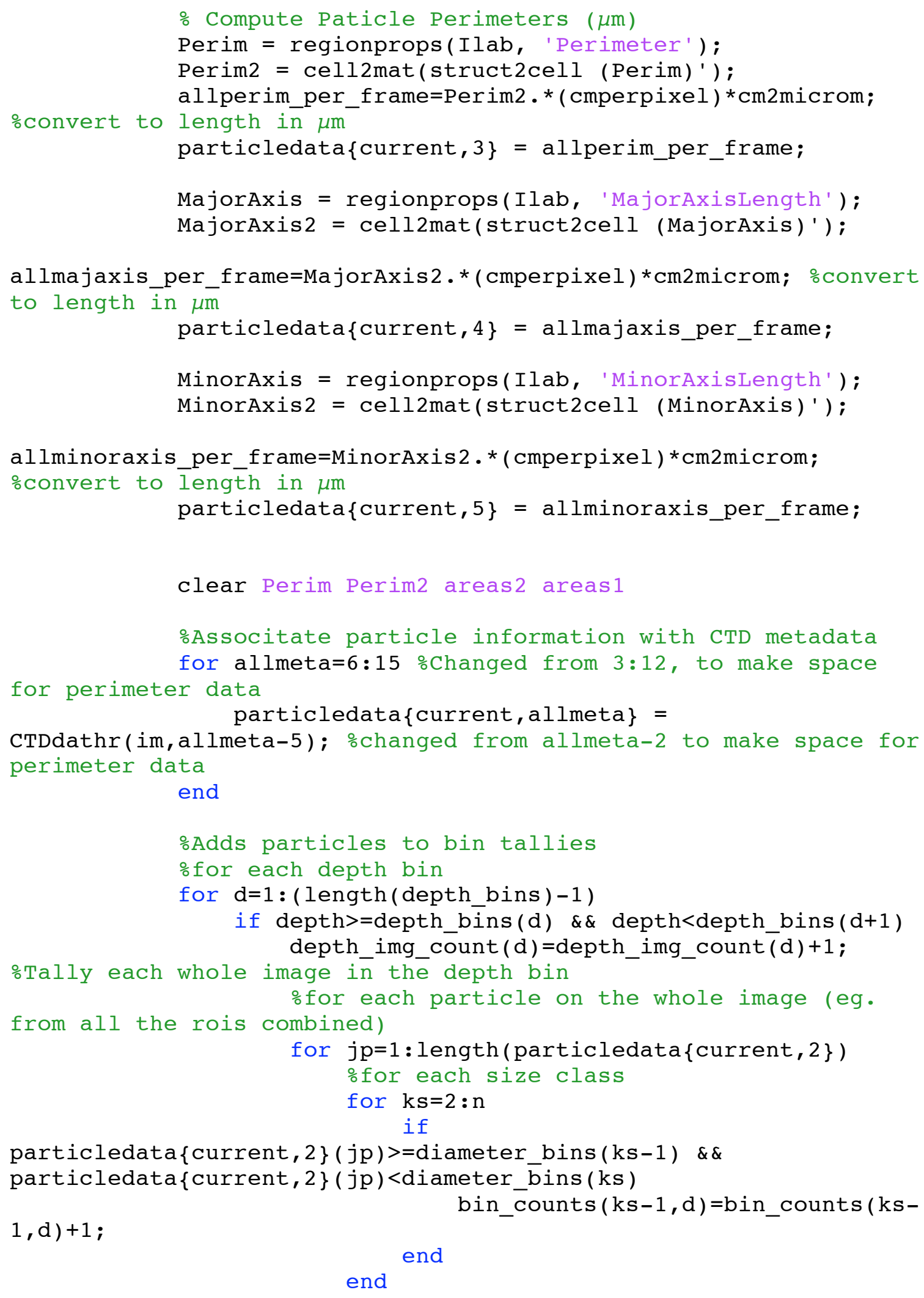




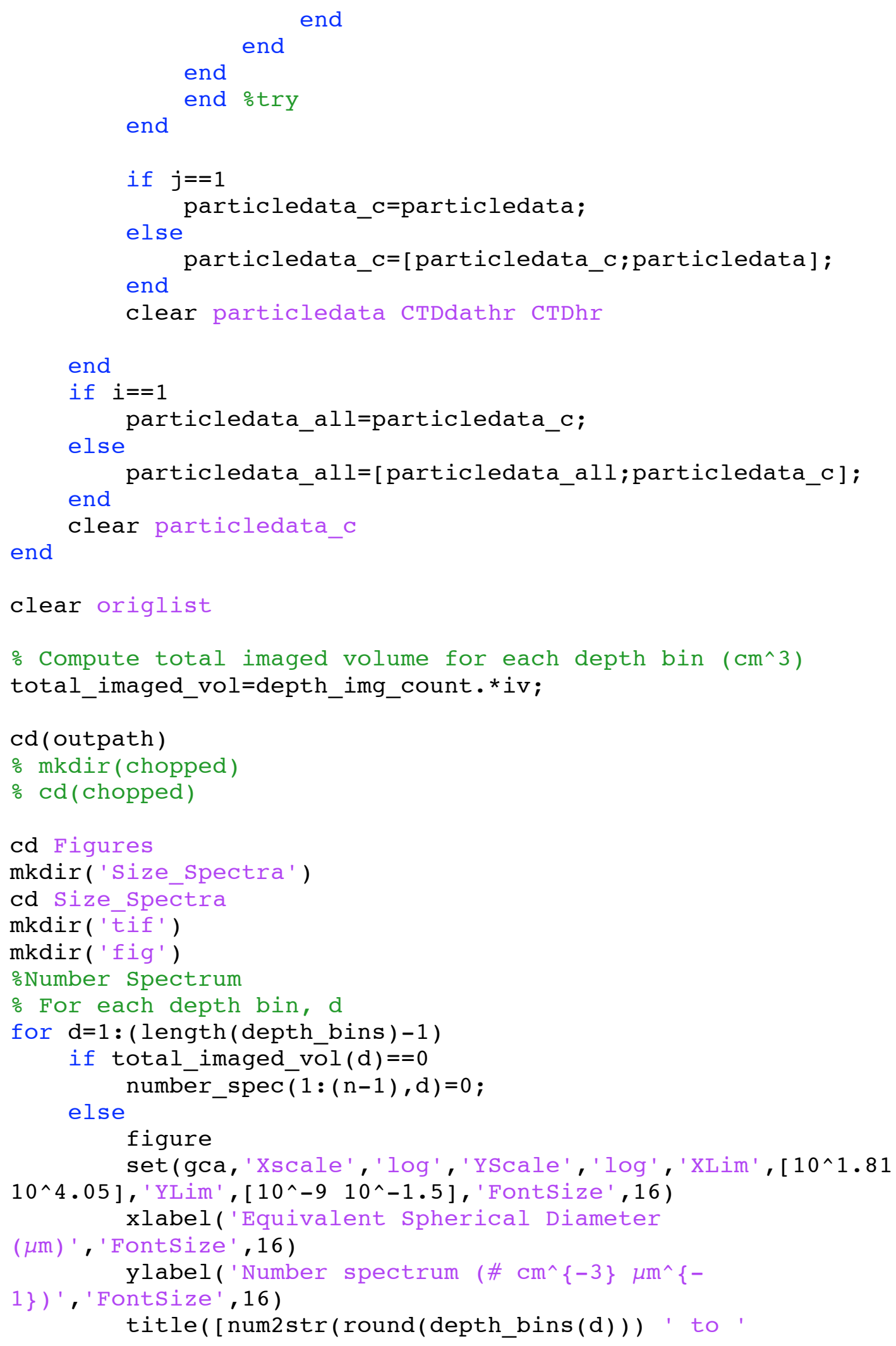




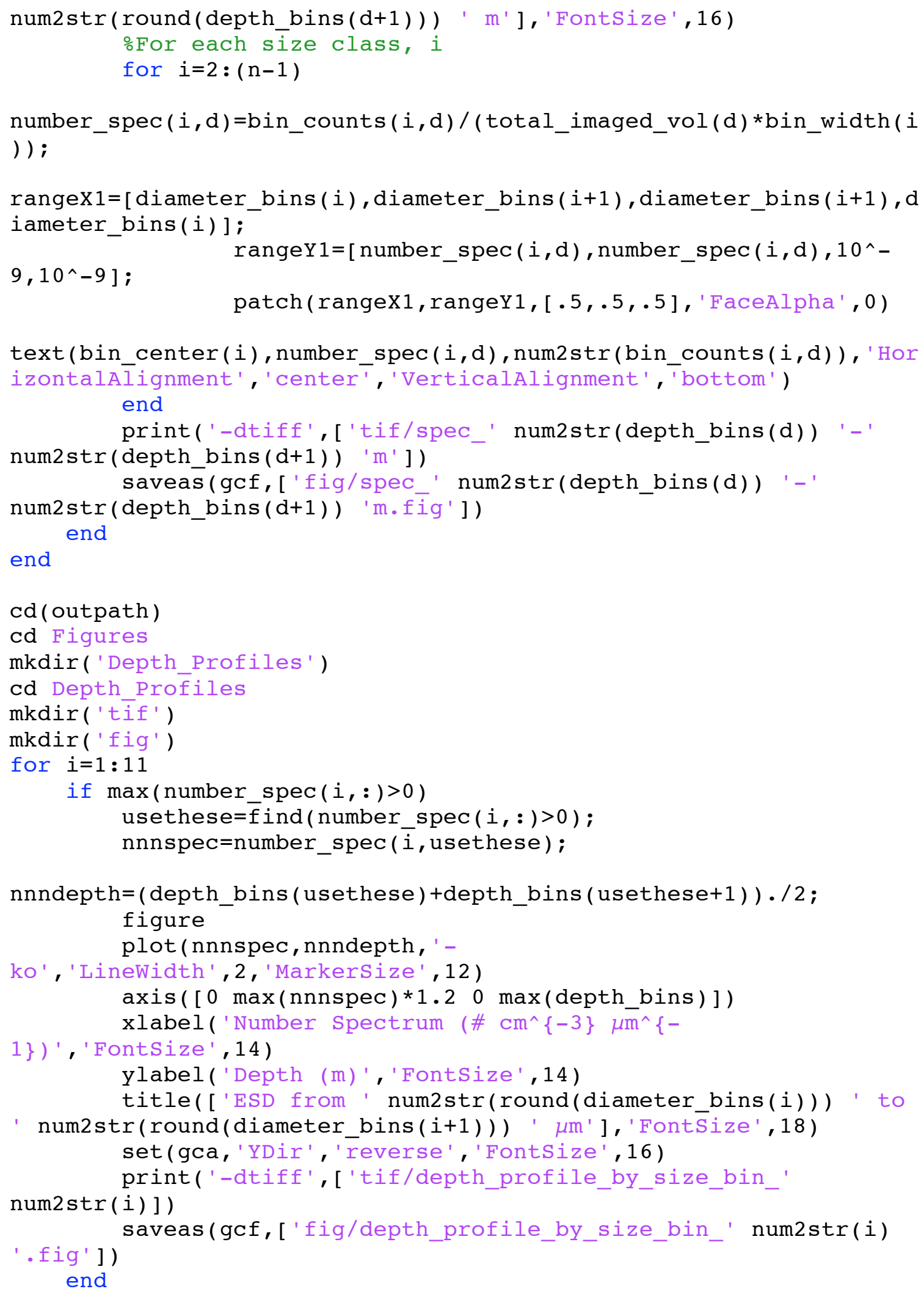




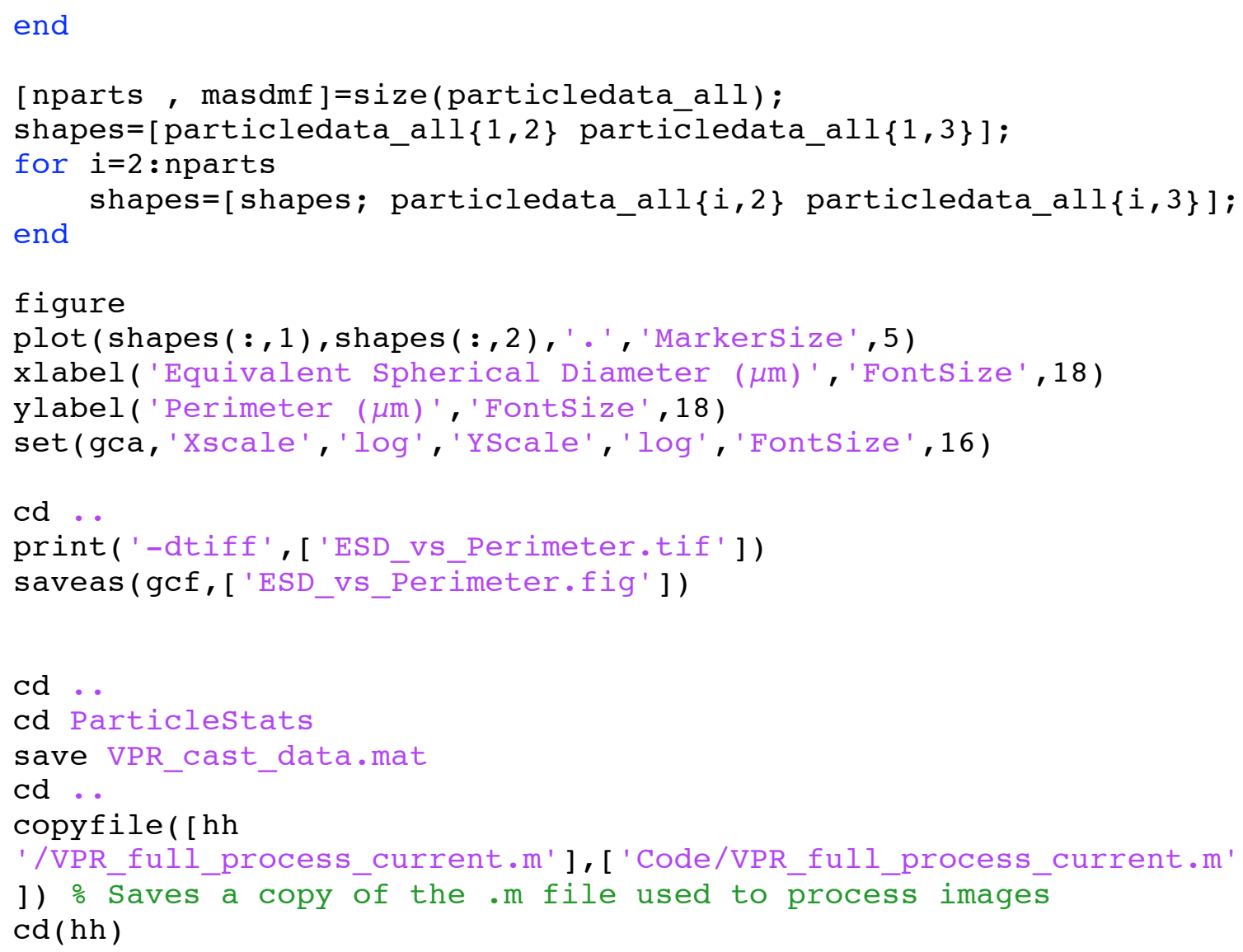




\section{APPENDIX IV}

MATLAB code for processing and analyzing the merged polyacrylamide gel images 
\% gel_mosaic_process.m

\% Written by Andrew M. P. McDonnell

\% Version $10 / 31 / 2010$

\% This takes the merged mosaic gel images that have been processed in

\% Photoshop by the application of a Canny Edge detection then

\% threshold to produce a binary image. Thi script analyzes the image to

\% calculate a particle flux size distribution

close all

clear all

clc

$\mathrm{hh}=\mathrm{pwd}$;

SampleID= 'BATS_May2009_G3'

image_name $=[$ SampleID '_thresh42C'];

image_type $=$ '.jpg';

$\mathrm{cd}$

/Users/drewmcd/Documents/Research/Thesis/AntarcticPeninsula/WAP_2 $009 /$ Traps/Gels/Outlined_Cleaned/Cropped

outpath =

' /Users/drewmcd/Documents/Research/Thesis/AntarcticPeninsula/WAP 2009 /Traps/Gels/AnalysisResults/Cleaned ';

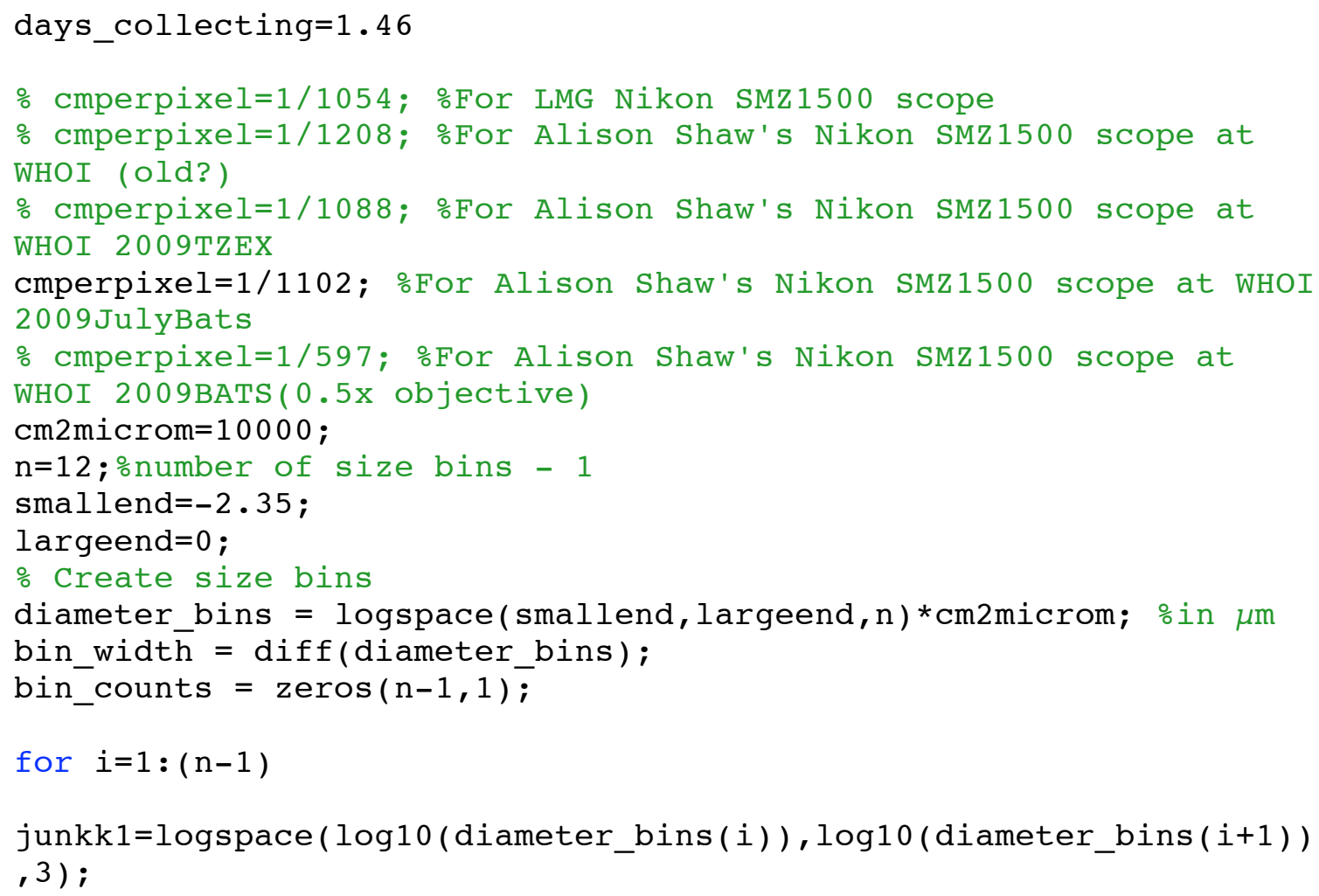




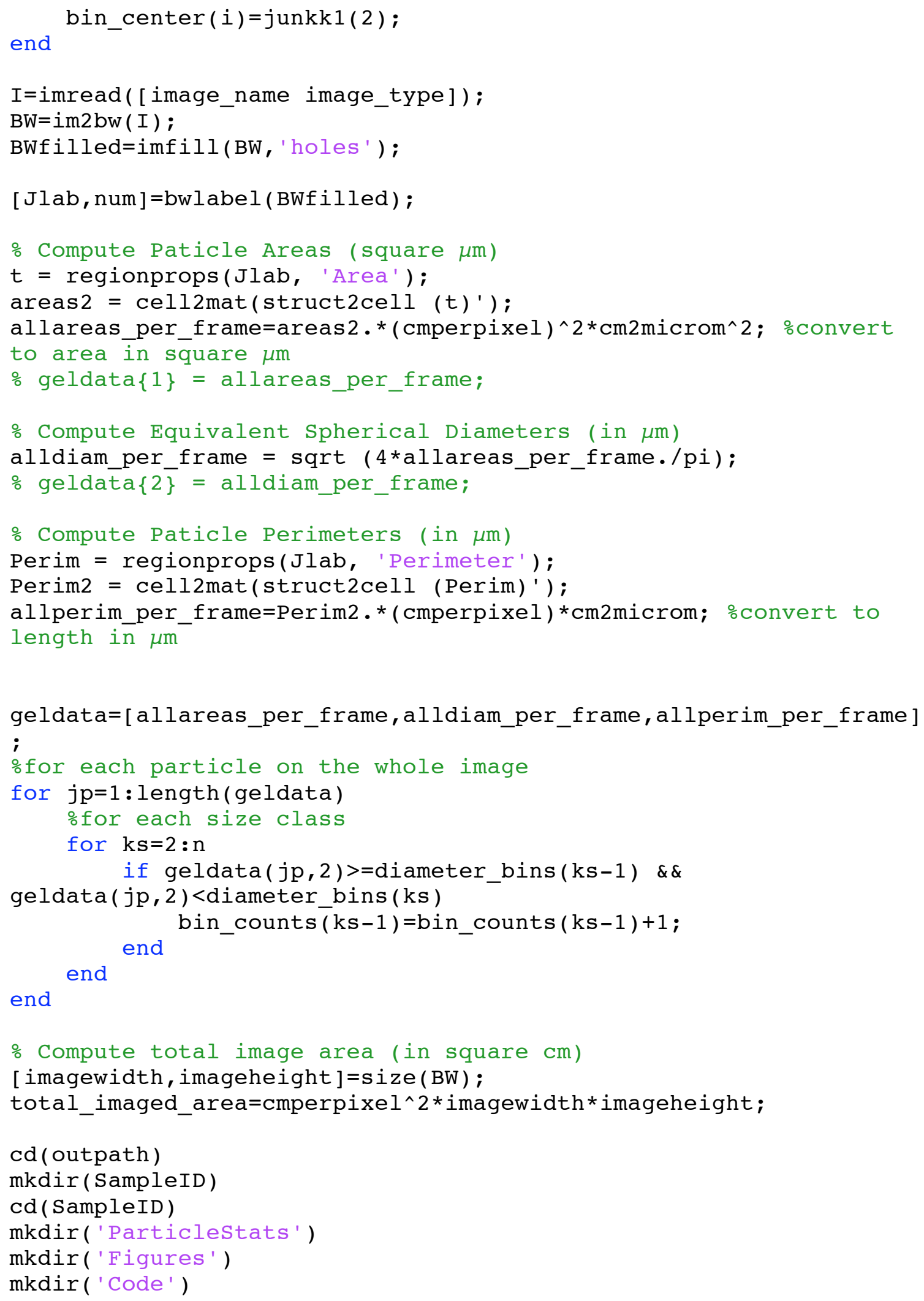




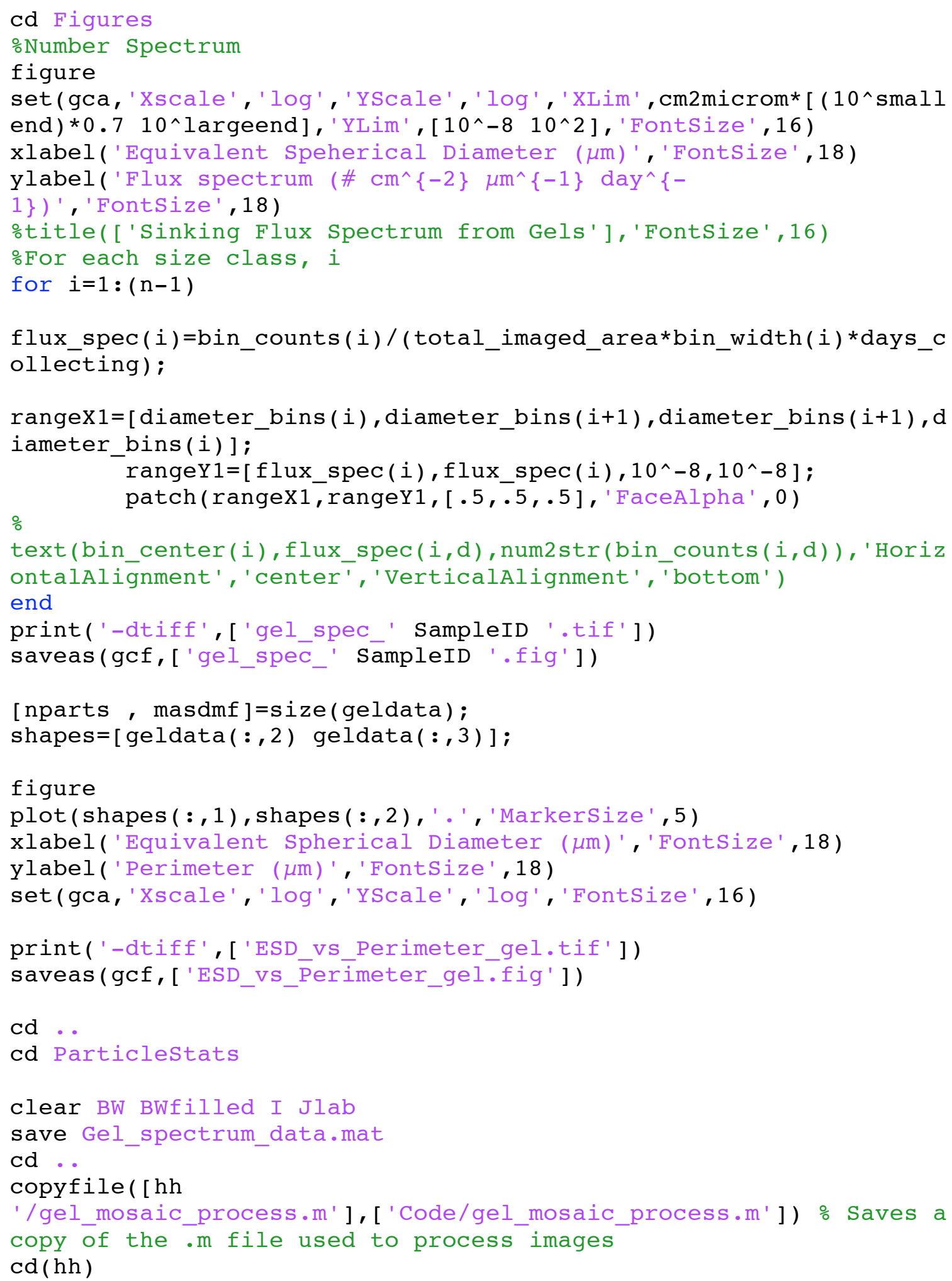


APPENDIX V

Table of average sinking velocities 
Table 1. Average sinking velocities reported in Chapter 2 (McDonnell and Buesseler 2010). These were calculated from the comparison of the concentration size distribution (determined from single VPR profiles) and the flux size distribution (determined from the polyacrylamide gel traps.

\begin{tabular}{|c|c|c|c|c|c|c|c|c|c|c|c|c|}
\hline \multirow[t]{4}{*}{ Cruise } & Location & $\begin{array}{c}\text { Depth } \\
\text { (m) }\end{array}$ & \multicolumn{10}{|c|}{ Average Sinking Velocity Distribution (m/day) } \\
\hline & & & \multicolumn{10}{|c|}{ Size } \\
\hline & & & & & & & Bins & & & & & \\
\hline & & & 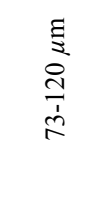 & 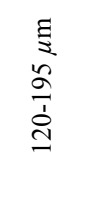 & 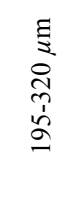 & 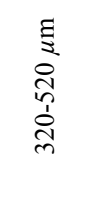 & 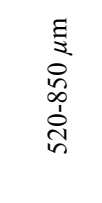 & $\begin{array}{l}\Xi \\
\$ \\
8 \\
\stackrel{+}{1} \\
\dot{0} \\
\infty \\
\infty\end{array}$ & 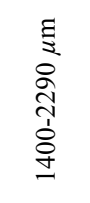 & 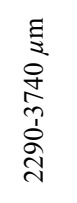 &  & 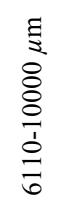 \\
\hline LMG0901 & PS1 & 50 & 87.8 & 48.4 & 135.3 & 60.4 & 83.0 & 115.4 & Inf & $\mathrm{NaN}$ & $\mathrm{NaN}$ & $\mathrm{NaN}$ \\
\hline LMG0901 & PS1 & 150 & 79.2 & 25.2 & 21.8 & 30.1 & 34.7 & 47.1 & 53.7 & Inf & $\mathrm{NaN}$ & $\mathrm{NaN}$ \\
\hline LMG0901 & PS1 & 250 & 90.1 & 55.0 & 56.4 & 54.2 & 157.6 & 137.2 & 134.7 & 11.0 & Inf & $\mathrm{NaN}$ \\
\hline LMG0901 & PS2 & 100 & 110.2 & 53.7 & 100.1 & 94.3 & 107.2 & 404.1 & Inf & Inf & Inf & $\mathrm{NaN}$ \\
\hline LMG0901 & PS2 & 200 & 143.6 & 67.0 & 38.0 & 36.5 & 73.9 & 81.1 & 91.5 & $\mathrm{NaN}$ & $\mathrm{NaN}$ & $\mathrm{NaN}$ \\
\hline LMG0901 & PS2 & 300 & 254.0 & 109.5 & 85.7 & 58.7 & 60.6 & 85.0 & 709.1 & Inf & Inf & $\mathrm{NaN}$ \\
\hline LMG0901 & PS3 & 50 & 263.3 & 211.5 & 137.0 & 301.6 & 630.0 & Inf & Inf & $\mathrm{NaN}$ & $\mathrm{NaN}$ & $\mathrm{NaN}$ \\
\hline LMG0901 & PS3 & 100 & 26.5 & 28.1 & 103.0 & 90.1 & 181.1 & Inf & 925.2 & Inf & $\mathrm{NaN}$ & $\mathrm{NaN}$ \\
\hline LMG0901 & PS3 & 150 & 57.7 & 38.4 & 45.4 & 73.1 & 76.6 & 150.1 & 308.1 & 88.0 & 44.0 & $\mathrm{NaN}$ \\
\hline LMG0902 & PS2 & 100 & 176.7 & 60.7 & 85.5 & 92.3 & 381.5 & Inf & Inf & $\mathrm{NaN}$ & $\mathrm{NaN}$ & $\mathrm{NaN}$ \\
\hline LMG0902 & PS2 & 200 & 295.8 & 135.8 & 100.3 & 67.5 & 35.1 & 9.2 & 0.0 & 0.0 & $\mathrm{NaN}$ & $\mathrm{NaN}$ \\
\hline LMG0902 & PS2 & 300 & 244.1 & 123.7 & 91.9 & 79.2 & 54.4 & 14.3 & 12.3 & 0.0 & $\mathrm{NaN}$ & $\mathrm{NaN}$ \\
\hline LMG0902 & PS1 & 50 & 5888.5 & 756.4 & 73.7 & 189.9 & 235.3 & 1200.3 & Inf & $\mathrm{NaN}$ & $\mathrm{NaN}$ & $\mathrm{NaN}$ \\
\hline LMG0902 & PS1 & 150 & 374.7 & 65.2 & 40.7 & 80.8 & 174.8 & 1189.1 & 771.3 & Inf & $\mathrm{NaN}$ & $\mathrm{NaN}$ \\
\hline LMG0902 & PS1 & 250 & 369.9 & 88.7 & 41.8 & 29.3 & 35.5 & 197.9 & $\operatorname{Inf}$ & $\mathrm{NaN}$ & $\mathrm{NaN}$ & $\mathrm{NaN}$ \\
\hline
\end{tabular}


APPENDIX VI

Table of abbreviations 
Table 1. Commonly used abbreviations in this thesis

\begin{tabular}{|l|l|}
\hline Abbreviation & Description \\
\hline ASVD & Average Sinking Velocity Size Distribution \\
\hline BATS & Bermuda Atlantic Time-series Study \\
\hline CSD & Concentration Size Distribution \\
\hline CTD & Conductivity Temperature Depth \\
\hline DOC & Dissolved Organic Carbon \\
\hline ESD & Equivalent Spherical Diameter \\
\hline FSD & Flux Size Distribution \\
\hline PAL & Palmer Long-term Ecological Research Study \\
\hline PM & Particulate Matter \\
\hline POC & Particulate Organic Carbon \\
\hline POM & Particulate Organic Matter \\
\hline PS & Process Study \\
\hline RESPIRE & REspiration of Sinking Particles In the subsuRface ocEan \\
\hline ROI & Region of Interest \\
\hline TEP & Transparent Exopolymeric Particles \\
\hline VPR & Video Plankton Recorder \\
\hline WAP & Western Antarctic Peninsula \\
\hline
\end{tabular}

